Psychology. Journal of the Higher School of Economics
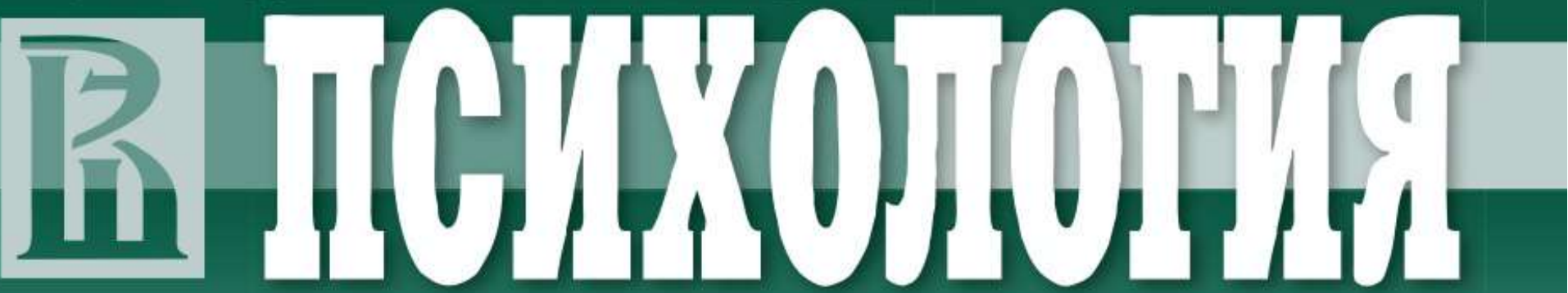

ЖУРНАЛ ВЫСШЕЙ ШКОЛЫ ЭКОНОМИКИ

B HOMEPE

Спецтема

«Психодиагностика»

-

Эффект взгляда-подсказки

в виртуальной среде

-

Интеллект регионов 


\section{Tом 18. № 1 2021}

Учредитель

Национальный исследовательский университет «Высшая школа экономики»

Главный редактор

B.А. Петровский (НИУ ВШЭ)

\section{Редакционная коллегия}

Дж. Берри (Университет Куинс, Канада)

Г.М. Бреслав (Балтийская международная академия, Латвия)

Я. Вальсинер (Ольборгский университет, Дания) Е.Л. Григоренко (МГУ им. М.В. Ломоносова и Центр ребенка Йельского университета, США) B.А. Ключарев (НИУ ВШЭ)

Д.А. Леонтьев (НИУ ВШЭ и МГУ им. М.В. Ломоносова)

B.Е. Лепский (ИФ РАН)

М. Линч (Рочестерский университет, США)

Д.В. Люсин (НИУ ВШЭ и ИП РАН)

Е.Н. Осин (НИУ ВШЭ)

А.Н. Поддьяков (НИУ ВШЭ)

Е.Б. Старовойтенко (НИУ ВШЭ)

Д.В. Ушаков (зам. глав. ред.) (ИП РАН)

М.В. Фаликман (НИУ ВШЭ)

А.В. Хархурин (НИУ ВШЭ)

ВД. Шадриков (зам. глав. ред.) (НИУ ВШЭ)

С.А. Щебетенко (НИУ ВШЭ)

C.P. Яголковский (зам. глав. ред.) (НИУ ВШЭ)

\section{Экспертный совет}

К.А. Абульханова-Славская (НИУ ВШЭ и ИП РАН)

Н.А. Алмаев (ИП РАН)

B.А. Барабанщиков (ИП РАН и МГППУ)

Т.Ю. Базаров (НИУ ВШЭ и МГУ им. М.В. Ломоносова)

А.К. Болотова (НИУ ВШЭ)

А.Н. Гусев (МГУ им. М.В. Ломоносова)

А.Л. Журавлев (ИП РАН)

A.B. Карпов (Ярославский государственный университет им. П.Г. Демидова)

П. Луиисано (Римский университет Ла Сапиенца, Италия)

А. Лэнгле (НИУ ВШЭ)

А.Б. Орлов (НИУ ВШЭ)

В.Ф. Петренко (МГУ им. М.В. Ломоносова)

B.M. Розин (ИФ РАН)

И.Н. Семенов (НИУ ВШЭ)

E.A. Сергиенко (ИП РАН)

т.Н. Уиакова (ИП РАН)

А.М. Черноризов (МГУ им. М.В. Ломоносова)

А.Г. Шмелев (МГУ им. М.В. Ломоносова)

П. Шмидт (НИУ ВШЭ и Гиссенский университет, Германия)

\section{ПСИХОЛОГИЯ Журнал Высшей школы экономики}

ISSN 1813-8918; e-ISSN: 2541-9226

«Психология. Журнал Высшей школы экономики» издается с 2004 г. Национальным исследовательским университетом «Высшая школа экономики» и поддерживается департаментом психологии НИУ ВШЭ. Миссия журнала - это

- повышение статуса психологии как фундаментальной и практико-ориентированной науки;

- формирование новых предметов и программ развития психологии как интердисциплинарной сферы исследований;

• интеграция основных достижений российской и мировой психологической мысли;

- формирование новых дискурсов и направлений исследований;

- предоставление площадки для обмена идеями, результатами исследований, а также дискуссий по основным проблемам современной психологии.

В журнале публикуются научные статьи по следующим основным темам:

- достижения и стратегии развития когнитивной, социальной и организационной психологии, психологии личности, персонологии, нейронаук;

- методология, история и теория психологии;

- методы и методики исследования в психологии;

- интердисциплинарные исследования;

- дискуссии по актуальным проблемам фундаментальных и прикладных исследований в области психологии и смежных наук.

Целевая аудитория журнала включает профессиональных психологов, работников образования, представителей органов государственного управления, бизнеса, экспертных сообществ, студентов, а также всех тех, кто интересуется проблемами и достижениями психологической науки.

Журнал выходит 1 раз в квартал и распространяется в России и за рубежом.

Выпускающий редактор Р.M. Байрамян

Редакторы О.В. Шапошникова, О.В. Петровская, Д. Вонсбро. Корректура Н.С. Самбу Переводы на английский К.А. Чистопольская, Е.Н. Гаевская

Компьютерная верстка E.A. Валуевой

Адрес редакции:

101000, г. Москва, Армянский пер. 4, корп. 2.

E-mail: psychology.hse@gmail.com

Сайт: http://psy-journal.hse.ru/

Перепечатка материалов только по согласованию с редакцией.

(с) НИУ ВШЭ, 2021 г. 


\section{Том 18. № 1 2021}

\section{ПСИХОЛОГИЯ Журнал Высшей школы экономики}

\section{СОДЕРЖАНИЕ}

\section{Специальная тема выпуска: Психодиагностика}

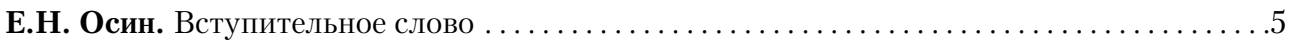

А.Ю. Калугин, С.А. Щебетенко, А.М. Мишкевич, К.Дж. Сото, О.П. Джон.

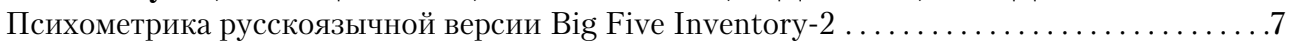

Т.О. Гордеева, О.А. Сычев, Е.Н. Осин. Диагностика диспозиционного оптимизма, валидность и надежность опросника ТДО-П ..............................

Н.Е. Веракса, А.Н. Веракса, М.Н. Гаврилова, Д.А. Бухаленкова, К.С. Тарасова.

Тест на понимание эмоций: адаптация русскоязычной версии на российской выборке детей дошкольного возраста . . . . . . . . . . . . . . . . . . . . . . . 56

О.Е. Хухлаев, В.В. Гриценко, А.В. Макарчук, О.С. Павлова, Н.В. Ткаченко, ШІ.А. Усубян, В.А. Шорохова. Разработка и адаптация методики «Интегративный опросник межкультурной компетентности» .............................. 71

T.Е. Хавенсон, А.А. Лукина. Мотивы инноваторов в образовании: подходы к определению и разработка шкалы для измерения . . . . . . . . . . . . . . . . . . . . 92

А.Н. Моспан, Д.А. Леонтьев. Апробация и валидизация методики веры в свободу/детерминизм (FAD-Plus) на российской выборке

\section{Статьи}

Е.А. Валуева, Е.М. Лаптева, А.А. Григорьев. Интеллект регионов России

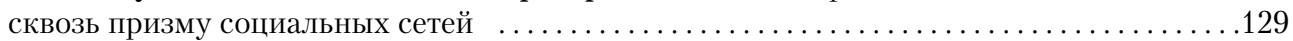

С.В. Морозова. Mathematische Psychologie: история конфликта . . . . . . . . . . . . . 145

В.М. Розин. Является ли реализация системно-информационного подхода

В.М. Петрова способом преодоления кризиса в психологии и других гуманитарных науках?

Г.В. Ожиганова. Духовные способности личности и продуктивная жизнедеятельность (на английском языке)

\section{Короткие сообщения}

А.Ю. Климочкина. Религиозная практика православных россиян как фактор экзистенциального благополучия

А.О. Петрова, Е.Г. Лунякова, М.В. Фаликман. Эффект взгляда-подсказки в виртуальной среде: влияние социальной установки и социальной дистанции

A.B. Зирко. Типы вокализаций в самовыражении и самоисследовании (на английском языке) 


\section{Vol. 18. No 1 2021}

Publisher

HSE University

\section{Editor-in-Chief}

Vadim Petrozsky, HSE University, Russian Federation

\section{Editorial board}

John Berry, Queen's University, Canada

Gershons Breslavs, Baltic International Academy, Latvia Maria Falikman, HSE University, Russian Federation

Elena Grigorenko, Lomonosov MSU, Russian Federation, and Yale Child Study Center, USA

Vasily Klucharev, HSE University, Russian Federation Anatoliy Kharkhurin, HSE University, Russian Federation

Dmitry Leontiev, HSE University and Lomonosov MSU, Russian Federation

Vladimir Lepskiy, Institute of Philosophy of RAS, Russian Federation

Martin Lynch, University of Rochester, USA

Dmitry Lyusin, HSE University and Institute of Psychology of RAS, Russian Federation

Evgeny Osin, HSE University, Russian Federation Alexander Poddiakov, HSE University, Russian Federation Sergei Shchebetenko, HSE University, Russian Federation Vladimir Shadrikov, Deputy Editor-in-Chief, HSE University, Russian Federation

Elena Starovoytenko, HSE University, Russian Federation Dmitry Ushakov, Deputy Editor-in-Chief, Institute of Psychology of RAS, Russian Federation

Jaan Valsiner, Aalborg University, Denmark

Sergey Yagolkozskiy, Deputy Editor-in-Chief, HSE University, Russian Federation

\section{Editorial council}

Ksenia Abulkhanova-Slavskaja, HSE University and Institute of Psychology of RAS, Russian Federation

Nikolai Almaer, Institute of Psychology of RAS, Russian Federation Vladimir Barabanschikoz, Institute of Psychology of RAS and Moscow University of Psychology and Education, Russian Federation

Takhir Bazarov, HSE University and Lomonosov MSU, Russian Federation

Alla Bolotova, HSE University, Russian Federation Alexander Chernorisov, Lomonosov MSU, Russian Federation Alexey Guser, Lomonosov MSU, Russian Federation Anatoly Karpov, Demidov Yaroslavl State University, Russian Federation

Alfried Ldngle, HSE University, Russian Federation

Pietro Lucisano (Sapienza University of Rome, Italia) Alexander Orlov, HSE University, Russian Federation Victor Petrenko, Lomonosov MSU, Russian Federation Vadim Rozin, Institute of Philosophy of RAS, Russian Federation Igor Semenov, HSE University, Russian Federation

Elena Sergienko, Institute of Psychology of RAS, Russian Federation Alexander Shmelev, Lomonosov MSU, Russian Federation

Peter Schmidt, HSE University, Russian Federation, and Giessen University, Germany

Tatiana Ushakova, Institute of Psychology of RAS, Russian Federation

Anatoly Zhuravlev, Institute of Psychology of RAS, Russian Federation
PSYCHOLOGY al of the Higher School of Economics
«Psychology. Journal of the Higher School of Economics» was established by the National Research University «Higher School of Economics» (HSE) in 2004 and is administered by the School of Psychology of HSE.

Our mission is to promote psychology both as a fundamental and applied science within and outside Russia. We provide a platform for development of new research topics and agenda for psychological science, integrating Russian and international achievements in the field, and opening a space for psychological discussions of current issues that concern individuals and society as a whole.

Principal themes of the journal include:

- methodology, history, and theory of psychology

- new tools for psychological assessment;

- interdisciplinary studies connecting psychology with economics, sociology, cultural anthropology, and other sciences;

- new achievements and trends in various fields of psychology;

- models and methods for practice in organizations and individual work;

- bridging the gap between science and practice, psychological problems associated with innovations;

- discussions on pressing issues in fundamental and applied research within psychology and related sciences.

Primary audience of the journal includes researchers and practitioners specializing in psychology, sociology, cultural studies, education, neuroscience, and management, as well as teachers and students of higher education institutions. The journal publishes 4 issues per year. It is distributed around Russia and worldwide.

\section{Managing editor R.M. Bayramyan}

Copy editing O.V. Shaposhnikova, O.V. Petrovskaya, N.S. Sambu, D. Wansbrough

Translation into English K.A. Chistopolskaya,

E.N. Gaevskaya

Page settings E.A. Valueva

Editorial office's address:

4 Armyanskiy pereulok, build. 2, 101000, Moscow,

Russia.

E-mail: psychology.hse@gmail.com

Website: http://psy-journal.hse.ru/

No part of this publication may be reproduced without the prior permission of the copyright owner

(C) HSE University, 2021 г. 
Vol. 18. No 1

2021
PSYCHOLOGY

Journal of the Higher School of Economics

\section{CONTENTS}

\section{Special Theme of the Issue. Psychodiagnostics}

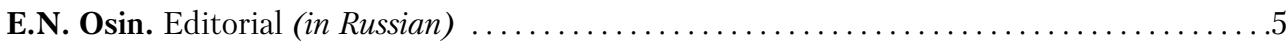

A.Yu. Kalugin, S.A. Shchebetenko, A.M. Mishkevich, C.J. Soto, O.P. John. Psychometric Properties of the Russian Version of the Big Five Inventory-2 (in Russian) ............... T.O. Gordeeva, O.A. Sychev, E.N. Osin. Diagnostics of Dispositional Optimism: Validity and Reliability of Russian Version of LOT-R (in Russian) ........................ 34

N.E. Veraksa, A.N. Veraksa, M.N. Gavrilova, D.A. Bukhalenkova, K.S. Tarasova. The Russian Version of the Test of Emotion Comprehension: Adaptation and Validation

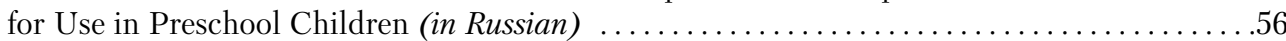

O.E. Khukhlaev, V.V. Gritsenko, A.V. Makarchuk, O.S. Pavlova, N.V. Tkachenko, Sh.A. Usubian, V.A. Shorokhova. Development and Adaptation of the Integrative Intercultural Competence Survey (in Russian) ............................... 71 T.E. Khavenson, A.A. Lukina. Measuring Motivation for Innovation in Education: Concept Definition and Scale Validation (in Russian)

A.N. Mospan, D.A. Leontiev. Approbation and Validation of the Freedom/Determinism Beliefs Inventory (FAD-Plus) in the Russian Sample (in Russian)

\section{Articles}

E.A. Valueva, E.M. Lapteva, A.A. Grigoriev. Regional IQ Differences in Russia through the Prism of Social Media (in Russian)

S.V. Morozova. Mathematische Psychologie: History of Conflict (in Russian)

V.M. Rozin. Is the Implementation of a System-Information Approach by V.M. Petrov a Method for Overcoming Crisis in Psychology and other Human Sciences? (in Russian) ..167 G.V. Ozhiganova. Spiritual Capacities of Personality and Productive Life Activity ........182

\section{Work in progress}

A.Yu. Klimochkina. Religious Practice of Russian Orthodox Christians as a Factor of Existential Well-Being (in Russian)

A.O. Petrova, E.G. Luniakova, M.V. Falikman. Gaze Cueing in Virtual Reality:

Effects of Social Set and Social Distance (in Russian)

A.V. Zirko. Types of Vocalizations in Self-Expression and Self-Inquiry 
Психология. Журнал Высшей школы экономики.

2021. T. 18. № 1. C. 5-6. DOI: 10.17323/1813-8918-2021-1-5-6

\section{Oт редакици}

\section{Дорогие читатели!}

Редакция журнала поздравляет члена нашей редакционной коллегии, руководителя департамента НИУ ВШЭ, профессора М.В. Фаликман с юбилеем! Полный текст поздравления размещен на сайте журнала https://psy-journal.hse.ru/news/318502709.html

\section{Специальная тема выпуска: Психодиагностика}

\section{Приглашенный редактор - Е.Н. Осин}

\section{ВСТУПИТЕЛЬНОЕ СЛОВО}

Прошедший год был наполнен беспрецедентными событиями, изменившими нашу жизнь, и характер этих изменений нам только предстоит понять и оценить. На первом месте, с большим отрывом - пандемия коронавируса, которая заслуженно привлекла внимание исследователей по всему миру, оказавшись уникальным естественным экспериментом. Тем не менее, в ожидании окончания пандемии (и новых исследовательских работ, выполненных в этом контексте), можно вспомнить фразу, приписываемую Фридриху Вильгельму I: «война войной, а обед по расписанию».

Ни пандемия коронавируса, ни иные неприятности не должны отвлечь нас от одной из важнейших задач психологии - разработки и адаптации новых психометрических инструментов. Сегодняшний специальный выпуск журнала «Психология. Журнал Высшей школы экономики» продолжает традицию предыдущих лет и представляет вниманию русскоязычных исследователей набор из шести современных психодиагностических методик, потребность в которых давно назрела.

Спецвыпуск открывает статья А.Ю. Калугина, С.А. Щебетенко, А.М. Мишкевич, К.Дж. Сото и О.П. Джона, которые представляют русскоязычную версию BFI-2 - новой версии опросника «Big Five Inventory» (BFI) О.П. Джона и К.Дж. Сото. Помимо базовых измерений «Большой пятерки» личностных черт, этот вариант методики включает 15 фасетных шкал, предоставляя более оптимальный баланс между объемом стимульного материала и полнотой получаемых данных об индивидуальных различиях.

В работе Т.О. Гордеевой, О.А. Сычева и Е.Н. Осина представлена новая версия Теста диспозиционного оптимизма (ТДО-П) - русскоязычного аналога теста LOT-R M. Шейера, Ч. Карвера и М. Бриджеса, сокращенной и пересмотренной 
версии методики «Life Orientations Test» (LOT) Ч. Карвера и М. Шейера. Описаны два исследования, которые дают более подробную информацию о психометрических характеристиках и конвергентной валидности обновленной версии методики на широких и репрезентативных выборках.

Статья Н.Е. Вераксы, А.Н. Вераксы, М.Н. Гавриловой, Д.А. Бухаленковой и К.С. Тарасовой сообщает об итогах русскоязычной адаптации Теста на понимание эмоций, «Test of Emotion Comprehension» (TEC) Ф. Понса и П. Харриса, который активно используется в международных исследованиях понимания эмоций у детей дошкольного возраста. Количество доступных инструментов для этой возрастной группы крайне мало - тем более отрадно, что теперь эта методика существует и на русском языке.

В работе О.Е. Хухлаева, В.В. Гриценко, А.В. Макарчук, О.С. Павловой, Н.В. Ткаченко, Ш.А. Усубян и В.А. Шороховой представлена новая методика «Интегративный опросник межкультурной компетентности», созданный авторами путем обобщения различных моделей межкультурной компетентности. Разработанный короткий и эвристичный инструмент обладает хорошими психометрическими характеристиками и предоставляет интересные возможности для исследователей, заинтересованных проблематикой отношений между культурами.

В статье Т.Е. Хавенсон и А.А. Лукиной представлена шкала мотивации инновационной деятельности в образовании, разработанная на основе англоязычной шкалы «Причины основания бизнеса» (PSED). Опросник измеряет выраженность четырех типов мотивации внедрения инноваций, запуска проектов, создания нового без привязки к конкретной сфере деятельности и, несмотря на валидизацию в контексте образования, может быть использован в самых различных исследовательских ситуациях.

Спецвыпуск завершает статья А.Н. Моспан и Д.А. Леонтьева, представляющая русскоязычную валидизацию опросника веры в свободу и детерминизм «Free Will and Determinism Plus Scale» (FAD-Plus) Д. Полуса и Дж. Кэри. Согласно данным представленных в работе исследований, вера в свободу человека (в противовес детерминизму) выступает адаптивной характеристикой личности и демонстрирует связи с психологическим благополучием, осмысленностью жизни и персональной ответственностью, вновь подтверждая идеи В. Франкла. Этот новый конструкт выглядит перспективным для развития исследований, в первую очередь, экзистенциального направления.

Перечисленные новые и обновленные методики измеряют различные конструкты - от базовых личностных черт и оптимизма до понимания эмоций и веры в человеческую свободу. Они предназначены для различных задач, условий и демографических групп. Авторы большинства статей включили в свои работы стимульный материал, сделав эти разработки доступными для всех заинтересованных исследователей. Мы надеемся, что эти инструменты обогатят психометрический инструментарий, доступный русскоязычным ученым, и помогут дальнейшей интеграции русскоязычных исследований в контекст мировой науки. Перефразируя античную пословицу, пандемия пройдет, а опросники - останутся.

E.H. Осин 
Психология. Журнал Высшей школы экономики,

2021. T. 18. № 1. C. 7-33. DOI: 10.17323/1813-8918-2021-1-7-33

\title{
ПСИХОМЕТРИКА РУССКОЯЗЫЧНОЙ ВЕРСИИ BIG FIVE INVENTORY-2
}

\author{
А.Ю. КАЛУГИН ${ }^{a}$, С.А. ЩЕБЕТЕНКО ${ }^{\mathrm{b}, \mathrm{c}}$, А.М. МИШКЕВИЧ \\ К.ДЖ. СОТО
}

\author{
${ }^{a}$ Пермский государственный гуманитарно-педагогический университет, 614990, Россия, г. Пермъ, \\ ул. Сибирская, 24 \\ ${ }^{b}$ Национальный исследовательский университет «Высшая школа экономики», 101000, Россия, \\ Москва, ул. Мясницкая, д. 20 \\ 'Пермский государственный национальный исследовательский университет, 614990, Россия, г. Пермь, \\ ул. Букирева, 15 \\ ${ }^{d}$ Колледж Колби, 04901, США, 4000 Мэйфлауэр Хилл, Уотервилл, итат Мэн \\ e Калифорнийский университета в Беркли, 94720, США, 2227 Пьемонт Авеню, Беркли, Калифорния
}

\section{Резюме}

Статья посвящена проверке психометрических характеристик русскоязычной версии методики Big Five Inventory-2. Данная методика измеряет пять черт личности, а также три аспекта (фасета) каждой черты. Сбор данных осуществлялся в сети Интернет, итоговая выборка составила 1787 человек (31.9\% мужчин) в возрасте от 14 до 54 лет (M = 26.31; $\mathrm{SD}=7.76)$. В ходе исследования было охвачено более десяти субъектов Российской Федерации. Структура опросника изучалась с помощью анализа главных компонент, конфирматорного факторного анализа и эксплораторного факторного анализа со случайным интерсептом (random intercept exploratory factor analysis). В результате была подтверждена структура опросника как на уровне шкал (черт), так и на уровне субшкал (аспектов черт). Оценка межгрупповой инвариантности показала, что можно говорить о строгой эквивалентности моделей в выборках по полу. Это позволяет сравнивать сырые баллы по шкалам и субшкалам опросника при оценке половых различий. Выявленные различия при сравнении по полу согласуются с имеющимися в науке данными о половых различиях в чертах. Надежность, измеренная, в частности, с помощью альфы Кронбаха и омеги Макдональда, продемонстрировала удовлетворительную, хорошую и высокую степень внутренней согласованности. Проверка дискриминативности шкал (коэффициент дельта Фергюсона в адаптации М. Хэнкинса) показала высокую степень способности опросника дифференцировать испытуемых по степени выраженности изучаемых признаков. Таким образом, русскоязычная версия опросника Big Five Inventory-2 может считаться надежным и валидным инструментом для измерения основополагающих черт личности и их аспектов.

Ключевые слова: «Большая пятерка», личность, Big Five Inventory-2, психометрика, валидность, надежность.

Публикация подготовлена в ходе проведения исследования (№ 19-01-003) в рамках Программы «Научный фонд Национального исследовательского университета "Высшая школа экономики” (НИУ ВШЭ)» в 2019-2020 гг. и в рамках государственной поддержки ведущих университетов Российской Федерации «5-100». 


\section{Введение}

Пятифакторная структура личности впервые встречается в англоязычных исследованиях середины прошлого века (Fiske, 1949; Norman, 1963; Tupes, Christal, 1992; и др.). Впервые применительно к чертам личности понятие «Большая пятерка» («The Big Five») употребил Л. Голдберг в 1981 г. Он развивал так называемую лексическую гипотезу (Allport, Odbert, 1936; Cattell, 1943; Galton, 1884), утверждающую, что черты личности находят отражение в языке. Предполагается, что путем применения техник редукции данных (особой популярностью здесь пользуется факторный анализ) из лексических единиц языка можно выделить структуру черт личности (Goldberg, 1981).

Модель «Большой пятерки» (БП $)$ состоит из следующих черт личности: Экстраверсия, Доброжелательность, Добросовестность, Нейротизм и Открытость опыту. БП пользуется широкой популярностью среди исследователей; ее валидность подтверждена и на российской популяции (Барановская, 2005; Егорова, Паршикова, 2016; Осин и др., 2015; Щебетенко, Вайнштейн, 2014; Shmelyov, Pokhilko, 1993; и др.).

Для измерения пяти черт личности существует целый ряд валидных и надежных методик (например, BFI, BFQ, NEO-PI-R и др.). Часть этих методик переведена на русский язык: «Локатор большой пятерки» (The Big Five Locator, BFL; Бурлачук, Королев, 2000); русскоязычная версия личностного опросника NEO-FFI (Орел, Сенин, 2008; Martin et al., 2002); русскоязычная версия «Маркеры факторов “Большой пятерки”» Л. Голдберга (International Personality Items Pool, IPIP; Князев и др., 2010); русскоязычная версия «Вопросника Большой Пятерки» (Big Five Inventory, BFI; Shchebetenko, 2014). Кроме этого, в последние годы опубликовано несколько русскоязычных версий кратких опросников (по 10 пунктов): две версии «Краткого Пятифакторного опросника личности» (Ten Item Personality Inventory, TIPI; Сергеева и др., 2016; Корнилова, Чумакова, 2016), а также русская версия «Короткого портретного опросника Большой пятерки» (Б5-10) (Егорова, Паршикова, 2016).

Данные методики в основном измеряют только пять черт личности. Нами обнаружено всего несколько тестов, измеряющих не только черты, но и их составляющие - аспекты, или фасеты (facets). Среди них русскоязычная версия 75-пунктного пятифакторного опросника (Хромов, 2000, 2010), русскоязычная версия 240-пунктного NEO-PI-R (Орел, Сенин, 2004), русскоязычная версия 170-пунктного Big Five Questionnaire (BFQ-2) (Осин и др., 2015). Таким образом, исследователь обычно стоит перед выбором: использовать достаточно объемную, но информативную методику, измеряющую как черты, так и фасеты, или более компактный вопросник, но измеряющий только черты.

Одной из самых перспективных в этом смысле методик на английском языке является новая версия широко известного вопросника BFI (John et al.,

${ }^{1}$ Существует также тесно связанная с БП традиция, именуемая «Пятифакторной моделью» (McCrae, Costa, 1987). 
1991, 2008). Недавно эта версия (BFI-2) была переведена нами на русский язык (Shchebetenko et al., 2020).

\section{Meтодика Big Five Inventory-2}

Первая версия BFI была разработана в конце 1980-х гг. Этот 44-пунктный инструмент находится в свободном доступе, что, в совокупности с хорошими психометрическими показателями, послужило его широкому применению при изучении черт личности, в том числе с использованием сети Интернет (John, Srivastava, 1999; Srivastava et al., 2003; и др.). Шкалы BFI показывают хорошую надежность и валидность; это относится как к оригинальной английской версии (John et al., 2008), так и к русскоязычной версии (Мишкевич, Щебетенко, 2017; Shchebetenko, 2014).

BFI-2 была опубликована в 2017 г. (Soto, John, 2017). Эта полностью переработанная версия сохранила все преимущества первого BFI. BFI-2 достаточно компактна: она состоит из 60 пунктов, сформулированных в виде коротких и понятных фраз. Это делает тест лаконичным, хотя каждая шкала имеет достаточное количество пунктов, что позволяет эффективно измерять черты. В то же время BFI-2 позволяет изучить не только общие черты, но и фасеты, из которых они состоят. В дополнение к этому шкалы BFI-2 полностью сбалансированы: шкала каждой черты состоит из трех субшкал (фасет), которые, в свою очередь, включают по четыре пункта - два прямых и два обратных.

Фасеты черт определялись в ходе эмпирических и теоретических исследований. В результате была сформирована следующая структура (Ibid.):

1. Экстраверсия (Extraversion)
а. Общительность (Sociability)
b. Настойчивость (Assertiveness)
c. Энергичность (Energy Level)

2. Доброжелательность (Agreeableness)
a. Сочувствие (Compassion)
b. Уважительность (Respectfulness)
c. Доверие (Trust)

3. Добросовестность (Conscientiousness)
а. Организованность (Organization)
b. Продуктивность (Productiveness)
c. Ответственность (Responsibility)

4. Негативная эмоциональность (Negative Emotionality)
a. Тревожность (Anxiety)
b. Депрессивность (Depression)
c. Эмоциональная изменчивость (Emotional Volatility)

5. Открытость опыту (Open-Mindedness)
а. Эстетичность (Aesthetic Sensitivity)
b. Любознательность (Intellectual Curiosity)
c. Творческое воображение (Creative Imagination) 
В кросс-культурном контексте существуют два основных подхода к идентификации черт личности (например: Burtăverde et al., 2018). Согласно первому (emic) подходу, необходимо определить те компоненты личности, которые являются культурно-специфическими. Например, А.Г. Шмелев в рамках лексической парадигмы выявил пятнадцать факторов личностных черт в русской культуре, которые затем соотнес с пятью факторами «Большой пятерки» (устойчивое сходство было обнаружено для четырех факторов) (Голдберг, Шмелев, 1993). Второй (etic) подход ставит своей задачей тестирование того, насколько некая теоретическая модель, валидизированная в одной культурной среде, может быть успешно перенесена в иную культурную среду. Адаптация иноязычных вопросников в новой среде является классическим примером еtic-подхода. К нему также относится и настоящая работа. Так, в нашем случае названия шкал и субшкал являются практически прямым переводом англоязычных наименований. В то же время культурная специфика российской среды нашла отражение в частичной коррекции содержания пунктов теста. Восемь экспертов-билингвов произвели прямой и обратный переводы пунктов BFI-2. Все спорные моменты были обсуждены в ходе онлайн-конференции переводчиков, а альтернативные варианты, по которым не удалось прийти к консенсусу, были сохранены для дальнейшей эмпирической проверки. В итоге двенадцать пунктов были заменены на более подходящие русскоязычные аналоги.

\section{Метод}

\section{Организация исследования}

Ранее нами был представлен дизайн адаптации BFI-2 к русскоязычной культуре, а также приведены некоторые психометрические показатели (Shchebetenko et al., 2020). Однако акцент в указанной статье был сделан на анализе половых и возрастных различий в чертах личности. Настоящая статья посвящена углубленному изучению надежности и валидности русской BFI-2 на основе нового массива данных, полученного в ходе онлайн-тестирования.

В сети Интернет авторами был создан сайт, на котором был размещен адаптированный вариант методики (с расширенным списком вопросов). Несмотря на то что тест привлекал посетителей «громким названием» («Кто ты в “Игре престолов”?»), в инструкции было указано, что авторы преследуют сугубо научные цели - создать русскую версию Big Five Inventory-2.

\section{Участники исследования}

Благодаря свободному распространению теста в сети Интернет удалось охватить пользователей из многих регионов РФ. В выборку вошли жители Перми и Пермского края, Москвы и Московской области, Санкт-Петербурга, Екатеринбурга, Волгограда, Уфы и Башкортостана, Хабаровска и 
Хабаровского края и др. Всего было протестировано 2067 человек; после удаления повторных попыток прохождения теста выборка сократилась до 1808, а после ограничения возрастного диапазона 14-54 годами $(\mathrm{M}=26.31$; $\mathrm{SD}=7.76$ ) осталось 1787 человек. Среди респондентов было 1217 женщин и 570 мужчин ( 68.1 и $31.9 \%$ соответственно).

\section{Допущения исследования}

Как и любой другой интернет-опрос, данный тест имеет несколько тонких моментов. Во-первых, поскольку отвечающие на тест были анонимны, они могли дать недостоверные сведения о своем возрасте, поле и регионе проживания. Во-вторых, «игровой формат» теста (когда предлагается узнать, кем бы являлся респондент в мире «Игры престолов») мог спровоцировать несерьезное отношение к тестированию, стремление давать ответы под конкретного персонажа, «поиграть с настройками».

Осознавая эти проблемы, мы постарались их учесть. Во-первых, очевидная валидность теста была подкреплена обширной инструкцией, поясняющей серьезность предлагаемой методики и ее научный характер. Во-вторых, параллельно шел сбор эмпирического материала традиционным способом на другой выборке и в очном формате. Это позволило впоследствии сравнить результаты, полученные в «офлайновой» и «онлайновой» средах (существенных различий выявлено не было, см.: Shchebetenko et al., 2020). В-третьих, мы постарались максимально широко распространить информацию об онлайнтестировании среди групп респондентов, с которыми непосредственно взаимодействовали, знали по трудовой деятельности (преподавательской и научной) и личным контактам. В-четвертых, была проведена подготовительная работа с данными по отбраковке повторных попыток прохождения теста (учитывался только первый вариант прохождения). Это снизило количество наблюдений, но позволило уменьшить влияние «игрового момента» (когда респонденты пытались получить другие результаты тестирования, отвечая иначе на некоторые вопросы). Указанные превентивные меры не исключали возможность обмана, однако могли способствовать снижению количества недостоверной информации, получаемой от респондентов.

\section{Методы статистической обработки}

Перед проведением основных статистических процедур, вслед за К. Сото и О. Джоном (Soto, John, 2017), данные были центрированы вокруг внутрииндивидуального среднего каждого респондента (без реверсирования обратных пунктов). Сото и Джон предлагают следующую процедуру центрирования: сначала вычисляется «индекс согласия» - средняя оценка ответов респондента на каждый вопрос опросника (среднее считается по строкам), затем из каждого ответа респондента вычитается его «индекс согласия». Хотя центрирование мало влияет на характеристики надежности и тесноту корреляционных связей со шкалами других методик в сравнении с «сырыми» данными, оно 
тем не менее повышает согласованность внутри аспектов черт и улучшает согласованность факторных структур (Soto, John, 2009).

Оценка нормальности распределения пунктов и шкал проводилась на основе асимметрии и эксцесса, так как в случае больших выборок критерии нормальности становятся чрезмерно чувствительными. Значения асимметрии и эксцесса в пределах \pm 1 могут считаться «отличными» для большинства психометрических целей, а \pm 2 - «приемлемыми» (George, Mallery, 2016, p. 114115).

Анализ структуры опросника проводился тремя методами: 1) анализом главных компонент (principal component analysis, PCA), 2) конфирматорным факторным анализом (confirmatory factor analysis, CFA), 3) эксплораторным факторным анализом со случайным интерсептом (random intercept exploratory factor analysis, RI-EFA; Aichholzer, 2014), одной из модификаций эксплораторного структурного моделирования (Exploratory Structural Equation Modeling, ESEM; Asparouhov, Muthen, 2009). Причины такого разнообразия подходов в следующем. Во-первых, РСА, являясь эксплораторным методом, позволяет оценить эмпирическую структуру данных в «поисковом режиме», однако не дает возможности сравнивать модели. Во-вторых, CFA позволяет оценить соответствие теоретической структуры эмпирическим данным и сравнивать различные модели, однако из-за большого количества пунктов и многофакторной структуры опросника найти приемлемую согласованность с помощью CFA затруднительно. В-третьих, ESEM объединяет сильные стороны эксплораторных и конфирматорных методов изучения структуры: действуя эксплораторным путем, он позволяет сравнивать модели.

С помощью РСА проверялось соответствие конструкта эмпирическим данным. На первом этапе количество компонент было ограничено пятью (по количеству черт личности), метод вращения - «varimax». На втором этапе РСА использовался отдельно для каждой шкалы-черты; задавались три главные компоненты (по количеству субшкал-фасет), метод вращения - «varimax». Дополнительно оценивалась усредненная корреляция пунктов с пунктами «своей» шкалы и пунктами других шкал.

C помощью CFA (метод MLR, устойчивый к отклонениям от нормального распределения) тестировались три модели. Модель 1 включала 5 латентных факторов, не связанных друг с другом, каждый фактор отражал одну из пяти черт «Большой пятерки». Модель 2 соответствовала модели 1, однако факторы коррелировали. Модель 3 соответствовала модели 2, допуская свободные ковариации ошибок между пунктами субшкал. В моделях использовались центрированные пункты.

C помощью RI-EFA проверялись модели 2 и 3. В данном случае использовались «сырые» пункты, так как RI-EFA - это бифакторная модель, в которой общий фактор отвечает за склонность респондента давать положительные ответы (acquiescence). Применялся алгоритм оценки MLR.

Для лучшей модели была проведена проверка инвариантности по полу. На первом этапе проверялась инвариантность структуры (configural invariance), т.е. предполагалось, что одни и те же переменные в сравниваемых группах 
образуют одни и те же латентные факторы. На втором этапе проверялась метрическая инвариантность (metric invariance): вводилось ограничение на равенство факторных нагрузок в сравниваемых группах. На третьем этапе проверялась скалярная инвариантность (scalar invariance): вводилось ограничение на равенство интерсептов. На четвертом этапе проверялась строгая инвариантность (strict invariance) дополнительно к скалярной инвариантности, предполагающая равенство дисперсии остатков в сравниваемых группах.

Помимо статистики $\chi^{2}$, чувствительной к размеру выборки и нарушению предположения о нормальности распределения (Chen, 2007, p. 465), мы опирались на более робастные критерии определения инвариантности. Предлагаются следующие пороги для выборки размером более 300: при тестировании метрической инвариантности $\triangle \mathrm{CFI}>0.01$ в дополнение к $\triangle \mathrm{RMSEA}$ $>0.015$ или $\triangle \mathrm{SRMR}>0.03$ будет свидетельствовать об отсутствии инвариантности. При тестировании скалярной инвариантности $\triangle \mathrm{CFI}>0.01$ в дополнение к $\triangle \mathrm{RMSEA}>0.015$ или $\triangle \mathrm{SRMR}>0.01$ также будет свидетельствовать об отсутствии инвариантности (там же).

При проведении РСА был использован пакет «psych», а при построении CFA - пакет «lavaan» среды языка программирования R. RI-EFA был проведен в программе Mplus v.8.

Надежность опросника проверялась несколькими способами. Традиционно использовалась $\alpha$ Кронбаха и стандартизованная $\alpha$. Однако $\alpha$ имеет чрезмерно жесткие допущения к своему использованию (в частности, тау-эквивалентность, равенство ковариаций пунктов в тесте и т.д.) и в случае нарушения этих требований занижает оценку надежности (McNeish, 2018). Поэтому для оценки внутренней согласованности использовалась также $\omega$ Макдональда (McDonald, 2013; Revelle, Zinbarg, 2009), позволяющая оценивать надежность иерархически организованных тестов.

Согласованность субшкал (фасет) со шкалой (чертой) и между собой изучалась с помощью скорректированной на затухание корреляции, учитывающей неабсолютную надежность шкал (Фер, Бакарак, 2010).

Важным психометрическим показателем шкалы является возможность различать респондентов по выраженности рассматриваемого признака - $\partial u c-$ криминативность. В определенной степени дискриминативность противостоит надежности, так как «использование заданий с широким перечнем возможных проявлений измеряемого свойства уменьшает взаимную корреляцию между заданиями» (Клайн, 1994, с. 205). Однако в опроснике важно учесть обе эти стороны.

Коэффициент $\triangle$ Фергюсона (Ferguson, 1949) позволяет оценить степень дискриминативности шкалы. Нами была использована его модификация (Hankins, 2007) для политомических шкал, таких как шкалы Ликерта. Дискриминативность вычислялась для шкал, основанных на «сырых» баллах, так как на основе центрированных шкалы не формировались.

Конвергентная и дискриминантная валидность. В рамках проведенного исследования не были собраны материалы, позволяющие судить о внешней 
конвергентной и дискриминантной валидности, однако читатель может обратиться в этой связи к нашей предыдущей публикации (Shchebetenko et al., $2020)^{2}$.

\section{Результаты}

\section{Описательные статистики}

Показатели асимметрии и эксцесса для пунктов опросника не превышали 2 по абсолютному значению. Семь пунктов в «сырых» баллах вышли за границу 1 (по модулю) по асимметрии и 20 - по эксцессу. В центрированных баллах три пункта вышли за пределы 1 для асимметрии и 16 пунктов для эксцесса. Таким образом, распределение пунктов соответствует нормальному на отличном и приемлемом уровне как по «сырым», так и по центрированным баллам. Качество центрированных пунктов было несколько выше.

Проверка распределения шкал и субшкал (таблица 1), рассчитанных по «сырым» баллам, показала, что по асимметрии и эксцессу ни одна из них не превышала по модулю единицы, что свидетельствует об отличном соответствии нормальному распределению. Однако визуальный анализ гистограмм не столь однозначен. В целом несколько асимметричными в сторону высоких значений выглядят шкалы Открытости опыту: Эстетичности, Любознательности и Творческого воображения, а также общая шкала Открытости опыту. Определенная степень отрицательной асимметрии была также присуща субшкалам Сочувствие и Ответственность. Эксцесс не был столь выражен и в основном имел отрицательное значение.

\section{Конструктная валидность теста и инвариантность по полу}

Таблицы с результатами РСА для пяти черт личности и 15 фасет вынесены в дополнительные материалы (таблицы Д1-Д6). В целом все пункты, кроме п. 11 (который эмпирически в большей степени был представлен в Негативной эмоциональности, чем в Экстраверсии), имели максимальные нагрузки в своих главных компонентах-шкалах. Для Негативной эмоциональности нагрузки соответствующих пунктов варьировали от 0.41 до 0.73 для «сырых» баллов и от 0.46 до 0.72 для центрированных в абсолютном выражении. Экстраверсия имела нагрузки соответствующих пунктов: от 0.33 до 0.73 для «сырых» баллов, от 0.38 до 0.72 для центрированных; Добросовестность - от 0.39 до 0.71 для «сырых» баллов, от 0.44 до 0.71 для центрированных; Доброжелательность - от 0.43 до 0.66 для «сырых» баллов, от 0.47 до 0.66 для центрированных; Открытость опыту - от 0.46 до 0.62 для «сырых» баллов, от 0.46 до 0.63 для центрированных. Таким образом, можно говорить о хорошем соответствии пятикомпонентной структуры опросника эмпирическим данным.

\footnotetext{
${ }^{2}$ Дополнительные материалы к статье см.: https://osf.io/hdbkr/.
} 
Таблица 1

Описательные статистики по шкалам и субшкалам BFI-2 (n = 1787)

\begin{tabular}{|l|l|c|c|c|c|c|c|}
\hline \multicolumn{2}{|c|}{ Шкалы } & Среднее & Медиана & Мода & $\begin{array}{c}\text { Стандартное } \\
\text { отклонение }\end{array}$ & $\begin{array}{c}\text { Асим- } \\
\text { метрия }\end{array}$ & Эксцесс \\
\hline 1 & Экстраверсия & 3.22 & 3.25 & 3.00 & 0.78 & -0.22 & -0.47 \\
\hline 1.1 & Общительность & 3.00 & 3.00 & 3.00 & 0.97 & 0.00 & -0.68 \\
\hline 1.2 & Настойчивость & 3.36 & 3.50 & 3.75 & 0.94 & -0.25 & -0.66 \\
\hline 1.3 & Энергичность & 3.29 & 3.25 & 3.75 & 0.98 & -0.27 & -0.67 \\
\hline 2 & Доброжелательность & 3.43 & 3.50 & 3.75 & 0.69 & -0.40 & 0.11 \\
\hline 2.1 & Сочувствие & 3.83 & 4.00 & 4.00 & 0.87 & -0.75 & 0.33 \\
\hline 2.2 & Уважительность & 3.66 & 3.75 & 3.75 & 0.79 & -0.51 & 0.12 \\
\hline 2.3 & Доверие & 2.80 & 2.75 & 3.00 & 0.89 & 0.03 & -0.47 \\
\hline 3 & Добросовестность & 3.45 & 3.50 & 3.33 & 0.74 & -0.25 & -0.36 \\
\hline 3.1 & Организованность & 3.13 & 3.00 & 2.50 & 1.00 & 0.00 & -0.80 \\
\hline 3.2 & Продуктивность & 3.34 & 3.50 & 4.00 & 0.92 & -0.22 & -0.61 \\
\hline 3.3 & Ответственность & 3.89 & 4.00 & 4.25 & 0.81 & -0.68 & 0.13 \\
\hline 4 & $\begin{array}{l}\text { Негативная } \\
\text { эмоциональность }\end{array}$ & 3.12 & 3.17 & 3.00 & 0.87 & -0.10 & -0.60 \\
\hline 4.1 & Тревожность & 3.29 & 3.25 & 3.00 & 1.04 & -0.25 & -0.73 \\
\hline 4.2 & Депрессивность & 2.96 & 3.00 & 3.00 & 1.04 & -0.01 & -0.83 \\
\hline 4.3 & $\begin{array}{l}\text { Эмоциональная } \\
\text { изменчивость }\end{array}$ & 3.12 & 3.25 & 3.75 & 1.06 & -0.12 & -0.86 \\
\hline 5 & Открытость опыту & 3.84 & 3.92 & 4.17 & 0.66 & -0.56 & 0.11 \\
\hline 5.1 & Эстетичность & 3.84 & 4.00 & 5.00 & 0.96 & -0.70 & -0.23 \\
\hline 5.2 & Любознательность & 3.84 & 4.00 & 4.00 & 0.78 & -0.62 & 0.22 \\
\hline 5.3 & $\begin{array}{l}\text { Творческое } \\
\text { воображение }\end{array}$ & 3.84 & 4.00 & 4.00 & 0.86 & -0.67 & 0.11 \\
\hline
\end{tabular}

В случае с фасетами особенно заметна роль центрирования пунктов, позволившего максимально нагружать соответствующие компоненты. Например, слабость структуры Доброжелательности при использовании «сырых» баллов нивелировалась при использовании центрированных баллов. В целом результаты РСА подтверждают разделение шкал черт на субшкалы фасет.

Усредненная абсолютная межпунктовая корреляция была рассчитана для четырех случаев (результаты приведены в дополнительных материалах, таблица Д7). Во-первых, усредненная корреляция пунктов внутри шкалы продемонстрировала умеренные и средние корреляции: от 0.27 до 0.52 для «сырых» баллов, от 0.28 до 0.54 для центрированных. Во-вторых, усредненная корреляция пунктов одной шкалы с пунктами других шкал была слабой: от 0.03 до 0.27 для «сырых» баллов, от 0.08 до 0.26 для центрированных. В-третьих, усредненная корреляция пунктов со шкалой была средней и высокой выраженности: 
от 0.57 до 0.81 для «сырых» баллов, от 0.58 до 0.83 для центрированных. В-четвертых, усредненная корреляция пунктов одной шкалы с другими шкалами была слабой и умеренной: от 0.06 до 0.46 для «сырых» баллов, от 0.06 до 0.47 для центрированных. Слабее всего с пунктами других шкал и другими шкалами были связаны пункты Открытости опыту, а сильнее всего - пункты Экстраверсии. Во всех случаях связь пунктов внутри одной шкалы и со своей шкалой оказывалась выше, чем связь с пунктами других шкал и с другими шкалами.

Далее были построены модели CFA и RI-EFA, результаты тестирования которых представлены в таблице 2 (подробнее в дополнительных материалах, таблица Д8).

Из таблицы 2 видно, что согласованность моделей CFA существенно ниже, чем RI-EFA. В частности, относительный хи-квадрат имел высокие значения $(>2)$, CFI и TLI - низкие $(<0.95)$, а RMSEA преодолел границу $<0.1$, но все же не достиг хорошего соответствия $(<0.05)$.

Первая модель RI-EFA приближалась к удовлетворительному соответствию эмпирическим данным по критериям $\chi^{2} / \mathrm{df}$, CFI и TLI, а по RMSEA показала хорошее соответствие. Вторая модель RI-EFA имела наилучшее соответствие данным по всем индексам пригодности $\left(\chi^{2} / \mathrm{df}\right.$, CFI, TLI, RMSEA) кроме уровня значимости для $\chi^{2}(p<0.001)^{3}$.

Инвариантность по полу рассматривалась для наилучшей модели (таблица 3 ). Конфигурационная модель имела хорошее соответствие данным: $\chi^{2} / \mathrm{df}=1.55$,

Таблица 2

Характеристики моделей CFA и RI-EFA (n = 1787)

\begin{tabular}{|c|c|c|c|c|c|c|}
\hline & $\chi^{2}(\mathrm{df})$ & $\chi^{2} / \mathbf{d f}$ & CFI & TLI & $\begin{array}{l}\text { RMSEA } \\
\text { [90\% CI] }\end{array}$ & BIC \\
\hline \multicolumn{7}{|l|}{ CFA } \\
\hline $\begin{array}{l}\text { М 1. Пять ортогональных } \\
\text { факторов }\end{array}$ & 24920.8 (1710) & 14.57 & 0.515 & 0.498 & $\begin{array}{c}0.092 \\
{[0.091 ; 0.093]}\end{array}$ & 771140 \\
\hline $\begin{array}{l}\text { М 2. Пять коррелирующих } \\
\text { факторов }\end{array}$ & $23712(1700)$ & 13.95 & 0.541 & 0.522 & $\begin{array}{c}0.090 \\
{[0.089 ; 0.091]}\end{array}$ & 769827 \\
\hline $\begin{array}{l}\text { М 3. Пять коррелирующих } \\
\text { факторов и фасеты }\end{array}$ & $15730(1610)$ & 9.77 & 0.707 & 0.678 & $\begin{array}{c}0.074 \\
{[0.073 ; 0.075]}\end{array}$ & 761414 \\
\hline \multicolumn{7}{|l|}{ RI-EFA } \\
\hline $\begin{array}{l}\text { М 1. Пять коррелирующих } \\
\text { факторов }\end{array}$ & 7855.4 (1479) & 5.31 & 0.835 & 0.803 & $\begin{array}{c}0.049 \\
{[0.048 ; 0.050]}\end{array}$ & 311715 \\
\hline $\begin{array}{l}\text { М 2. Пять коррелирующих } \\
\text { факторов и фасеты }\end{array}$ & 2780.9 (1389) & 2.00 & 0.964 & 0.954 & $\begin{array}{c}0.024 \\
{[0.022 ; 0.025]}\end{array}$ & 306680 \\
\hline
\end{tabular}

Примечание. $\chi^{2}(\mathrm{df})$ - значение статистики хи-квадрат со степенями свободы (статистика во всех случаях значима на уровне $p<0.001)$; $\chi^{2} / \mathrm{df}-$ относительный хи-квадрат; CFI - сравнительный индекс соответствия; TLI - индекс Такера-Льюиса; RMSEA - корень среднеквадратичной ошибки аппроксимации; ВIC - Байесовский информационный критерий.

\footnotetext{
${ }^{3}$ Данный показатель чувствителен к объему выборки, поэтому в случае больших выборок рекомендуют ориентироваться на более робастные критерии (Крамер, 2007, с. 58-59).
} 


\begin{tabular}{|c|c|c|c|c|c|c|}
\hline \multirow{13}{*}{ 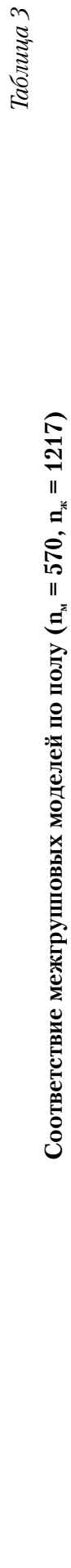 } & 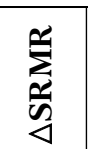 & & $\begin{array}{l}10 \\
8 \\
0\end{array}$ & $\begin{array}{l}\overline{8} \\
\dot{0}\end{array}$ & $\stackrel{\dddot{8}}{0}$ & \multirow[b]{13}{*}{ 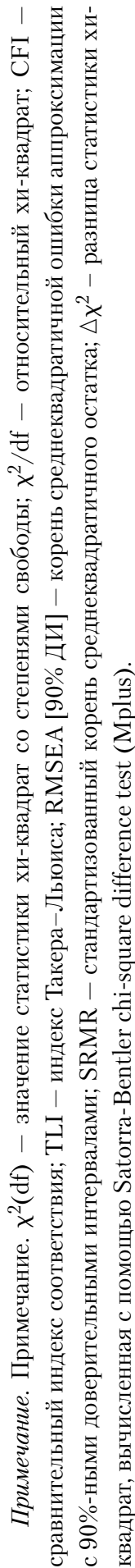 } \\
\hline & 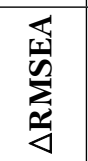 & & $\begin{array}{l}\tilde{8} \\
0 \\
0\end{array}$ & $\begin{array}{l}8 \\
:\end{array}$ & $\begin{array}{l}8 \\
8 \\
0\end{array}$ & \\
\hline & 它 & & $\begin{array}{l}\tilde{8} \\
0 \\
0\end{array}$ & 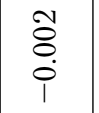 & $\begin{array}{l}\tilde{8} \\
0 \\
0\end{array}$ & \\
\hline & 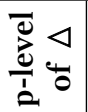 & & $\stackrel{N}{\stackrel{N}{O}}$ & $\begin{array}{l}\tilde{8} \\
\dot{0} \\
v\end{array}$ & $\begin{array}{l}\tilde{8} \\
\dot{0} \\
v\end{array}$ & \\
\hline & $\ddot{8}$ & & 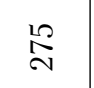 & in & 8 & \\
\hline & $\stackrel{x}{x}$ & & 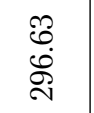 & 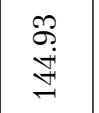 & ָ̃ & \\
\hline & 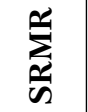 & $\begin{array}{l}\stackrel{1}{0} \\
\stackrel{0}{0} \\
0\end{array}$ & ஜ̂. & $\stackrel{\ddot{\theta}}{0}$ & ஜै. & \\
\hline & 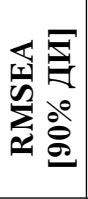 & 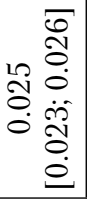 & 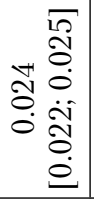 & 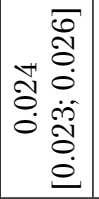 & 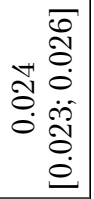 & \\
\hline & $\vec{E}$ & 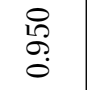 & 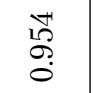 & ฟิ & $\begin{array}{l}\tilde{V} \\
\text { İ } \\
0\end{array}$ & \\
\hline & 空 & $\begin{array}{l}\overrightarrow{8} \\
\stackrel{8}{0}\end{array}$ & $\begin{array}{l}8 \\
\stackrel{8}{\circ} \\
0\end{array}$ & 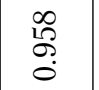 & $\begin{array}{l}\hat{1} \\
\stackrel{2}{\circ} \\
0\end{array}$ & \\
\hline & $\underset{x}{\frac{y}{*}}$ & 占 & $\stackrel{\vec{\rho}}{\rightarrow}$ & గึ & 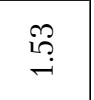 & \\
\hline & $\underset{\substack{0 \\
x}}{\tilde{y}}$ & 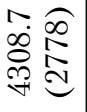 & 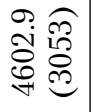 & 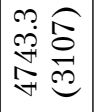 & 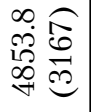 & \\
\hline & & 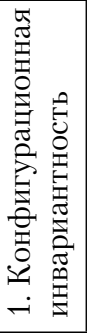 & 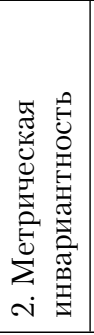 & 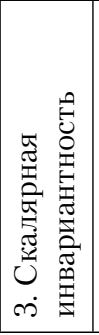 & 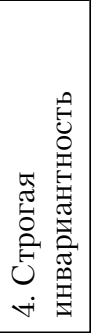 & \\
\hline
\end{tabular}


$\mathrm{CFI}=0.961$, RMSEA $=0.025$. Таким образом, подтвердилось соответствие структуры опросника в мужской и женской подвыборках. Метрическая инвариантность значимо не отличалась от конфигурационной как по $\Delta \chi^{2}(p=0.177)$, так и по более робастным критериям: $\triangle \mathrm{CFI}=-0.001, \triangle \mathrm{RMSEA}=-0.001$, $\triangle \mathrm{SRMR}=0.005$. Таким образом, факторные нагрузки также были инвариантны между мужчинами и женщинами. Скалярная инвариантность по полу поддерживалась $\triangle \mathrm{CFI}=-0.002, \triangle \mathrm{RMSEA}=0.000, \triangle \mathrm{SRMR}=0.001$, однако уровень значимости для $\Delta \chi^{2}$ был меньше 0.001. Строгая инвариантность также находила подтверждение по $\triangle \mathrm{CFI}=-0.001, \triangle \mathrm{RMSEA}=0.000, \triangle \mathrm{SRMR}=0.003$, однако $\Delta \chi^{2}(60)=112.23, p<0.001$.

В целом соответствие модели в группах по полу вплоть до строгой инвариантности свидетельствует о том, что различия в средних по шкалам и субшкалам русского BFI-2 будут характеризовать истинные различия в характеристиках личности мужчин и женщин, а не артефакты измерения.

В дополнительных материалах (таблица Д9) приведены результаты сравнения черт и фасетов BFI-2 по полу. Три из пяти основных шкал имели существенные различия: Доброжелательность $(t(1785)=4.43 ; p<.001)$ и Негативная эмоциональность $(t(1785)=7.72 ; p<0.001)$ были более присущи женщинам. Экстраверсия была несколько выше у мужчин $(t(1785)=-2.43 ; p=0.015)$. Все фасеты Доброжелательности и Негативной эмоциональности были значимо выше у женщин. Аспект Экстраверсии Настойчивость превалировал у мужчин $(t(1785)=-3.16 ; p=0.002)$. Аспекты Открытости опыту не были столь однозначны: к Любознательности $(t(1785)=-3.31 ; p=0.001)$ и Творческому воображению $(t(1785)=-3.88 ; p<0.001)$ были больше склонны мужчины, а к Эстетичности $(t(1785)=5.41 ; p<0.001)-$ женщины. При этом по самой шкале Открытости опыту значимые различия по полу не были обнаружены.

\section{Проверка надежности}

Усредненная $\alpha$ Кронбаха для пяти шкал была 0.84 для «сырых» баллов и 0.85 для центрированных, что является хорошим показателем внутренней согласованности. Усредненная $\alpha$ Кронбаха для 15 субшкал была 0.75 для «сырых» и 0.77 для центрированных, что свидетельствует об удовлетворительной согласованности. А.Г. Шмелев $(2013$, с. 307$)$ указывает на то, что разумный диапазон $\alpha$ Кронбаха для личностных тестов-опросников составляет 0.70-0.80. Учитывая, что субшкалы BFI-2 состоят только из четырех пунктов, полученные оценки говорят об их высокой внутренней согласованности. Усредненная общая $\omega$ Макдональда имела более высокие значения согласованности: для шкал -0.88 (0.89 для центрированных), для субшкал -0.79 (0.80 для центрированных). Из шкал наименьшую согласованность имела Открытость опыту $(\alpha=0.81 / 0.82 ; \omega=0.86 / 0.87)$, из субшкал Любознательность $(\alpha=0.63 / 0.66 ; \omega=0.69 / 0.69)$, которая входит в Открытость опыту, с чем, возможно, связана меньшая согласованность всей шкалы. Наибольшую согласованность из шкал продемонстрировала Негативная эмоциональность 
$(\alpha=0.88 / 0.89 ; \omega=0.91 / 0.92)$, из субшкал - Творческое воображение $(\alpha=0.81$ / $0.83 ; \omega=0.85 / 0.85)$. Подробнее показатели надежности для шкал и субшкал приведены в таблице 4 (расширенная версия - в дополнительных материалах, таблица Д11).

В дополнительных материалах (таблица Д10) представлена интеркорреляция шкал опросника; выше диагонали приведена корреляция с поправкой на затухание, учитывающая надежность коррелирующих шкал: близкие к 1 значения свидетельствуют о тесной связи истинных измеряемых феноменов (Фер, Бакарак, 2010)4. Скорректированная корреляция субшкал с общей шкалой своего домена по всем чертам была близка к единице. Несколько выделяется шкала Открытость опыту: она была слабее связана со своими субшкалами - с Эстетичностью $\left(r_{\text {cor }}=0.93\right)$ и с Творческим воображением $\left(r_{\text {cor }}=0.93\right)$. Более того, между собой указанные субшкалы также имели значимую, но умеренную связь $\left(r_{\text {сог }}=0.31\right)$.

\section{Проверка дискриминативности}

Дискриминативность шкал и субшкал опросника представлена в таблице 4. Значения, близкие к единице, означают высокую дискриминативность, близость к нулю - низкую дискриминативность. Значения для шкал варьировали от 0.98 до 0.99. У субшкал дискриминативность была несколько ниже, однако достаточно высокая: от 0.96 до 0.99 .

\section{Обсуждение}

Русскоязычная версия BFI-2 продемонстрировала хорошие психометрические качества. Структура опросника подтвердилась как на уровне черт (шкал), так и на уровне фасет (субшкал). Вслед за К. Сото и О. Джоном (Soto, John, 2017) авторы адаптации рекомендуют использовать центрированные пункты при проведении психометрических исследований, так как это позволяет учесть склонность респондентов к крайним ответам.

При оценке конструктной валидности некоторые проблемы возникли с однозначностью пункта 11 вопросника, но в пределах шкалы он достаточно хорошо работал. Мы решили сохранить формулировку пункта, так как для кросс-культурных исследований важна совместимость и аналогичность конструктов.

С этим связана еще одна рекомендация: для большей кросс-культурной согласованности пункт 28 , во всех отношениях хорошо представляющий шкалу Добросовестности, в прикладных исследованиях использовать вместе с пунктом 61 (представлен в Приложении). Сначала мы рекомендуем оценить факторную структуру и внутреннюю согласованность Добросовестности, используя пункт 61 , а не пункт 28 . В случае если пункт 61 плохо соотносится с субшкалой Ответственность, рекомендуется вместо него использовать пункт 28.

\footnotetext{
${ }^{4}$ Отметим, что скорректированные коэффициенты корреляции могут выходить за пределы \pm 1 (Muchinsky, 1996).
} 
Таблица 4

Показатели надежности и дискриминативности опросника BFI-2

\begin{tabular}{|c|c|c|c|c|c|}
\hline & Шкалы & $\begin{array}{c}\alpha \\
\text { Кронбаха }\end{array}$ & $\begin{array}{c}\text { Стандарти- } \\
\text { зированная } \\
\alpha\end{array}$ & $\begin{array}{c}\omega \\
\text { Макдональда }\end{array}$ & $\begin{array}{c}\text { Дискриминативность } \\
\Delta \text { Фергосона } \\
\text { [95\% ДИ] }\end{array}$ \\
\hline 1 & Экстраверсия & $0.86 / 0.87$ & $0.86 / 0.87$ & $0.89 / 0.90$ & $0.991[0.989 ; 0.991]$ \\
\hline 1.1 & Общительность & $0.78 / 0.80$ & $0.78 / 0.80$ & $0.84 / 0.84$ & 0.988 [0.985; 0.989] \\
\hline 1.2 & Настойчивость & $0.75 / 0.77$ & $0.75 / 0.77$ & $0.78 / 0.78$ & 0.985 [0.982; 0.987$]$ \\
\hline 1.3 & Энергичность & $0.78 / 0.80$ & $0.78 / 0.80$ & $0.82 / 0.82$ & 0.987 [0.984; 0.989$]$ \\
\hline 2 & $\begin{array}{l}\text { Доброжелатель- } \\
\text { ность }\end{array}$ & $0.83 / 0.84$ & $0.84 / 0.85$ & $0.86 / 0.87$ & $0.985[0.983 ; 0.986]$ \\
\hline 2.1 & Сочувствие & $0.75 / 0.76$ & $0.76 / 0.77$ & $0.81 / 0.81$ & 0.967 [0.963; 0.969$]$ \\
\hline 2.2 & Уважительность & $0.69 / 0.72$ & $0.70 / 0.73$ & $0.72 / 0.74$ & 0.965 [0.961; 0.968$]$ \\
\hline 2.3 & Доверие & $0.68 / 0.71$ & $0.68 / 0.71$ & $0.75 / 0.75$ & $0.979[0.975 ; 0.981]$ \\
\hline 3 & Добросовестность & $0.84 / 0.85$ & $0.84 / 0.85$ & $0.88 / 0.89$ & 0.989 [0.987; 0.989$]$ \\
\hline 3.1 & Организованность & $0.78 / 0.79$ & $0.78 / 0.80$ & $0.80 / 0.83$ & $0.99[0.987 ; 0.991]$ \\
\hline 3.2 & Продуктивность & $0.69 / 0.71$ & $0.71 / 0.73$ & $0.77 / 0.77$ & $0.983[0.98 ; 0.985]$ \\
\hline 3.3 & Ответственность & $0.71 / 0.74$ & $0.72 / 0.75$ & $0.77 / 0.77$ & $0.964[0.96 ; 0.966]$ \\
\hline 4 & $\begin{array}{l}\text { Негативная } \\
\text { эмоциональность }\end{array}$ & $0.88 / 0.89$ & $0.88 / 0.89$ & $0.91 / 0.92$ & 0.994 [0.992; 0.994$]$ \\
\hline 4.1 & Тревожность & $0.80 / 0.82$ & $0.80 / 0.82$ & $0.84 / 0.84$ & $0.991[0.989 ; 0.992]$ \\
\hline 4.2 & Депрессивность & $0.79 / 0.82$ & $0.79 / 0.82$ & $0.83 / 0.84$ & 0.993 [0.991; 0.994$]$ \\
\hline 4.3 & $\begin{array}{l}\text { Эмоциональная } \\
\text { изменчивость }\end{array}$ & $0.80 / 0.82$ & $0.80 / 0.82$ & $0.83 / 0.83$ & 0.994 [0.991; 0.995$]$ \\
\hline 5 & Открытость опыту & $0.81 / 0.82$ & $0.82 / 0.82$ & $0.86 / 0.87$ & $0.983[0.981 ; 0.984]$ \\
\hline 5.1 & Эстетичность & $0.78 / 0.79$ & $0.79 / 0.80$ & $0.82 / 0.82$ & $0.968[0.963 ; 0.971]$ \\
\hline 5.2 & Любознательность & $0.63 / 0.66$ & $0.64 / 0.66$ & $0.69 / 0.69$ & $0.963[0.959 ; 0.965]$ \\
\hline 5.3 & $\begin{array}{l}\text { Творческое } \\
\text { воображение }\end{array}$ & $0.81 / 0.83$ & $0.81 / 0.83$ & $0.85 / 0.85$ & $0.965[0.962 ; 0.968]$ \\
\hline
\end{tabular}

Примечание. Слева от косой черты результаты по «сырым» данным, справа - по центрированным; [95\% ДИ] - 95\%-ные доверительные интервалы для $\triangle$ Фергюсона.

Оценка межгрупповой инвариантности показала строгую эквивалентность моделей в выборках по полу. Это позволяет при оценке половых различий сравнивать сырые баллы по шкалам и субшкалам BFI-2. 
В этом исследовании сравнение по полу выявило значимые различия. В частности, значения Доброжелательности и Негативной эмоциональности в большей степени выражены у женщин, а Экстраверсии (включая Настойчивость), Любознательности и Творческого воображения - у мужчин. Полученные результаты согласуются с имеющимися данными о половых различиях в чертах (Bleidorn et al., 2009; Costa et al., 2001; Schmitt et al., 2008; и др.). Психометрические исследования российских авторов также поддерживают обнаруженные половые различия: в исследовании Г.Г. Князева с соавт. (2010) выявлено, что женщины более уступчивы (доброжелательны) и эмоционально нестабильны; в исследовании Е.Н. Осина с соавт. (2015) - женщины более дружелюбны и менее эмоционально стабильны, мужчины более доминантны и менее эмпатичны; в исследовании С.А. Щебетенко (Shchebetenko, 2017) на двух выборках $(\mathrm{N}>1300)$ женщины были более доброжелательны и нейротичны, но в одной из этих выборок женщины также показали более высокую Экстраверсию и Открытость опыту; в исследовании А.М. Мишкевич и С.А. Щебетенко (2018) - Доброжелательность, Нейротизм и Открытость опыту были выше у девушек, нежели у юношей.

В известном исследовании Дж. Аллика с соавт. (Allik et al., 2009) было охвачено 33 региона Российской Федерации, а общее количество респондентов превысило 7 тыс., в исследовании использовалась методика NEO-PI-R. Среди множества изучаемых параметров были рассмотрены также половые различия.

Следует учесть, что наше исследование отличалось от исследования Дж. Аллика с коллегами по ряду важных параметров. Во-первых, структура фасет NEO-PI-R и BFI-2 заметно различается. Во-вторых, в силу большего объема выборки исследование Дж. Аллика с коллегами определяет в качестве статистически значимых и минимальные различия. Это объясняет то, почему в нем обнаружено заметно больше достоверных половых различий. В-третьих, отличался дизайн исследования. В частности, в нашем случае использован самоотчетный опросник; в исследовании Аллика с соавт., где респондентам предлагалось представить другого человека, изучались представления о типичном представителе этноса. Несмотря на эти ограничения, по целому ряду показателей наблюдалась согласованность паттернов половых различий.

В частности, в NEO-PI-R Assertiveness и Ideas (в BFI-2 близкий аспект Любознательность) были выше у мужчин; аспекты Trust, Altruism, Compliance, Anxiety, Angry Hostility, Depression, Aesthetics и их близкие аналоги в русском BFI-2 (Доверие, Сочувствие, Уважительность, Тревожность, Эмоциональная изменчивость, Депрессивность, Эстетичность) были значимо выше у женщин. С другой стороны, в ряде случаев наблюдались расхождения. Близкие аналоги аспектов Gregariousness, Activity, Positive Emotions, Order, Dutifulness и Self-discipline в нашем исследовании (Общительность, Энергичность, Организованность, Ответственность, Продуктивность) у мужчин и женщин не различаются, в исследовании Дж. Аллика с соавт., напротив, были выше у женщин; аналог аспекта Fantasy в нашем исследовании (Творческое воображение) был выше у мужчин, в исследовании Дж. Аллика с 
соавт. - у женщин (о содержательном сопоставлении шкал двух методик см.: Soto, John, 2017).

Факторной валидности недостаточно, чтобы утверждать, что методика позволяет измерять то, на что она направлена (например: DeVellis, 2017). Другими важными видами конструктной валидности являются конвергентная и дискриминантная. В рамках проведенного исследования не были собраны материалы, позволяющие судить об этих видах валидности, однако данные предыдущего исследования (Shchebetenko et al., 2020) позволяют сделать некоторые выводы. Так, шкалы BFI-2 сильно коррелировали с аналогичными шкалами методики «Маркеры факторов “Большой пятерки”» (МФБП) (Князев и др., 2010; Goldberg et al., 2006) и слабо либо умеренно с другими шкалами МФБП: Экстраверсия BFI-2 с Экстраверсией МФБП $-r=0.84$, Доброжелательность BFI-2 с Доброжелательностью МФБП $-r=0.75$, Добросовестность BFI-2 с Добросовестностью МФБП $-r=0.83$, Негативная эмоциональность BFI-2 с Нейротизмом МФБП $-r=-0.86$, Открытость опыту BFI-2 с Интеллектом МФБП $-r=0.73$. Таким образом, близкие по содержанию переменные теоретически обоснованно коррелировали со шкалами BFI-2 (Shchebetenko et al., 2020).

Внутренняя согласованность, измеренная несколькими способами, продемонстрировала удовлетворительную, хорошую и высокую степень выраженности. Отметим, что количество пунктов напрямую связано с надежностью по внутренней согласованности: шкалы, имеющие меньшее количество пунктов, автоматически показывают более низкую надежность. Это одна из проблем коротких шкал. Четырехпунктовые субшкалы BFI-2, измеряющие аспекты черт, могут считаться короткими шкалами. Возможно, что с этим связана их меньшая степень надежности в сравнении со шкалами-чертами.

Проверка дискриминативности шкал показала высокую степень способности опросника дифференцировать испытуемых по степени выраженности изучаемых признаков. Это также подтверждает психометрическую состоятельность русского BFI-2.

Таким образом, русскоязычная версия опросника Big Five Inventory-2 может считаться надежным и валидным инструментом для измерения основополагающих черт личности и их аспектов.

\section{Ограничения и перспективы исследования}

Отметим некоторые ограничения нашего исследования:

- В исследовании приняли участие, прежде всего, жители городов-миллионников, поэтому его результаты могут в большей степени отражать мнения городского населения России.

- Более двух третей выборки составили женщины, что могло привести к искажению результатов из-за их большего вклада в сравнении с мужчинами в общую оценку. Однако полученная инвариантность измерения по полу ослабляет это ограничение. 
- «Игра престолов» - сериал, который был интересен разным людям, но его зритель, вероятно, имел некоторые особенности. Например, в нашем исследовании в основном была представлена молодежь; другие возрасты были в него включены меньше.

- Очевидно, что наши результаты не охватывают русскоязычную популяцию, не пользующуюся Интернетом.

Перспективами дальнейших исследований может стать улучшение репрезентативности выборки: расширение возрастного диапазона и выравнивание возрастных когорт, выравнивание выборки по полу, привлечение к исследованию жителей отдаленных округов и областей, ориентация не только на интересующихся сериалом «Игра престолов». Как показывает ряд исследований, личностные особенности могут серьезно различаться не только между странами, но и между регионами одной страны (Allik et al., 2009; Sugonyaev et al., 2019). Поэтому есть смысл определить тестовые нормы не только по возрасту и полу, но также по месту проживания.

\section{Благодарности}

Мы признательны Роберту Ли Бейтсу (Пермь, Россия), Кристине Дюма (Альбукерке, Нью-Мексико, США), Асе Касимовой (Левен, Бельгия), Елизавете Клеро (Париж, Франция), Елене Сали (Лондон, Великобритания), Анне Уайт (Вестлейк, Огайо, США), Тимуру Халиуллину (Университет Западной Виргинии, США) и Анастасии Яковлевой (Лондонский университет Биркбек, Великобритания) за помощь в переводе BFI-2 на русский язык.

\section{Конфликт интересов}

Права на Big Five Inventory-2 принадлежат Кристоферу Дж. Сото и Оливеру П. Джону.

\section{Литература}

Барановская, М. С. (2005). Пятифакторная модель личности П. Коста и Р. МакКрея и ее взаимосвязь с факторными теориями личности Г. Айзенка и Р. Кеттелла. Психологический журнал, $26(4), 52-57$.

Бурлачук, Л. Ф., Королев, Д. К. (2000). Адаптация опросника для диагностики пяти факторов личности. Вопросы психологии, 1, 126-134.

Голдберг, Л. Р., Шмелев, А. Г. (1993). Межкультурное исследование лексики личностных черт: «Большая пятерка» факторов в английском и русском языках. Психологический журнал, 14(4), 32-39. 
Егорова, М. С., Паршикова, О. В. (2016). Психометрические характеристики Короткого портретного опросника Большой пятерки (Б5-10). Психологические исследования: электронный научный журнал, 9(45), 9. Режим доступа: http://psystudy.ru

Клайн, П. (1994). Справочное руководство по конструированию тестов. Киев: ПАН Лтд.

Князев, Г. Г., Митрофанова, Л. Г., Бочаров, В. А. (2010). Валидизация русскоязычной версии опросника Л. Голдберга «Маркеры факторов “Большой пятерки”». Психологический журнал, 31(5), 100-110.

Корнилова, Т. В., Чумакова, М. А. (2016). Апробация краткого опросника Большой пятерки (ТІРІ, КОБТ). Психологические исследования: электронный научный журнал, 9(46), 5. Режим доступа: http://psystudy.ru

Крамер, Д. (2007). Математическая обработка данных в социальных науках: современные методы. М.: Академия.

Мишкевич, А. М., Щебетенко, С. А. (2017). Психометрика русскоязычной версии Big Five Inventory: новые свидетельства. В кн. А. Л. Журавлев, В. А. Кольцова (ред.), Фундаментальные и прикладные исследования современной психологии: результаты и перспективы развития (с. 771-776). М.: Изд-во «Институт психологии РАН».

Мишкевич, А. М., Щебетенко, С. А. (2018). Половые различия по чертам «Большой Пятерки»: взгляд через призму установок на черты. Психология. Журнал Высшей школы экономики, 15(3), 562-572.

Орел, В. Е., Сенин, И. Г. (2004). Личностный опросник NEO PI-R. Руководство по применению. Ярославль: НПЦ «Психодиагностика».

Орел, В. Е., Сенин, И. Г. (2008). Личностные опросники NEO-PI-R и NEO-FFI. Руководство по применению. Ярославль: НПЦ «Психодиагностика».

Осин, Е. Н., Рассказова, Е. И., Неяскина, Ю. Ю., Дорфман, Л. Я., Александрова, Л. А. (2015). Операционализация пятифакторной модели личностных черт на российской выборке. Психологическая диагностика, 3, 80-104.

Сергеева, А. С., Кириллов, Б. А., Джумагулова, А. Ф. (2016). Перевод и адаптация краткого пятифакторного опросника личности (TIPI-RU): оценка конвергентной валидности, внутренней согласованности и тест-ретестовой надежности. Экспериментальная психология, 9(3), 138 154. doi:10.17759/exppsy.2016090311

Фер, Р. М., Бакарак, В. Р. (2010). Психометрика: Введение. Челябинск: Издательский центр ЮУрГУ.

Хромов, А. Б. (2000). Пятифакторный опросник личности: Учебно-методическое пособие. Курган: Изд-во Курганского государственного университета.

Хромов, А. Б. (2010). Пятифакторный личностный опросник: тест 5FPQ: методические указания к выполнению контрольного задания по общему психологическому практикуму для студентов направлений (спещиальностей) 030301. Курган: Изд-во Курганского государственного университета.

Шмелев, А. Г. (2013). Практическая тестология. Тестирование в образовании, прикладной психологии и управлении персоналом. М.: ООО «ИПЦ “Маска”».

Щебетенко, С. А., Вайнштейн, С. В. (2014). Большая Пятерка черт личности: эксплицитноимплицитный подход. Психология и психотехника, 1, 69-82.

Ссылки на зарубежные источники см. в разделе References после англоязычного блока. 


\section{Русская версия Big Five Inventory-2}

Приложение

В этом тесте перечислены несколько десятков качеств человека. Вам нужно оценить, насколько каждое из этих качеств вам соответствует. Например, верно ли то, что вы являетесь человеком, которому нравится проводить время с другими? Пожалуйста, в каждой строке теста отметьте крестиком поле цифры в соответствии с этим ключом:

\begin{tabular}{|c|c|c|c|c|}
\hline 1 & 2 & 3 & 4 & 5 \\
\hline $\begin{array}{c}\text { совсем } \\
\text { не согласен }\end{array}$ & $\begin{array}{c}\text { скорее } \\
\text { не согласен }\end{array}$ & нейтрально & $\begin{array}{c}\text { скорее } \\
\text { согласен }\end{array}$ & $\begin{array}{c}\text { полностью } \\
\text { согласен }\end{array}$ \\
\hline
\end{tabular}

Я -человек...

\begin{tabular}{|c|c|c|c|c|c|c|}
\hline & & - & - & & + & + \\
\hline 1. & общительный, открытый & 1 & 2 & 3 & 4 & 5 \\
\hline 2. & сопереживающий и добросердечный & 1 & 2 & 3 & 4 & 5 \\
\hline 3. & склонный быть неорганизованным & 1 & 2 & 3 & 4 & 5 \\
\hline 4. & расслабленный, хорошо справляющийся со стрессом & 1 & 2 & 3 & 4 & 5 \\
\hline 5. & мало интересующийся искусством & 1 & 2 & 3 & 4 & 5 \\
\hline 6. & напористый & 1 & 2 & 3 & 4 & 5 \\
\hline 7. & относящийся к другим людям с уважением & 1 & 2 & 3 & 4 & 5 \\
\hline 8. & предпочитающий отдыхать, а не работать & 1 & 2 & 3 & 4 & 5 \\
\hline 9. & в случае неудачи не теряющий оптимизма & 1 & 2 & 3 & 4 & 5 \\
\hline 10. & интеллектуальный & 1 & 2 & 3 & 4 & 5 \\
\hline 11. & часто чувствующий себя уставшим & 1 & 2 & 3 & 4 & 5 \\
\hline 12. & склонный искать ошибки в поступках других людей & 1 & 2 & 3 & 4 & 5 \\
\hline 13. & заслуживающий доверия, постоянный & 1 & 2 & 3 & 4 & 5 \\
\hline 14. & $\begin{array}{l}\text { настроения - с эмоциональными «взлетами» и } \\
\text { «падениями» }\end{array}$ & 1 & 2 & 3 & 4 & 5 \\
\hline 15. & изобретательный, находящий нестандартные решения & 1 & 2 & 3 & 4 & 5 \\
\hline 16. & склонный быть молчаливым & 1 & 2 & 3 & 4 & 5 \\
\hline 17. & мало сочувствующий другим людям & 1 & 2 & 3 & 4 & 5 \\
\hline 18. & собранный, любящий во всем порядок & 1 & 2 & 3 & 4 & 5 \\
\hline 19. & нервничающий по любому поводу & 1 & 2 & 3 & 4 & 5 \\
\hline
\end{tabular}




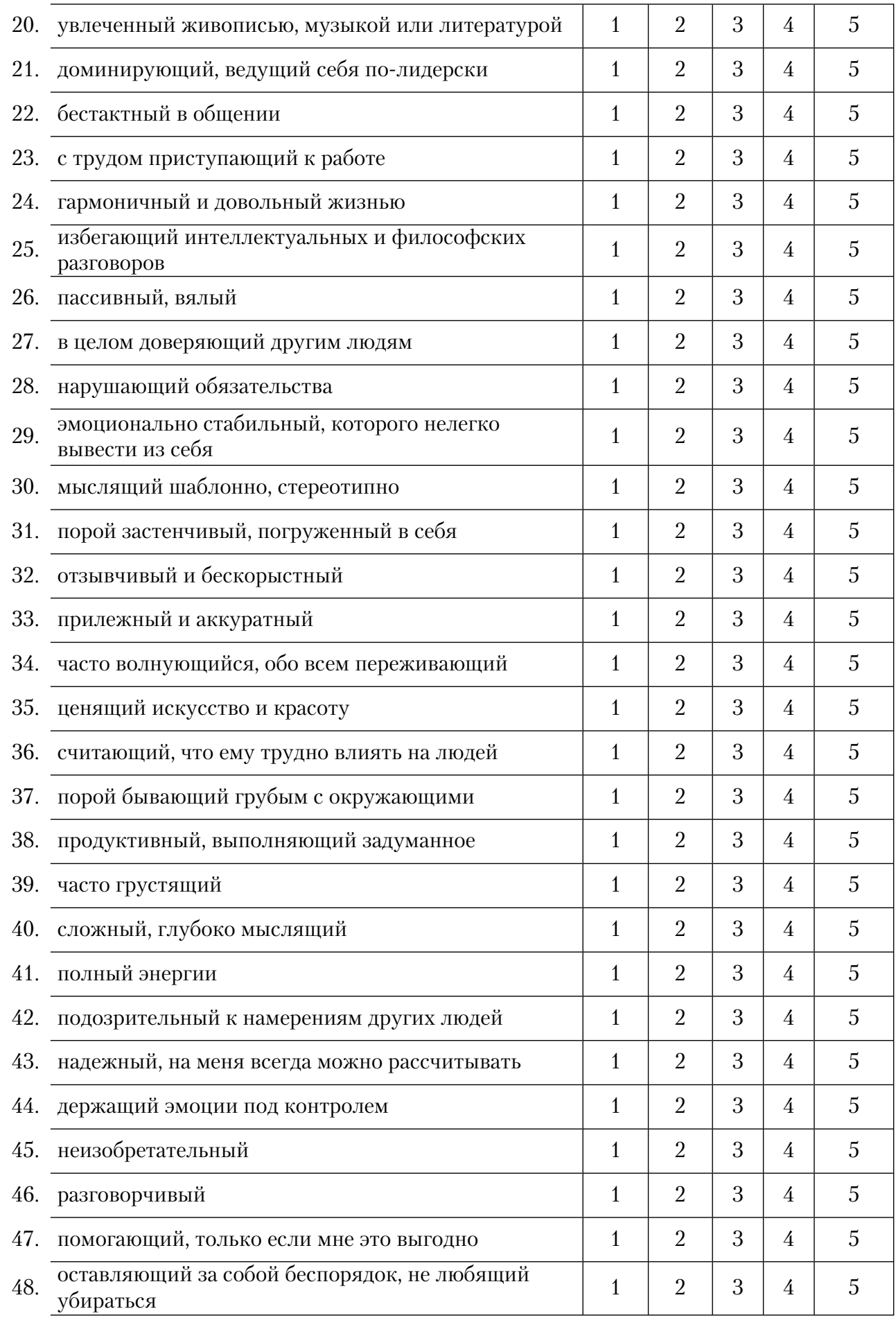




\begin{tabular}{|c|c|c|c|c|c|c|}
\hline 49. & редко тревожащийся или боящийся & 1 & 2 & 3 & 4 & 5 \\
\hline 50 . & считающий, что театр и поэзия - это скучно & 1 & 2 & 3 & 4 & 5 \\
\hline 51. & предпочитающий, чтобы решения принимали другие & 1 & 2 & 3 & 4 & 5 \\
\hline 52. & вежливый, учтивый в общении с другими & 1 & 2 & 3 & 4 & 5 \\
\hline 53. & настойчивый, доводящий дело до конца & 1 & 2 & 3 & 4 & 5 \\
\hline 54. & склонный к печали, депрессии & 1 & 2 & 3 & 4 & 5 \\
\hline 55. & мало интересующийся абстрактными идеями & 1 & 2 & 3 & 4 & 5 \\
\hline 56. & излучающий энтузиазм, заражающий им окружающих & 1 & 2 & 3 & 4 & 5 \\
\hline 57. & склонный видеть в других людях только хорошее & 1 & 2 & 3 & 4 & 5 \\
\hline 58. & часто ведущий себя безответственно & 1 & 2 & 3 & 4 & 5 \\
\hline 59. & эмоциональный, неуравновешенный & 1 & 2 & 3 & 4 & 5 \\
\hline 60. & генерирующий новые идеи, оригинально мыслящий & 1 & 2 & 3 & 4 & 5 \\
\hline 61. & бывающий легкомысленным & 1 & 2 & 3 & 4 & 5 \\
\hline
\end{tabular}

\section{Ключ}

Черты:

Экстраверсия (Е): 1, 6, 11R, 16R, 21, 26R, 31R, 36R, 41, 46, 51R, 56

Доброжелательность (Склонность к согласию) (А): 2, 7, 12R, 17R, 22R, 27, 32, 37R, 42R, 47R, 52, 57

Добросовестность (Контроль импульсивности) (C): 3R, 8R, 13, 18, 23R, 28R (61R) 33, 38, 43, 48R, 53, 58R

Негативная эмоциональность (Нейротизм) (N): 4R, 9R, 14, 19, 24R, 29R, 34, 39, 44R, 49R, 54, 59

Открытость опыту (O): 5R, 10, 15, 20, 25R, 30R, 35, 40, 45R, 50R, 55R, 60

Аспекты черт:

Общительность (E1): 1, 16R, 31R, 46

Настойчивость (Ассертивность) (E2): 6, 21, 36R, 51R

Энергичность (Е3): 11R, 26R, 41, 56

Сочувствие (A1): 2, 17R, 32, 47R

Уважительность (A2): 7, 22R, 37R, 52

Доверие (А3): 12R, 27, 42R, 57

Организованность (C1): 3R, 18, 33, 48R

Продуктивность (C2): 8R, 23R, 38, 53

\footnotetext{
${ }^{1}$ Сначала мы рекомендуем оценить факторную структуру и внутреннюю согласованность шкалы Добросовестность, используя пункт 61, а не пункт 28. В случае если пункт 61 плохо соотносится с субшкалой Ответственность, рекомендуется вместо него использовать пункт 28.
} 
Ответственность (C3): 13, 28R (61R), 43, 58R

тревожность (N1): 4R, 19, 34, 49R

Депрессивность (N2): 9R, 24R, 39, 54

Эмоциональная изменчивость (Эмочиональная волатильность) (N3): 14, 29R, 44R, 59

Эстетичность (O1): 5R, 20, 35, 50R

Любознательность (O2): 10, 25R, 40, 55R

Творческое воображение (Личностная креативность) (O3): 15, 30R, 45R, 60

Цифры в строке означают порядковый номер пункта. $\mathrm{R}$ - реверсивный пункт. Перекодировка обязательна при расчете внутренней согласованности $(1=5)(2=4)$ $(4=2)(5=1)$.

Калугин Алексей Юрьевич - заведующий кафедрой, кафедра практической психологии, Пермский государственный гуманитарно-педагогический университет, кандидат психологических наук, доцент.

Сфера научных интересов: психология личности, психология индивидуальности, анализ данных.

Контакты: kaluginau@yandex.ru

Щебетенко Сергей Александрович - профессор, департамент психологии, Национальный исследовательский университет «Высшая школа экономики»; профессор, кафедра психологии развития, Пермский государственный национальный исследовательский университет, доктор психологических наук.

Сфера научных интересов: психология личности и индивидуальных различий, социальная психология, методология исследований.

Контакты: sshchebetenko@hse.ru

Мишкевич Арина Михайловна - старший преподаватель, кафедра психологии развития, Пермский государственный национальный исследовательский университет, кандидат психологических наук.

Сфера научных интересов: психология личности, социальные установки.

Контакты: ArinaMishkevich@ya.ru

Сото Кристофер Дж. - доцент, факультет психологии, колледж Колби (США), $\mathrm{PhD}$ (Калифорнийский университет в Беркли).

Сфера научных интересов: структура личности, онтогенетическое развитие личности, связи черт личности с жизненными проявлениями, психологические измерения.

Контакты: christopher.soto@colby.edu

Джон Оливер П. - профессор, факультет психологии, Калифорнийский университет в Беркли (США), $\mathrm{PhD}$ (Орегонский университет).

Сфера научных интересов: Я-концепция, точность и ошибки самовосприятия, развитие личности и ее оценка в течение жизни, переживание и выражение эмоций, межкультурные различия.

Контакты: o_johnx5@berkeley.edu 


\title{
Psychometric Properties of the Russian Version of the Big Five Inventory-2
}

\author{
A.Yu. Kalugina, S.A. Shchebetenko ${ }^{\mathrm{b}, \mathrm{c}}$, A.M. Mishkevich ${ }^{\mathrm{c}}$, C.J. Soto ${ }^{\mathrm{d}}$, O.P. John ${ }^{\mathrm{e}}$ \\ ${ }^{a}$ Perm State Humanitarian Pedagogical University, 24 Sibirskaya Str., Perm, 614990, Russian Federation \\ ${ }^{b}$ HSE University, 20 Myasnitskaya Str., Moscow, 101000, Russian Federation \\ ${ }^{c}$ Perm State University, 15 Bukireva Str., Perm, 614990, Russian Federation \\ ${ }^{d}$ Colby College, 04901, USA, 4000 Mayflower Hill, Waterville, ME \\ 'University of California, Berkeley, 94720, USA, 2227 Piedmont Avenue, Berkeley, CA
}

\begin{abstract}
The present article aims to assess psychometric characteristics of a Russian version of the Big Five Inventory-2 (BFI-2). This questionnaire measures five basic personality domains, as well as three facets per domain. We collected data from an Internet sample comprised of 1,787 people ( $31.9 \%$ of men) aged from 14 to 54 years $(\mathrm{M}=26.31$; $\mathrm{SD}=7.76)$. The study covered over ten regions of the Russian Federation. The factorial structure of the BFI-2 was examined using the principal component analysis, confirmatory factor analysis and random intercept exploratory factor analysis. The five-factor structure of the BFI-2 was confirmed both at the domain and facet levels. Strict measurement invariance was obtained across sex, which makes it possible to compare raw scores of the questionnaire when assessing sex differences. Sex differences obtained in this study were consistent with those published in the extant literature. Across the BFI-2 subscales, internal consistency measured by the Cronbach's alpha and McDonald's omega ranged from satisfactory to excellent. The Ferguson's delta (adapted by M. Hankins) was high which shows that the Russian BFI-2 can distinguish individuals with various manifestations of a domain or facet. To summarize, the Russian version of the BFI-2 represents a reliable and valid tool for measuring the basic traits of personality.
\end{abstract}

Keywords: The Big Five; personality; Big Five Inventory-2; psychometrics, validity, reliability.

\section{References}

Aichholzer, J. (2014). Random intercept EFA of personality scales. Journal of Research in Personality, 53, 1-4. doi:10.1016/j.jrp.2014.07.001

Allik, J., Realo, A., Mxttus, R., Pullmann, H., Trifonova, A., McCrae, R. R., \& 56 Members of the Russian Character and Personality Survey. (2009). Personality traits of Russians from the observer's perspective. European Journal of Personality, 23, 567-588. doi:10.1002/per.721

Allport, G. W., \& Odbert, H. S. (1936). Trait-names: A psycho-lexical study. In J. Peterson (Ed.), Psychological Monographs (pp. 1-171). Princeton, NJ: Psychological Review Publications.

Asparouhov, T., \& Muthen, B. O. (2009). Exploratory structural equation modeling. Structural Equation Modeling, 16, 397-438. doi:10.1080/10705510903008204 
Baranovskaya, M. S. (2005). Pyatifaktornaya model' lichnosti P. Kosta i R. MakKreya i ee vzaimosvyaz' s faktornymi teoriyami lichnosti G. Aizenka i R. Kettella [Five Factor model of personality by P. Costa and R. McCrae and its relations with the factor theories of personality by $\mathrm{H}$. Eysenck and R. Cattell]. Psikhologicheskii Zhurnal, 26(4), 52-57. (in Russian)

Bleidorn, W., Kandler, C., Riemann, R., Spinath, F. M., \& Angleitner, A. (2009). Patterns and sources of adult personality development: growth curve analyses of the NEO PI-R scales in a longitudinal twin study. Journal of Personality and Social Psychology, 97, 142-155. doi:10.1037/a0015434

Burlachuk, L. F., \& Koroljov, D. K. (2000). Adaptation of the big five locator scale. Voprosy Psikhologii, 1, 126-134. (in Russian)

Burtăverde, V., de Raad, B., \& Zanfirescu, A.-Ş. (2018). An emic-etic approach to personality assessment in predicting social adaptation, risky social behaviors, status striving and social affirmation. Journal of Research in Personality, 76, 113-123. doi:10.1016/j.jrp.2018.08.003

Cattell, R. B. (1943). The description of personality: basic traits resolved into clusters. The Journal of Abnormal and Social Psychology, 38, 476-506. doi:10.1037/h0054116

Chen, F. F. (2007). Sensitivity of goodness of fit indexes to lack of measurement invariance. Structural Equation Modeling: A Multidisciplinary Journal, 14, 464-504. doi:10.1080/10705510701301834

Costa, P., Jr., Terracciano, A., \& McCrae, R. R. (2001). Gender differences in personality traits across cultures: Robust and surprising findings. Journal of Personality and Social Psychology, 81, 322-331. doi:10.1037/0022-3514.81.2.322

Cramer, D. (2007). Matematicheskaya obrabotka dannykh v sotsial'nykh naukakh: sovremennye metody [Mathematical data processing in social sciences: modern methods]. Moscow: Akademiya. (in Russian; trans. of: Cramer, D. (2007). Advanced quantitative data analys. Maidenhead, UK/Philadelphia, PA: Open University Press.)

DeVellis, R. F. (2017). Scale development: Theory and applications (4th ed.). Los Angeles, CA: SAGE Publishing.

Egorova, M. S., \& Parshikova, O. V. (2016). Validation of the Short Portrait Big Five Questionnaire (BF-10). Psikhologicheskie Issledovaniya, 9(45), 9. Retrieved from http://psystudy.ru (in Russian)

Ferguson, G. A. (1949). On the theory of test discrimination. Psychometrika, 14, 61-68. doi:10.1007/BF02290141

Fiske, D. W. (1949). Consistency of the factorial structures of personality ratings from different sources. The Journal of Abnormal and Social Psychology, 44, 329-344.

Furr, R. M., \& Bacharach, V. R. (2010). Psikhometrika: Vvedenie [Psychometrics: An introduction]. Chelyabinsk: Izdatel'skii tsentr YuUrGU. (in Russian; Furr, R. M., \& Bacharach, V. R. (2007). Psychometrics: An introduction. Sage Publications.)

Galton, F. (1884). Measurement of character. Fortnightly Review, 36, 179-185.

George, D., \& Mallery, P. (2016). IBM SPSS Statistics 23 step by step: A simple guide and reference. New York, NY: Routledge.

Goldberg, L. R. (1981). Language and individual differences: The search for universals in personality lexicons. Review of Personality and Social Psychology, 2(1), 141-165.

Goldberg, L. R., Johnson, J. A., Eber, H. W., Hogan, R., Ashton, M. C., Cloninger, C. R., \& Gough, H. G. (2006). The international personality item pool and the future of public-domain personality measures. Journal of Research in Personality, 40(1), 84-96.

Goldberg, L. R., \& Shmelev, A. G. (1993). Mezhkul'turnoe issledovanie leksiki lichnostnykh chert: "Bol'shaya pyaterka" faktorov v angliiskom i russkom yazykakh [Intercultural study of the names 
of personality traits: Big Five Factors in English and Russian]. Psikhologicheskii Zhurnal, 14(4), 32-39. (in Russian)

Hankins, M. (2007). Questionnaire discrimination: (re)-introducing coefficient $\delta$. BMC Medical Research Methodology, 7(1), 19. doi:10.1186/1471-2288-7-19

John, O., Donahue, E. M., \& Kentle, R. L. (1991). The Big Five Inventory - Versions 4a and 54. Berkeley, CA: Institute of Personality and Social Research, University of California, Berkeley.

John, O. P., Naumann, L. P., \& Soto, C. J. (2008). Paradigm shift to the integrative big five trait taxonomy. In O. P. John, R. W. Robins, \& L. A. Pervin (Eds.), Handbook of personality: Theory and research (pp. 114-158). New York, NY: Guilford Press.

John, O. P., \& Srivastava, S. (1999). The Big Five trait taxonomy: History, measurement, and theoretical perspectives. In L. A. Pervin \& O. P. John (Eds.), Handbook of personality: Theory and research (pp. 102-138). New York, NY: Guilford Press.

Khromov, A. B. (2000). Pyatifaktornyi oprosnik lichnosti [A Five Factor personality test]. Kurgan: Kurgan State University. (in Russian)

Khromov, A. B. (2010). Pyatifaktornyi lichnostnyi oprosnik: test 5FPQ [A Five Factor Personality Questionnaire: Test 5FPQ]. Kurgan: Kurgan State University. (in Russian)

Kline, P. (1994). Spravochnoe rukovodstvo po konstruirovaniyu testov [A guideline in test construction]. Kiev: PAN Ltd. (in Russian)

Knyazev, G. G., Mitrofanova, L. G., \& Bocharov, V. A. (2010). Validization of Russian version of Goldberg's "Big-Five Factor Markers" Inventory. Psikhologicheskii Zhurnal, 31(5), 100-110. (in Russian)

Kornilova, T. V., \& Chumakova, M. A. (2016). Development of the Russian version of the Brief Big Five Questionnaire (TIPI). Psikhologicheskie Issledovaniya, 9(46), 5. Retrieved from http://psystudy.ru (in Russian)

Martin, T. A., Costa, P. T., Oryol, V. E., Rukavishnikov, A. A., \& Senin, I. G. (2002). Applications of the Russian NEO-PI-R. In R. R. McCrae \& J. Allik (Eds.), The Five-Factor Model of personality across cultures (pp. 261-277). Boston, MA: Springer.

McCrae, R. R., \& Costa, P. T. (1987). Validation of the five-factor model of personality across instruments and observers. Journal of Personality and Social Psychology, 52, 81-90. doi:10.1037/00223514.52.1.81

McDonald, R. P. (2013). Test theory: A unified treatment. Sussex, UK: Psychology Press.

McNeish, D. (2018). Thanks coefficient alpha, we'll take it from here. Psychological Methods, 23, 412433. doi:10.1037/met0000144

Mishkevich, A. M., \& Shchebetenko, S. A. (2017). Psikhometrika russkoyazychnoi versii Big Five Inventory: novye svidetel'stva [Psychometric qualities of the Russian version of Big Five Inventory: a new evidence]. In A. L. Zhuravlev \& V. A. Kol'tsova (Eds.), Fundamental'nye i prikladnye issledovaniya sovremennoi psikhologii: rezul'taty i perspektivy razvitiya [Fundamental and applied research in contemporary psychology: results and perspectives of development] (pp. 771776). Moscow: Institute of Psychology of the RAS. (in Russian)

Mishkevich, A. M., \& Shchebetenko, S. A. (2018). Sex differences in the Big Five of personality: Looking through the attitudes toward traits. Psychology. Journal of Higher School of Economics, 15(3), 562-572. (in Russian)

Muchinsky, P. M. (1996). The correction for attenuation. Educational and Psychological Measurement, 56, 63-75. doi:10.1177/0013164496056001004 
Norman, W. T. (1963). Toward an adequate taxonomy of personality attributes: Replicated factor structure in peer nomination personality ratings. The Journal of Abnormal and Social Psychology, 66, 574-583. doi:10.1037/h0040291

Orel, V. E., \& Senin, I. G. (2004). Lichnostnyi oprosnik NEO PI-R. Rukovodstvo po primeneniyu [Personality Questionnaire NEO PI-R. A Guideline]. Yaroslavl': NPTs "Psikhodiagnostika". (in Russian)

Orel, V. E., \& Senin, I. G. (2008). Lichnostnye oprosniki NEO-PI-R i NEO-FFI. Rukovodstvo po primeneniyu [Personality Questionnaires NEO-PI-R and NEO-FFI. A Guideline]. Yaroslavl': NPTs "Psikhodiagnostika". (in Russian)

Osin, E. N., Rasskazova, E. I., Neyaskina, Yu. Yu., Dorfman, L. Ya., \& Aleksandrova, L. A. (2015). Operatsionalizatsiya pyatifaktornoi modeli lichnostnykh chert na rossiiskoi vyborke [Operationalization of a 5-factor model of personality traits in a Russian sample]. Psikhologicheskaya Diagnostika, 3, 80-104. (in Russian)

Revelle, W., \& Zinbarg, R. E. (2009). Coefficients alpha, beta, omega, and the glb: Comments on Sijtsma. Psychometrika, 74, 145-154. doi:10.1007/s11336-008-9102-z

Schmitt, D. P., Realo, A., Voracek, M., \& Allik, J. (2008). Why can't a man be more like a woman? Sex differences in Big Five personality traits across 55 cultures. Journal of Personality and Social Psychology, 94, 168-182. doi:10.1037/0022-3514.94.1.168

Sergeeva, A. S., Kirillov, B. A., \& Dzhumagulova, A. F. (2016). Translation and adaptation of short five factor personality questionnaire (TIPI-RU): convergent validity, internal consistency and testretest reliability evaluation. Eksperimental'naya Psikhologiya [Experimental Psychology (Russia)], 9(3), 138-154. doi:10.17759/exppsy.2016090311 (in Russian)

Shchebetenko, S. A. (2014). "The best man in the world": Attitudes toward personality traits. Psychology. Journal of the Higher School of Economics, 11(3), 129-148.

Shchebetenko, S. (2017). Reflexive characteristic adaptations explain sex differences in the Big Five: But not in neuroticism. Personality and Individual Differences, 111, 153-156. doi:10.1016/j.paid.2017.02.013

Shchebetenko, S. A., \& Vainshtein, S. V. (2014). Bol'shaya Pyaterka chert lichnosti: eksplitsitnoimplitsitnyi podkhod [Big Five of personality traits: An explicit-implicit approach]. Psikhologiya $i$ Psikhotekhnika, 1, 69-82. (in Russian)

Shchebetenko, S., Kalugin, A. Y., Mishkevich, A. M., Soto, C. J., \& John, O. P. (2020). Measurement invariance and sex and age differences of the Big Five Inventory-2: Evidence from the Russian version. Assessment, 27, 472-486. doi:10.1177/1073191119860901

Shmelev, A. G. (2013). Prakticheskaya testologiya. Testirovanie v obrazovanii, prikladnoi psikhologii $i$ upravlenii personalom [Practical Testology. Testing in Education, applied psychology and human resources management]. Moscow: IPTs "Maska". (in Russian)

Shmelyov, A. G., \& Pokhilko, V. I. (1993). A taxonomy oriented study of Russian personality trait names. European Journal of Personality, 7, 1-17. doi:10.1002/per.2410070102

Soto, C. J., \& John, O. P. (2009). Ten facet scales for the Big Five Inventory: Convergence with NEO PI-R facets, self-peer agreement, and discriminant validity. Journal of Research in Personality, 43, 84-90. doi:10.1016/j.jrp.2008.10.002

Soto, C. J., \& John, O. P. (2017). The next Big Five Inventory (BFI-2): Developing and assessing a hierarchical model with 15 facets to enhance bandwidth, fidelity, and predictive power.Journal of Personality and Social Psychology, 113, 117-143. doi:10.1037/pspp0000096 
Srivastava, S., John, O. P., Gosling, S. D., \& Potter, J. (2003). Development of personality in early and middle adulthood: Set like plaster or persistent change? Journal of Personality and Social Psychology, 84, 1041-1053. doi:10.1037/0022-3514.84.5.1041

Sugonyaev, K., Grigoriev, A., \& Lynn, R. (2019). Regional differences in intelligence and personality in the Russian Federation and their social and demographic correlates. Mankind Quarterly, 60(2), $256-271$.

Tupes, E. C., \& Christal, R. E. (1992). Recurrent personality factors based on trait ratings. Journal of Personality, 60, 225-251. doi:10.1111/j.1467-6494.1992.tb00973.x

Alexey Yu. Kalugin - Head of the Department, Department of Practical Psychology, Perm State Humanitarian Pedagogical University, PhD.

Research Area: personality psychology, psychology of individuality, data analysis.

E-mail: kaluginau@yandex.ru

Sergei A. Shchebetenko - Professor, School of Psychology, HSE University; Professor, Department of Developmental Psychology, Perm State University, D.Sc.

Research Area: personality and individual differences, social psychology, methodology.

E-mail: sshchebetenko@hse.ru

Arina M. Mishkevich - Senior Lecturer, Department of Developmental Psychology, Perm State University, PhD (HSE University).

Research Area: personality psychology, social attitudes.

E-mail: ArinaMishkevich@ya.ru

Christopher J. Soto - Associate Professor, Department of Psychology, Colby College (USA), PhD (University of California, Berkeley).

Research Area: personality structure, lifespan personality development, relations between personality traits and life outcomes, psychological measurement.

E-mail: christopher.soto@colby.edu

Oliver P. John - Professor in the Department of Psychology, University of California, Berkeley (USA), PhD (University of Oregon).

Research Area: self-concept, self-perception accuracy and biases, personality development and assessment across the lifespan, emotion experience and expression, cultural differences.

E-mail: o_johnx5@berkeley.edu 
Психология. Журнал Высшей школы экономики.

2021. T. 18. № 1. C. 34-55. DOI: 10.17323/1813-8918-2021-1-34-55

\title{
ДИАГНОСТИКА ДИСПОЗИЦИОННОГО ОПТИМИЗМА, ВАЛИДНОСТЬ И НАДЕЖНОСТЬ ОПРОСНИКА ТДО-П
}

\author{
Т.О. ГОРДЕЕВА ${ }^{\text {a, b }}$, О.А. СЫЧЕВ ${ }^{\mathrm{c}}$, Е.Н. ОСИН
}

\begin{abstract}
${ }^{a}$ МГУ имени М.В. Ломоносова, 119991, Россия, Москва, Ленинские горы, д. 1
${ }^{b}$ Национальный исследовательский университет «Высшая школа экономики», 101000, Россия, Москва, ул. Мясницкая, д. 20

'Алтайский государственный гуманитарно-педагогический университет имени В.М. Шукшина, 659333, Россия, Алтайский край, Бийск, ул. Короленко, д. 53
\end{abstract}

\begin{abstract}
Резюме
Под диспозиционным оптимизмом понимается когнитивная установка, включающая генерализованные ожидания относительно будущего или тенденцию индивида верить в то, что в будущем его ждет больше хороших событий, чем плохих. Согласно результатам исследований, показатели диспозиционного оптимизма связаны с меньшей депрессией, лучшим физическим здоровьем, психологическим благополучием, лучшими межличностными отношениями; основным постулируемым механизмом этих связей является влияние оптимизма на мотивацию, что проявляется в готовности оптимистов прилагать усилия, направленные на решение жизненных задач. В статье представлены результаты апробации теста диспозиционного оптимизма (ТДО-П) - русскоязычного аналога теста LOT-R M. Шейера, Ч. Карвера и М. Бриджеса, пересмотренной версии методики LOT. Апробация этой обновленной версии проводилась в двух исследованиях - на выборке студентов и аспирантов разных вузов $(\mathrm{n}=406)$ и репрезентативной выборке россиян разных возрастов и профессий $(\mathrm{n}=1509)$. Оба исследования свидетельствуют о высокой надежности опросника по внутренней согласованности ( $\alpha$ Кронбаха составил 0.78). С помощью конфирматорного факторного анализа показана двухфакторная структура методики с ортогональными факторами оптимизма и стиля ответов. Валидность методики подтверждается существенными корреляциями с показателями психологического благополучия и умеренными, но статистически значимыми корреляциями с показателями оптимистического мышления. В пользу конструктной валидности ТДО-П также свидетельствуют корреляции с показателями саморегуляции, надеждой и жизнестойкостью. В статье представлены подробные данные о связи оптимизма с социально-демографическими характеристиками: полом, возрастом, уровнем образования. На основе полученных данных приведены ориентировочные статистические нормы. Методика может быть использована исследователями и практиками для получения данных о выраженности диспозиционного оптимизма как личностной черты, описывающей генерализованные ожидания относительно будущего.
\end{abstract}

Ключевые слова: диспозиционный оптимизм, оптимизм, пессимизм, психологическое благополучие, валидность, надежность теста.

Статья подготовлена в результате проведения исследования в рамках Программы фундаментальных исследований НИУ ВШЭ и в рамках государственной поддержки ведущих университетов Российской Федерации «5-100». 


\section{Введение}

Интерес к проблеме оптимизма изначально был обусловлен простым наблюдением, показывающим, что психически здоровые люди склонны мыслить оптимистично в отношении себя, своего потенциала и своего будущего. Было выдвинуто предположение, что оптимистическое мышление позволяет поддерживать психологическое благополучие, избегать депрессии и более продуктивно реагировать на жизненные трудности и препятствия, сохраняя уверенность в их разрешимости и проявляя упорство. Современные исследования оптимизма осуществляются главным образом в рамках двух психологических подходов - концепции диспозиционного оптимизма Ч. Карвера и М. Шейера и концепции атрибутивного стиля, предложенной М. Селигманом c соавт. (Seligman et al., 1979) и разработанной позднее К. Петерсоном (Peterson, Steen, 2002).

Ключевым в переформулированной теории выученной беспомощности и депрессии, разработанной М. Селигманом, Л. Абрамсон и Дж. Тисдейлом, является понятие атрибутивного (или объяснительного) стиля. Под атрибутивным стилем понимается характерный способ, которым люди объясняют себе причины различных жизненных событий, имевших место в прошлом. Человек с оптимистическим атрибутивным стилем склонен к объяснению позитивных событий постоянными, универсальными и внутренними причинами, а с пессимистическим стилем - вре́менными, конкретными и внешними. Негативные события при оптимистическом атрибутивном стиле, напротив, будут объясняться с обращением к конкретным, вре́менным и внешним причинам, а при пессимистическом - к причинам универсального, постоянного и внутреннего характера. Исследования показывают, что оптимистический/пессимистический атрибутивный стиль надежно связан с депрессией и психологическим благополучием, также имеются данные о его роли в саморегуляции и успешности деятельности (см.: Gordeeva et al., 2020).

В подходе диспозиционного оптимизма (ДО) под оптимизмом/пессимизмом понимается личностная черта, представляющая собой обобщенную тенденцию человека верить в то, что в будущем его ждет больше хороших событий, чем плохих. Изначально предполагалось, что ДО может выступать защитным фактором в ситуациях столкновения с жизненными трудностями, такими как болезнь, стимулируя более продуктивные копинг-стратегии и поддерживая здоровье (Scheier, Carver, 1985). Постепенно сфера исследований ДО расширилась, и к настоящему времени изучены связи оптимизма с психологическим благополучием, успешностью деятельности, межличностными отношениями и др. Интенсивность этих исследований во многом была стимулирована легкостью измерения оптимизма.

Конструкт ДО принадлежит к разряду личностных переменных, описывающих позитивное мышление, наряду с такими понятиями, как оптимистический атрибутивный стиль, надежда или самоэффективность. От вышеупомянутых конструктов он отличается тем, что фокусируется на обобщенных позитивных ожиданиях относительно будущего без уточнения средств или 
источников, с помощью которых эти результаты могут быть достигнуты (например, человек может быть оптимистом и потому, что уверен в своих способностях, а может и потому, что верит в то, что нравится другим людям). Изначально в соответствии с моделью поведенческой саморегуляции Ч. Карвера и М. Шейера, корни которой лежат в традициях теорий мотивации как ожидаемой ценности, утверждалось, что оптимизм связан с мотивацией и настойчивостью: оптимисты склонны к проявлению усилий, в то время как пессимисты склонны к отказу от активных усилий и решения проблем.

Благодаря предложенной в 1985 г. самоотчетной методике, получившей название «Тест жизненной ориентации» (Life Orientation Test, LOT), и его более поздней улучшенной версии (LOT-R, 1994) (Scheier, Carver, 1985) диспозиционный оптимизм стал активно исследоваться и в результате оказался широко используемым объяснительным конструктом в самых разных областях современной психологии. Рассмотрим кратко основные полученные результаты, представляющие не только научный, но и широкий практический интерес.

ДО и физическое здоровъе. Результаты исследований и ряд метаанализов показывают, что ДО связан с физическим здоровьем, в том числе подверженностью сердечно-сосудистым и онкологическим заболеваниям, выживаемостью от этих болезней, общей продолжительностью жизни, риском суицидальных попыток, иммунным функционированием, а также с показателями, обусловленными беременностью, физическими симптомами и болью (Andersson, 1996; Carver, Scheier, 2014; Rasmussen et al., 2009; Rozanski et al., 2019; Tindle et al., 2009). В недавнем метаанализе, включившем 15 исследований (n = 229391, среднее время наблюдений - 14 лет) (Rozanski et al., 2019), было показано, что оптимизм связан со сниженным риском развития сердечно-сосудистых заболеваний и смертности от всех типов причин.

Наибольший интерес представляют проспективные исследования, в которых оптимизм рассматривается как предиктор состояния физического здоровья и различных заболеваний, прежде всего сердечно-сосудистых и онкологических. Например, в исследовании Дж. Боэм с соавт. на восьмитысячной выборке британских мужчин и женщин было показано, что у тех, кто был более оптимистичен (верхняя треть выборки) в начале исследования, вероятность развития сердечно-сосудистых заболеваний в течение пяти лет наблюдения была на 27\% меньше по сравнению с теми, кто был менее оптимистичен (нижняя треть) (Boehm et al., 2011). В другом исследовании, включавшем наблюдение на протяжении 8-летнего периода за 97253 американскими женщинами (в том числе евроамериканками и афроамериканками) 50-79-летнего возраста, здоровых в начале исследования, результаты были похожи - в группе наиболее оптимистичных женщин было отмечено значимое снижение показателей смертности от ишемической болезни сердца (ИБС) относительно наименее оптимистичных. Оптимисты (верхняя четверть наиболее оптимистичных по сравнению с нижней четвертью, т.е. пессимистами) также имели значимо сниженные показатели смертности от целого ряда причин (на 14\% для смерти по любой причине, на 16\% ниже для инфаркта миокарда, на 
9\% для развития ИБС, на $30 \%$ для смертности, связанной с ИБС, и на 24\% для смертности от сердечно-сосудистых заболеваний), за исключением смертности от рака, показанной только на выборке афроамериканок (Tindle et al., 2009).

В качестве причин такого рода зависимостей рассматриваются особенности копинг-стратегий оптимистов и их стратегии поведения, связанного со здоровьем. Предполагалось, что, сталкиваясь с проблемами, связанными со здоровьем, оптимисты демонстрируют более продуктивные паттерны совладающего поведения, эмоций и поведенческого реагирования (например, едят больше овощей и фруктов, выполняют регулярные упражнения, отказываются от курения), чем пессимисты. Было показано, что, сталкиваясь с болью, оптимисты менее склонны катастрофизировать свое состояние. В метаанализе, проведенном Дж. Боэм с соавт., были подвергнуты анализу три типа поведения, наиболее достоверно связанного с меньшим риском развития сердечно-сосудистых заболеваний: физическая активность, диета и курение сигарет (Boehm et al., 2018). В анализ были включены 34 размера эффекта для физической активности $(\mathrm{n}=90845), 15$ - для диеты $(\mathrm{n}=47931)$ и 15 - для курения сигарет $(\mathrm{n}=15052)$. Исследование показало, что более оптимистичные люди склонны вести более здоровый образ жизни по сравнению с менее оптимистичными, однако размеры эффекта были небольшими $\left(r_{\text {физакт. }}=0.07, r_{\text {диета }}=0.12\right.$, $r_{\text {курение }}=0.07$, все $\left.p<0.001\right)$. К сожалению, большинство исследований были кросс-секционными, соответственно уровень доказательности этих данных невысок и требует дополнительных данных проспективного характера, а также анализа иммунологических и других физиологических механизмов, опосредующих влияние оптимизма на здоровье.

ДО и психологическое благополучие. Связь ДО с психическим здоровьем, включая показатели депрессии, враждебности и тревоги, а также благополучием, включая удовлетворенность жизнью и счастье, были показаны как в корреляционных, так и в лонгитюдных исследованиях (Carver, Scheier, 2014; Scheier et al., 2001). Наиболее исследованной является связь ДО с депрессией. Так, метаанализ 42 исследований $(\mathrm{n}=10359)$ связи оптимизма и депрессии показал, что эта связь является достаточно надежной $(r=-0.43)$ и отрицательной (Andersson, 1996). Еще больший интерес представляют данные недавнего метаанализа 59 исследований (Gallagher et al., 2020), свидетельствующие о том, что оптимизм обладает защитным эффектом в отношении развития посттравматических расстройств (ПТСД), т.е. оптимизм способствует развитию посттравматической резистентности $(r=-0.29[-0.33 ;-0.25])$, и эта связь не изменяется в зависимости от пола или возраста.

ДО и успешность в деятельности. Большинство исследований диспозиционного оптимизма сфокусированы на его вкладе в физическое здоровье как ресурс преодоления трудных жизненных ситуаций, травм и болезней. Результаты исследований связи ДО с академическими и профессиональными достижениями показывают менее однозначные результаты. На материале учебных достижений школьников эта связь варьирует от незначимой до слабой позитивной. Результаты метаанализа шести исследований свидетельствуют о слабой позитивной связи между ДО и академическими достижения- 
ми студентов ( $r=0.11, \mathrm{n}=1364)$ (Richardson et al., 2012). Результаты наших исследований не подтверждают связи ДО с академическими достижениями российских студентов и школьников (Гордеева и др., 2017) при наличии подобных связей в случае оптимистического атрибутивного стиля (Gordeeva et al., 2020), хотя ДО обнаружил связи с показателями саморегуляции, вносящими позитивный вклад в достижения.

На выборке работников кол-центров было обнаружено, что оптимисты демонстрировали более низкий уровень воспринимаемого стресса на работе и меньший конфликт между работой и личной жизнью. Тем не менее пессимисты демонстрировали более высокую производительность и удовлетворенность трудом, а также меньший уровень намерений бросить работу (Tuten, Neidermeyer, 2004). Очевидно, что механизмы связи оптимизма с поведением человека в достиженческих ситуациях являются весьма сложными и зависят как от специфики и условий самой деятельности, так и от сформированности других процессов саморегуляции, которые обеспечивают эффективность деятельности. Механизмом этих связей может выступать бо́льшая целеустремленность и настойчивость оптимистов, а также их готовность более продуктивно справляться с неудачами, используя стратегии позитивной реинтерпретации и роста (Carver, Scheier, 2014). Оптимистичные люди, высоко оценивающие вероятность успеха, склонны поддерживать свои усилия при движении к цели, в то время как пессимисты чаще отказываются от усилий, демонстрируя низкий уровень мотивации и настойчивости (Scheier et al., 2001). Вместе с тем в некоторых ситуациях оптимисты могут недооценивать возникающие трудности и вкладывать меньше усилий в подготовку к ним. Последние исследования показывают, что оптимисты склонны стремиться к достижению целей, имеющих для них приоритетную значимость, и не отличаются от пессимистов по вовлеченности в достижение целей, имеющих низкий приоритет (Carver, Scheier, 2014). Все это может объяснять неоднозначные связи оптимизма с объективно измеряемыми показателями успешности в деятельности.

Недавно возникшая область исследований связана с изучением роли оптимизма в межличностных отношениях. Результаты этих исследований показывают, что ДО предсказывает лучшие отношения с окружающими и бо́льшую удовлетворенность отношениями. Оптимисты склонны быть более заботливыми и вовлеченными родителями, они проявляют в отношениях теплый и слегка доминирующий стиль общения, лучше справляются с кризисами в отношениях и сообщают о большей социальной поддержке со стороны окружающих (Ibid.). На материале данных, полученных как в лаборатории, так и в реальной жизни, было показано, что в дискуссиях со своими близкими (супругами и партнерами) оптимисты склонны более конструктивно подходить к решению проблем и больше работать над своими отношениями (Ibid.).

Существуют разнообразные практики повышения оптимизма, главным образом с опорой на когнитивно-бихевиоральную психотерапию и позитивную психологию. Метаанализ Дж. Маллуффа и Г. Шутте, основанный на анализе 29 исследований ( $\mathrm{n}=3319)$, показал, что психологические интервенции действительно могут повысить оптимизм (Malouff, Schutte, 2017), при этом 
был обнаружен значительный размер эффекта $(\mathrm{g}=0.41)$. Согласно анализам модерации, более высокие показатели эффекта имели место в случае очных интервенций по сравнению с заочными (онлайн). Наилучший эффект был показан для упражнения «Мое лучшее возможное Я» (Best Possible Self), которое предлагалось выполнять по 5 минут в день в течение двух недель, представляя свое наилучшее возможное будущее, которое может наступить благодаря постановке целей и предпринятым усилиям, в трех областях - личной, отношениях с другими и профессиональной. Тем не менее, поскольку ДО как личностная черта обладает определенной стабильностью во времени, особенно в случае отсутствия больших перемен в жизни, его развитие в долгосрочной перспективе может требовать существенных усилий.

Диагностика диспозиционного оптимизма (ДО). Опросник LOT изначально состоял из четырех позитивно сформулированных (оптимистических) утверждений, четырех обратных (негативно сформулированных) утверждений и четырех филлеров, призванных отвлечь внимание испытуемых от истинных целей диагностики и снизить социальную желательность (Scheier, Carver, 1985). Тест получил широкое распространение в психологии здоровья, а также в других областях, связанных с проблематикой позитивного личностного функционирования. Однако со временем содержательная валидность оригинальной версии методики стала подвергаться критике, поскольку некоторые утверждения, входящие в ее состав, не вполне соответствовали строгому определению диспозиционного оптимизма как обобщенных ожиданий относительно будущего.

Для решения этой проблемы в 1994 г. М. Шейер, Ч. Карвер и М. Бриджес предложили обновленный вариант опросника (Scheier et al., 1994). В процессе разработки новой версии методики были исключены два пункта, не полностью соответствовавшие четко сформулированному конструкту диспозиционного оптимизма. Поскольку оба удаленных пункта имели позитивные формулировки, число прямых и обратных пунктов оказалось несбалансированным, что привело к решению удалить еще один негативный пункт и добавить одно позитивное утверждение («В целом я ожидаю, что со мной произойдет больше хорошего, чем плохого»). В результате в состав методики вошли только утверждения, содержание которых отражает обобщенные ожидания позитивных или негативных будущих событий (Ibid.). Полученная в результате методика LOT-R получила широкое распространение (Herzberg et al., 2006; Monzani et al., 2014; Nakano, 2004).

B ряде исследований структуры LOT и LOT-R была показана предпочтительность двухфакторной модели, в рамках которой оптимизм и пессимизм выступают как два относительно независимых фактора, имеющих умеренную обратную связь (Vautier et al., 2003). Исследования в разных странах мира с использованием локализованных версий зачастую также показывают предпочтительность двухфакторной модели (Herzberg et al., 2006; Nakano, 2004; Гордеева и др., 2010), что интерпретируется в пользу рассмотрения двух отдельных параметров оптимизма. Другие авторы, напротив, отстаивают однофакторную структуру методики, причем для доказательства преимуществ 
однофакторной структуры LOT-R иногда используют дополнительный ортогональный фактор стиля ответов, объединяющий обратные пункты (Monzani et al., 2014). Стиль ответов отражает тенденцию в большей или меньшей мере соглашаться со всеми пунктами опросника независимо от их прямого или обратного содержания. Для контроля этой тенденции в модель однофакторного опросника вводится дополнительный фактор, объединяющий только обратные (или только прямые) задания, независимый от общего фактора. Соответствие подобной модели данным подтверждает гипотезу об однофакторной структуре при наличии дополнительного вклада стиля ответов.

В целом дискуссия исследователей относительно однофакторной или двухфакторной структуры методики аналогична обсуждениям любых личностных методик с прямыми и обратными утверждениями, которые могут рассматриваться в качестве полюсов единого конструкта, когда двухфакторная структура выступает артефактом метода измерения, или двух различных коррелирующих конструктов. Большинство исследователей, в том числе и авторы методики, рассматривают диспозиционный оптимизм как единый конструкт из соображений простоты и в силу выраженной связи позитивных и негативных утверждений.

В нашей стране в связи с ростом интереса к личностному потенциалу и позитивным личностным свойствам был разработан Тест диспозиционного оптимизма (ТДО), представляющий собой русскоязычную версию LOT (Гордеева и др., 2010). Несмотря на хорошие психометрические характеристики, его содержательная валидность, как и валидность англоязычного оригинала (LOT), не является бесспорной. В этой связи целью данного исследования стала разработка пересмотренной версии ТДО, аналогичной LOT-R. Для анализа психометрических характеристик новой версии методики были проведены два исследования.

\section{Исследование 1}

В первом исследовании на выборке студентов и магистрантов были проанализированы структура методики, ее надежность и валидность.

\section{Методика}

В ходе разработки пересмотренной версии опросника с целью улучшения содержательной валидности по аналогии с англоязычными версиями опросника из опросника ТДО были исключены два прямых пункта («Я всегда во всем ищу позитив» и «Я верю в то, что все, что происходит, - к лучшему») и один обратный («Я мало верю в то, что будущее будет хорошим»). В соответствии c LOT-R было добавлено одно утверждение «В целом я ожидаю, что со мной произойдет больше хорошего, чем плохого». Перевод пунктов осуществлялся двумя высококвалифицированными психологами, свободно владеющими русским и английским языками, процедура включала прямой и обратный перевод пунктов. Утверждения-наполнители (филлеры) не менялись. 
Полученный в результате текст ТДО-П (см. Приложение) полностью отвечает требованию содержательной валидности и соответствует англоязычному оригиналу.

Для анализа внешней валидности всем испытуемым предъявляли 13 утверждений, которые включали пункты, входящие как в исходную, так и в пересмотренную версии ТДО. Результаты рассчитывались по ключам отдельно для ТДО и ТДО-П.

Исследование конструктной (конвергентной и дискриминантной) валидности пересмотренной версии шкалы диспозиционного оптимизма осуществлялось с помощью ряда методик, оценивающих показатели субъективного благополучия, оптимистического атрибутивного стиля и саморегуляции:

- Шкала удовлетворенности жизнью SWLS Э. Динера в адаптации Е.Н. Осина и Д.А. Леонтьева (2020), включающая пять пунктов, оцениваемых по семибалльной шкале Ликерта (надежность $\alpha$ Кронбаха $=0.86^{1}$ ).

- Шкала Субъективного счастья SHS C. Любомирски в адаптации Е.Н. Осина и Д.А. Леонтьева (2020), включающая четыре пункта, оцениваемых по семибалльной шкале $(\alpha=0.82)$.

- Опросник стиля объяснения успехов и неудач СТОУН-В (сокращенная версия) Т.О. Гордеевой с соавт. (2009), оценивающая оптимистическое мышление в ситуациях успехов и неудач. Методика включает десять ситуаций, предполагаемая причина каждой из них оценивается по трем параметрам (глобальности, стабильности и контролируемости) с использованием шестибалльной шкалы. Коэффициент $\alpha$ для шкалы оптимистического мышления в ситуациях успеха составил 0.90 , в ситуациях неудач -0.79 , по отдельным субшкалам - от 0.74 до 0.86 , за исключением шкалы контролируемости в ситуациях неудач $(\alpha=0.66)$.

- Опросник самоорганизации деятельности Е.Ю. Мандриковой (2010). В данном исследовании использовались шкалы «Планомерность», «Настойчивость», «Целеустремленность». Каждая из шкал включает от четырех до шести пунктов, согласие с которыми необходимо оценить по семибалльной шкале Ликерта ( $\alpha$ составляет 0.78 для планомерности, 0.84 для настойчивости и 0.86 для целеустремленности).

В исследовании приняли участие 406 человек, из них 223 магистранта и аспиранта НИЯУ МИФИ, которые проходили исследование в форме онлайн-опроса, и 183 студента отделения заочного обучения АГГПУ им. В.М. Шукшина, заполнявших опросники в традиционной бланковой форме. Статистически значимых различий между этими подгруппами не обнаружилось, поэтому можно говорить о том, что форма проведения (традиционная или онлайн) не оказывает существенного влияния на результаты LOT-R, которые будут рассматриваться в целом по выборке. Среди участников исследования было 130 мужчин, 174 женщины, 102 испытуемых пол не указали. Средний возраст участников $\mathrm{M}=21.58$ ( $\mathrm{SD}=5.27)$, подавляющее большинство (96\%) принадлежит к возрастной группе 18-30 лет.

${ }^{1}$ Здесь и далее приведены показатели внутренней согласованности, полученные в данном исследовании. 
Статистический анализ данных проводился с использованием программ $\mathrm{R}$ и Jamovi. Для анализа факторной структуры методики проводился конфирматорный факторный анализ (КФА) в программе Mplus с использованием робастного алгоритма MLR, устойчивого по отношению к отклонениям от нормальности распределения.

\section{Результаты}

С учетом результатов предыдущих исследований в ходе анализа структуры предложенной методики проверялось три модели: однофакторная (1Ф), двухфакторная с коррелирующими факторами оптимизма и пессимизма (2КФ, см. рисунок 1a) и двухфакторная с ортогональными факторами диспозиционного оптимизма и стиля ответов (2ОФ, см. рисунок 1б).

В результате КФА для модели 1 Ф были получены неудовлетворительные показатели соответствия данным (см. таблицу 1). Модели $2 К Ф$ и $2 О Ф$ показывают очень близкие оценки соответствия данным, хотя для модели $2 К Ф$ эти величины несколько лучше. Сравнение величины информационного критерия Акаике для моделей 2КФ (6623.2) и 2ОФ (6625) также показывает некоторое превосходство первой модели.

Значение коэффициента надежности $\alpha$ Кронбаха, равное 0.79 , свидетельствует о высокой внутренней согласованности методики. Коэффициент корреляции с полной версией ТДО также был высоким $(r=0.96 ; p<0.001 ; \mathrm{n}=$ 406). Данные, свидетельствующие о конструктной валидности методики, были получены в ходе анализа связей диспозиционного оптимизма с показателями субъективного благополучия, саморегуляции деятельности и оптимистического атрибутивного стиля (см. таблицу 2).

В соответствии с теоретически обоснованными ожиданиями были обнаружены существенные корреляции с показателями психологического благополучия

Рисунок 1

Факторные модели пересмотренной версии теста диспозиционного оптимизма (все коэффициенты значимы при $p<0.01$ )

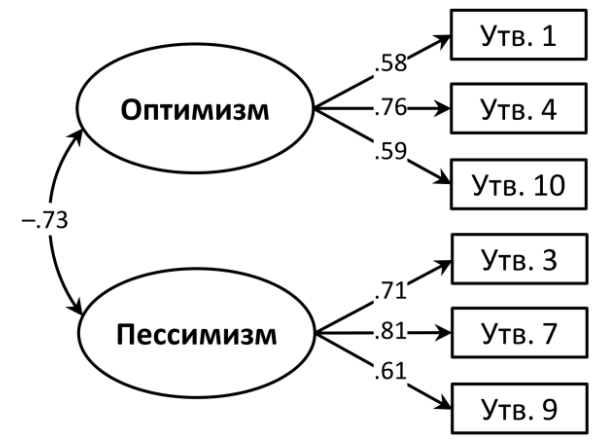

1а. Модель $2 К Ф$

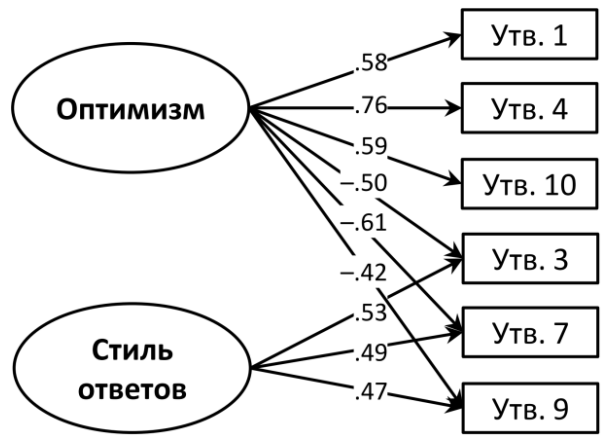

1б. Модель $2 \mathrm{O}$ 
Таблица 1

Результаты конфирматорного факторного анализа трех альтернативных моделей структуры пересмотренного теста диспозиционного оптимизма $(\mathrm{n}=406)$

\begin{tabular}{|l|c|c|c|c|c|c|c|c|}
\hline Модель & $\boldsymbol{\chi}^{2}$ & $\mathbf{d f}$ & $\boldsymbol{p}$ & CFI & TLI & RMSEA & Д.И. для RMSEA & PCLOSE \\
\hline $1 Ф$ & 40.616 & 9 & $<0.001$ & 0.910 & 0.851 & 0.093 & $0.065,0.123$ & 0.007 \\
\hline 2 КФ & 8.221 & 8 & 0.412 & 0.999 & 0.999 & 0.008 & $0.000,0.059$ & 0.889 \\
\hline 2 ОФ & 6.843 & 6 & 0.336 & 0.998 & 0.994 & 0.019 & $0.000,0.069$ & 0.804 \\
\hline
\end{tabular}

Примечание. CFI - сравнительный индекс согласия; TLI - ненормированный индекс согласия Такера-Льюиса; RMSEA - среднеквадратическая ошибка аппроксимации; Д.И. для RMSEA - доверительный интервал среднеквадратической ошибки аппроксимации; PCLOSE - вероятность попадания величины RMSEA, свидетельствующая о хорошем соответствии модели данным интервал от 0 до 0.05 .

Таблица 2

Описательная статистика и корреляции диспозиционного оптимизма с другими шкалами и показателями

\begin{tabular}{|c|c|c|c|c|}
\hline Методика & $\begin{array}{c}\text { Шкала } \\
\end{array}$ & ТДО-П поз. & ТДО-П нег. & ТДО-П \\
\hline SWLS $(n=384)$ & $\begin{array}{l}\text { Шкала Удовлетворенности } \\
\text { жизнью }\end{array}$ & $0.41^{* * *}$ & $-0.37 * * *$ & $0.44^{* * *}$ \\
\hline SHS $(n=217)$ & Шкала Субъективного счастья & $0.58 * * *$ & $-0.52^{* * *}$ & $0.62^{* * *}$ \\
\hline \multirow{8}{*}{$\begin{array}{l}\text { СТОУН-В, } \\
\text { оптимистиче- } \\
\text { ский } \\
\text { атрибутивный } \\
\text { стиль (n = 214) }\end{array}$} & Глобальность успехов & $0.16^{*}$ & $-0.16^{*}$ & $0.17 *$ \\
\hline & Контролируемость успехов & $0.15^{*}$ & $-0.27 * * *$ & $0.24^{* * *}$ \\
\hline & Стабильность успехов & $0.26 * * *$ & $-0.31^{* * *}$ & $0.32 * * *$ \\
\hline & Глобальность неудач & $0.20 * *$ & $-0.22^{* *}$ & $0.23^{* * *}$ \\
\hline & Контролируемость неудач & 0.01 & -0.07 & 0.05 \\
\hline & Стабильность неудач & $0.21 * *$ & $-0.16^{*}$ & $0.20^{* *}$ \\
\hline & Оптимизм в ситуациях успехов & $0.23^{* * *}$ & $-0.30^{* * *}$ & $0.29 * * *$ \\
\hline & Оптимизм в ситуациях неудач & $0.23 * * *$ & $-0.25^{* * *}$ & $0.27 * * *$ \\
\hline \multirow[t]{3}{*}{ ОСД $(\mathrm{n}=221)$} & Настойчивость & $0.14^{*}$ & $-0.25^{* * *}$ & $0.22^{* *}$ \\
\hline & Планирование & $0.39 * * *$ & $-0.31 * * *$ & $0.39^{* * *}$ \\
\hline & Целеустремленность & $0.51^{* * *}$ & $-0.46^{* * *}$ & $0.55^{* * *}$ \\
\hline \multicolumn{2}{|c|}{ Среднее (общее, $\mathrm{n}=406$ ) } & 8.68 & 3.97 & 16.71 \\
\hline \multicolumn{2}{|c|}{ Стд. отклонение (общее) } & 2.32 & 2.80 & 4.46 \\
\hline \multicolumn{2}{|c|}{ Среднее мужчины $(\mathrm{n}=130)$} & 8.81 & 4.15 & 16.66 \\
\hline \multicolumn{2}{|c|}{ Стд. отклонение (мужчины) } & 2.21 & 2.86 & 4.54 \\
\hline \multicolumn{2}{|c|}{ Среднее женщины (n = 174) } & 8.60 & 4.02 & 16.59 \\
\hline \multicolumn{2}{|c|}{ Стд. отклонение (женщины) } & 2.23 & 2.78 & 4.35 \\
\hline
\end{tabular}

${ }^{*} p<0.05,{ }^{* *} p<0.01,{ }^{* * *} p<0.001$.

Примечание. ТДО-П поз. - фактор позитивных ожиданий; ТДО-П нег. - фактор негативных ожиданий; ТДО-П - общая оценка по шкале диспозиционного оптимизма. 
( $r$ от 0.44 до 0.62$)$, а также показателями саморегуляции деятельности ( $r$ от 0.22 до 0.55). Среди показателей саморегуляции наиболее тесную связь с диспозиционным оптимизмом показала целеустремленность; это может означать, что способность субъекта сконцентрироваться на цели опирается на оптимистические ожидания успеха в ее достижении.

Показатели стиля объяснения успехов и неудач продемонстрировали умеренные статистически значимые корреляции с диспозиционным оптимизмом (за исключением шкалы контролируемости неудач).

При расщеплении шкалы на факторы позитивных и негативных ожиданий каждый из факторов демонстрирует корреляции, полностью аналогичные итоговой шкале ТДО-П. Сравнение средних значений в выборках мужчин и женщин (см. таблицу 2) с помощью критериев Стьюдента и Манна-Уитни показало отсутствие значимых различий.

\section{Исследование 2}

Целью второго исследования стала проверка факторной структуры и надежности методики на широкой репрезентативной выборке, дополнение данных о валидности, анализ роли социально-демографических факторов оптимизма (пола, возраста, образования) и получение норм.

\section{Методики}

Для диагностики использовалась описанная в исследовании 1 пересмотренная версия теста диспозиционного оптимизма. Для сбора дополнительных данных о валидности применялись следующие методики:

- Шкала Удовлетворенности жизнью SWLS Э. Динера в адаптации Д.А. Леонтьева и Е.Н. Осина $(2020)(\alpha=0.86)$.

- Шкала Диспозиционной надежды Ч. Снайдера с соавт. (Snyder et al., 1991) (русская версия Т.О. Гордеевой и Е.Н. Осина), включающая шкалы «Активность (целенаправленность энергии)» и «Пути (планирование достижения целей)». Каждая шкала включает по четыре пункта, согласие с которыми оценивается по пятибалльной шкале Ликерта ( $\alpha=0.79$ и 0.83 соответственно).

- Краткая версия теста жизнестойкости (Осин, Рассказова, 2013), включающая 12 утверждений, образующих три шкалы - вовлеченности, контроля и принятия риска, включающих по четыре пункта, согласие с которыми оценивается по четырехбалльной шкале Ликерта (коэффициент $\alpha$ для субшкал составил 0.81, 0.69 и 0.68 соответственно, для общего показателя жизнестойкости -0.88$)$.

- С целью анализа связи ДО с поддерживающим здоровье поведением в анкету был включен вопрос: «Занимаетесь ли вы спортом, физкультурой в свое свободное время? Сколько дней за последний месяц вы занимались спортом, физкультурой?», допускающий пять вариантов ответа («Не занимаюсь спортом или физкультурой в свободное время» и «Занимался 1-5 дней», $\ll 6-10$ дней», «11-20 дней» и «21-31 день»). 
В исследовании использовалась репрезентативная выборка жителей г. Томска и трех районов Томской области, данные были собраны в рамках проекта «Субъективные индикаторы качества жизни населения Томской области». Выборка составлялась путем систематического (шагового) отбора с коррекцией по половозрастным квотам. В исследовании приняли участие 1509 человек, в том числе 643 мужчины и 866 женщин в возрасте от 18 до 95 лет $(\mathrm{M}=42.57 ; \mathrm{SD}=16.33)$. В ходе статистического анализа результатов применялись те же методы и компьютерные программы, что и в исследовании 1.

Данные собирались в форме индивидуального устного опроса респондентов. Несмотря на определенные недостатки такого метода сбора данных (прежде всего большие временнь́е и материальные затраты, а также возможная роль личности интервьюера в сборе данных), он имеет и ряд преимуществ, в частности, возможность охватить недоступные при других формах опроса категории населения (Schröder, 2016).

\section{Результать}

Как и в первом исследовании, в ходе анализа факторной структуры методики было проверено три модели: однофакторная (1Ф), двухфакторная с коррелирующими факторами оптимизма и пессимизма (2КФ, см. рисунок $2 \mathrm{a})$ и двухфакторная с ортогональными факторами диспозиционного оптимизма и стиля ответов (2ОФ, см. рисунок 2б).

Результаты анализа, приведенные в таблице 3, свидетельствуют о том, что однофакторная модель не подтверждается данными. Модели 2КФ (рисунок 2) и 2ОФ показали хорошее соответствие данным, при этом в отличие от первого исследования модель 2ОФ выглядит более предпочтительной. Этот вывод также подтверждается величиной информационного критерия Акаике для моделей 2КФ (25448.5) и 2ОФ (25436.5).

В данном исследовании подтвердилась высокая внутренняя согласованность методики $(\alpha=0.78)$. В ходе анализа валидности методики в соответствии с ожиданиями обнаружились существенные корреляции с показателями психологического благополучия, диспозиционной надежды, жизнестойкости и поведения, направленного на поддержание здоровья (таблица 4). Так же как и в первом исследовании, корреляции факторов позитивных и негативных ожиданий

Таблица 3

Результаты конфирматорного факторного анализа трех альтернативных моделей структуры пересмотренного теста диспозиционного оптимизма $(\mathbf{n}=1509)$

\begin{tabular}{|l|c|c|c|c|c|c|c|c|}
\hline Модель & $\boldsymbol{\chi}^{2}$ & $\mathbf{d f}$ & $\boldsymbol{p}$ & CFI & TLI & RMSEA & Д.И. для RMSEA & PCLOSE \\
\hline $1 Ф$ & 181.356 & 9 & $<0.001$ & 0.876 & 0.794 & 0.113 & $0.099,0.127$ & 0.000 \\
\hline ККФ & 46.630 & 8 & $<0.001$ & 0.972 & 0.948 & 0.057 & $0.041,0.073$ & 0.223 \\
\hline 2ОФ & 35.506 & 6 & $<0.001$ & 0.979 & 0.947 & 0.057 & $0.040,0.076$ & 0.233 \\
\hline
\end{tabular}


Рисунок 2

Факторные модели пересмотренной версии теста диспозиционного оптимизма (все коэффициенты значимы при $p<0.01$ )

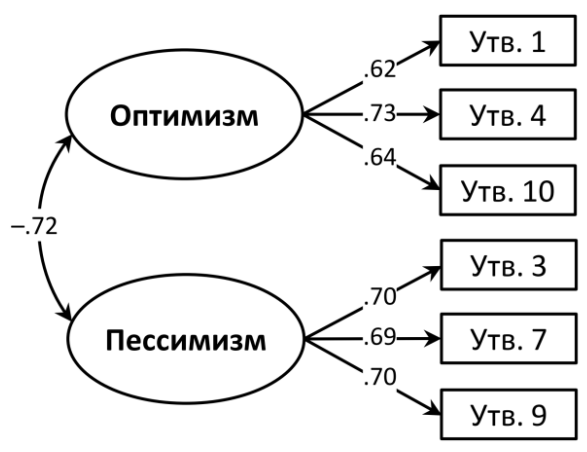

2а. Модель $2 К Ф$

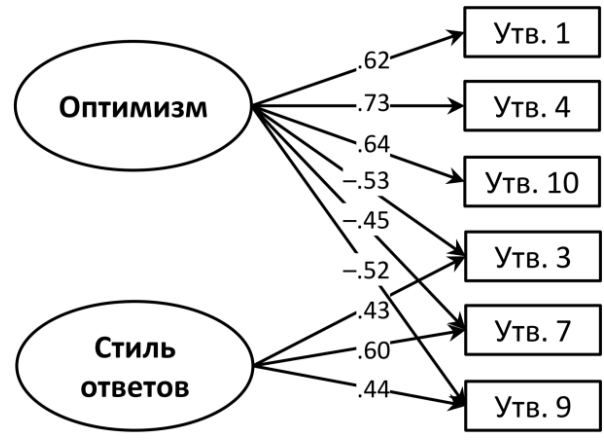

2б. Модель 2ОФ

Таблица 4

Корреляции диспозиционного оптимизма с другими шкалами и показателями

\begin{tabular}{|c|c|c|c|c|}
\hline Методика & Шкала & ТДО-П поз. & ТДО-П нег. & тДО-П \\
\hline SWLS $(n=1482)$ & $\begin{array}{l}\text { Шкала Удовлетворенности } \\
\text { жизнью }\end{array}$ & $0.38 * * *$ & $-0.33 * * *$ & $0.40^{* * *}$ \\
\hline \multirow{3}{*}{$\begin{array}{l}\text { Шкала } \\
\text { Диспозиционной } \\
\text { надежды } \\
(\mathrm{n}=1486)\end{array}$} & $\begin{array}{l}\text { Активность } \\
\text { (целенаправленность) }\end{array}$ & $0.54^{* * *}$ & $-0.38 * * *$ & $0.51^{* * *}$ \\
\hline & Пути (планирование) & $0.44^{* * *}$ & $-0.31 * * *$ & $0.42^{* * *}$ \\
\hline & Надежда (сумма шкал) & $0.54^{* * *}$ & $-0.38 * * *$ & $0.51^{* * *}$ \\
\hline \multirow{4}{*}{$\begin{array}{l}\text { Шкала } \\
\text { Жизнестойкости } \\
(\mathrm{n}=1476)\end{array}$} & Вовлеченность & $0.39^{* * *}$ & $-0.46^{* * *}$ & $0.49^{* * *}$ \\
\hline & Контроль & $0.32 * * *$ & $-0.45^{* * *}$ & $0.45^{* * *}$ \\
\hline & Принятие риска & $0.42^{* * *}$ & $-0.49 * * *$ & $0.53^{* * *}$ \\
\hline & Жизнестойкость (сумма шкал) & $0.43^{* * *}$ & $-0.53 * * *$ & $0.56^{* * *}$ \\
\hline Анкета $(\mathrm{n}=1477)$ & Время на занятия физкультурой & $0.07 * *$ & $-0.15^{* * *}$ & $0.13^{* * *}$ \\
\hline
\end{tabular}

${ }^{*} p<0.05,{ }^{* *} p<0.01,{ }^{* * *} p<0.001$.

с внешними критериями существенно не отличаются от тех, что показывает общая шкала ТДО-П.

С целью стандартизации методики для каждой из шкал были вычислены средние значения и стандартные отклонения в целом по выборке, а также отдельно для мужчин и женщин с учетом возрастной категории (см. таблицу 5).

Распределение итоговых баллов по ТДО-П характеризуется умеренной асимметрией $(A s=-0.52)$ с большей частотой относительно высоких значений, что свидетельствует об отличии от нормального закона распределения (критерий Шапиро-Уилка $\mathrm{W}=0.96 ; p<0.001)$. Сравнение средних значений, полученных в исследовании 1, с данными исследования 2 свидетельствует о 
Таблица 5

Описательная статистика по пересмотренной версии теста диспозиционного оптимизма

\begin{tabular}{|c|c|c|c|}
\hline \multirow{2}{*}{ Пол/Возраст } & \multirow{2}{*}{ Объем выборки } & \multicolumn{2}{|c|}{ ТДО-П } \\
\hline & & $\mathrm{M}$ & $\mathrm{SD}$ \\
\hline \multicolumn{4}{|c|}{ Женский } \\
\hline $17-20$ & 54 & 16.94 & 4.39 \\
\hline $21-30$ & 121 & 18.90 & 4.46 \\
\hline $31-40$ & 222 & 18.20 & 4.13 \\
\hline $41-50$ & 172 & 17.79 & 4.69 \\
\hline $51-60$ & 128 & 16.58 & 4.71 \\
\hline Более 60 & 165 & 16.26 & 5.36 \\
\hline Все возрастные группы & 862 & 17.50 & 4.70 \\
\hline \multicolumn{4}{|c|}{ Мужской } \\
\hline $17-20$ & 84 & 17.51 & 4.81 \\
\hline $21-30$ & 135 & 18.04 & 4.79 \\
\hline $31-40$ & 140 & 16.89 & 4.67 \\
\hline $41-50$ & 108 & 16.31 & 4.74 \\
\hline $51-60$ & 87 & 15.66 & 4.75 \\
\hline Более 60 & 89 & 15.37 & 5.36 \\
\hline Все возрастные группы & 643 & 16.70 & 4.90 \\
\hline \multicolumn{4}{|c|}{ Вся выборка } \\
\hline $17-20$ & 138 & 17.29 & 4.64 \\
\hline $21-30$ & 256 & 18.45 & 4.64 \\
\hline $31-40$ & 362 & 17.69 & 4.39 \\
\hline $41-50$ & 280 & 17.22 & 4.75 \\
\hline $51-60$ & 215 & 16.21 & 4.73 \\
\hline Более 60 & 254 & 15.95 & 5.37 \\
\hline Все возрастные группы & 1505 & 17.20 & 4.80 \\
\hline
\end{tabular}

Примечание. М - среднее значение; SD - стандартное отклонение. Четыре женщины не указали возраст, их данные при составлении таблицы не учитывались.

наличии статистически значимых различий по диспозиционному оптимизму (критерий Манна-Уитни $Z=2.17 ; p=0.03$; величина эффекта $d$ Коэна $=0.10$ ). Возможно, более высокие средние значения во второй выборке являются следствием устной формы опроса, усиливающей тенденцию к социально желательным ответам (Schröder, 2016). Вместе с тем величина различий в диспозиционном оптимизме при разном формате предъявления является довольно слабой (в пределах 0.1 стандартного отклонения), так что на практике этим фактом можно пренебречь.

Результаты анализа гендерных различий показывают, что диспозиционный оптимизм у женщин выражен несколько сильнее, чем у мужчин $(Z=3.78$; $p<0.01 ; d$ Коэна $=0.16)$. Анализ распределения диспозиционного оптимизма в разных возрастных группах с помощью критерия Краскала-Уоллиса показывает статистически значимый, хотя и довольно слабый эффект возраста $\left(\chi^{2}(5)=46.99 ; p<0.001\right.$; размер эффекта $\left.\eta^{2}=0.031\right)$. Эффект возраста на общий показатель диспозиционного оптимизма остается статистически 
значимым при $p<0.001$ в выборках мужчин и женщин по отдельности (см. рисунок 3 ). Взаимодействие факторов пола и возраста в двухфакторном дисперсионном анализе не показывает статистической значимости.

Аналогичный слабый эффект на оптимизм показывает уровень образования (коэффициент корреляции Спирмена $R_{s}=0.10 ; p<0.001 ; \mathrm{n}=1497$ ), однако анализ по отдельным возрастным группам показывает, что этот эффект является статистически значимым лишь в возрасте $31-40$ лет $\left(R_{s}=0.22 ; p<0.001\right.$; $\mathrm{n}=356)$.

\section{Обсуждение результатов}

C целью разработки русскоязычной версии LOT-R были проведены два исследования, в результате был получен новый вариант методики диспозиционного оптимизма, обладающий большей содержательной валидностью, чем LOT и соответствующая ему русскоязычная версия ТДО (Гордеева и др., 2010). Анализ факторной структуры предложенной версии показал непригодность однофакторной модели, в то время как модель с двумя коррелирующими факторами и модель с дополнительным ортогональным фактором стиля ответов имеют близкие показатели соответствия данным. Последняя модель лучше всего соответствует теоретическим представлениям об однофакторной структуре методики (Carver, Scheier, 2014; Scheier et al., 1994) и поэтому является предпочтительной. В пользу однофакторной модели также свидетельствует тот факт, что в ходе проведенного анализа валидности факторы

Рисунок 3

Средние значения диспозиционного оптимизма в разных возрастных группах (вертикальные отрезки отражают величину 95\%-ного доверительного интервала)

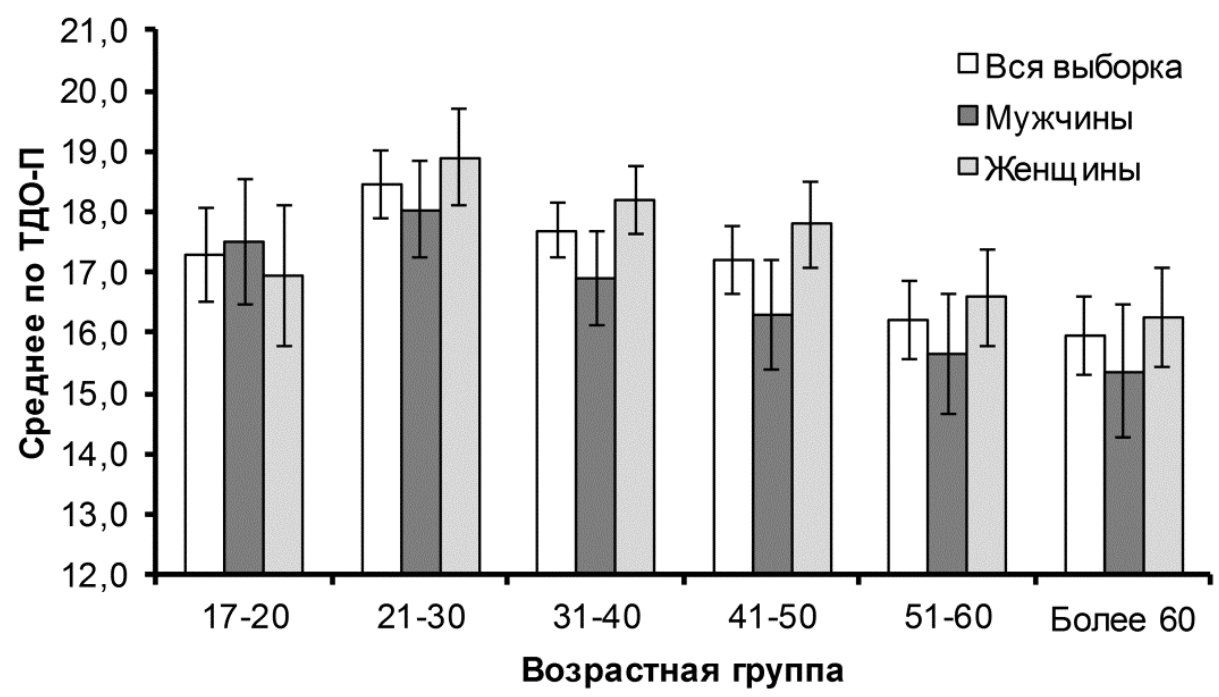


позитивных и негативных ожиданий показали корреляции с внешними критериями, полностью аналогичные друг другу и общему показателю по шкале.

Конструктную валидность методики подтверждают полученные данные о связи диспозиционного оптимизма с показателями психологического благополучия, хорошо соответствующие теоретическим представлениям о роли диспозиционного оптимизма и результатам других исследований (Carver, Scheier, 2014; Гордеева и др., 2010). Умеренные, статистически значимые корреляции диспозиционного оптимизма с оптимистическим атрибутивным стилем соответствуют результатам зарубежных исследований (Carver, Scheier, 2014) и данным, полученным в наших прошлых исследованиях (Гордеева и др., 2010).

Среди корреляций с регуляторными переменными особое место занимает связь оптимизма с целеустремленностью, демонстрирующая его важность для целенаправленной деятельности в полном соответствии с теорией (Carver, Scheier, 2014). Тесные связи диспозиционного оптимизма со шкалами диспозиционной надежды также подтверждают валидность методики ввиду того, что оба этих конструкта характеризуют обобщенные ожидания, однако надежда включает основания для подобных ожиданий - уверенность в способности справиться с трудностями и найти пути решения проблем (Snyder et al., 1991). Как и в зарубежных исследованиях (Boehm et al., 2018), диспозиционный оптимизм на российской выборке показал слабую, но статистически значимую связь с временем, отводимым на занятия физической культурой и спортом.

Выводы о связи диспозиционного оптимизма с возрастом соответствуют аналогичным данным зарубежных исследователей (Glaesmer et al., 2012; Hinz et al., 2017; Zenger et al., 2013): испытуемые старших возрастов демонстрируют меньший оптимизм, чем молодые. Эти результаты можно сопоставить с полученными также на российских выборках данными о возрастных различиях по оптимистическому атрибутивному стилю (Гордеева и др., 2019), демонстрирующими слабую, но статистически значимую тенденцию к росту с возрастом оптимистического мышления в ситуациях неудач $(r=0.13 ; p<0.001)$. Можно предположить, что имеют место два разнонаправленных процесса, связанных с необходимостью индивида адаптивно реагировать на приближающуюся старость и окончание жизни: с одной стороны, закономерно уменьшаются позитивные ожидания относительно будущего, однако, с другой - человек начинает более оптимистично оценивать происходящие с ним негативные жизненные события, что может смягчать негативное ви́дение будущего.

Полученные нами результаты о связи диспозиционного оптимизма с образованностью также хорошо соответствуют аналогичным данным зарубежных исследователей, свидетельствующим о том, что оптимизм растет с уровнем образования (Glaesmer et al., 2012; Hinz et al., 2017). Данный результат также представляется достаточно закономерным, так как образование дает основания для более позитивных прогнозов относительно собственной жизни и карьеры.

Результаты относительно большей выраженности оптимизма у российских женщин подтверждают выводы, полученные нами ранее с помощью опросника 
ТДО (Гордеева и др., 2010). Однако выраженность гендерных различий в оптимизме невелика и, очевидно, носит культурно-специфический и преходящий характер. Так, по данным немецких исследователей, полученным на различных репрезентативных выборках, диспозиционный оптимизм обнаруживает как несколько бо́льшую выраженность у женщин (Hinz et al., 2017), так и бо́льшую выраженность у мужчин (Glaesmer et al., 2012), при этом размер эффектов невелик. Данные на латиноамериканской (Zenger et al., 2013) и норвежской выборках (Schou-Bredal et al., 2017) свидетельствуют об отсутствии гендерных различий в диспозиционном оптимизме.

\section{Выводы}

1. Предложенная пересмотренная версия теста диспозиционного оптимизма (ТДО-П), соответствующая опроснику LOT-R M. Шейера, Ч. Карвера и M. Бриджеса, обладает высокой надежностью и содержательной валидностью.

2. Методика ТДО-П показывает двухфакторную структуру с независимыми факторами оптимизма и стиля ответов, поскольку опросник включает позитивные и обратные им негативные ожидания. Полученные результаты свидетельствуют в пользу внешней и конструктной валидности, а также высокой внутренней согласованности методики. Конвергентная валидность методики была продемонстрирована с использованием шкал Удовлетворенности жизнью, Субъективного счастья, Оптимистического атрибутивного стиля, Надежды, Саморегуляции деятельности и Жизнестойкости.

3. Таким образом, согласно приведенным нормам, предлагаемый инструмент является валидной и надежной методикой, может использоваться для измерения диспозиционного оптимизма в индивидуальной диагностике, а также в скрининговых и клинических исследованиях.

\section{Литература}

Гордеева, Т. О., Осин, Е. О., Шевяхова, В. Ю. (2009). Диагностика оптимизма как стиля объяснения успехов и неудач: опросник СТОУН. М.: Смысл.

Гордеева, Т. О., Сычев, О. А., Осин, Е. Н. (2010). Разработка русскоязычной версии Теста диспозиционного оптимизма (LOT). Психологическая диагностика, 2, 36-64.

Гордеева, Т. О., Сычев, О. А., Осин, Е. Н. (2017). Оптимистический атрибутивный стиль и диспозиционный оптимизм: эмпирическая проверка сходства и различия двух конструктов. Психология. Журнал Высшей школы экономики, 14(4), 756-765.

Гордеева, Т. О., Сычев, О. А., Осин, Е. Н., Титова-Грэншам, В. А. (2019). Краткий опросник оптимистического атрибутивного стиля. Психологический журнал, 40(6), 76-86. doi:10.31857/S020595920007323-1

Мандрикова, Е. Ю. (2010). Разработка опросника самоорганизации деятельности (ОСД). Психологическая диагностика, 2, 87-111. 
Осин, Е. Н., Леонтьев, Д. А. (2020). Краткие русскоязычные шкалы диагностики субъективного благополучия: психометрические характеристики и сравнительный анализ. Мониторинг общественного мнения: экономические и социальные перемены, 1, 117-142. doi:10.14515/monitoring.2020.1.06

Осин, Е. Н., Рассказова, Е. И. (2013). Краткая версия теста жизнестойкости: психометрические характеристики и применение в организационном контексте. Вестник Московского университета. Серия 14. Психология, 2, 147-165.

Ссылки на зарубежные источники см. в разделе References после англоязычного блока.

\section{Методика ТдО-П}

Приложение

Оцените, насколько хорошо приведенные ниже утверждения могут относиться к Вам, используя следующую шкалу оценок: 1 - не согласен(на); 2 - скорее не согласен(на); 3 - ни да, ни нет; 4 - скорее согласен(на); 5 - полностью согласен(на).

1. В неопределенных ситуациях я обычно верю, что все будет хорошо.

2. Меня не очень легко вывести из себя.

3. От будущего я не жду ничего особенно хорошего.

4. Я всегда с оптимизмом смотрю в будущее.

5. Общение с друзьями доставляет мне большое удовольствие.

6. Для меня важно всегда быть занятым.

7. Я не строю особенно оптимистических планов на будущее.

8. Меня нелегко расстроить.

9. Я редко надеюсь на то, что со мной произойдет что-то хорошее.

10. В целом я ожидаю, что со мной произойдет больше хорошего, чем плохого.

Количественная оценка ответов: не согласен - 0 баллов; скорее не согласен - 1 балл; ни да, ни нет -2 балла; скорее согласен -3 балла; полностью согласен -4 балла.

Утверждения-наполнители: 2, 5, 6, 8 .

Прямые утверждения: 1, 4, 10.

Обратные утверждения: $3,7,9$.

Итоговый балл по шкале диспозиционного оптимизма вычисляется путем суммирования оценок по утверждениям $1,4,10,3,7,9$, при этом оценки по обратным утверждениям должны быть инвертированы $(0=4 ; 1=3 ; 3=1 ; 4=0)$.

Гордеева Тамара Олеговна - профессор, кафедра психологии, образования и педагогики, факультет психологии, МГУ имени М.В. Ломоносова; ведущий научный сотрудник, Международная лаборатория позитивной психологии личности и мотивации, Национальный исследовательский университет «Высшая школа экономики», доктор психологических наук.

Сфера научных интересов: психология мотивации, саморегуляция, оптимизм, успех в деятельности, благополучие.

Контакты: tamgordeeva@gmail.com 
Сычев Олег Анатольевич - доцент, кафедра психологии, Алтайский государственный гуманитарно-педагогический университет имени В.М. Шукшина, кандидат психологических наук.

Сфера научных интересов: позитивная психология, мотивация, оптимизм, математические методы в психологии.

Контакты: osn1@mail.ru

Осин Евгений Николаевич - доцент, департамент психологии; ведущий научный сотрудник; зам. зав. Международной лаборатории позитивной психологии личности и мотивации, Национальный исследовательский университет «Высшая школа экономики», кандидат психологических наук.

Сфера научных интересов: позитивная психология, смысл жизни, отчуждение, психометрика.

\title{
Diagnostics of Dispositional Optimism: Validity and Reliability of Russian Version of LOT-R
}

\author{
T.O. Gordeeva ${ }^{a, b}$, O.A. Sychev ${ }^{c}$, E.N. Osin ${ }^{b}$ \\ ${ }^{a}$ Lomonosov Moscow State University, 1 Leninskie Gory, Moscow, 119991, Russian Federation \\ ${ }^{b}$ HSE University, 20 Myasnitskaya Str., Moscow, 101000, Russian Federation \\ ' Shukshin Altai State University for Humanities and Pedagogy, 53 Korolenko str., Altai region, Biysk, \\ 659333, Russian Federation
}

\begin{abstract}
According to C. Carver and M. Scheier, dispositional optimism is a cognitive disposition (personal trait) which includes general expectations about the future or person's tendency to believe that there will be more positive events in the future than negative ones. Many researches showed that optimism as positive expectations is related to better indicators of physical health, psychological well-being, better interpersonal relationships. The main posited mechanism of these relations is the influence of optimism on motivation that manifests itself in readiness of optimists to make efforts to solve problems that occur in their lives. The paper presents the results of approbation of the LOT-R, revised version of dispositional optimism questionnaire developed by M. Scheier, C. Carver and M. Bridges. Validation was realized in two studies - in the sample of undergraduate and postgraduate students of different universities $(n=406)$ and in the representative Russian sample $(\mathrm{N}=1509)$. Both of these studies demonstrated a high reliability of the questionnaire $(\alpha=0.78)$. Using confirmatory factor analysis, the two-factor structure (including optimism factor and style of answer factor) was confirmed. The validity of the Russian version of LOT-R is supported by substantive correlations with indicators of psychological well-being and moderate but statistically significant correlations with indicators of optimistic attributional style. The construct validity of the test is also supported by correlations with indicators of self-regulation, hope, and hardiness. Detailed information about the association between dispositional optimism and sociodemographic variables (gender, age and educational level) are presented. The statistical norms are provided. The LOT-R questionnaire provides wide
\end{abstract}


opportunities for Russian psychologists to continue the research on dispositional optimism and its impact on health, well-being, performance, and interpersonal relationships.

Keywords: dispositional optimism, optimism, pessimism, LOT-R, psychological well-being, validity, reliability.

\section{References}

Andersson, G. (1996). The benefits of optimism: A meta-analytic review of the Life Orientation Test. Personality and Individual Differences, 21(5), 719-725.

Boehm, J. K., Chen, Y., Koga, H., Mathur, M. B., Vie, L. L., \& Kubzansky, L. D. (2018). Is optimism associated with healthier cardiovascular-related behavior? Meta-analyses of 3 health behaviors. Circulation Research, 122(8), 1119-1134. doi:10.1161/CIRCRESAHA.117.310828

Boehm, J. K., Peterson, C., Kivimaki, M., \& Kubzansky, L. (2011). A prospective study of positive psychological well-being and coronary heart disease. Health Psychology: Official Journal of the Division of Health Psychology, American Psychological Association, 30(3), 259-267. doi:10.1037/a0023124

Carver, C. S., \& Scheier, M. F. (2014). Dispositional optimism. Trends in Cognitive Sciences, 18(6), 293-299.

Gallagher, M. W., Long, L. J., \& Phillips, C. A. (2020). Hope, optimism, self-efficacy, and posttraumatic stress disorder: A meta-analytic review of the protective effects of positive expectancies. Journal of Clinical Psychology, 76(3), 329-355. doi:10.1002/jclp.22882

Glaesmer, H., Rief, W., Martin, A., Mewes, R., Brähler, E., Zenger, M., \& Hinz, A. (2012). Psychometric properties and population-based norms of the Life Orientation Test Revised (LOT-R). British Journal of Health Psychology, 17(2), 432-445. doi:10.1111/j.2044-8287.2011.02046.x

Gordeeva, T. O., Osin, E. N., \& Shevyakhova, V. Yu. (2009). Diagnostika optimizma kak stilya ob"yasneniya uspekhov i neudach: oprosnik STOUN [Diagnostics of the optimism as an attributional style of explaining of successes and failures]. Moscow: Smysl. (in Russian)

Gordeeva, T., Sheldon, K., \& Sychev, O. (2020). Linking academic performance to optimistic attributional style: attributions following positive events matter most. European Journal of Psychology of Education, 35, 21-48. doi:10.1007/s10212-019-00414-y

Gordeeva, T. O., Sychev, O. A., \& Osin, E. N. (2010). Razrabotka russkoyazychnoi versii testa dispozitsionnogo optimizma (LOT) [The development of a Russian version of the test of dispositional optimism (LOT)]. Psychologicheskaya Diagnostika, 2, 36-64. (in Russian)

Gordeeva, T. O., Sychev, O. A., \& Osin, E. N. (2017). Optimistic attributional style and dispositional optimism: Empirical study of similarities and differences between two conctructs. Psychology. Journal of Higher School of Economics, 14(4), 756-765. (in Russian)

Gordeeva, T. O., Sychev, O. A., Osin, E. N., \& Titova Grandchamp, V. A. (2019). Kratkii oprosnik optimisticheskogo atributivnogo stilya [Optimistic attributional style: Assessment and associations with well-being and self-regulation]. Psikhologicheskii Zhurnal, 40(6), 76-86. doi:10.31857/S020595920007323-1 (in Russian) 
Herzberg, P. Y., Glaesmer, H., \& Hoyer, J. (2006). Separating optimism and pessimism: a robust psychometric analysis of the revised Life Orientation Test (LOT-R). Psychological Assessment, 18(4), 433-438.

Hinz, A., Sander, C., Glaesmer, H., Brähler, E., Zenger, M., Hilbert, A., \& Kocalevent, R.-D. (2017). Optimism and pessimism in the general population: Psychometric properties of the Life Orientation Test (LOT-R). International Journal of Clinical and Health Psychology, 17(2), 161170. doi:10.1016/j.ijchp.2017.02.003

Malouff, J. M., \& Schutte, N. S. (2017). Can psychological interventions increase optimism? A metaanalysis. The Journal of Positive Psychology, 12(6), 594-604. doi:10.1080/17439760.2016.1221122

Mandrikova, E. Yu. (2010). Razrabotka oprosnika samoorganizatsii deyatel'nosti (OSD) [The development of self-organization of activity questionnaire]. Psychologicheskaya Diagnostika, 2, 87-111. (in Russian)

Monzani, D., Steca, P., \& Greco, A. (2014). Brief report: Assessing dispositional optimism in adolescence - Factor structure and concurrent validity of the Life Orientation Test - Revised.Journal of Adolescence, 37(2), 97-101. doi:10.1016/j.adolescence.2013.11.006

Nakano, K. (2004). Psychometric properties of the Life Orientation Test-Revised in samples of Japanese students. Psychological Reports, 94(3), 849-855. doi:10.2466/pr0.94.3.849-855

Osin, E. N., \& Leontiev, D. A. (2020). Brief Russian-language instruments to measure subjective wellbeing: Psychometric properties and comparative analysis. Monitoring of Public Opinion: Economic and Social Changes Journal, 1, 117-142. doi:10.14515/monitoring.2020.1.06 (in Russian)

Osin, E. N., \& Rasskazova, E. I. (2013). A short version of the Hardiness Test: Psychometric properties and organizational application. Moscow University Psychology Bulletin, 2, 147-165. (in Russian)

Peterson, C., \& Steen, T. A. (2002). Optimistic explanatory style. In C. R. Snyder \& S. J. Lopez (Eds.), Handbook of positive psychology (pp. 244-256). Oxford University Press.

Rasmussen, H. N., Scheier, M. F., \& Greenhouse, J. B. (2009). Optimism and physical health: a metaanalytic review. Annals of Behavioral Medicine: A Publication of the Society of Behavioral Medicine, 37(3), 239-256. doi:10.1007/s12160-009-9111-x

Richardson, M., Abraham, C., \& Bond, R. (2012). Psychological correlates of university students' academic performance: A systematic review and meta-analysis. Psychological Bulletin, 138(2), 353-387. doi:10.1037/a0026838

Rozanski, A., Bavishi, C., Kubzansky, L. D., \& Cohen, R. (2019). Association of optimism with cardiovascular events and all-cause mortality: a systematic review and meta-analysis. JAMA Network Open, 2(9), e1912200. doi:10.1001/jamanetworkopen.2019.12200

Scheier, M. F., \& Carver, C. S. (1985). Optimism, coping, and health: assessment and implications of generalized outcome expectancies. Health Psychology: Official Journal of the Division of Health Psychology, American Psychological Association, 4(3), 219-247.

Scheier, M. F., Carver, C. S., \& Bridges, M. W. (1994). Distinguishing optimism from neuroticism (and trait anxiety, self-mastery, and self-esteem): A reevaluation of the Life Orientation Test.Journal of Personality and Social Psychology, 67(6), 1063-1078.

Scheier, Carver, C. S., \& Bridges, M. W. (2001). Optimism, pessimism, and psychological well-being. In E. C. Chang (Ed.), Optimism and pessimism: Implications for theory, research, and practice (pp. 189-216). Washington, DC: American Psychological Association.

Schou-Bredal, I., Heir, T., Skogstad, L., Bonsaksen, T., Lerdal, A., Grimholt, T., \& Ekeberg, Ø. (2017). Population-based norms of the Life Orientation Test-Revised (LOT-R). International Journal of Clinical and Health Psychology, 17(3), 216-224. doi:10.1016/j.ijchp.2017.07.005 
Schröder, J. (2016). Face-to-face surveys. GESIS survey guidelines. Mannheim, DE: GESIS - Leibniz Institute for the Social Sciences. doi:10.15465/gesis-sg_en_005

Seligman, M. E., Abramson, L. Y., Semmel, A., \& von Baeyer, C. (1979). Depressive attributional style. Journal of Abnormal Psychology, 88(3), 242-247. doi:10.1037/0021-843X.88.3.242

Snyder, C. R., Harris, C., Anderson, J. R., Holleran, S. A., Irving, L. M., Sigmon, S. T., ... Harney, P. (1991). The will and the ways: development and validation of an individual-differences measure of hope. Journal of Personality and Social Psychology, 60(4), 570-585.

Tindle, H. A., Chang, Y.-F., Kuller, L. H., Manson, J. E., Robinson, J. G., Rosal, M. C., ... Matthews, K. A. (2009). Optimism, cynical hostility, and incident coronary heart disease and mortality in the women's health initiative. Circulation, 120(8), 656-662. doi:10.1161/CIRCULATIONAHA.108.827642

Tuten, T. L., \& Neidermeyer, P. E. (2004). Performance, satisfaction and turnover in call centers: The effects of stress and optimism. Journal of Business Research, 57(1), 26-34. doi:10.1016/S01482963(02)00281-3

Vautier, S., Raufaste, E., \& Cariou, M. (2003). Dimensionality of the Revised Life Orientation Test and the status of filler items. International Journal of Psychology, 38(6), 390-400. doi:10.1080/00207590344000222

Zenger, M., Finck, C., Zanon, C., Jimenez, W., Singer, S., \& Hinz, A. (2013). Evaluation of the Latin American version of the Life Orientation Test-Revised. International Journal of Clinical and Health Psychology, 13(3), 243-252. doi:10.1016/S1697-2600(13)70029-2

Tamara O. Gordeeva - Professor, Department of Psychology, Lomonosov Moscow State University; Lead Research Fellow, International Research Laboratory of Positive Psychology of Personality and Motivation, HSE University, DSc in Psychology.

Research Area: motivation, self-regulation, optimism, well-being.

E-mail: tamgordeeva@gmail.com

Oleg A. Sychev - Associate Professor, Research Fellow, Altai State Humanities Pedagogical University, Ph.D in Psychology.

Research Area: positive psychology, motivation, optimism, statistical methods in psychology.

E-mail: osn1@mail.ru

Evgeny N. Osin - Associate Professor, Lead Research Fellow, International Research Laboratory of Positive Psychology of Personality and Motivation, HSE University, Ph.D in Psychology.

Research Area: positive psychology, meaning of life, alienation, psychometrics.

E-mail: evgeny.n.osin@gmail.com 


\title{
ТЕСТ НА ПОНИМАНИЕ ЭМОЦИЙ: АДАПТАЦИЯ РУССКОЯЗЫЧНОЙ ВЕРСИИ НА РОССИЙСКОЙ ВЫБОРКЕ ДЕТЕЙ ДОШКОЛЬНОГО ВОЗРАСТА
}

\author{
Н.Е. ВЕРАКСА, А.Н. ВЕРАКСА \\ Д.А. БУХАЛЕНКОВА ${ }^{\mathrm{a}}$, К.С. ТАРАСОВА ${ }^{\mathrm{a}}$
}

${ }^{a}$ МГУ имени М.В. Ломоносова, 119991, Россия, Москва, Ленинские горы,, д. 1

\section{Резюме}

В статье представлены результаты адаптации русскоязычной версии методики Тест на понимание эмоций (Test of Emotion Comprehension; Pons, Harris, 2000). Адаптация методики проводилась в период с 2019 по 2020 г. на выборке 596 детей 5-6 лет. Спустя год 351 ребенок был повторно протестирован для оценки способности методики отражать возрастную динамику в развитии понимания эмоций. В целях изучения теоретической структуры, лежащей в основе инструмента, был применен конфирматорный факторный анализ. Эмпирические данные, полученные на российской выборке, подтвердили высокое соответствие русскоязычной версии инструмента ее оригинальной теоретической модели. Результат применения Q-теста Кохрана равенства пропорций указал на приемлемую надежность методики на основе внутренней согласованности ее компонентов. Валидность методики подтверждается наличием умеренных положительных связей общего уровня понимания эмоций и отдельных компонентов теста с распознаванием эмоций по лицевой экспрессии (Affect Recognition subtest NEPSY-II). Как и в оригинальной версии теста, на российской выборке не были выявлены гендерные различия ни по одному из компонентов теста. Анализ связанных с возрастом различий в успешности выполнения методики детьми при первичном и повторном тестировании показал, что количество правильных ответов по всем компонентам методики значимо увеличилось через год после первого обследования, что свидетельствует о способности методики отражать возрастную динамику. В результате работ по адаптации теста были получены российские нормы для детей 5-6 и 6-7 лет. Использование теста в дальнейшем открывает широкие возможности для международного сотрудничества в эмпирических целях для изучения природы понимания эмоций в дошкольном возрасте и в практических для диагностики или разработки программ эмоционального развития детей.

Ключевые слова: понимание эмоций, тест на понимание эмоций, эмоциональное развитие, распознавание эмоций, дошкольный возраст.

\section{Введение}

Понимание эмоций определяется как способность понимать природу, причины и последствия собственных эмоций и эмоций окружающих. Понимание

Исследование выполнено при финансовой поддержке РНФ (проект № 19-18-00521). 
эмоций включает распознавание, описание, объяснение, прогнозирование выражения эмоций в повседневной жизни и контроль над ним (Pons et al., 2004) и является компонентом многоуровневой системы репрезентаций ментальных феноменов и социального познания в подходе «модель психического» (Сергиенко, 2014; Прусакова, 2005). В англоязычной профессиональной литературе устоявшимся термином для обозначения данной линии развития является «theory of mind» (Wellman, 1992; Bender et al., 2011).

Проведенные исследования выявили значимое влияние понимания эмоций на психологическое состояние детей. Было показано, что дети, хорошо понимающие эмоции, реже страдают от тревожных и депрессивных состояний, реже демонстрируют агрессивное поведение (например: Trentacosta, Fine, 2010). Также было показано, что понимание эмоций связано с развитием таких просоциальных компетенций, как взаимодействие и игра со сверстниками (Mathieson, Banerjee, 2011), способность разрешать конфликты (Franco et al., 2017; Liao et al., 2014). В последнее время все большее число исследований показывает, что понимание эмоций является сильным предиктором успешности дальнейшей адаптации детей к школьному обучению (Garrett-Peters et al., 2017) и их академической успеваемости (Franco et al., 2017; Jyzsa, Barrett, 2018). Важно отметить, что результаты проведенных исследований в высокой степени согласуются с теоретическими представлениями, сформулированными А.В. Запорожцем о том, что только согласованное функционирование эмоциональной и когнитивной сфер в их единстве способно обеспечить успешное выполнение ребенком любой деятельности (Запорожец, 1985).

В свете указанных причин оценка понимания эмоций детьми дошкольного возраста представляет интерес как для исследовательской, так и для практической деятельности психологов. В процессе создания, стандартизации и усовершенствования методов в этой области был сформулирован ряд сложностей, с которыми столкнулись разработчики методик по оценке понимания эмоций у детей (Pons, Harris, 2003). Во-первых, отмечается методологическая несогласованность в понимании различных аспектов эмоций. В некоторых случаях не разделяются такие аспекты эмоционального развития, как распознавание эмоций, понимание эмоций, эмоциональная регуляция и теория сознания. Требованием к современным диагностическим инструментам выступает необходимость разделения перечисленных линий эмоционального развития. Другим примером методологической несогласованности является непредставленность в некоторых моделях таких аспектов понимания эмоций, как понимание морально-нравственных конфликтов (стыд, гордость, вина) или смешанных эмоций (радость и страх одновременно). В некоторых моделях также анализируется способность ребенка понимать и отличать друг от друга притворные и реальные эмоции, в то время как в других этот аспект игнорируется. Во-вторых, было выяснено, что диагностика понимания эмоций требует использования невербальных типов заданий, в которых ребенку не нужно использовать речь, чтобы дать ответ. Методики, в которых от ребенка требуется вербальный ответ, могут показать ложный результат из-за потенциального влияния побочных факторов, таких как, например, понимание устной 
речи ребенком или уровень развития коммуникативных навыков. Пример исследования и создания диагностического инструментария при изучении понимания эмоций с учетом указанных требований у российских детей дошкольного возраста представляет диссертационная работа О.А. Прусаковой «Генезис понимания эмоций» (Прусакова, 2005).

За последние несколько десятилетий эмпирические исследования позволили уточнить методологические представления о развитии понимания эмоций. Основным продвижением в этой области является определение и подробное описание основных стадий, через которые проходит развитие понимания эмоций в теоретической модели П. Харриса, Ф. Понса (Pons et al., 2004). Первую стадию дети проходят в возрасте $3-5$ лет, когда учатся понимать внешние причины эмоций (распознавание основных эмоций окружающих по лицевой экспрессии и мимике и понимание влияния внешних обстоятельств и желаний на эмоции). Вторая стадия наступает в возрасте 5-7 лет, в ее ходе дети постепенно понимают, что личные убеждения и воспоминания могут вызывать различные эмоции и что некоторые эмоции можно скрывать. Затем на третьей стадии, в возрасте $7-9$ лет, дети учатся регулировать свои эмоции с помощью когнитивных стратегий, узнают, что моральные правила могут влиять на эмоции и что эмоциональные состояния бывают противоречивыми (Pons, Harris, 2005; Pons et al., 2003; Saltzman et al., 2018).

Для адаптации была выбрана методика Test of Emotion Comprehension (Pons, Harris, 2000), поскольку она наиболее полно соответствует указанным выше методологическим и процедурным критериям. Методика построена на невербальном типе ответов ребенка и позволяет оценить общий уровень понимания эмоций, а также входящие в него компоненты. Соответствие эмпирических данных теоретической структуре инструмента было подтверждено с помощью конфирматорного факторного анализа $\left(\chi^{2}=0.997\right.$; CFI $=1.000$; RMSEA $=0.000)$. С разрешения авторов данная методика была переведена на русский язык (подробное описание методики представлено ниже). Методика переведена на 21 язык и широко используется исследователями в Англии, Италии, Бразилии, Китае, Норвегии и других странах (Albanese et al., 2006; Tang et al., 2018; Fidalgo et al., 2018), что обеспечивает возможность проведения международных исследований. Работы, проведенные с использованием данного теста, показали, что он обладает хорошей надежностью и конструктной валидностью (например: Tang et al., 2018).

Результаты исследований свидетельствуют о наличии индивидуальных различий в способности детей понимать эмоции на каждой стадии. Выявлены некоторые индивидуальные, семейные и культурные факторы, определяющие индивидуальную изменчивость в становлении понимания эмоций: образование матерей (Cutting, Dunn, 1999), убеждения матерей об эмоциях (GarrettPeters et al., 2017; Kerstad, 2016), эмоциональный словарь родителей (Kerstad, 2016). Ряд исследований был посвящен когнитивным и аффективным аспектам развития самого ребенка, которые также влияют на становление способности понимания эмоций (De Stasio et al., 2014; von Salisch et al., 2013). Таким образом, необходимость выработки норм рассматриваемой методики на российской 
выборке продиктована индивидуальной изменчивостью показателей понимания эмоций в дошкольном возрасте, связанной с потенциальным влиянием перечисленных факторов.

\section{Материалы и методы}

\section{Выборка}

Данные для адаптации методики были получены на выборке из 596 детей старшего дошкольного возраста ( $\mathrm{M}=5.09, \mathrm{SD}=0.37)$, посещавших муниципальные детские сады г. Москвы. Спустя год 351 ребенок $(\mathrm{M}=6.07, \mathrm{SD}=0.47)$ повторно прошел тестирование для оценки способности методики отражать возрастную динамику в развитии понимания эмоций. Обследование проводилось индивидуально в дошкольных образовательных учреждениях, которые посещали дети. Данные для адаптации методики были собраны в период с 2019 по 2020 г.

\section{Методики}

На основе теоретической модели П. Харриса, Ф. Понса, упомянутой во введении, был разработан Test of Emotion Comprehension (Pons, Harris, 2000). Данный тест предназначен для оценки понимания эмоций у детей в возрасте от 3 до 11 лет. Стимульный материал теста представляет собой иллюстрированную книгу с простыми историями. В каждом задании ребенку рассказывают историю, а затем предлагают выбрать «то чувство, которое испытывает герой истории» из четырех рисунков с различными выражениям лица героя в нижней части страницы. Ответы невербальны, ребенку достаточно указать выбранный вариант. В тесте содержатся контрольные вопросы для проверки понимания ребенком историй. В процессе апробации методики все истории и названия эмоций были переведены на русский язык и затем в процессе обратного перевода отредактированы Франциско Понсом (одним из авторов методики). Также с авторами методики были обсуждены и согласованы процедурные особенности проведения теста.

Методика имеет трехуровневую структуру понимания эмоций, которая включает Внешний, Психический компоненты и Мета компонент. Каждый компонент содержит в себе несколько показателей, описание которых приведено ниже (см. рисунок 1). Первый компонент, который обозначен авторами как «Внешний», является базовым и сосредоточен на внешних аспектах эмоций. Второй компонент, названный авторами «Психический», является промежуточным по уровню сложности и включает в себя различные психические аспекты понимания эмоций. Третий компонент «Мета» является самым сложным и сосредоточен на понимании детьми того, как человек может отслеживать и анализировать собственные эмоциональные состояния. По каждому компоненту баллы варьируются от 0 до 3. Общий уровень понимания эмоций определяется путем вычисления суммы баллов по всем компонентам и составляет от 0 до 9 баллов. 


\section{Структура методики Тест на понимание эмоций}

Рисунок 1

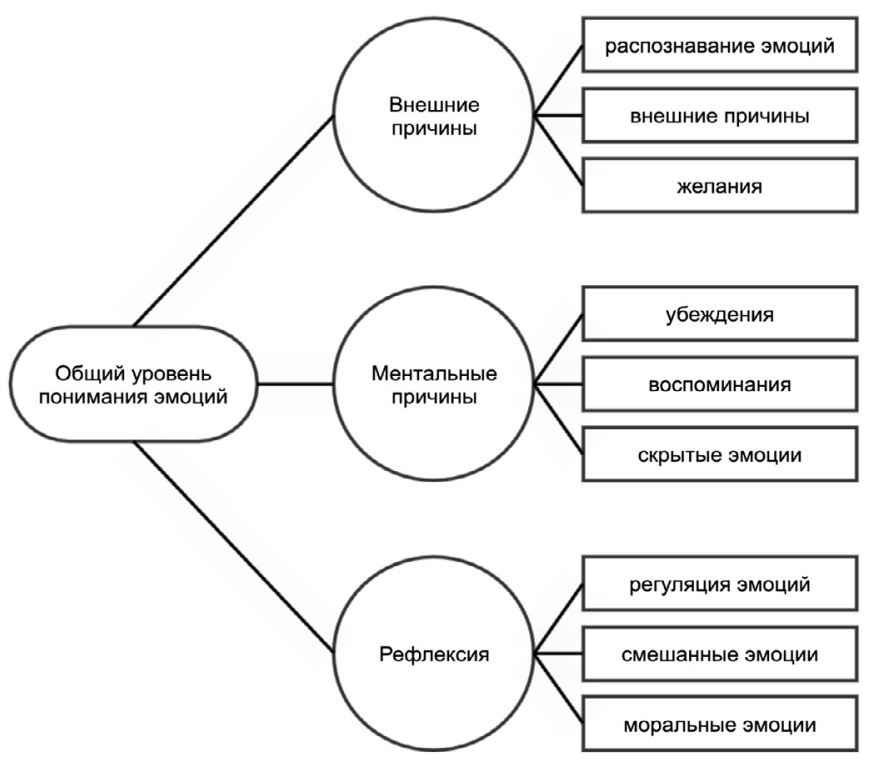

(I) Распознавание эмоций - показатель, который оценивает способность ребенка распознавать и называть эмоции. В тесте содержится пять заданий на оценку данного показателя. Все задания построены следующим образом: «Посмотри на эти четыре картинки и покажи мальчика (или девочку), которому грустно».

(II) Внешние причины - показатель, который оценивает понимание ребенком того, что эмоции могут быть вызваны внешними ситуациями. В тесте содержится четыре задания, направленные на оценку данного показателя. Пример задания: «Катя получает подарок на день рождения. Что чувствует Катя в этот момент?»

(III) Желания - показатель, который оценивает понимание того, что два человека могут испытывать разные эмоции по поводу одной и той же ситуации из-за того, что у них разные желания. В тесте содержится два задания на оценку данного показателя. Пример задания: «Саша любит кока-колу, а Сережа ненавидит кока-колу. Когда они захотели пить, то обнаружили, что в холодильнике есть бутылка кока-колы. Что чувствует Саша? А что чувствует Сережа?»

(IV) Убеждения - показатель, который оценивает понимание того, что убеждения людей могут влиять на то, какие эмоции вызывает у них та или иная ситуация. Тест содержит одно задание, которое направлено на оценку данного показателя: «Это кролик, а это волк, который хочет его съесть». Ребенку показывают изображение волка, а затем закрывают заслонкой, показывая, что он прячется за деревьями. «Знает ли кролик, что волк прячется за кустами? Что сейчас чувствует кролик?» 
(V) Воспоминания - показатель, который оценивает понимание того, что воспоминания могут оказывать влияние на эмоциональные переживания. В тесте содержится одно задание, которое направлено на оценку данного показателя: «Алиса очень грустит, потому что ее кролика съел волк. На следующий день Алиса смотрит на фотографию своей подруги. Что в этот момент чувствует Алиса? А потом Алиса увидела на фото своего кролика. Что в этот момент чувствует Алиса?»

(VI) Cкрытыле эмоции - показатель, который оценивает понимание несоответствия между реальными и внешне выражаемыми эмоциями. В тесте содержится одно задание, которое направлено на оценку данного показателя: «У Вани есть магнитные шарики, а у Коли такой игрушки нет. Коля улыбается, потому что не хочет показывать Ване, что он чувствует внутри. Что Коля чувствует на самом деле?»

(VII) Регуляция эмоций - показатель, который оценивает понимание того, что с негативными эмоциями можно совладать с помощью когнитивных стратегий. В тесте содержится одно задание, которое направлено на оценку данного показателя: «Алиса грустит из-за того, что ее кролика больше нет. Что она может сделать, чтобы справиться с грустью?»

(VIII) Смешанные әмоции - показатель, который оценивает понимание того, что люди могут иметь противоречивые смешанные эмоции в связи с определенными ситуациями. В тесте содержится одно задание, которое направлено на оценку данного показателя: «Маша смотрит на свой новый велосипед, который ей только что подарили. Но думает, что может поранить себя, потому что раньше никогда не ездила на двухколесном велосипеде. Что сейчас чувствует Маша?»

(IX) Моральные эмоции - показатель, который оценивает осознание того, что негативные эмоции возникают в результате морально неприемлемого поведения и, наоборот, позитивные эмоции - от морально одобряемых поступков. В тесте содержится одно задание, которое направлено на оценку данного показателя: «Вова был в гостях и взял шоколадное печенье без разрешения матери своего друга, и он решил никогда не признаваться в этом проступке. Что Вова чувствует по этому поводу?»

Для проверки конструктной валидности теста была применена русскоязычная версия субтеста Affect Recognition из батареи психоневрологических тестов NEPSY-II (Developmental NEuroPSYchological Assessment) (Korkman et al., 2007). Данная методика направлена на оценку способности распознавать эмоции по лицевой экспрессии. Диагностику проводили опытные тестеры, прошедшие обучение по применению инструментария NEPSY-II на английском языке. Испытуемым демонстрировались фотографии детских лиц, которые выражают радость, грусть, гнев, страх, отвращение и спокойствие, и просили в каждом задании показать двух детей, которые испытывают одно и то же чувство. Методика широко применяется в зарубежной исследовательской практике. Однако поскольку она не адаптирована на российской выборке, в данном исследовании была проведена оценка ее одномерности с помощью конфирматорного факторного анализа. Полученные значения свидетельствуют о 
соответствии эмпирических данных ожидаемой модели «один фактор на шкалу»: $\chi^{2} / \mathrm{df}=182.893 / 119(p<0.001)$; сравнительный индекс пригодности $\mathrm{CFI}=0.823$; среднеквадратичная ошибка приближения RMSEA =0.037. Ранее в ряде эмпирических исследований (например: Korkman et al., 2007; Kervinen, 2015) было подтверждено, что способности, оцениваемые с помощью данной методики, образуют единый фактор эмоционального развития, куда относится также и понимание эмоций. Теоретически ожидаемо наличие значимой связи между результатами детей по данному тесту и Внешним компонентом Теста на понимание эмоций, поскольку и в том и в другом случае речь идет о распознавании эмоций по лицевой экспрессии. Внешний компонент методики Тест на понимание эмоций дополнительно включает в себя и понимание внешних причин эмоций, и понимание влияния желаний на эмоции.

\section{Результаты адаптации теста}

\section{Оценка структуры методики}

Факторная структура русскоязычной версии методики Тест на понимание эмоций прошла оценку с помощью конфирматорного факторного анализа. Анализ проводился с использованием программы Structural Equation Modeling Software v.6.2 (EQS v.6.2). В качестве метода оценки модели были использованы индексы: значение критерия $\chi^{2} / \mathrm{df}=22.702 / 24$ ( $\left.p=0.53\right)$; сравнительный индекс пригодности CFI = $1.000>0.90$; среднеквадратичная ошибка приближения RMSEA $=0.000<0$. Полученные значения свидетельствуют о высоком соответствии русскоязычной версии инструмента ее оригинальной теоретической модели. Эмпирические данные, полученные на российской выборке, соответствуют исходной модели с тремя факторами (Внешний, Психический, Мета). Корректировка модели не потребовалась.

\section{Оценка надежности теста}

Для оценки надежности был применен Q-тест Кохрана равенства пропорций, поскольку все пункты адаптируемого инструмента являются дихотомическими. На материале полученных эмпирических данных Q-тест Кохрана позволил оценить, одинаково ли оказался расщеплен набор дихотомических пунктов по Внешнему, Психическому и Мета компонентам теста, каждый из которых содержит по три дихотомических показателя. Статистическая значимость коэффициентов равенства пропорций по каждому из компонентов оказалась меньше критического значения $(p \leqslant 0.005)$, что свидетельствует о внутренней согласованности компонентов адаптируемого инструмента.

\section{Проверка нормальности распределения}

Проверка нормальности распределения с помощью теста КолмогороваСмирнова была проведена для трех основных компонентов теста (Внешний, 
Психический, Мета) и для общего уровня понимания эмоций (общий балл). Тест Колмогорова-Смирнова показал, что распределение данных не соответствует нормальному по всем показателям. При этом наблюдается эффект потолка по Внешнему компоненту теста, что соответствует установленной возрастной периодизации развития понимания эмоций, согласно которой указанный компонент понимания эмоций окончательно формируется в возрасте 3-5 лет (рисунок 2).

\section{Оценка конструктной валидности теста}

Анализ конструктной валидности производился путем корреляционного анализа связи компонентов адаптируемого инструмента с результатами русскоязычной версии широко используемой в зарубежной исследовательской практике методики, направленной на оценку распознавания эмоции (Affect Recognition). Так как распределение данных по используемым методикам не соответствовало нормальному, был применен критерий корреляции Спирмена. Результаты представлены в таблице 1.

Рисунок 2

Распределение баллов по трем компонентам методики и общему уровню понимания эмоций $(\mathrm{N}=596)$
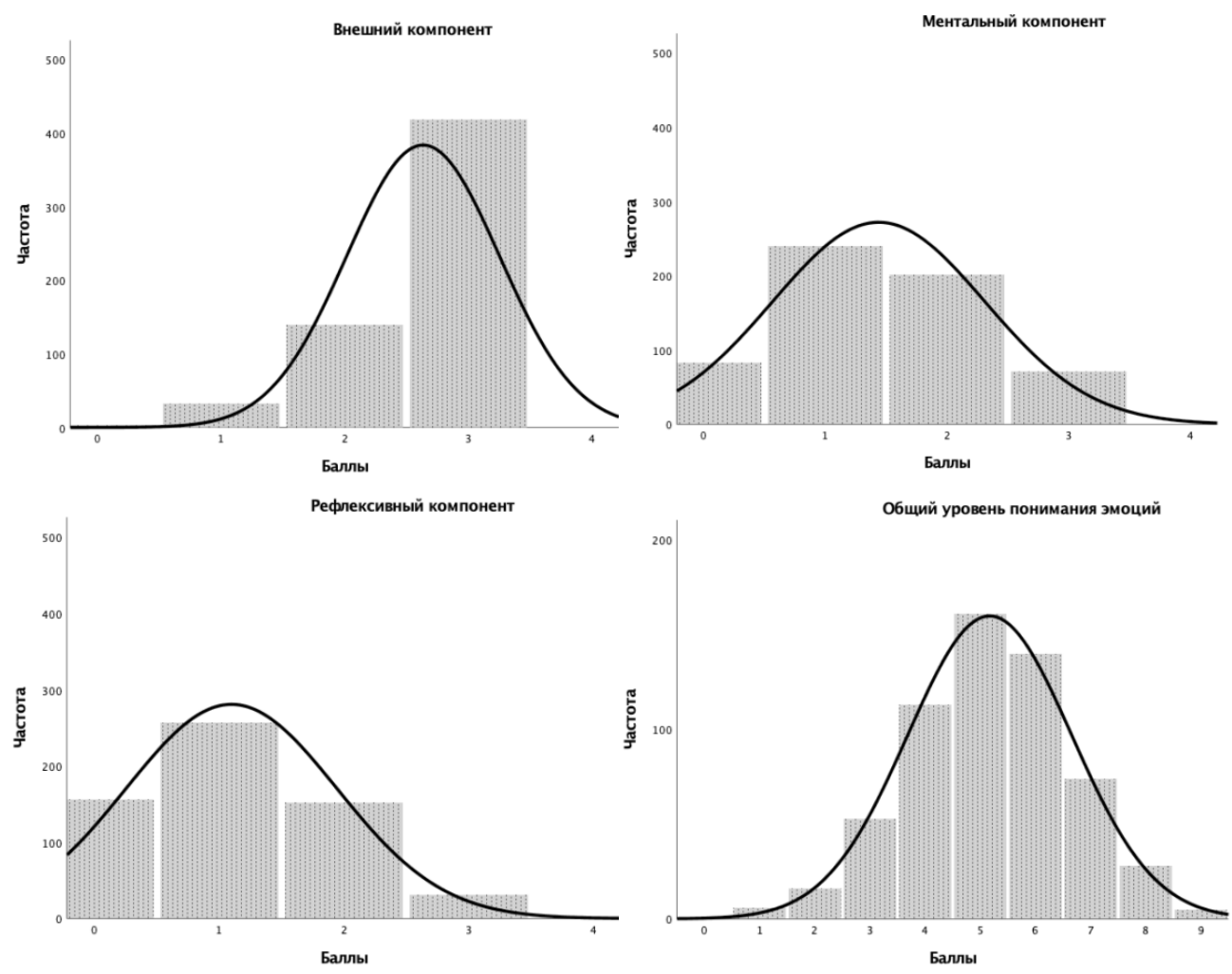
Связь компонентов Теста на понимание эмоций с распознаванием эмоций $(\mathrm{N}=596)$

\begin{tabular}{|l|c|c|c|c|}
\hline & $\begin{array}{c}\text { Внешний } \\
\text { компонент }\end{array}$ & $\begin{array}{c}\text { Психический } \\
\text { компонент }\end{array}$ & Мета компонент & Общий балл \\
\hline Внешний компонент & - & & & \\
\hline Психический компонент & $0.102^{*}$ & - & & \\
\hline Мета компонент & 0.038 & $0.130^{* *}$ & - & \\
\hline Общий балл & $0.453^{* *}$ & $0.712^{* *}$ & $0.651^{* *}$ & - \\
\hline Распознавание эмоций & $0.185^{* *}$ & $0.082^{*}$ & $0.085^{*}$ & $0.165^{* *}$ \\
\hline
\end{tabular}

${ }^{*} p<0.05,{ }^{* *} p<0.01$.

Выявлена теоретически ожидаемая значимая положительная связь между общим баллом адаптируемого инструмента и способностью детей распознавать эмоции. Отдельно Внешний компонент оказался умеренно связан со способностью распознавать эмоции, абсолютные значения полученного коэффициента при этом соответствуют ожидаемым. Психический компонент слабо связан с распознаванием эмоций, что, вероятно, обусловлено сфокусированностью данного компонента теста на ментальных причинах эмоций, что не всегда связано с лицевой экспрессией. Связь Мета компонента со способностью распознавать эмоции также оказалась слабой, что может быть частично объяснено тем, что отслеживание и анализ собственных эмоциональных состояний могут зачастую не выражаться с помощью лицевой экспрессии.

\section{Нормы и гендерные различия}

Анализ гендерных различий был произведен с применением непараметрического критерия Манна-Уитни, так как распределение баллов по всем показателям теста отличалось от нормального. Различия между успешностью выполнения теста девочками и мальчиками не были выявлены как по общему уровню понимания эмоций, так и по отдельным компонентам (таблица 2). Линейный регрессионный анализ также показал, что пол ребенка не является значимым предиктором общего уровня понимания эмоций $(\beta=0.177 ; p=0.147)$.

Спустя год после первого тестирования часть детей прошла повторное тестирование, что позволило получить данные о развитии понимания эмоций

Нормы выполнения теста для детей 5-6 лет $(\mathrm{N}=596)$

\begin{tabular}{|l|c|c|c|c|}
\hline \multirow{2}{*}{} & \multicolumn{2}{|c|}{ Мальчики (N = 299) } & \multicolumn{2}{c|}{ Девочки (N = 297) } \\
\cline { 2 - 5 } & $\mathrm{M}$ & $\mathrm{SD}$ & $\mathrm{M}$ & $\mathrm{SD}$ \\
\hline Внешний компонент & 2.63 & 0.62 & 2.64 & 0.62 \\
\hline Психический компонент & 1.37 & 0.86 & 1.51 & 0.88 \\
\hline Мета компонент & 1.08 & 0.81 & 1.11 & 0.88 \\
\hline Общий балл & 5.08 & 1.43 & 5.26 & 1.54 \\
\hline
\end{tabular}


с течением времени. Результаты повторного тестирования приведены в таблице 3 отдельно для девочек и мальчиков. Анализ гендерных различий с применением непараметрического критерия Манна-Уитни при повторном тестировании также не выявил значимых различий между девочками и мальчиками ни по одному из компонентов методики.

Т-критерий Вилкоксона был применен для анализа связанных с возрастом различий в успешности выполнения методики детьми при первичном и повторном тестировании. Анализ показал, что количество правильных ответов по всем компонентам методики значимо увеличилось через год после первого обследования (общий уровень понимания эмоций $Z=-9.56$, при $p<0.001$; Внешний компонент $Z=-7.27$, при $p<0.001$; Психический компонент $Z=-7.13$, при $p<0.001$; Мета компонент $Z=-5.73$, при $p<0.001)$. Результаты анализа свидетельствуют о том, что адаптируемый инструмент отражает возрастную динамку в развитии как общего уровня понимания эмоций, так и его компонентов.

\section{Обсуждение и заключение}

Применение методики Тест на понимание эмоций позволяет оценивать девять показателей понимания эмоций у детей дошкольного возраста. Результаты применения методики позволяют увидеть подробную картину развития понимания эмоций у детей с 3 до 11 лет. Несмотря на то что для полного завершения адаптации методики необходимы значительные усилия, настоящая работа позволяет уточнить представления об особенностях развития понимания эмоций у российских детей 5-7 лет.

Одно из существенных преимуществ данной методики заключается в том, что, несмотря на относительную простоту процедуры проведения, получаемые данные позволяют проанализировать развитие сразу нескольких компонентов и ряда отдельных показателей понимания эмоций (Rocha et al., 2015). Проверка соответствия факторной структуры русскоязычной версии методики с помощью конфирматорного факторого анализа подтвердила, что полученные на российской выборке детей 5-6 лет эмпирические данные укладываются в заданную при разработке теоретическую трехкомпонентную модель (Внешний, Психический и Мета).

Оценка конструктной валидности была произведена с помощью корреляционного анализа компонентов методики с результатами выполнения детьми

Таблица 3

Нормы выполнения теста для детей 6-7 лет $(\mathrm{N}=351)$

\begin{tabular}{|l|c|c|c|c|}
\hline \multirow{2}{*}{} & \multicolumn{2}{|c|}{ Мальчики (N = 171) } & \multicolumn{2}{c|}{ Девочки (N = 180) } \\
\cline { 2 - 5 } & $\mathrm{M}$ & $\mathrm{SD}$ & $\mathrm{M}$ & $\mathrm{SD}$ \\
\hline Внешний компонент & 2.88 & 0.38 & 2.82 & 0.45 \\
\hline Психический компонент & 1.71 & 0.88 & 1.72 & 0.82 \\
\hline Мета компонент & 1.43 & 0.83 & 1.52 & 0.94 \\
\hline Общий балл & 6.02 & 1.29 & 6.06 & 1.40 \\
\hline
\end{tabular}


теста на распознавание эмоций. Общий уровень понимания эмоций и Внешний компонент теста оказались значимо умеренно связаны с распознаванием эмоций по лицевой экспрессии, что соответствовало теоретическим ожиданиям. Однако связь Психического и Мета компонентов адаптируемого инструмента с распознаванием эмоций оказалась слабой, что, вероятно, объясняется ментальной нагрузкой указанных компонентов. Наличие в методике заданий различного уровня сложности позволяет использовать ее для диагностики детей в достаточно широком возрастном диапазоне. В рамках данного исследования был проведен анализ связанных с возрастом различий в успешности выполнения методики детьми. Количество правильных ответов по всем компонентам методики значимо увеличилось через год после первого обследования, что свидетельствует о том, что адаптируемый инструмент способен отражать возрастную динамку. Как и в оригинальной версии теста, в русскоязычной выборке не были выявлены гендерные различия ни по одному из компонентов теста. Аналогичные результаты были получены при адаптации данного теста на итальянской, английской и китайской выборке (Albanese et al., 2006; Tang et al., 2018; Fidalgo et al., 2018).

В целом результаты проведенного психометрического анализа подтверждают пригодность адаптированной русскоязычной версии Теста на понимание эмоций. Данная методика представляет собой надежный, валидный инструмент оценки понимания эмоций, в том числе и при применении на российской выборке. В результате работ по адаптации теста были получены российские нормы для детей в возрасте 5-6 и 6-7 лет. Возможно использование теста в эмпирических целях для изучения природы понимания эмоций в дошкольном и начальном школьном возрасте, а также в практических целях для диагностики с последующей дачей индивидуальных рекомендаций или разработкой программ эмоционального развития детей дошкольного и младшего школьного возраста. Применение русскоязычной версии теста открывает большие возможности для международного сотрудничества, поскольку ранее инструмент уже был переведен на 21 язык, адаптирован и широко используется исследователями в Англии, Италии, Бразилии, Китае, Норвегии и других странах.

\section{Литература}

Запорожец, А. В. (1985). Воспитание эмоций и чувств у дошкольника. В кн. А. Д. Кошелева (ред.), Эмоииональное развитие дошкольника (с. 26-28). М.: Просвещение.

Прусакова, О. А. (2005). Генезис понимания эмоций (Докторская диссертация). Государственный университет гуманитарных наук, Москва.

Сергиенко, Е. А. (2014). Модель психического как парадигма познания социального мира. Психологические исследования: электронный научный журнал, 7(36), 6. Режим доступа: http://psystudy.ru

Ссылки на зарубежные источники см. в разделе References после англоязычного блока. 
Веракса Николай Евгеньевич - профессор, кафедра психологии образования и педагогики, факультет психологии, МГУ имени М.В. Ломоносова, доктор психологических наук, профессор.

Сфера научных интересов: дошкольное образование, педагогика, психология развития.

Контакты: neveraksa@gmail.com

Веракса Александр Николаевич - заведующий кафедрой, кафедра психологии образования и педагогики, факультет психологии, МГУ имени М.В. Ломоносова, доктор психологических наук, профессор.

Сфера научных интересов: психология образования, педагогика, эмоциональное развитие. Контакты: veraksa@yandex.ru

Гаврилова Маргарита Николаевна - младший научный сотрудник, кафедра психологии образования и педагогики, факультет психологии, МГУ имени М.В. Ломоносова.

Сфера научных интересов: психология эмоций, дошкольный возраст.

Контакты: gavrilovamrg@gmail.com

Бухаленкова Дарья Алексеевна - младший научный сотрудник, кафедра психологии образования и педагогики, факультет психологии, МГУ имени М.В. Ломоносова.

Сфера научных интересов: психология эмоций, регуляторные функции, психология образования.

Контакты: d.bukhalenkova@inbox.ru

Тарасова Кристина Сергеевна - младший научный сотрудник, кафедра психологии образования и педагогики, факультет психологии, МГУ имени М.В. Ломоносова.

Сфера научных интересов: психология эмоций, регуляторные функции, психология образования.

Контакты: christinap@bk.ru

\title{
The Russian Version of the Test of Emotion Comprehension: Adaptation and Validation for Use in Preschool Children
}

\author{
N.E. Veraksa ${ }^{a}$, A.N. Veraksa ${ }^{a}$, M.N. Gavrilova ${ }^{a}$, D.A. Bukhalenkova ${ }^{a}$, K.S. Tarasova ${ }^{a}$ \\ ${ }^{a}$ Lomonosov Moscow State University, 1 Leninskie Gory, Moscow, 119991, Russian Federation
}

\begin{abstract}
The article presents the results of the Russian adaptation of the Test of Emotion Comprehension (Pons, Harris, 2000). The adaptation was conducted between 2019 and 2020 on a sample of 596 children 5-6 years old. One year later, 351 children were retested to assess the ability of the tool to reflect age dynamics in development of emotion understanding. Confirmatory factor analysis was applied to examine the theoretical structure underlying the tool. The empirical data obtained on the Russian sample confirmed the high correspondence of the Russian version of the tool to its original theoretical model. The result of applying Cochran's Q-test of equal proportions indicated acceptable reliability of the tool based on the internal consistency of its components. The validity of the test is confirmed by moderate positive correlations between the general level of emotion comprehension and individual test components with facial
\end{abstract}


emotion recognition (Affect Recognition subtest NEPSY-II). Similar to the original version of the test, no gender differences were revealed for any of the test components in the Russian sample. The analysis of age-related differences in children's performance on the test during initial and repeated testing showed that the number of correct answers in all components of the test significantly increased one year after the first examination, which verifies the ability of the instrument to reflect age dynamics. As a result of adaptation of the test, Russian norms for children of 5-6 and 6-7 years old were obtained. The future application of the test opens up broad possibilities for international cooperation in empirical studies of the nature of emotion understanding in preschool age and in practical tasks, such as diagnostics or design of programs for children's emotional development.

Keywords: emotion understanding, Test of Emotion Comprehension, emotional development, emotion recognition, preschool age.

\section{References}

Albanese, O., Grazzani, I., Molina, P., Antoniotti, C., Arati, L., Farina, E., \& Pons, F. (2006). Children's emotion understanding: preliminary data from the Italian validation project of Test of Emotion Comprehension (TEC). In F. Pons et al. (Eds.), Toward emotional competences (pp. 39-53). Aalborg, DK: Aalborg University Press.

Bender, P. K., Pons, F., Harris, P. L., \& de Rosnay, M. (2011). Do young children misunderstand their own emotions? European Journal of Developmental Psychology, 8(3), 331-348.

Cutting, A. L., \& Dunn, J. (1999). Theory of mind, emotion understanding, language, and family background: Individual differences and interrelations. Child Development, 70(4), 853-865. doi:10.1111/1467-8624.00061

De Stasio, S., Fiorilli, C., \& Di Chiacchio, C. (2014). Effects of verbal ability and fluid intelligence on children's emotion understanding. International Journal of Psychology, 49(5), 409-414. doi:10.1002/ijop.12032

Fidalgo, A. M., Tenenbaum, H. R., \& Aznar, A. (2018). Are there gender differences in emotion comprehension? Analysis of the test of emotion comprehension. Journal of Child and Family Studies, 27(4), 1065-1074.

Franco, M. da G., Beja, M. J., Candeias, A., \& Santos, N. (2017). Emotion understanding, social competence and school achievement in children from primary school in Portugal. Frontiers in Psychology, 8, 1-15. doi:10.3389/fpsyg.2017.01376

Garrett-Peters, P. T., Castro, V. L., \& Halberstadt, A. G. (2017). Parents' beliefs about children's emotions, children's emotion understanding, and classroom adjustment in middle childhood. Social Development, 26(3), 575-590. doi:10.1111/sode.12222

Jyzsa, K., \& Barrett, K. C. (2018). Affective and social mastery motivation in preschool as predictors of early school success: a longitudinal study. Early Childhood Research Quarterly, 45, 81-92. doi:10.1016/j.ecresq.2018.05.007

Kerstad, S. B. (2016). Young children's emotion understanding: The impact of parent and child factors, socioeconomic status, and culture (Thesis for the Degree of Philosophiae Doctor). Norwegian University of Science and Technology, Trondheim. Retrieved from https://ntnuopen.ntnu.no/ntnu- 
xmlui/bitstream/handle/11250/2409891/Silja\%20Berg\%20K\%c3\%a5rstad_PhD.pdf?sequence=1 \&isAllowed $=\mathrm{y}$

Kervinen, S. (2015). Exploration of the internal structure of the NEPSY-II (Master's Thesis). University of Helsinki, Finland. Retrieved from https://helda.helsinki.fi/bitstream/handle/10138/156462/ Silja_Kervinen_pg_2015.pdf

Korkman, M., Kirk, U., \& Kemp, S. (2007). Administration manual NEPSY-II. San Antonio, TX: Harcourt Assessment.

Liao, Z., Li, Y., \& Su, Y. (2014). Emotion understanding and reconciliation in overt and relational conflict scenarios among preschoolers. International Journal of Behavioral Development, 38(2), 111117. doi:10.1177/0165025413512064

Mathieson, K., \& Banerjee, R. (2011). Peer play, emotion understanding, and socio-moral explanation: The role of gender. British Journal of Developmental Psychology, 29(2), 188-196. doi:10.1111/j.2044-835X.2010.02020.x

Pons, F., \& Harris, P. (2000). Test of emotion comprehension: TEC. University of Oxford.

Pons, F., \& Harris, P. L. (2005). Longitudinal change and longitudinal stability of individual differences in children's emotion understanding. Cognition and Emotion, 19(8), 1158-1174. doi:10.1080/02699930500282108

Pons, F., Harris, P. L., \& de Rosnay, M. (2004). Emotion comprehension between 3 and 11 years: Developmental periods and hierarchical organization. European Journal of Developmental Psychology, 1(2), 127-152. doi:10.1080/17405620344000022

Pons, F., Lawson, J., Harris, P. L., \& De Rosnay, M. (2003). Individual differences in children's emotion understanding. Scandinavian Journal of Psychology, 44(4), 347-353. doi:10.1111/14679450.00354

Prusakova, O. A. (2005). Genezis ponimaniya emotsii [The genesis of understanding emotions] (Doctoral dissertation). Gosudarstvennyi Universitet Gumanitarnykh Nauk, Moscow, Russian Federation. (in Russian)

Rocha, A., Roazzi, A., Da Silva, A., Candeias, A., Minervino, C. M., Roazzi, M., \& Pons, F. (2015). Test of emotion comprehension: Exploring the underlying structure through Confirmatory Factor Analysis and Similarity Structure Analysis. In A. Roazzi, B. Campello, \& W. Bilsky (Eds.), Facet theory: Searching for structure in complex social, cultural and psychological phenomena (pp. 66-84). Recife, BR: Editora UFPE.

Saltzman, J. A., Fiese, B. H., Bost, K. K., \& McBride, B. A. (2018). Development of appetite self-regulation: Integrating perspectives from attachment and family systems theory. Child Development Perspectives, 12(1), 51-57. doi:10.1111/cdep.12254

Sergienko, E. A. (2014). Theory of Mind as a paradigm of social cognition. Psikhologicheskie Issledovaniya, 7(36), 6. Retrieved from http://psystudy.ru (in Russian)

Tang, Y., Harris, P. L., Pons, F., Zou, H., Zhang, W., \& Xu, Q. (2018). The understanding of emotion among young Chinese children. International Journal of Behavioral Development, 42(5), 512-517.

Trentacosta, C. J., \& Fine, S. E. (2010). Emotion knowledge, social competence, and behavior problems in childhood and adolescence: a meta-analytic review. Social Developement, 19(1), 1-29. doi:10.1111/j.1467-9507.2009.00543.x

Von Salisch, M., Haenel, M., \& Freund, P. A. (2013). Emotion understanding and cognitive abilities in young children. Learning and Individual Differences, 26, 15-19. doi:10.1016/j.lindif.2013.04.001

Wellman, H. M. (1992). The child's theory of mind. The MIT Press. 
Zaporozhets, A. V. (1985). Vospitanie emotsii i chuvstv u doshkol'nika [Cultivation of emotions and feelings in a preschooler]. In A. D. Kosheleva (Ed.), Emotsional'noe razvitie doshkol'nika [Emotional development of a preschooler] (pp. 26-28). Moscow: Prosveshchenie. (in Russian)

Nikolay E. Veraksa - Professor, chair of psychology of education and pedagogy, Faculty of Psychology, Lomonosov Moscow State University.DSc in Psychology, Professor.

Research Area: preschool education, pedagogy, psychology of development.

E-mail: neveraksa@gmail.com

Alexander N. Veraksa - Head, chair of psychology of education and pedagogy, Faculty of Psychology, Lomonosov Moscow State University, DSc in Psychology, Professor.

Research Area: psychology of education, pedagogy, emotional development.

E-mail: veraksa@yandex.ru

Margarita N. Gavrilova - Junior Research Fellow, chair of psychology of education and pedagogy, Faculty of Psychology, Lomonosov Moscow State University.

Research Area: psychology of emotions, preschool age.

E-mail: gavrilovamrg@gmail.com

Daria A. Bukhalenkova - Junior Research Fellow, chair of psychology of education and pedagogy, Faculty of Psychology, Lomonosov Moscow State University.

Research Area: psychology of emotions, regulatory functions, psychology of education.

E-mail: d.bukhalenkova@inbox.ru

Kristina S. Tarasova - Junior Research Fellow, chair of psychology of education and pedagogy, Faculty of Psychology, Lomonosov Moscow State University.

Research Area: psychology of emotions, regulatory functions, psychology of education.

E-mail: christinap@bk.ru 
Психология. Журнал Высшей школы экономики,

2021. T. 18. № 1. C. 71-91. DOI: 10.17323/1813-8918-2021-1-71-91

\title{
РАЗРАБОТКА И АДАПТАЦИЯ МЕТОДИКИ «ИНТЕГРАТИВНЫЙ ОПРОСНИК МЕЖКУЛЬТУРНОЙ КОМПЕТЕНТНОСТИ»
}

\author{
О.Е. ХУХЛАЕВ \\ Н.В. ТКАЧЕНКО ${ }^{\mathrm{a}}$, Ш.А. УСУБЯН ${ }^{\text {a }}$ В.А. ШОРОХОВА
}

${ }^{a}$ Московский государственный психолого-педагогический университет, 127051, Россия, Москва,
ул. Сретенка, д. 29
${ }^{b}$ Федеральньй научно-методический центр в области психологии и педагогики толерантности,
127055, Москва, ул. Образщова, д. 11

Резюме

В статье приводятся описание разработки и результаты апробации новой методики «Интегративный опросник межкультурной компетентности», направленной на изучение способности эффективно функционировать при общении с представителями различных культур и в разных культурных средах. Опросник создан на основе интеграции 52 конструктов из 14 методов измерения межкультурной компетентности. Исследование $(\mathrm{N}=$ 1024) показало, что методика содержит четыре субшкалы: «Межкультурная стабильность» (индивидуальные особенности личности, которые позволяют человеку быть устойчивым к стрессовым ситуациям межкультурного общения), «Межкультурный интерес» (желание общаться с людьми из других культур, интерес к культуре и культурным различиям), «Отсутствие этноцентризма» (установка на уважение и принятие культурного разнообразия) и «Управление межкультурным взаимодействием» (владение широким спектром коммуникативных навыков, важных при межкультурном общении). Субшкалы обладают хорошей внутренней согласованностью, а также инвариантностью с некоторыми ограничениями в части сравнения людей разных возрастов. Исследование также продемонстрировало внешнюю валидность методики. Шкалы «Интегративного опросника межкультурной компетентности» положительно связаны с «Расширенной шкалой культурного интеллекта». Люди, демонстрирующие более высокие показатели по отдельным шкалам опросника, отличаются бо́льшим количеством конкретных межкультурных достижений. Наблюдаются предсказуемые взаимосвязи опросника с показателями адаптации иностранных студентов, выраженностью эмоционального выгорания и самоэффективности у педагогов, работающих в мультикультурной среде.

Ключевые слова: межкультурная компетентность, межкультурная коммуникация, культурный интеллект.

Исследование выполнено при поддержке РФФИ, проект № 19-013-00892 «Интегративная социально-психологическая модель оценки и прогнозирования эффективности межкультурного взаимодействия».

Авторы благодарят доктора психологических наук, зав. кафедрой психологии КЧГУ имени У.Д. Алиева Ф.О. Семенову и студентов КЧГУ имени У.Д. Алиева за содействие в проведении исследования. 


\section{Введение}

Межкультурная компетентность в наиболее широком контексте рассматривается как способность человека эффективно функционировать при общении с представителями различных культур и в разных культурных средах (Whaley, Davis, 2007). Ее важность для решения конкретных профессиональных задач в мультикультурной среде очевидна. Причем если достижение определенного уровня межкультурной компетентности позволяет решать проблемы, связанные с культурными различиями, то высокий уровень межкультурных способностей позволяет использовать культурное разнообразие и как ресурс (Хухлаев, Чибисова, 2010). В этой связи вопрос измерения межкультурной компетентности является крайне актуальным как для исследовательского поля, так и для психологической практики.

Теоретическое понимание межкультурной компетентности крайне разнообразно и многообразно: существует более 30 моделей межкультурной компетентности и более чем 300 конструктов, которые являются ее составляющими (Leung et al., 2014). Инструментов измерения межкультурной компетентности также достаточно много. Разные авторы обозначают различное количество методик с доказанной внешней и внутренней валидностью (Matsumoto, Hwang, 2013; Leung et al., 2014). Из них на российской выборке адаптирована лишь одна - «Расширенная шкала культурного интеллекта» (Солдатова и др., 2018). Данная методика базируется на крайне актуальном, но весьма своеобразном теоретическом подходе к пониманию межкультурной компетентности - теории культурного интеллекта как одного из видов социального интеллекта (Earley, Ang, 2003), нацеленного на решение задач, связанных с кросс-культурным взаимодействием. Существуют и другие, концептуально отличающиеся подходы к теоретическому пониманию межкультурной компетентности, воплощенные в конкретные инструменты ее измерения (например, модель кросскультурного психологического капитала - Dollwet, Reichard, 2014).

При этом значительная часть зарубежных инструментов измерения межкультурной компетентности предназначена для коммерческого использования, охраняется авторским правом, в связи с чем существенно затруднено решение вопроса их перевода и адаптации.

Следует подчеркнуть, что ряд инструментов, позиционирующихся как нацеленные на измерение межкультурной компетентности, по факту изучают более широкие личностные особенности. Так, многие вопросы из широкоизвестного «Опросника мультикультурной личности» (MPQ) (Van der Zee, Van Oudenhoven, 2000, 2001) сформулированы без учета специфики межкультурного общения (например, «Я имею устоявшиеся привычки»).

Мы считаем, что индивидуальные особенности, не являющиеся специфичными для межкультурной коммуникации, следует измерять соответствующими универсальными инструментами, прошедшими широкую апробацию. Такой подход позволяет избежать спутанности между разными видами компетентности, а также личностными особенностями, способствующими тому или иному виду деятельности. 
В силу всех причин, указанных выше, существует потребность в методике измерения межкультурной компетентности: а) адаптированной к российскому контексту, б) созданной на основе интеграции широкого круга подходов к пониманию данного феномена и в) нацеленной на измерение именно межкультурной компетентности, а не более широких феноменов. В данной статье изложено теоретическое обоснование, описан процесс создания и приведены результаты исследования внутренней и внешней валидности русскоязычного «Интегративного опросника межкультурной компетентности», созданного на основе комплексного анализа ряда подходов к пониманию процесса достижения эффективности в межкультурном общении.

Основываясь на подходе К. Леунга (Leung) и его коллег (Leung et al., 2014), мы выбрали рамочную структуру межкультурной компетентности из трех составляющих.

Межкультурные черть - наиболее устойчивые индивидуально-личностные образования, определяющие те или иные паттерны поведения человека в условиях межкультурного взаимодействия и тем самым способствующие или препятствующие успешности межкультурной адаптации. Межкультурные установки - особенности мировоззрения, связанные с межкультурным общением и обеспечивающие его мотивацию, которая, в свою очередь, приводит к эффективности межкультурного взаимодействия. Межкультурные умения и навыки индивида непосредственно обеспечивают его эффективность в конкретных межкультурных взаимодействиях.

Для интегративного анализа мы выбрали 14 моделей межкультурной компетентности, получившие эмпирическое подтверждение и часто используемые в зарубежных исследованиях. Их подробный анализ опубликован отдельно (Гриценко и др., 2020). Мы выделили все конструкты, которые авторы данных моделей включили в свои подходы, и провели их содержательное сопоставление. После удаления полностью дублирующих конструктов мы разделили оставшиеся по трем составляющим межкультурной компетентности: «Межкультурные черты» (20 конструктов), «Межкультурные установки» (11 конструктов) и «Межкультурные умения и навыки» (21 конструкт). При отнесении мы ориентировались на название конструкта и его содержание, как описанное автором, так и отраженное в вопросах, предназначенных для его изучения. Далее, внутри каждой из составляющих межкультурной компетентности мы объединили и дали одно название схожим и/или взаимодополняющим конструктам. Так, к примеру, фактор «Межкультурное общение» из Опросника межкультурной готовности (The Intercultural Readiness Chec; Van der Zee, Brinkmann, 2004) был объединен со схожей шкалой «Коммуникативные навыки» мультикомпонентого подхода к межкультурной компетентности (Multicomponent approach of CCC; Bartel-Radic, Giannelloni, 2017) и дополняющим конструктом «Посредничество между людьми с разными интересами» Теста для измерения межкультурной компетентности (Test to Measure Intercultural Competence; Schnabel et al., 2015) в одну шкалу «Управление межкультурным взаимодействием». 
В результате была сформирована теоретическая интегративная модель компетентности, которая легла в основу разработки опросника. Она состояла из девяти конструктов: Межкультурная стабильность, Межкультурная гибкость, Межкультурная открытость, Межкультурный интерес, Отсутствие этноцентризма, Культурная сензитивность, Межкультурная эмпатия, Толерантность к межкультурной неопределенности (Khukhlaev et al., 2020). $\mathrm{Ha}$ основании данной модели были сгенерированы утверждения «Интегративного опросника межкультурной компетентности». Исходным материалом для формулировки утверждений выступали методики измерения межкультурной компетентности, включенные в первичный анализ (Гриценко и др., 2020), инструментарий которых находился в открытом доступе. Так, опросник культурного интеллекта распространяется свободно и даже переведен на русский язык (Солдатова и др., 2018), а Шкала межкультурного адаптационного потенциала ICAPS (Matsumoto et al., 2001) представляет собой инструмент с ключом, закрытым для пользователей, поэтому не могла быть использована нами. Также мы использовали широкий круг опросников, направленных на диагностику более универсальных конструктов (например «открытость»), адаптируя утверждения для контекста межкультурного общения. Из одной методики было использовано не более трех пунктов, многие из них были существенно изменены с целью соответствия нормам русского языка. Ввиду этих изменений содержание опросника является авторским.

Исследование было направлено на проверку внешней и внутренней валидности опросника и проходило в один этап.

\section{Метод}

Выборка. В исследовании приняло участие 1024 респондента, проживающих в настоящее время в России (75.9\% женщин, $\mathrm{n}=777)$, от 18 до 65 лет $(\mathrm{M}=$ $33.9, \mathrm{SD}=14.4)$. Из них 383 респондента $(37 \%)$ заняты в сфере образования (83 учителя начальной школы, 25 учителей средней школы, 149 педагогов высшей школы, 126 занимают иные должности в образовании), 111 - работают в области бизнеса (11\%), 81 - заняты в сфере государственного и муниципального управления ( $8 \%)$.

Остальные респонденты указали иную сферу занятости, не указали профессиональную принадлежность или не имеют в настоящее время какой-либо профессиональной занятости (в том числе в связи с обучением).

$42 \%$ респондентов $(\mathrm{n}=426)$ во время проведения исследования являлись студентами вузов, среди них 156 человек - иностранные студенты, обучающиеся в основном в РУДН и МГППУ (из Италии, Китая и Туркмении) с хорошим владением русским языком.

Все респонденты заполняли «Интегративный опросник межкультурной компетентности» и отвечали на вопросы - маркеры межкультурных достижений. $62 \%$ респондентов $(\mathrm{n}=638)$ также заполняли опросник культурного интеллекта. Педагоги высших и средних учебных заведений, работающие с мигрантами/иностранными студентами $(\mathrm{n}=53 / 94)$, отвечали на вопросы, 
связанные с самоэффективностью и эмоциональным выгоранием от межкультурного взаимодействия. Иностранные студенты дополнительно заполняли опросники, направленные на диагностику их психологической и социокультурной адаптации.

\section{Методики}

«Интегративный опросник межкультурной компетентности». Шкала разработана авторским коллективом под руководством О.Е. Хухлаева. Вопросы были сгенерированы на основании существующих опросников межкультурной компетентности, а также иных инструментов, направленных на изучение индивидуальных особенностей, с ней связанных. Все вопросы были сформулированы так, чтобы они касались именно межкультурной направленности и общения с людьми из других культур. Например, суждение «Я считаю себя легко адаптирующимся человеком» из опросника глобальных компетенций (Global Competencies Inventory; Bird et al., 2010) было изменено на «Я легко адаптируюсь к нормам и правилам другой культуры».

По каждой из девяти шкал теоретической интегративной модели межкультурной компетентности (см. выше) было сгенерировано по 10 пунктов, из которых затем были удалены суждения, понимание которых на русском языке может быть затруднено. В результате был составлен опросник из 70 суждений с пятибалльной шкалой оценки (от 1 - «Полностью не согласен» до 5 «Полностью согласен»), отражающих каждый из девяти конструктов интегративной модели межкультурной компетентности. Количество сгенерированных вопросов превышало необходимое с целью последующего отбора утверждений, обеспечивающих наилучшие психометрические показатели.

Для проверки внешней валидности были использованы следующие измерения.

Вопросы - маркеры межкультурных достижений. Мы использовали четыре вопроса, которые в различных исследованиях межкультурной компетентности используются как конкретные маркеры наличия у человека достижений в области межкультурного взаимодействия: «У вас много друзей другой культуры?» (варианты ответов «Да» и «Нет»), «У вас есть успешный опыт жизни/учебы/работы за рубежом?» (варианты ответов «Да» и «Нет»), «Сколькими языками вы владеете (включая родной/родные языки)? (напишите цифру)», «Сколько стран вы посетили за последние 5 лет? (напишите цифру)».

Расширенная шкала культурного интеллекта позволяет определить выраженность четырех основных компонентов культурного интеллекта (CQ способности индивида эффективно функционировать и взаимодействовать в ситуациях, характеризующихся культурным многообразием) (Ang et al., 2006; Солдатова и др., 2018). Методика состоит из 4 шкал (метакогнитивный, когнитивный, мотивационный и поведенческий компоненты CQ), включающих 37 утверждений с семибалльной шкалой оценки (от 1 - «Полностью не согласен» до $7-$ «олностью согласен»). 
Психологическая адаптация. Использована шкала измерения удовлетворенности собой из опросника MIRIPS (Mutual Intercultural Relations in Plural Societies; MIRIPS, n.d.), переведенного и адаптированного для использования в России (Лебедева, Татарко, 2009). Шкала содержит 9 утверждений с пятибалльной шкалой оценки (от 1 - «Полностью не согласен» до 5 «Полностью согласен»).

Социокультурная адаптация. Мы использовали адаптированную шкалу из опросника MIRIPS (Там же), включающую 21 обратный вопрос (например, «Укажите, пожалуйста, в какой мере вы испытываете в России трудности в установлении и поддержании контактов с людьми»). Респонденту предлагалось 5 вариантов ответов: от 1 - «Абсолютно не согласен» до 5 - «Абсолютно согласен». Далее ответы перекодировались.

Эмоциональное выгорание педагога от межкультурного взаимодействия. Мы использовали шкалу из шести вопросов, разработанную М. Татаром и Г. Горенчиком (Tatar, Horenczyk, 2003) и переведенную Н.А. Лариным (Ларин, $2017)$, для оценки степени личного и профессионального благополучия педагога, которое зависит от того, как он справляется с трудностями, возникающими в поликультурном классе. Для школьных учителей опросник был направлен на самоанализ работы с детьми-мигрантами, а для преподавателей вузов с иностранными студентами. Респондент мог согласиться или не согласиться с утверждениями, используя 5-балльную шкалу (от 1 - «Полностью не согласен» до 5 - «Полностью согласен»).

Самоэффективность педагога в работе с мигрантами. Мы использовали шкалу из шести вопросов, разработанную М. Татаром и др. (Tatar et al., 2011) для оценки веры учителя в то, что он успешно работает с учениками-мигрантами, в переводе на русский язык О.Е. Хухлаева. Для школьных учителей опросник был направлен на самоанализ работы с детьми-мигрантами, а для преподавателей вузов - с иностранными студентами. Респондент мог согласиться или не согласиться с утверждениями, используя 5-балльную шкалу (от 1 - «Полностью не согласен» до 5 - «Полностью согласен»).

\section{Результаты}

Структура опросника. В первой части опишем результаты эмпирической проверки опросника, созданного на основе интегративной модели межкультурной компетентности, включая последовательность действий по уменьшению количества суждений.

Вначале каждая шкала была проверена на согласованность пунктов с помощью коэффициента альфа Кронбаха. Посредством исключения утверждений и анализа последующих изменений коэффициента альфа должны были быть сформированы более короткие шкалы. Однако пять шкал из девяти представленных в теоретической модели опросника не показали достаточной степени надежности и были исключены из последующего анализа. Эксплораторный факторный анализ (метод вращения Варимакс) также показал, что утверждения, сгенерированные для таких шкал, как «Межкультурная гибкость», 
«Межкультурная открытость», «Культурная сензитивность», «Межкультурная эмпатия» и «Толерантность к межкультурной неопределенности», не составляют отдельных факторов.

Таким образом, проверка факторной структуры опросника осуществлялась на сокращенных четырех шкалах: «Межкультурная стабильность» (индивидуальные особенности личности, которые позволяют человеку быть устойчивым к стрессовым ситуациям межкультурного общения), «Межкультурный интерес» (желание общаться с людьми из других культур, интерес к культуре и культурным различиям), «Отсутствие этноцентризма» (установка на уважение и принятие культурного разнообразия в сочетании с отношением к культурным различиям как к множеству вариантов при отсутствии превосходства той или иной культуры) и «Управление межкультурным взаимодействием» (владение широким спектром коммуникативных навыков, важных при межкультурном общении, обеспечивающих подстройку под собеседника из другой культуры и позволяющих договориться с ним). Конфирматорный факторный анализ с помощью программы AMOS 22.0 продемонстрировал недостаточное соответствие исходным данным и рекомендованным нормам по некоторым показателям (Hu, Bentler, 1999) (см. таблицу 1, модель 1).

Далее были проанализированы индексы модификации на наличие ковариаций ошибок между различными суждениями. Анализ пунктов с выявленной сильной связью показал, что данные суждения схожи по смысловой нагрузке (например, «После общения с человеком другой культуры меня часто терзает чувство вины» и «После общения с людьми из другой культуры я чувствую себя совершенно разбитым», $\left.\chi^{2}=45.21\right)$. В результате в модель были включены четыре ковариации. Для данного варианта был повторно проведен конфирматорный факторный анализ, который показал, что модель демонстрирует лучшее соответствие эмпирическим данным (см. таблицу 1, модель 2). При этом показатель TLI (индекс Тьюкера-Льюиса), являющийся релятивистским индексом соответствия, независимым от размера выборки (Marsh et al., 1988), немного не достигает требуемой нормы 0.95. Однако если рассматривать индексы соответствия в сочетании друг с другом, то видно, что параметры модели выходят за рамки риска возникновения ошибок (при TLI $\leqslant 0.91$ показатель SRMR $\geqslant 0.07)$ и свидетельствуют о наличии риска недостоверной

Таблица 1

Показатели Интегративного опросника межкультурной компетентности

\begin{tabular}{|l|c|c|c|c|c|c|c|c|c|c|c|c|}
\hline \multicolumn{1}{|c|}{ Модели } & $\boldsymbol{\chi}^{2}$ & $\boldsymbol{p}$ & $\mathbf{d f}$ & $\boldsymbol{\chi}^{2} / \mathbf{d f}$ & TLI & RMSEA & GFI & AGFI & CFI & AIC & BIC & SRMR \\
\hline № 1. 4 шкалы & 584.72 & 0.00 & 129 & 4.55 & 0.88 & 0.06 & 0.94 & 0.91 & 0.90 & 668.72 & 876.33 & 0.05 \\
\hline $\begin{array}{l}\text { № 2. 4 шкалы с } \\
\text { ковариациями }\end{array}$ & 448.31 & 0.00 & 125 & 3.58 & 0.91 & 0.05 & 0.95 & 0.93 & 0.93 & 450.31 & 767.70 & 0.05 \\
\hline $\begin{array}{l}\text { № 3. 4 шкалы с } \\
\text { ковариациями и } \\
\text { общим фактором } \\
\text { второго порядка }\end{array}$ & 564.25 & 0.00 & 127 & 4.44 & 0.89 & 0.06 & 0.94 & 0.92 & 0.90 & 652.25 & 869.74 & 0.06 \\
\hline
\end{tabular}


оценки (Hu, Bentler, 1999). Также модель соотносится с другим сочетанием критериев соответствия: RMSEA $\leqslant 0.5$ и SRMR $\leqslant 0.6$. Таким образом, можно говорить о том, что параметры модели соответствуют эмпирическим данным.

Распределение пунктов по шкалам и стандартизированные факторные нагрузки представлены на рисунке 1.

Была проверена дополнительная гипотеза о существовании вложенной модели с пятью шкалами и одним вторичным фактором - общим показателем межкультурной компетентности (см. таблицу 1, модель 3). Она продемонстрировала менее приемлемые показатели соответствия и в дальнейшем не участвовала в анализе.

Данные о надежности шкал, средние значения и стандартные отклонения представлены в таблице 2 и свидетельствуют о хороших показателях надежности методики.

Рисунок 1

\section{Структура Интегративного опросника межкультурной компетентности}

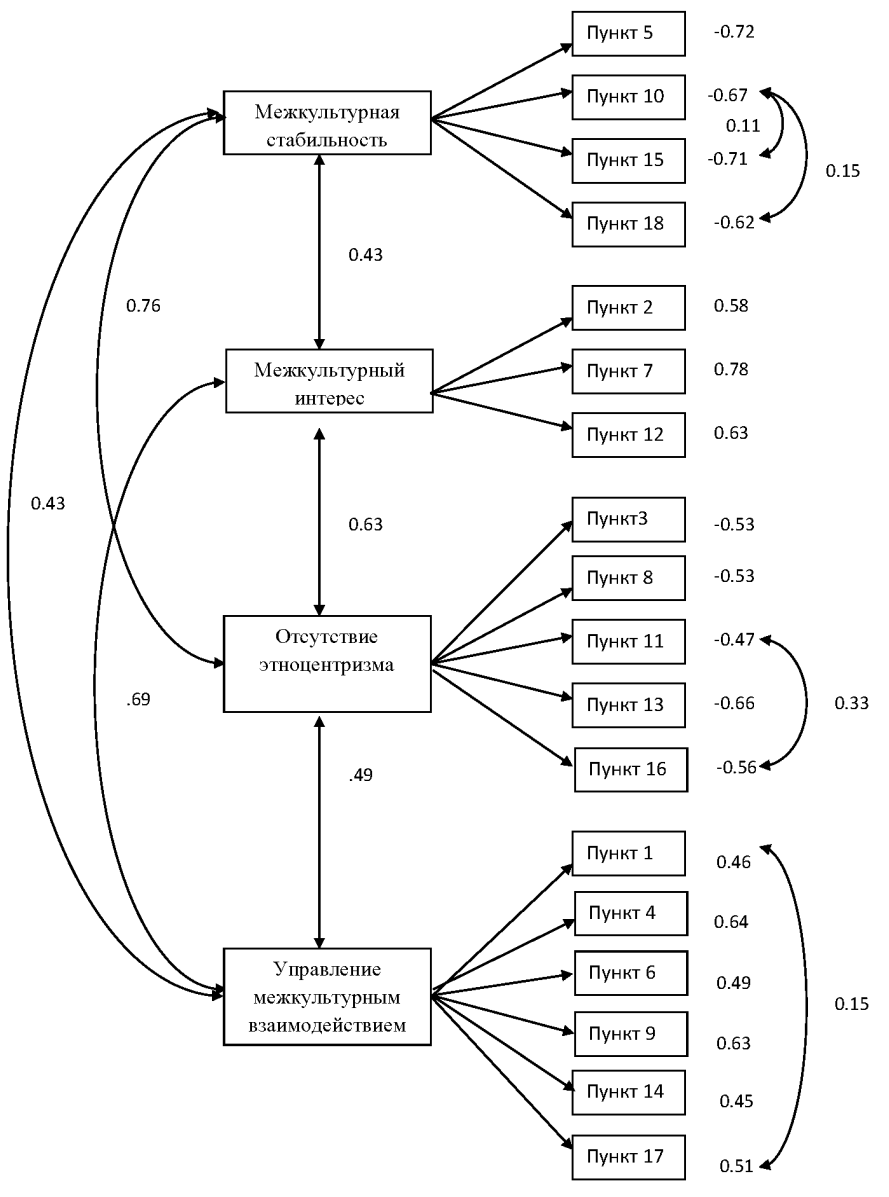


Структурная валидность опросника. Для дальнейшей проверки структурной валидности четырехфакторной структуры опросника был проведен мультигрупповой факторный анализ (таблица 3). Респонденты были разделены сначала на мужчин $(\mathrm{n}=247)$ и женщин $(\mathrm{n}=777)$, а затем на людей до 33 лет включительно $(\mathrm{n}=577)$ и старше 34 лет $(\mathrm{n}=447)$. В первом случае параметры межгруппового сравнения показывают, что опросник обладает конфигурационной, метрической и скалярной инвариантностью. При возрастном сравнении обнаружено, что опросник демонстрирует конфигурационную и скалярную, но не метрическую инвариантность ( $\triangle$ CFI больше 0.01) (Cheung, Rensvold, 2002). Несмотря на данные о том, что факторные нагрузки суждений могут быть различны для людей разного возраста (отсутствие метрической инвариантности), достижение скалярной инвариантности, показывающей, что нагрузки разных суждений вносят эквивалентный вклад в латентную переменную, свидетельствует о противоречивых перспективах возрастных сравнений по шкалам опросника. Этот вопрос требует дальнейшего изучения.

Внешняя валидность. Проверка внешней валидности опросника состояла из нескольких этапов, осуществлявшихся на различных выборках. Для ее

Таблица 2

Интеркорреляции и описательные статистики шкал

Интегративного опросника межкультурной компетентности

\begin{tabular}{|l|c|c|c|c|c|c|c|c|}
\hline \multicolumn{1}{|c|}{ Шшкалы } & $\mathbf{n}$ & $\mathbf{M}$ & $\mathbf{S D}$ & $\boldsymbol{\alpha}$ & $\mathbf{1}$ & $\mathbf{2}$ & $\mathbf{3}$ & $\mathbf{4}$ \\
\hline $\begin{array}{l}\text { Межкультрная } \\
\text { стабильность }\end{array}$ & 1021 & 3.24 & 0.74 & 0.77 & 1 & $0.29^{* *}$ & $0.55^{* *}$ & $0.31^{* *}$ \\
\hline Межкультурный интерес & 1017 & 4.05 & 0.72 & 0.71 & $0.29^{* *}$ & 1 & $0.43^{* *}$ & $0.49^{* *}$ \\
\hline Отсутствие этноцентризма & 1001 & 3.13 & 0.64 & 0.71 & $0.55^{* *}$ & $0.43^{* *}$ & 1 & $0.34^{* *}$ \\
\hline $\begin{array}{l}\text { Управление межкультурным } \\
\text { взаимодействием }\end{array}$ & 1008 & 3.83 & 0.59 & 0.70 & $0.31^{* *}$ & $0.49^{* *}$ & $0.34^{* *}$ & 1 \\
\hline
\end{tabular}

$* * p<0.01$.

Таблица 3

Результаты мультигруппового конфирматорного факторного анализа

\begin{tabular}{|c|c|c|c|c|c|c|c|c|c|c|}
\hline Группы & Модель & $\chi^{2}$ & df & $\chi^{2} / \mathrm{df}$ & TLI & RMSEA & CFI & AIC & SRMR & $\Delta \mathrm{CFI}$ \\
\hline \multirow{3}{*}{$\begin{array}{l}\text { Гендерные } \\
\text { группы } \\
\text { (мужчины, } \\
\text { женщины) }\end{array}$} & $\begin{array}{l}\text { Конфигурационная } \\
\text { инвариантность }\end{array}$ & 605.38 & 250 & 2.42 & 0.906 & 0.037 & 0.923 & 789.38 & 0.064 & - \\
\hline & $\begin{array}{l}\text { Метрическая } \\
\text { инвариантность }\end{array}$ & 590.35 & 264 & 2.26 & 0.916 & 0.035 & 0.928 & 754.35 & 0.074 & 0.005 \\
\hline & $\begin{array}{l}\text { Скалярная } \\
\text { инвариантность }\end{array}$ & 633.80 & 275 & 2.30 & 0.913 & 0.036 & 0.922 & 767.80 & 0.076 & 0.006 \\
\hline \multirow{3}{*}{$\begin{array}{l}\text { Возрастные } \\
\text { группы (до } 33 \\
\text { лет, от } 34 \text { и } \\
\text { старше) }\end{array}$} & $\begin{array}{l}\text { Конфигурационная } \\
\text { инвариантность }\end{array}$ & 644.77 & 250 & 2.66 & 0.890 & 0.400 & 0.910 & 848.79 & 0.053 & - \\
\hline & $\begin{array}{l}\text { Метрическая } \\
\text { инвариантность }\end{array}$ & 589.92 & 264 & 2.23 & 0.918 & 0.350 & 0.930 & 745.92 & 0.055 & 0.020 \\
\hline & $\begin{array}{l}\text { Скалярная } \\
\text { инвариантность }\end{array}$ & 614.76 & 275 & 2.23 & 0.918 & 0.350 & 0.927 & 748.76 & 0.055 & 0.003 \\
\hline
\end{tabular}


определения были выбраны методики, измеряющие свойства, с которыми, согласно теоретическим представлениям, должна быть связана межкультурная компетентность. Методика измерения культурного интеллекта позволяет определить способности индивида эффективно функционировать и взаимодействовать в ситуациях, характеризующихся культурным многообразием (Ang et al., 2006). Вопросы - маркеры межкультурных достижений - отражают наличие у человека конкретных успехов в области межкультурного взаимодействия, что должно являться прямым следствием межкультурной компетентности. Кроме того, межкультурная компетентность в конкретной социальной ситуации должна предсказывать личную и/или профессиональную успешность в культурно иной среде. Для иностранных студентов показателями успешности могут выступать критерии их психологической и социокультурной адаптации (Лебедева, Татарко, 2009), а для педагогов, работающих с учащимися других культур, - самоэффективность и низкое эмоциональное выгорание (Tatar, Horenczyk, 2003; Tatar et al., 2011). Описательная статистика и корреляции представлены в таблицах 4-6.

Все шкалы интегративного опросника межкультурной компетентности демонстрируют корреляции со всеми компонентами культурного интеллекта CQ. C первым вопросом-маркером межкультурных достижений «Сколько стран вы посетили за последние 5 лет?» крайне слабо связаны все шкалы опросника, кроме шкалы «Отсутствие этноцентризма» (таблица 4).

Выявление связи показателей Интегративного опросника межкультурной компетентности с ответами на второй-четвертый вопросы-маркеры межкультурных достижений проводилось с помощью серии однофакторных дисперсионных анализов (ANOVA). Средние значения всех показателей представлены в таблице 5. Респонденты, сообщившие о наличии успешного опыта жизни, учебы или работы за рубежом, демонстрируют более высокий уровень межкультурной стабильности $(\mathrm{F}=5.06, p=0.02)$, межкультурного интереса $(\mathrm{F}=24.02$, $p=0.00)$ и способностей к управлению межкультурным взаимодействием ( $\mathrm{F}=7.19$, $p=0.01)$. Те из испытуемых, кто согласился с тем, что у них много друзей из другой культуры, демонстрируют более высокие показатели по всем шкалам Интегративного опросника межкультурной компетентности $(\mathrm{F}=9.23 / 95.36$ / $26.90 / 18.68, p \leqslant 0.002)$. Респонденты, владеющие тремя и более языками (включая родной), показывают более высокую межкультурную стабильность $(\mathrm{F}=13.67, p=0.00)$, а те, кто говорят только на одном языке, демонстрируют более низкий уровень межкультурного интереса $(\mathrm{F}=7.39, p=0.00)$.

На трех подвыборках проверялось наличие взаимосвязей шкал Интегративного опросника межкультурной компетентности с показателями межкультурной эффективности, имеющими отношение к конкретной социальной ситуации (таблица 6).

У иностранных студентов, обучающихся в вузах Москвы, все шкалы Интегративного опросника межкультурной компетентности связаны с выраженностью их социокультурной адаптации. С эффективностью психологической адаптации связаны шкалы «Межкультурный интерес» и «Управление межкультурным взаимодействием». 
Таблица 4

Корреляции между компонентами культурного интеллекта CQ, вопросом-маркером межкультурных достижений и показателями Интегративного опросника межкультурной компетентности

\begin{tabular}{|l|c|c|c|c|c|c|c|c|}
\hline & $\mathbf{n}$ & $\mathbf{M}$ & $\mathbf{S D}$ & $\boldsymbol{\alpha}$ & $\mathbf{M C т}$ & $\mathbf{M И}$ & ОЭЦ & УМВ \\
\hline Мотивационный CQ & 638 & 5.11 & 0.95 & 0.75 & $0.42^{* *}$ & $0.57^{* *}$ & $0.43^{* *}$ & $0.64^{* *}$ \\
\hline Когнитивный CQ & 624 & 4.80 & 0.88 & 0.79 & $0.23^{* *}$ & $0.35^{* *}$ & $0.20^{* *}$ & $0.49^{* *}$ \\
\hline Метакогнитивный CQ & 631 & 5.16 & 0.93 & 0.81 & $0.31^{* *}$ & $0.37^{* *}$ & $0.29^{* *}$ & $0.69^{* *}$ \\
\hline Поведенческий CQ & 637 & 4.81 & 0.99 & 0.77 & $0.21^{* *}$ & $0.35^{* *}$ & $0.20^{* *}$ & $0.59^{* *}$ \\
\hline $\begin{array}{l}\text { Сколько стран вы посети- } \\
\text { ли за последние 5 лет? }\end{array}$ & 917 & 2.47 & 20.15 & - & $0.11^{* *}$ & $0.11^{* *}$ & 0.12 & $0.11^{* *}$ \\
\hline
\end{tabular}

** $p<0.01$.

Примечание. Здесь и далее: МСт - Межкультурная стабильность; МИ - Межкультурный интерес; ОЭЦ - Отсутствие этноцентризма; УМВ - Управление межкультурным взаимодействием.

Таблица 5

Средние значения показателей Интегративного опросника межкультурной компетентности в связи с ответами на вопросы - маркеры межкультурных достижений (ANOVA)

\begin{tabular}{|l|c|c|c|c|c|c|c|c|c|}
\hline \multirow{2}{*}{ Вопросы } & \multirow{2}{*}{ Ответы } & \multicolumn{2}{c|}{ МСт } & \multicolumn{2}{c|}{ МИ } & \multicolumn{2}{c|}{ ОЭЦ } & \multicolumn{2}{c|}{ УМВ } \\
\cline { 3 - 10 } & $\mathrm{M}$ & $\mathrm{SD}$ & $\mathrm{M}$ & $\mathrm{SD}$ & $\mathrm{M}$ & $\mathrm{SD}$ & $\mathrm{M}$ & $\mathrm{SD}$ \\
\hline $\begin{array}{l}\text { У вас есть успеш- } \\
\text { ный опыт жизни/ } \\
\text { учебы/работы за } \\
\text { рубежом? }\end{array}$ & Да & $1.80^{*}$ & 0.80 & $4.19^{* *}$ & 0.65 & 3.15 & 0.66 & $3.90^{* *}$ & 0.58 \\
\cline { 2 - 11 } & Нет & 1.70 & 0.66 & 3.96 & 0.75 & 3.12 & 0.63 & 3.80 & 0.58 \\
\hline $\begin{array}{l}\text { У вас много друзей } \\
\text { из другой культуры? }\end{array}$ & Да & $3.33^{* *}$ & 0.71 & $4.25^{* *}$ & 0.62 & $3.23^{* *}$ & 0.63 & $3.92^{* *}$ & 0.58 \\
\hline $\begin{array}{l}\text { Сколькими языками } \\
\text { вы владеете? }\end{array}$ & 3.19 & 0.72 & 3.82 & 0.77 & 3.02 & 0.64 & 3.75 & 0.57 \\
\cline { 2 - 11 } & 2 & 3.11 & 0.60 & $3.90^{*}$ & 0.78 & 3.12 & 0.56 & 3.77 & 0.52 \\
\cline { 2 - 11 } & 3 & $3.33^{* *}$ & 0.85 & 4.15 & 0.69 & 3.09 & 0.71 & 3.85 & 0.59 \\
\hline
\end{tabular}

${ }^{*} p<0.05,{ }^{* *} p<0.01$.

Все шкалы Интегративного опросника межкультурной компетентности отрицательно связаны с эмоциональным выгоранием учителя от межкультурного взаимодействия. Самоэффективность учителя в работе с детьми-мигрантами связана со шкалой «Управление межкультурным взаимодействием».

У педагогов высшей школы ощущение их самоэффективности при работе с иностранными студентами связано с самооценкой управления межкультурным взаимодействием, а также с межкультурным интересом. Эмоциональное выгорание преподавателей вузов от межкультурного общения связано со шкалами «Межкультурная стабильность» и «Межкультурный интерес». 
Таблица 6

Корреляции между показателями Интегративного опросника межкультурной компетентности и методиками проверки внешней валидности у иностранных студентов и педагогов

\begin{tabular}{|l|c|c|c|c|c|c|c|c|}
\hline \multicolumn{1}{|c|}{ Шкалы методик } & $\mathbf{n}$ & $\mathbf{M}$ & $\mathbf{S D}$ & $\boldsymbol{\alpha}$ & $\mathbf{M C т}$ & $\mathbf{M И}$ & ОЭЦ & УМВ \\
\hline $\begin{array}{l}\text { Психологическая } \\
\text { адаптация }\end{array}$ & 156 & 3.65 & 0.58 & 0.84 & 0.12 & $0.36^{* *}$ & 0.10 & $0.42^{* *}$ \\
\hline $\begin{array}{l}\text { Социокультурная } \\
\text { адаптация }\end{array}$ & 156 & 2.84 & 0.65 & 0.92 & $0.48^{* *}$ & $0.30^{* *}$ & $0.49^{* *}$ & $0.37^{* *}$ \\
\hline $\begin{array}{l}\text { Эмоциональное } \\
\text { выгорание учителя } \\
\begin{array}{l}\text { от межкультурного } \\
\text { взаимодействия }\end{array}\end{array}$ & 53 & 2.29 & 0.61 & 0.73 & $-0.48^{* *}$ & $-0.49^{* *}$ & $-0.54^{* *}$ & $-0.47^{* *}$ \\
\hline $\begin{array}{l}\text { Самоэффективность } \\
\text { учителя в работе с } \\
\text { детьми-мигрантами }\end{array}$ & 53 & 3.93 & 0.48 & 0.83 & 0.09 & 0.10 & -0.06 & $0.32^{*}$ \\
\hline $\begin{array}{l}\text { Эмоциональное } \\
\text { выгорание педагога } \\
\text { вуза от межкультур- } \\
\text { ного взаимодействия }\end{array}$ & 94 & 2.19 & 0.52 & 0.72 & $-0.39 * *$ & $-0.32^{* *}$ & -0.12 & -0.18 \\
\hline $\begin{array}{l}\text { Самоэффективность } \\
\text { педагога вуза в рабо- } \\
\text { те с иностранными } \\
\text { студентами }\end{array}$ & 94 & 3.90 & 0.53 & 0.79 & 0.14 & $0.43^{* *}$ & 0.04 & $0.48^{* *}$ \\
\hline
\end{tabular}

${ }^{*} p<0.05,{ }^{* *} p<0.01$.

\section{Обсуждение}

В данном исследовании была описана процедура разработки методики «Интегративный опросник межкультурной компетентности», проанализированы ее структура и валидность.

Было показано, что настоящая методика включает четыре субшкалы, отражающие различные аспекты межкультурной компетентности, понимаемой как способность личности эффективно функционировать при общении с представителями различных культур и в разных культурных средах (Whaley, Davis, 2007). Таким образом, эмпирическое подтверждение было найдено только по четырем из теоретически обоснованных девяти шкал интегративного измерения межкультурной компетентности. Возможно, это связано с тем, что данные шкалы также дублировали друг друга. Отчасти этот факт подтверждается тем, что в шкалу «Отсутствие этноцентризма» было введено одно суждение, сгенерированное для шкалы «Межкультурная открытость», что существенно улучшило психометрические показатели опросника. С другой стороны, нельзя исключить вероятность культурной специфичности определенных измерений межкультурной компетентности, выявленных в одной 
культурной среде, но не обнаруженных в российской выборке. Кроме того, вероятно, данный результат мог быть следствием сознательно выбранного авторского подхода. Как было отмечено, все аспекты теоретической модели межкультурной компетентности были сформулированы как культурно-специфические (например, «толерантность к межкультурной неопределенности»). В соответствии с этим сгенерированы и пункты опросника. Однако вполне вероятно, что некоторые составляющие, включаемые авторами в межкультурную компетентность, не являются специфичными по отношению к ней и не могут быть измерены применительно только к ситуации межкультурного общения. Так, толерантность к неопределенности, по всей видимости, неэффективно измерять исключительно в межкультурном контексте, а лучше использовать устоявшиеся универсальные методы ее оценки. Таким образом, можно говорить, что эмпирически подтвержденные четыре шкалы опросника отражают четыре специфических компонента межкультурной компетентности, имеющих отношение непосредственно к межкультурному общению.

Выявленные корреляции всех шкал Интегративного опросника межкультурной компетентности со всеми компонентами культурного интеллекта CQ показывают сопоставимость измеряемых конструктов. Определение культурного интеллекта как «способности индивида эффективно функционировать и взаимодействовать в ситуациях, характеризующихся культурным многообразием» (Солдатова и др., 2018, с. 512), по сути, соответствует определению межкультурной компетентности, используемому в исследовании. Однако схожесть в данном случае не обязательно свидетельствует о прямом соответствии, так как данные определения построены путем обозначения результата - эффективного функционирования в межкультурной среде. При этом подходы к тому, как и с помощью чего будет обеспечен данный результат, могут быть разные, что и подтверждается разной выраженностью взаимных корреляций двух методик.

Наиболее выражены взаимосвязи $(r \geqslant 0.5)$ шкалы «Управление межкультурным взаимодействием» со всеми компонентами CQ, кроме Когнитивного и шкалы «Межкультурный интерес» с Мотивационным CQ. «Интегративный опросник межкультурной компетентности» не включает знаниевого компонента. Этим объясняются более низкие корреляции его шкал с Когнитивным компонентом CQ, включающим в себя общие и контекстные знания о культурных системах. Согласно современным подходам к психологии способностей, знания являются не их составляющими, а скорее средством, условием их реализации (Шадриков, 2010). С нашей точки зрения, использование знаниевого компонента в измерении межкультурных способностей эффективно только в формате теста ситуационных суждений (Личутина, 2017), когда знания неразрывно связаны с реализацией их на практике в конкретном выборе. В области межкультурной компетентности такая задача может быть реализована в формате культурного ассимилятора (Bhawuk, 2001), используемого отдельными специалистами для измерения межкультурной компетентности (Bartel-Radic, Giannelloni, 2017; Schnabel et al., 2015).

B наибольшей степени со шкалами Интегративного опросника межкультурной компетентности связан Мотивационный $\mathrm{CQ}$, включающий интерес к 
межкультурному разнообразию, представление о возможной выгоде от межкультурного общения и уверенность в собственной эффективности в кросскультурной среде. По содержанию конструкта Мотивационный $\mathrm{CQ}$ тесно пересекается со шкалами интегративной модели межкультурной компетентности, вошедшими в опросник, что и обуславливает их взаимосвязь.

Метакогнитивный CQ (планирование, осознание и контроль над межкультурным общением) и Поведенческий $\mathrm{CQ}$ (гибкость и точность в межкультурном общении) наиболее сильно связаны со шкалой опросника «Управление межкультурным взаимодействием» также по причине высокой содержательной схожести изучаемых конструктов.

В целом можно сказать, что Интегративный опросник межкультурной компетентности является средством измерения, отчасти схожим, а отчасти отличающимся от «Расширенной шкалы культурного интеллекта». Основная специфика изучаемого опросника связана со шкалами «Отсутствие этноцентризма» и «Межкультурная стабильность», а схожесть - со шкалой «Управление межкультурным взаимодействием».

Выявлено, что люди, демонстрирующие более высокие показатели по ряду шкал опросника, отличаются большим количеством конкретных межкультурных достижений: у них больше друзей, принадлежащих другой культуре, они знают больше иностранных языков и с большей вероятностью имеют успешный опыт жизни, учебы или работы за рубежом. Наибольший вклад в достижение данных результатов вносят «Межкультурная стабильность» и «Межкультурный интерес», т.е. сочетание позитивного настроя на межкультурное общение со стрессоустойчивостью в межкультурном взаимодействии.

Взаимосвязи шкал опросника с показателями адаптации иностранных студентов носят предсказуемый характер. Социокультурная адаптация у мигрантов (в том числе и иностранных студентов) зависит от степени их включенности в контакты с представителями принимающей культуры и межгрупповых установок (Лебедева, 2009). Высокий уровень межкультурной компетентности по всем шкалам опросника во многом будет определять количество и качество межкультурных контактов у студента, обучающегося за рубежом.

Психологическая адаптация мигрантов зависит от событий жизни и социальной поддержки (Там же). Наличие высоких показателей по шкале «Межкультурный интерес» свидетельствует о мотивации на принятие иностранными студентами поддержки от представителей принимающей культуры, а шкала «Управление межкультурным взаимодействием» отражает способности индивида эту поддержку получить.

Высокий уровень межкультурной компетентности по всем шкалам опросника связан с более низкой выраженностью эмоционального выгорания. Эмоциональное выгорание определяется как психологический синдром, возникающий в ответ на хронический профессиональный стресс и характеризующийся истощением, отстраненностью от работы и циничным к ней отношением, а также ощущением профессиональной некомпетентности (Maslach et al., 2001). Показано, что отношение педагогов к культурному разнообразию в образовательной среде как к проблеме повышает риски эмоционального 
выгорания от межкультурного взаимодействия, а обозначение культурных различий в образовании как ценности - снижает (Gutentag et al., 2018). Очевидно, что межкультурная компетентность во всех своих аспектах обеспечивает для педагога эффективный барьер на пути эмоционального выгорания.

Самоэффективность педагога при работе в культурно разноообразной среде связана преимущественно со шкалой опросника «Управление межкультурным взаимодействием». Педагог с более высокими показателями по данной шкале отличается развитой способностью к планированию и контролю результатов межкультурной коммуникации. Это не может не приводить его к ощущению собственной способности выполнять требуемые задачи в работе с учащимися другой культуры.

Интегративный опросник межкультурной компетентности является комплексной методикой, интегрирующей ряд показателей межкультурной компетентности, и может быть эффективно использован для исследования предпосылок межкультурной успешности на российских выборках.

При этом необходимо отметить следующие ограничения исследования. Отсутствие метрической инвариантности опросника при сравнении людей разного возраста требует дальнейшего изучения, в том числе и с более узкими возрастными диапазонами. Также необходимы межгрупповые сравнения представителей разных профессиональных сфер.

Кроме того, было найдено эмпирическое подтверждение только четырем из теоретически обоснованных девяти шкал измерения межкультурной компетентности. Возможно, это связано с недоработками в процессе генерации пунктов опросника и требует использования других подходов для создания шкал, измеряющих данные конструкты.

\section{Литература}

Гриценко, В. В., Павлова, О. С., Ткаченко, Н. В., Усубян, Ш. А., Хухлаев, О. Е., Шорохова, В. А. (2020). Анализ зарубежных эмпирических моделей межкультурной компетентности и методик для ее оценки. Современная зарубежная психология, 1(9), 103-113. doi:10.17759/jmfp.2020090111

Ларин, Н. А. (2017). Феномен эмоционального выгорания при межкультурном взаимодействии. Психология и психотехника, 3, 1-9. Режим доступа: https://nbpublish.com/library_read_article.php?id=23962

Лебедева, Н. М. (2009). Теоретические подходы к исследованию взаимных установок и стратегий межкультурного взаимодействия мигрантов и населения России. В кн. Н. М. Лебедева, А. Н. Татарко (ред.), Стратегии межкультурного взаимодействия мигрантов и населения России (с. 10-62). М.: РУДН.

Лебедева, Н. М., Татарко, А. Н. (ред.). (2009). Стратегии межкультурного взаимодействия мигрантов и населения России. М.: РУДН.

Личутина, Э. И. (2017). Тест ситуативных суждений как метод диагностики решений профессиональных проблем. Экономика и менеджмет инноващионных технологий, 1. Режим доступа: http://ekonomika.snauka.ru/2017/01/13784 
Солдатова, Г. У., Чигарькова, С. В., Рассказова, Е. И. (2018). Апробация русскоязычной версии расширенной шкалы культурного интеллекта. Психология. Журнал Высшей школь экономи$\kappa и, 3(15), 510-526$.

Хухлаев, О. Е., Чибисова, М. Ю. (2010). Теоретические и практические вопросы межкультурной коммуникации: современные тенденции. Психологическая наука и образование, 5(2). Режим доступа: http://psyjournals.ru/psyedu_ru/2010/n5/Huhlaev_Chibisova.shtml

Шадриков, В. Д. (2010). Вопросы психологической теории способностей. Психология. Журнал Высшей школь экономики, 3(7), 41-56.

Ссылки на зарубежные источники см. в разделе References после англоязычного блока.

\section{Интегративный опросник межкультурной компетентности}

Приложение

Просим ответить на несколько вопросов, касающихся вашего общения с людьми других культур. Это могут быть иностранцы, люди других национальностей и/или этнических групп. Людей других культур мы встречаем, не только оказавшись за рубежом; в нашей многонациональной стране каждый ежедневно имеет возможность общаться с ними.

Оцените, насколько вы согласны с каждым утверждением.

\begin{tabular}{|c|c|c|c|c|}
\hline $\begin{array}{c}\text { Полностью } \\
\text { согласен }\end{array}$ & $\begin{array}{c}\text { Скорее } \\
\text { согласен }\end{array}$ & $\begin{array}{c}\text { В чем-то согласен, } \\
\text { в чем-то нет }\end{array}$ & $\begin{array}{c}\text { Скорее } \\
\text { не согласен }\end{array}$ & $\begin{array}{c}\text { Полностью } \\
\text { не согласен }\end{array}$ \\
\hline 5 & 4 & 3 & 2 & 1 \\
\hline
\end{tabular}

1. Я уверен, что могу эффективно работать с людьми различных культур.

2. Мне нравится общаться с людьми других культур.

3. Я не буду общаться с человеком другой культуры, если он действует, исходя из своих культурных норм.

4.В межкультурном общении я стараюсь принимать во внимание мнение каждой стороны и только потом принимать решение.

5. Когда я общаюсь с людьми другой культуры, нервы у меня напряжены до предела.

6. Если у меня планируется важная встреча с человеком другой культуры, я пытаюсь представить, какие могут быть культурные различия между нами.

7. Мне нравится знакомиться с людьми других культур.

8. Я не буду общаться с человеком другой культуры, если ее традиции мне чужды.

9. Я проверяю правильность моего понимания другой культуры в процессе межкультурного общения.

10. После общения с людьми другой культуры я чувствую себя совершенно разбитым.

11. Есть такие культуры, к которым я испытываю презрение.

12. Мне нравится общаться с людьми другой культуры, которая существенно отличается от моей.

13. Я доверяю только людям моей культуры. 
14. Я корректирую свои представления о другой культуре в процессе взаимодействия с ее носителями.

15. От межкультурного общения я не жду ничего хорошего.

16. Есть такие культуры, среди которых - почти все плохие люди.

17. Я могу преодолевать трудности, возникающие при общении с людьми другой культуры.

18. После общения с человеком другой культуры меня терзает чувство вины.

\section{Ключ:}

Межкультурная стабильность $*$ : 5, 10, 15, 18

Межкультурный интерес: 2, 7, 12

Отсутствие этночентризма* : 3, 8, 11, 13, 16

Управление межкультурным взаимодействием: 1, 4, 6, 9, 14, 17

* Обратная шкала.

Хухлаев Олег Евгеньевич - заведующий кафедрой, кафедра этнопсихологии и психологических проблем поликультурного образования, Московский государственный психологопедагогический университет, кандидат психологических наук.

Сфера научных интересов: кросс-культурная психология, психология межгрупповых отношений, социально-психологический тренинг.

Контакты: huhlaevoe@mgppu.ru

Гриценко Валентина Васильевна - профессор, кафедра этнопсихологии и психологических проблем поликультурного образования, Московский государственный психологопедагогический университет, доктор психологических наук.

Сфера научных интересов: кросс-культурная психология, психология миграции, социально-психологическая адаптация.

Контакты: gritsenko2006@yandex.ru

Макарчук Анна Владимировна - программный директор, Федеральный научно-методический центр в области психологии и педагогики толерантности, кандидат психологических наук.

Сфера научных интересов: межкультурный тренинг, психология межкультурной коммуникации, психология и педагогика толерантности.

Контакты: anna.m@tolerancecenter.ru

Павлова Ольга Сергеевна - доцент, кафедра этнопсихологии и психологических проблем поликультурного образования, Московский государственный психолого-педагогический университет, кандидат психологических наук.

Сфера научных интересов: кросс-культурная психология, психология религии, кросс-культурные технологии психологической помощи.

Контакты: os_pavlova@mail.ru

Ткаченко Наталья Владимировна - доцент, кафедра этнопсихологии и психологических проблем поликультурного образования, Московский государственный психолого-педагогический университет, кандидат психологических наук.

Сфера научных интересов: кросс-культурная психология, психология межгрупповых отношений, поликультурное образование, психологическое сопровождение исследовательской деятельности учащихся, полевая этнопсихология.

Контакты: tkachenkonv@mgppu.ru 
Усубян Шушаник Араевна - аспирант, кафедра этнопсихологии и психологических проблем поликультурного образования, Московский государственный психолого-педагогический университет.

Сфера научных интересов: кросс-культурная психология, психология межгрупповых отношений, обучение за рубежом.

Контакты: usubyansha@mgppu.ru

Шорохова Валерия Альбертовна - преподаватель, кафедра этнопсихологии и психологических проблем поликультурного образования, Московский государственный психологопедагогический университет, кандидат психологических наук.

Сфера научных интересов: кросс-культурная психология, психология религии.

Контакты: shorohovava@mgppu.ru

\title{
Development and Adaptation of the Integrative Intercultural Competence Survey
}

\author{
O.E. Khukhlaev ${ }^{a}$, V.V. Gritsenko ${ }^{a}$, A.V. Makarchuk ${ }^{b}$, O.S. Pavlova ${ }^{a}$, N.V. Tkachenko ${ }^{a}$, \\ Sh.A. Usubian ${ }^{a}$, V.A. Shorokhova ${ }^{a}$
}

\begin{abstract}
${ }^{a}$ Moscow State University of Psychology and Education, 29 Sretenka Str., Moscow, 127051, Russian Federation

${ }^{b}$ Federal research and methodology center for tolerance psychology and education, 11 Obraztsova Str., Moscore, 127055, Russian Federation
\end{abstract}

\begin{abstract}
The paper presents the development and the results of testing a new tool Integrative Intercultural Competency Questionnaire, aimed at studying the ability to function effectively in an intercultural communication context. The questionnaire was created on the basis of the integration of 52 constructs from 14 methods for measuring intercultural competence. The research $(\mathrm{N}=1024)$ revealed that the tool contains four subscales: Intercultural Stability (individual personality characteristics that allow a person to be resistant to stressful situations of intercultural communication), Intercultural Interest (desire to communicate with people from other cultures, interest in culture and cultural differences), Lack of Ethnocentrism (respect and acceptance of cultural diversity) and Management of Intercultural Interaction (wide range of communication skills, important for intercultural communication). The subscales have good internal consistency and invariance with some limitations in comparing people of different ages. The research also demonstrated the external validity of the tool. The subscales of the Integrative Intercultural Competency Questionnaire are positively associated with the Extended Cultural Intelligence Scale. People who demonstrate higher rates on individual scales of the questionnaire are distinguished by a large number of specific intercultural achievements. Correlations of the subscales with indicators of adaptation of foreign students, emotional burnout, and self-efficacy among teachers working in a multicultural environment are observed.
\end{abstract}

Keywords: intercultural competence, intercultural communication, cultural intelligence. 


\section{References}

Ang, S., Van Dyne, L., \& Koh, C. (2006). Personality correlates of the four-factor model of cultural intelligence. Group and Organization Management, 31, 100-123. doi:10.1177/1059601105275267

Bartel-Radic, A., \& Giannelloni, J. L. (2017). A renewed perspective on the measurement of cross-cultural competence: an approach through personality traits and cross-cultural knowledge. European Management Journal, 35(5), 632-644. doi:10.1016/j.emj.2017.02.003

Bhawuk, D. P. S. (2001). Evolution of culture assimilators: Toward theory-based assimilators. International Journal of Intercultural Relations, 25(2), 141-163.

Bird, A., Mendenhall, M., Stevens, M., \& Oddou, G. (2010). Defining the content domain of intercultural competence for global leaders. Journal of Managerial Psychology, 25(8), 810-828.

Cheung, G., \& Rensvold, R. (2002). Evaluating Goodness-of-Fit Indexes for testing measurement invariance. Structural Equation Modeling, 9(2), 233-255.

Dollwet, M., \& Reichard R. (2014). Assessing cross-cultural skills: validation of a new measure of cross-cultural psychological capital. The International Journal of Human Resource Management, 25(12), 1669-1696.

Earley, P. S., \& Ang, S. (2003). Cultural intelligence: individual interactions across cultures. Palo Alto, CA: Stanford University Press.

Gritsenko, V. V., Pavlova, O. S., Tkachenko, N. V., Usubian, Sh. A., Khukhlaev, O. E., \& Shorohova, V. A. (2020). Analysis of foreign empirical models of intercultural competence and methods for its evaluation. Sovremennaya Zarubezhnaya Psihologiya [Journal of Modern Foreign Psychology], 1(9), 103-113. doi:10.17759/jmfp.2020090111 (in Russian)

Gutentag, T., Horenczyk, G., \& Tatar, M. (2018). Teachers' approaches toward cultural diversity predict diversity-related burnout and self-efficacy. Journal of Teacher Education, 69(4), 408-419.

Hu, L., \& Bentler, P. M. (1999). Cutoff criteria for fit indexes in covariance structure analysis: Conventional criteria versus new alternatives. Structural Equation Modeling: A Multidisciplinary Journal, 6(1), 1-55. doi:10.1080/10705519909540118

Khukhlaev, O. E., \& Chibisova, M. Yu. (2010). Theoretical and practical issues of intercultural communication: contemporary trends. Psikhologicheskaya Nauka i Obrazovanie psyedu.ru [Psychological Science and Education psyedu.ru], 2(5). Retrieved from http://psyjournals.ru/psyedu_ru/2010/n5/Huhlaev_Chibisova.shtml (in Russian)

Khukhlaev, O. E., Gritsenko, V. V., Pavlova, O. S., Tkachenko, N. V., Usubyan, Sh. A., \& Shorohova, V. A. (2020). Comprehensive model of intercultural competence: theoretical substantiation. RUDN Journal of Psychology and Pedagogics, 1(17), 13-28. doi:10.22363/2313-1683-2020-17-1-13-28

Larin, N. A. (2017). Fenomen emocional'nogo vygoraniya pri mezhkul'turnom vzaimodejstvi [The phenomenon of emotional burnout during intercultural interacti]. Psihologiya i Psihotekhnika, 3, 1-9. Retrieved from https://nbpublish.com/library_read_article.php?id=23962 (in Russian)

Lebedeva, N. M. (2009). Teoreticheskie podhody k issledovaniyu vzaimnyh ustanovok i strategij mezhkul'turnogo vzaimodejstviya migrantov i naseleniya Rossii [Theoretical approaches to the study of mutual attitudes and strategies for intercultural interaction of migrants and the population of Russia]. In N. M. Lebedeva \& A. N. Tatarko (Eds.), Strategii mezhkul'turnogo vzaimodeistviya migrantov $i$ naseleniya Rossii [Strategies for intercultural interaction between migrants and the population of Russia] (pp. 10-62). Moscow: RUDN University. (in Russian) 
Lebedeva, N. M., \& Tatarko, A. N. (Eds.). (2009). Strategii mezhkul'turnogo vzaimodeistviya migrantov inaseleniya Rossii [Strategies for intercultural interaction between migrants and the population of Russia]. Moscow: RUDN University. (in Russian)

Leung, K., Ang, S., \& Tan, M. L. (2014). Intercultural competence. The Annual Review of Organizational Psychology and Organizational Behavior, 1, 489-519.

Lichutina, E. I. (2017). Situational judgments test. Ekonomika i menedzhment innovatsionnykh tekhnologii [Economics and Innovations Management], 1. Retrieved from http://ekonomika.snauka.ru/en/2017/01/13784 (in Russian)

Marsh, H. W., Balla, J. R., \& McDonald, R. P. (1988). Goodness of fit indexes in confirmatory factor analysis: The effect of sample size. Psychological Bulletin, 103, 391-410.

Maslach, C., Schaufeli, W. B., \& Leiter, M. P. (2001). Job burnout. Annual Review of Psychology, 52, 397-422. doi:10.1146/annurev.psych.52.1.397

Matsumoto, D., \& Hwang, H.C. (2013). Assessing cross-cultural competence: a review of available tests. Journal of Cross-Cultural Psychology, 44, 849-873.

Matsumoto, D., Leroux, J., Ratzlaff, C., Tatani, H., Uchida, H., Kim, C. \& Arak, S. (2001). Development and validation of a measure of intercultural adjustment potential in Japanese sojourners: The Intercultural Adjustment Potential Scale (ICAPS). International Journal of Intercultural Relations. 25, 483-510.

MIRIPS (Mutual Intercultural Relations in Plural Societies). (n.d.). Retrieved from http://www.victoria.ac.nz/cacr/research/mirips

Schnabel, D., Kelava, A., Van de Vijver, F., \& Seifert, L. (2015). Examining psychometric properties, measurement invariance, and construct validity of a short version of the Test to Measure Intercultural Competence (TMIC-S) in Germany and Brazil. International Journal of Intercultural Relations, 49, 137-155.

Shadrikov, V. D. (2010). The problems of psychological theory of abilities. Psychology. Journal of the Higher School of Economics, 3(7), 41-56. (in Russian)

Soldatova, G. U., Chigarkova, S. V., \& Rasskazova, E. I. (2018). Approbation of Expanded Cultural Intelligence Scale in Russian. Psychology. Journal of the Higher School of Economic, 3(15), 510526. (in Russian)

Tatar, M., Ben-Uri, I., \& Horenczyk, G. (2011). Assimilation attitudes predict lower immigrationrelated self-efficacy among Israeli immigrant teachers. European Journal of Psychology of Education, 26, 247-255.

Tatar, M., \& Horenczyk, G. (2003). Diversity-related burnoutamong teachers. Teaching and Teacher Education, 19, 397-408.

Van der Zee, K., \& Brinkmann, U. (2004). Construct validity evidence for the intercultural readiness check against the Multicultural Personality Questionnaire. International Journal of Selection and Assessment, 12(3), 285-290.

Van Der Zee, K. I., \& Van Oudenhoven, J. P. (2000). The Multicultural Personality Questionnaire: A multidimensional instrument of multicultural effectiveness. European Journal of Personality, 14(4), 291-309.

Van der Zee, K. I., \& Van Oudenhoven, J. P. (2001). The Multicultural Personality Questionnaire: Reliability and validity of self- and other ratings of multicultural effectiveness. Journal of Research in Personality, 35, 278-288.

Whaley, A. L, \& Davis, K. E. (2007). Cultural competence and evidence-based practice in mental health services: a complementary perspective. American Psychologist, 62, 563-574. 
Oleg E. Khukhlaev - Head of the department, Department of Cross-cultural Psychology and Multicultural Education, Moscow State University of Psychology \& Education, PhD in Psychology.

Research Area: cross-cultural psychology, intergroup relations, social-psychological training.

E-mail: huhlaevoe@mgppu.ru

Valentina V. Gritsenko - Professor, Department of Cross-cultural Psychology and Multicultural Education, Moscow State University of Psychology \& Education, DSc in Social Psychology.

Research Area: cross-cultural psychology, psychology of migration, socio-psychological adaptation.

E-mail: gritsenko2006@yandex.ru

Anna V. Makarchuk - Program Director, Federal research and methodology center for tolerance psychology and education, $\mathrm{PhD}$ in Psychology.

Research Area: intercultural training, psychology of the intercultural communication, tolerance psychology and education.

E-mail: anna.m@tolerancecenter.ru

Olga S. Pavlova - Associate Professor, Department of Cross-cultural Psychology and Multicultural Education, Moscow State University of Psychology \& Education, PhD in Psychology.

Research Area: cross-cultural psychology, psychology of religion, cross-cultural technology of psychological assistance.

E-mail: os_pavlova@mail.ru

Natalia V. Tkachenko - Associate Professor, Department of Cross-cultural Psychology and Multicultural Education, Moscow State University of Psychology \& Education, PhD in Psychology.

Research Area: cross-cultural psychology, intergroup relations, multicultural education, psychological assistance of young researchers, field ethnopsychology.

E-mail: tkachenkonv@mgppu.ru

Shushanik A. Usubian - PhD student, Department of Cross-cultural Psychology and Multicultural Education, Moscow State University of Psychology \& Education.

Research Area: cross-cultural psychology, psychology of intergroup relations, study abroad.

Contacts: usubyansha@mgppu.ru

Valeria A. Shorokhova - Senior Lecturer, Department of Cross-cultural Psychology and Multicultural Education, Moscow State University of Psychology \& Education.

Research Area: cross-cultural psychology, psychology of religion.

E-mail: shorohovava@mgppu.ru 
Психология. Журнал Высшей школы экономики.

2021. T. 18. № 1. C. 92-108. DOI: 10.17323/1813-8918-2021-1-92-108

\title{
МОТИВЫ ИННОВАТОРОВ В ОБРАЗОВАНИИ: ПОДХОДЫ К ОПРЕДЕЛЕНИЮ И РАЗРАБОТКА ШКАЛЫ ДЛЯ ИЗМЕРЕНИЯ
}

\author{
Т.Е. ХАВЕНСОН ${ }^{\mathrm{a}}$, А.А. ЛУКИНА \\ ${ }^{a}$ Национальный исследовательский университет «Высшая школа экономики», 101000, Россия, \\ Москва, ул. Мясниикая, д. 20
}

\section{Резюме}

Причины, по которым внутри и вне системы образования появляются инновации, способные существенно изменить или улучшить традиционно закрытую сферу, активно изучаются в последние десятилетия. Однако ощущается дефицит разработанных методик для измерения мотивации внешних и внутренних акторов создавать инновационные проекты. В статье описываются подходы к измерению самого конструкта «мотивация инновационной деятельности» и результаты адаптации инструмента для измерения мотивов создания инновационных проектов в сфере образования. За основу была взята англоязычная шкала «Причины основания бизнеса» (PSED). В рамках исследования шкала была переведена на русский язык, адаптирована для группы инноваторов в образовании и валидизирована с использованием классического подхода, сочетающего методологию разведывательного и конфирматорного факторного анализа (РФА и КФА), а также дополнительную оценку внутренней согласованности выявленных подшкал, сравнение оригинальной англоязычной и русскоязычной версий, содержательную интерпретацию каждой подшкалы. Адаптация шкалы проводилась на выборке инноваторов в сфере образования - участников Конкурса инноваций в образовании $(\mathrm{N}=286)$. Итоговая шкала включает 16 суждений и позволяет оценить выраженность четырех мотивационных установок начала инновационной деятельности: «Значимость для общества», «Инновации и креативность», «Самореализация и достижение» и «Финансы и независимость». Выявленные мотивы отражают определенные стремления и цели инноваторов, задавая содержание и направленность их образовательных проектов. Предлагаемый инструмент может быть использован в исследовательских и практических целях для изучения мотивации проактивных акторов в образовании, а также близких групп, вовлеченных в развитие социально-значимых сфер. Полная версия итоговой методики приведена в Приложении к статье, содержит инструкции для респондентов и правила подсчета баллов по 4 подшкалам.

Ключевые слова: мотивация к инновациям, PSED, адаптация методики, измерение мотивов инновационной деятельности.

\section{Введение}

Современные тренды развития общества, экономики и, как следствие, системы образования вызывают необходимость существенных изменений образовательных институтов. Важную роль в этом процессе приобретают

Публикация подготовлена при поддержке РФФИ, проект № 17-03-00837. 
индивидуальные игроки образовательного поля, именуемые также «низовыми инноваторами» (от англ. grassroots - низовой, массовый),- это люди, которые создают собственные независимые проекты, отталкиваясь от проблем и вопросов, возникающих в локальном контексте (OECD, 2014; Seyfang, Smith, 2007; Shirley, 2017; Кузьминов, Фрумин, 2018). Низовые инновации (или инновации снизу) обладают большим потенциалом для трансформации социальных институтов, поскольку способны оперативно реагировать на актуальные вызовы, заполнять существующие дефициты (Phelps, 2018) и изменять общепринятые нормы и практики (Battilana et al., 2009).

В России, несмотря на закрытость системы образования, низовые инновации пронизывают разные сферы образования, включая все ступени формального и сегменты дополнительного образования (Королева и др., 2017). Проекты возникают как внутри системы - их создают учителя, директора школ, преподаватели вузов и др., - так и за ее пределами (через деятельность родителей, студентов, предпринимателей). Их появление - это индикатор активности на местах и формирования поля новых перспективных разработок в сфере образования, направленных на обновление системы.

Важной характеристикой низовых инноваций является личная мотивация инноваторов: в отличие от формальной рабочей или учебной ситуации, которая предполагает превалирование интересов организации над индивидуальными целями, низовые инновации создаются добровольно и целиком зависят от их создателя, что открывает возможности для реализации многообразия мотивационных установок (Хавенсон и др., 2018). От мотивации инноваторов во многом зависят направленность и содержание низовых инноваций (Elfving, 2008; Jones et al., 2021), которые, в свою очередь, формируют ландшафт современного образования и задают направление его дальнейшего развития. В целом социально-психологический портрет инноватора, важным компонентом которого является мотивация, играет ключевую роль для проектов на ранней стадии развития (Frese, Gielnik, 2014). В этой связи мотивационные установки низовых инноваторов становятся важным объектом для изучения. Понимание этих установок позволит учитывать их в современной образовательной политике, разрабатывать релевантные механизмы их поддержки и в целом формировать среду, необходимую для развития инноваций. Необходимость изучения мотивации низовых инноваторов предполагает разработку соответствующих методик, учитывающих особенности этой группы.

Целью настоящего исследования является разработка методики для изучения мотивации инноваторов в сфере образования. Для этого была осуществлена адаптация шкалы «Причины начала бизнес-проектов», созданной в рамках американского исследования динамики предпринимательства (Panel Study of Entrepreneurial Dynamics, PSED; Carter et al., 2004). В отличие от других методик, направленных на измерение предпринимательских намерений (Ajzen, 1991; Shapero, Sokol, 1982), степени детерминированности деятельности и соотношения внутренней и внешней мотивации (Deci, Ryan, 1985), данный инструмент позволяет изучить содержательные аспекты мотивации инноваторов через измерение конкретной направленности их деятельности. 
Отдельные элементы опросника PSED часто применяются в современных исследованиях, апробированы и валидизированы для разных стран. В частности, они использовались для идентификации социальных предпринимателей (Quigley et al., 2015), изучения предпринимательских намерений студентов (Богатырева, Широкова, 2017) и мотивации социальных предпринимателей (Xu et al., 2014). Однако именно мотивационная компонента опросника PSED не валидизирована и не переведена на русский язык.

\section{Обзор подходов к измерению мотивов начала новых проектов}

В отсутствие необходимых измерительных инструментов, адаптированных для инноваторов в сфере образования, представляется релевантным рассмотреть ключевые подходы к измерению мотивов в психологии и предпринимательских исследованиях, поскольку инновационная деятельность в образовании может считаться частным случаем предпринимательской активности (Attali, Yemini, 2017).

В работах по изучению мотивации превалирует теория самодетерминации (self-determination theory) (Deci, Ryan, 1985), согласно которой мотивация варьируется по степени самостоятельности и независимости поведения. Опорными точками на этом континууме выступают три типа мотивации: внутренняя, внешняя мотивация и амотивация. Эта теория позволяет определить степень интернализации мотивации и режим регуляции действий, однако не учитывает конкретной направленности поведения, его содержательных причин.

В литературе по проблемам предпринимательства начало деятельности также изучается с точки зрения внешней и внутренней мотивации. В этой связи можно выделить две традиции: теории побуждения (drive theories) и теории поощрения (incentive theories) (Carsrud, Brännback, 2011). Теории побуждения исходят из того, что ключевым драйвером начала собственного бизнес-проекта является внутренняя потребность (например, достижения или независимости). Теории поощрения, напротив, рассматривают предпринимательскую активность как мотивированную возможным вознаграждением (доход, мобильность, престиж).

Однако последние исследования указывают на необходимость сочетать эти подходы, оставляя позади традицию одностороннего рассмотрения мотивации, поскольку бизнес-активность часто мотивирована сочетанием целей и имеет сразу несколько направлений (Caringal-Go, Hechanova, 2018; Ganguli et al., 2018; Перикова и др., 2020). Как показывают исследования, деятельность социальных предпринимателей мотивирована комбинацией экономических и неэкономических причин, причем ключевая роль отводится последним (Douglas, Prentice, 2019; Seelos, Mair, 2005; Zahra et al., 2009).

Близким направлением исследований бизнес-мотивации является изучение предпринимательских намерений: индивидуальных факторов, предшествующих решению открыть свое дело. Традиционными считаются две объяснительные модели: теория намеренного поведения (Theory of Planned 
Behavior; Ajzen, 1991, 2002) и модель предпринимательских намерений (Entrepreneurial Intentions Model; Shapero, Sokol, 1982). С точки зрения первой, интенция начать какую-либо деятельность (в том числе собственный бизнес) определяется следующими индивидуальными факторами: а) установками по отношению к деятельности (ожидаемые результаты); б) субъективными нормами (роль социального окружения при принятии решения); в) воспринимаемым контролем над деятельностью (perceived behavioral control оценка способности начать деятельность и достичь желаемого результата). Модель предпринимательских намерений предполагает три фактора, определяющих решение начать предпринимательскую деятельность: а) предпочтение предпринимательской деятельности (perceived desirability); б) предрасположенность к действиям (propensity to act); в) вера в осуществимость задуманного проекта (perceived feasibility). По этой теме осуществлен ряд исследований (Teixeira et al., 2018; Широкова и др., 2015; и др.).

Несмотря на распространенность данных подходов, исследователи отмечают необходимость расширения традиционных моделей для изучения предпринимательских намерений и процесса начала предпринимательской деятельности. Обращается внимание на роль целеполагания, мотивации и ценностей акторов в принятии решения о создании бизнеса (Fayolle et al., 2014; Tortia et al., 2020; Schlaegel, Koenig, 2013; Перикова и др., 2020). В частности, внимание к мотивам позволяет приблизиться к изучению связки «намерение-деятельность», поскольку конкретные причины создания проектов задают определенную траекторию их развития, направленность деятельности создателей.

\section{Шкала причин начала бизнес-проекта PSED}

Исходя из необходимости создания методики, учитывающей широкий спектр возможных мотивационных установок и содержательное наполнение инноваций, за основу была взята шкала «Причины начала бизнес-проектов», разработанная в рамках Панельного исследования предпринимательской динамики PSED. Ввиду многообразия возможных причин деятельности, шкала носит интегративный характер: она основана не на конкретной теоретической модели, а на метаанализе эмпирических исследований в сфере предпринимательства (Carter et al., 2004), в результате которого было выделено семь типов мотивов начала предпринимательской деятельности:

1) инновации - стремление создать что-то новое;

2) независимость - намерение быть более свободным и гибким при управлении своим временем;

3) экстернальная валидация - желание общественного признания и потребность в одобрении семьи, друзей и других членов сообщества;

4) роли - стремление продолжать семейные традиции или следовать примеру других;

5) финансовый успех - инструментальная ценность богатства, стремление к материальному благополучию и повышению финансового состояния;

6) самореализация - стремление к личностному росту и самовыражению; 
7) улучшение общества - стремление к социальным изменениям и помощи окружающим.

Каждому из мотивационных типов соответствует ряд суждений (таблица 1).

В связи с метааналитическим способом создания шкалы ее использование и интерпретация результатов в большой степени зависят от цели исследования и особенностей изучаемой группы. Выделенные типы мотивов нередко видоизменяются в зависимости от эмпирического объекта: мотив может складываться из сочетания нескольких типов, которые рассматриваются как отдельные в оригинальной версии шкалы (Quigley et al., 2015). Помимо этого, отсутствие заложенной теоретической модели дает исследователям свободу в плане выбора отдельных индикаторов в зависимости от специфики изучаемой группы (Xu et al., 2014).

\section{Методология}

\section{Прощедура адаптащии шкаль PSED}

Процедура адаптации шкалы проводилась в несколько этапов (Muñiz et al., 2013; International Test Commission, 2017).

1. Перевод вопросника с применением техники двойного перевода.

2. Пилотаж переведенной анкеты. На теоретическом этапе были проведены пять интервью с экспертами, в ходе которых обсуждались релевантность и адекватность формулировок. В роли экспертов выступали исследователи в сфере образования. Затем проводился эмпирический этап пилотирования -

Распределение суждений по группам мотивов в шкале PSED

Таблица 1

\begin{tabular}{|l|l|}
\hline \multicolumn{1}{|c|}{ Название мотива } & \multicolumn{1}{c|}{ Индикаторы } \\
\hline Инновации & $\begin{array}{l}\text { Разработать идею нового продукта или услуги } \\
\text { Быть на передовом крае образовательных технологий } \\
\text { Развить свою личность }\end{array}$ \\
\hline Независимость & $\begin{array}{l}\text { Работать так, как я считаю нужным } \\
\text { Быть более гибким в своем графике работы }\end{array}$ \\
\hline $\begin{array}{l}\text { Экстернальная валида- } \\
\text { ция }\end{array}$ & $\begin{array}{l}\text { Заслужить уважение друзей } \\
\text { Повысить свой статус } \\
\text { Чего-то добиться, получить признание }\end{array}$ \\
\hline Роли & Продолжать семейное дело \\
\hline Финансовый успех & $\begin{array}{l}\text { Повысить собственный заработок } \\
\text { Построить бизнес, который смогли бы унаследовать мои дети } \\
\text { Иметь устойчивое финансовое положение, независимость } \\
\text { Стать состоятельным человеком }\end{array}$ \\
\hline Самореализация & $\begin{array}{l}\text { Испытать себя } \\
\text { Реализовать свое личное ви́дение, понимание }\end{array}$ \\
\hline Улучшение общества & $\begin{array}{l}\text { Запустить социальные перемены } \\
\text { Улучшить общество или его часть } \\
\text { Помочь другим людям }\end{array}$ \\
\hline
\end{tabular}


10 когнитивных интервью с инноваторами в образовании, в которых использовались техники пересказа вопроса, размышлений вслух и двойного интервью.

3. Пилотный онлайн-опрос. Он проводился для определения основных паттернов ответов и исключения вопросов, которые получили большое количество средних или однообразных ответов.

4. Основной этап сбора данных (апрель-май 2015). В ходе онлайн-опроса было опрошено 437 участников Конкурса инноваций в образовании (далее КИвО)․․ Тип выборки - невероятностная сплошная стихийная.

Инноваторы в образовании представляют собой широкую общность, включающую сотрудников как образовательных, так и сторонних организаций, что в значительной степени затрудняет поиск универсальных индикаторов их идентификации. В этой связи КИвО представляется удачной платформой для сбора данных, поскольку позволяет однозначно зафиксировать причастность каждого участника к инновационной деятельности в образовании на основании факта его участия в конкурсе. Аналогичный подход был использован в исследованиях инноваторов в областях технологий и спорта (Hellström et al., 2002). Исходя из этого, апробация шкалы на этой группе позволяет обеспечить ее валидность при изучении других представителей генеральной совокупности - акторов, реализующих собственные инициативы в образовательной сфере.

\section{Стратегия анализа мотивационной структурь}

На первом шаге анализа использовались процедуры разведывательного факторного анализа (РФА). С помощью РФА была выявлена мотивационная структура группы инноваторов в образовании, основанная на собранных данных, и оценено соответствие структуры, полученной на российской выборке, структуре, предложенной авторами опросника PSED.

На втором этапе использовался метод конфирматорного факторного анализа (КФА). С помощью КФА была уточнена первоначальная модель, полученная в результате РФА, и статистически подтверждена итоговая мотивационная структура.

\section{Результаты}

\section{Факторная структура русскоязычной версии опросника PSED}

\section{Поиск мотивационной структуры инноваторов с помощью РФА}

В ходе анализа ответов респондентов на вопросы о причинах создания инновационных проектов в ряде суждений было обнаружено значительное

\footnotetext{
${ }^{1}$ КИвО - крупнейший российский отраслевой конкурс инновационных образовательных проектов широкой направленности. Сбор данных проводился в период после окончания приема заявок на конкурс до объявления его результатов путем рассылки опроса на электронные адреса участников. Приглашались все участники без ограничений по количеству человек от одной команды.
} 
количество пропусков. Переменные «Продолжать семейное дело» и «Построить бизнес, который смогли бы унаследовать мои дети» (38 и 25\% пропусков соответственно) были исключены из финальной версии шкалы. Это связано с содержательными моментами: вероятно, суждения оказались нерелевантными деятельности инноваторов и по этой причине вызвали затруднения. РФА методом максимального правдоподобия проводился на выборке заполненных кейсов $(\mathrm{N}=286)$.

Тестировались модели с ортогональным и косоугольным вращением. В качестве итоговой была выбрана четырехфакторная модель с 16 суждениями и косоугольным вращением Promax (таблицы 2, 3). При выборе вращения учитывались как статистические критерии, так и теоретические предположения о

Таблица 2

\section{Статистики модели}

\begin{tabular}{|l|c|}
\hline \multicolumn{1}{|c|}{ Статистика } & Значение \\
\hline КМО & 0.832 \\
\hline Тест сферичности Бартлетта & $\chi^{2}=1579, \mathrm{df}=120, p=0.000$ \\
\hline Процент общей объясненной дисперсии & $59 \%$ \\
\hline
\end{tabular}

Таблица 3

Результаты РФА

\begin{tabular}{|l|c|c|c|c|c|}
\hline \multicolumn{1}{|c|}{ Виды мотивации } & $\mathbf{1}$ & $\mathbf{2}$ & $\mathbf{3}$ & $\mathbf{4}$ & Общность \\
\hline Помочь другим людям & 0.75 & & & & 0.54 \\
\hline Запустить социальные перемены & 0.79 & & & & 0.66 \\
\hline Улучшить общество или его часть & 0.82 & & & & 0.69 \\
\hline Реализовать свое личное ви́дение, понимание & & 0.76 & & & 0.60 \\
\hline Работать так, как я считаю нужным & & 0.68 & & & 0.45 \\
\hline $\begin{array}{l}\text { Быть на передовом крае образовательных } \\
\text { технологий }\end{array}$ & & 0.66 & & & 0.46 \\
\hline Разработать идею нового продукта или услуги & & 0.57 & & & 0.41 \\
\hline Быть более гибким в своем графике работы & & & & 0.48 & 0.47 \\
\hline Повысить собственный заработок & & & & 0.87 & 0.78 \\
\hline $\begin{array}{l}\text { Иметь устойчивое финансовое положение, } \\
\text { независимость }\end{array}$ & & & & 0.89 & 0.78 \\
\hline Стать состоятельным человеком & & & & 0.86 & 0.79 \\
\hline Заслужить уважение друзей & & & 0.75 & & 0.57 \\
\hline Испытать себя & & & 0.71 & & 0.47 \\
\hline Чего-то добиться, получить признание & & & 0.70 & & 0.60 \\
\hline Развить свою личность & & & 0.65 & & 0.50 \\
\hline Повысить свой статус & & & 0.64 & & 0.60 \\
\hline \hline 1. Значимость для общества & - & 0.31 & 0.20 & 0.07 & \\
\hline 2. Инновации и креативность & & - & 0.42 & 0.35 & \\
\hline 3. Самореализация и достижение & & - & 0.48 & \\
\hline 4. Финансы и независимость & & & - & \\
\hline
\end{tabular}


полимотивированности деятельности и, следовательно, коррелированности получаемых факторов.

\section{Подтверждение мотивационной структуры инноваторов с помощью КФА}

Выбранное четырехфакторное решение было протестировано с помощью КФА методом максимального правдоподобия. Первоначальная модель была изменена в соответствии с содержательными и статистическими соображениями (значениями модификационных индексов). Необходимость каждой модификации проверялась тестом на сравнение хи-квадратов двух вложенных моделей.

Добавлены корреляции между всеми мотивами, что значительно улучшило значения всех статистик согласия (модель 1 в таблице 4 и рисунок 1). Это подтверждает корректность выбора косоугольного решения в РФА: создание

Статистики согласия моделей КФА

Таблица 4

\begin{tabular}{|l|c|c|c|}
\hline Статистики согласия & Модель 1 & Модель 2 & Модель 3 \\
\hline$\chi^{2}$ & 210 & 193 & 178 \\
\hline Значимость $\chi^{2}$ & 0.000 & 0.000 & 0.000 \\
\hline $\mathrm{df}$ & 98 & 97 & 96 \\
\hline SRMR & 0.06 & 0.06 & 0.06 \\
\hline CFI & 0.93 & 0.94 & 0.95 \\
\hline TLI & 0.91 & 0.92 & 0.93 \\
\hline RMSEA & 0.06 & 0.06 & 0.06 \\
\hline
\end{tabular}

Итоговая модель КФА

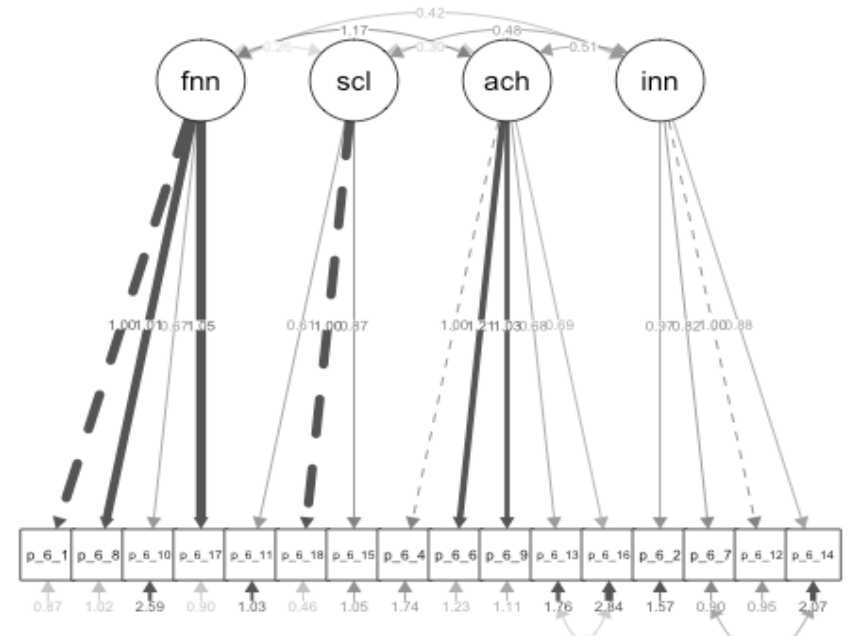


образовательных проектов - полимотивированная деятельность, не заданная одним направлением.

Добавлены корреляции остатков переменных внутри факторов: «Развить свою личность» и «Испытать себя» в факторе «Самореализация и достижение» (модель 2), «Разработать идею нового продукта или услуги» и «Работать так, как я считаю нужным» в факторе «Инновации и креативность» (модель 3). Модель 3 в высокой степени согласуется с данными и была выбрана в качестве итоговой (рисунок 1).

\section{Интерпретация полученных факторов}

Структура шкалы включает четыре фактора, каждый из которых соответствует мотиву создания образовательных проектов: «Значимость для общества», «Инноващии и креативность», «Самореализация и достижение» $и Ф и-$ нансы и независимость». Мотивы отражают определенные стремления и цели инноваторов, задавая содержание и направленность их образовательных проектов. Некоторые факторы обнаруживают высокую корреляцию между собой (таблица 3), однако содержательно каждая группа вопросов интерпретируется как отдельный мотив начала инновационных проектов в образовании.

Выраженность каждого фактора - это усредненное значение входящих в него суждений, которые оценивались респондентами по семибалльной шкале². Середина шкалы, отражающая среднюю выраженность мотива, равняется 3.5.

\section{Мотив «Значимость для общества» (3 суждения)}

Фактор отражает причины создания инновационных проектов, связанные с улучшением жизни окружающих и образовательной системы в целом.

Высокий балл по данному фактору свидетельствует о том, что для инноваторов важно привносить позитивные социальные изменения с помощью своего проекта. Низкий балл отражает низкую значимость просоциальных целей при создании образовательного проекта.

\section{Мотив «Инновачии и креативность» (4 суждения)}

Фактор отражает причины начала проектов, связанные со стремлением и готовностью быть на передовом крае инноваций, предлагать системе образования оригинальные идеи для ее модернизации и задействовать свою креативность в работе над проектом.

Высокий балл по этому фактору свидетельствует о том, что создание проекта рассматривается как способ проявления креативности и инновационности. Низкий балл - о том, что при создании проекта инноватор не руководствуется установкой на принципиальную новизну и творческий характер своей идеи.

\footnotetext{
${ }^{2}$ Мы используем средние значения входящих в фактор суждений вместо предсказанных факторных значений (factor scores) для большей интерпретируемости факторов (Grice, 2001). Расчет корреляций Пирсона показал тесную связь между предсказанными факторными значениями и средними значениями (>0.95).
} 


\section{Мотив «Самореализащия и достижение» (5 суждений)}

Фактор отражает причины создания образовательных проектов, связанные с актуализацией собственного потенциала, повышением статуса, в том числе через общественное признание важности проекта.

Высокий балл свидетельствует о том, что создание проекта связано в том числе с важностью личностного роста и самореализацией для автора проекта. Низкий балл отражает невысокую роль этих целей.

\section{Мотив «Финансы и независимость» (4 суждения)}

Фактор отражает причины создания проектов, связанные с достижением большей личной независимости и материального благополучия.

Высокий балл по данному фактору свидетельствует о том, что при создании проекта инноватор руководствуется стремлением сделать свою жизнь более гибкой и свободной, повысить собственную эффективность и добиться финансовой стабильности. Низкий балл свидетельствует о низкой значимости целей, связанных с повышением материального достатка и достижением независимости.

\section{Факторная структура шкаль PSED в оригинальной (англоязычной) и русскоязычной версиях}

По результатам анализа, мотивационная структура инноваторов в образовании отличается от заложенной в PSED и обнаруженной у группы социальных предпринимателей (Carter et al., 2004; Quigley et al., 2015). Мотив «Значимость для общества» соответствует мотиву улучшения общества в исследовании PSED. Мотив «Инновации и креативность» представляет собой сочетание мотивов инноваций, независимости и самореализации. Мотив «Самореализация и достижение» вобрал элементы мотивов экстернальной валидации, самореализации и инноваций по PSED. Причем два фактора в русскоязычной методике включили в себя сужения из факторов инноваций и самореализации оригинальной методики, они разделились содержательно. В первый фактор «Инновации и креативность» вошли суждения, в большей степени отражающие стремление инноватора проявить свою креативность и быть на передовом крае науки и инноваций. В то время как ко второму «Самореализация и достижение» - в большей степени относятся суждения, отражающие именно стремление к реализации потенциала. Другие суждения в этом факторе относятся к фактору экстернальной валидации, что позволяет дать этому фактору предложенную нами содержательную интерпретацию. Мотив «Финансы и независимость» включает элементы мотивов независимости и финансового успеха. Таким образом, инноваторы в образовании как члены принципиально иной социальной группы характеризуются специфической мотивационной структурой, которая отражает широту направленности их деятельности, несводимой только к предпринимательской. Создание проектов может быть связано как с личностными устремлениями, так и с желанием позитивных изменений на локальном и системном уровнях. 


\section{Проверка надежности опросника}

В дополнение к результатам КФА, надежность полученной структуры была проверена с помощью коэффициента согласованности альфа Кронбаха (таблица 5). Оценка надежности всех переменных одновременно не проводилась, так как подшкалы рассматриваются отдельно друг от друга. Исходя из результатов, факторы «Финансы и независимость», «Самореализация и достижение» и «Значимость для общества» обладают высокой надежностью: суждения внутри каждого из этих факторов хорошо согласованы между собой.

Фактор «Инновации и креативность» имеет более низкое значение. Детальный анализ этой подшкалы показал низкую корреляцию между суждениями «Работать так, как я считаю нужным» (№ 15) и «Разработать идею нового продукта или услуги» (№ 13). Попарные коэффициенты корреляций внутри фактора отражены в таблице 6. Удаление суждения № 15 привело к небольшому увеличению альфы (с 0.59 до 0.61). Тем не менее оно значимо коррелирует с остальными в подшкале. Также результаты факторного анализа методом главных компонент отдельно на четырех суждениях этого фактора свидетельствуют о наибольшей оптимальности однофакторной структуры исходя из критерия Кайзера и из высоких факторных нагрузок всех суждений. Исключение переменной № 15 привело к менее интерпретируемой модели. Учитывая статистические результаты КФА и дополнительных проверок, в целом удовлетворительную величину коэффициента согласованности и содержательную важность суждения, было решено сохранить первоначальное наполнение данного фактора.

Таблица 5

Показатели надежности факторов русскоязычной версии опросника PSED

\begin{tabular}{|c|l|c|}
\hline № шкалы & \multicolumn{1}{|c|}{ Название фактора } & Альфа \\
\hline 1 & Финансы и независимость & 0.84 \\
\hline 2 & Самореализация и достижение & 0.78 \\
\hline 3 & Значимость для общества & 0.72 \\
\hline 4 & Инновации и креативность & 0.59 \\
\hline
\end{tabular}

Таблица 6

Коэффициенты корреляции суждений внутри фактора «Инновации и креативность»

\begin{tabular}{|c|c|c|c|}
\hline № суждения & $\mathbf{1 4}$ & $\mathbf{1 3}$ & $\mathbf{1 6}$ \\
\hline 14 & 1 & $0.313^{* *}$ & $0.340^{* *}$ \\
\hline 13 & $0.313^{* *}$ & 1 & $0.375^{* *}$ \\
\hline 16 & $0.340^{* *}$ & $0.375^{* *}$ & 1 \\
\hline 15 & $0.237^{* *}$ & 0.068 & $0.339^{* *}$ \\
\hline
\end{tabular}

$* * p<0.01$. 


\section{Заключение}

Несмотря на то что мотивация начала низовой инновационной деятельности в образовании, т.е. включения новой группы людей в существующую сферу общественной жизни, является одним из ключевых элементов портрета таких акторов, ощущается дефицит инструментов для измерения их мотивации. Для заполнения этой ниши в ходе исследования была разработана методика изучения мотивации к созданию инновационных проектов в образовании. Она представляет собой шкалу из 16 суждений, каждое из которых соответствует определенным причинам создания собственного проекта. Шкала позволяет оценить выраженность четырех мотивационных установок начала инновационной деятельности: «Значимость для общества», «Инновации и креативность», «Самореализация и достижение» и «Финансы и независимость».

Факторный анализ шкалы, проведенный в рамках классического подхода совмещения методов РФА и КФА, показал, что русскоязычной версии соответствует четырехфакторная структура. Дополнительный анализ оценки внутренней согласованности подшкал (альфа Кронбаха, корреляционный и факторный анализ) показал в целом высокую надежность обнаруженной структуры.

Разработанная методика может использоваться в исследовательских целях для изучения мотивов создания проектов или мотивации участия в деятельности по развитию социально значимых сфер в группах, схожих с инноваторами в образовании: низовых и институциональных инноваторов, социальных предпринимателей, резидентов стартап-акселераторов и т.п.

Кроме решения исследовательских задач, шкала обладает потенциалом прикладного использования. С практической точки зрения методика может применяться лицами, занимающимися разработкой политики в сфере поддержки индивидуальных проектов и создания среды, благоприятной для развития низовых инноваций в образовании и других социальных сферах. Понимание мотивов позволит предлагать диверсифицированные способы поддержки проектов и создания среды в зависимости от выявленной мотивации.

\section{Литература}

Богатырева, К., Широкова, Г. (2017). От предпринимательских намерений - к созданию бизнеса: опыт российских студентов. Форсайт, 11(3), 25-36.

Королева, Д. О., Хавенсон, Т. Е., Андреева, А. А. (2017). Ландиафт образовательных инноваций: содержание и структура. М.: НИУ ВШЭ.

Кузьминов, Я. И., Фрумин, И. Д. (ред.). (2018). Двенадиать решений для нового образования (Доклад Центра стратегических разработок и Высшей школы экономики). М.: НИУ ВШЭ. Режим доступа: https://publications.hse.ru/books/218061780

Перикова, Е. И., Атаманова, И. В., Богомаз, С. А. (2020). Специфика психологической готовности к инновационной деятельности молодежи Санкт-Петербурга и Томска. Science for Education Today, 10(1), 62-78. doi:10.15293/2658-6762.2001.04

Хавенсон, Т. Е., Королева, Д. О., Лукина, А. А. (2018). Акторы образовательных инноваций: Ценности и мотивация. М.: НИУ ВШЭ. Режим доступа: https://publications.hse.ru/books/227119446 
Широкова, Г. В., Цуканова, Т. В., Богатырева, К. А. (2015). Университетская среда и предпринимательская активность студентов: Роль бизнес-опыта и предпринимательской самоэффективности. Вопросы образования, 3, 171-207.

Ссылки на зарубежные источники см. в разделе References после англоязычного блока.

Приложение

Методика измерения мотивов инноваторов в образовании

Ниже приведен список суждений, составляющих опросник, и инструкция, предваряющая вопросы. Суждения должны предъявляться респондентам в случайном порядке.

\section{Инструкция}

Ниже приведена серия утверждений, отражающих различные причины реализации инновационных проектов. В каждом из них есть 7 возможных ответов. Ответы варьируются от 1 - причина совсем не важна до 7 - причина очень важна, 4 - отражает нейтральное отношение. Отметьте, пожалуйста, насколько каждая причина важна лично для вас. Отметьте, пожалуйста, только один вариант, который наиболее точно отражает ваше мнение по отношению к утверждению. Пожалуйста, ответьте на все вопросы.

\begin{tabular}{|c|c|c|c|c|c|c|c|c|}
\hline \multirow[t]{2}{*}{ № } & \multirow[t]{2}{*}{ Утверждение } & \multicolumn{7}{|c|}{$\begin{array}{c}\text { Причина совсем не важна (1) - } \\
\text { причина очень важна (7) }\end{array}$} \\
\hline & & & & & & & & \\
\hline 1. & Чего-то добиться, получить признание & 1 & 2 & 3 & 4 & 5 & 6 & 7 \\
\hline 2. & Развить свою личность & 1 & 2 & 3 & 4 & 5 & 6 & 7 \\
\hline 3. & Заслужить уважение друзей & 1 & 2 & 3 & 4 & 5 & 6 & 7 \\
\hline 4. & Повысить свой статус & 1 & 2 & 3 & 4 & 5 & 6 & 7 \\
\hline \multirow[t]{2}{*}{5.} & Испытать себя & 1 & 2 & 3 & 4 & 5 & 6 & 7 \\
\hline & \multicolumn{8}{|l|}{ Мотив «Финансы и независимость» } \\
\hline 6. & Повысить собственный заработок & 1 & 2 & 3 & 4 & 5 & 6 & 7 \\
\hline 7. & $\begin{array}{l}\text { Иметь устойчивое финансовое положение, } \\
\text { независимость }\end{array}$ & 1 & 2 & 3 & 4 & 5 & 6 & 7 \\
\hline 8. & Быть более гибким в своем графике работы & 1 & 2 & 3 & 4 & 5 & 6 & 7 \\
\hline \multirow[t]{2}{*}{9.} & Стать состоятельным человеком & 1 & 2 & 3 & 4 & 5 & 6 & 7 \\
\hline & \multicolumn{8}{|l|}{ Мотив «Значимость для общества» } \\
\hline 10. & Запустить социальные перемены & 1 & 2 & 3 & 4 & 5 & 6 & 7 \\
\hline 11. & Улучшить общество или его часть & 1 & 2 & 3 & 4 & 5 & 6 & 7 \\
\hline \multirow[t]{2}{*}{12.} & Помочь другим людям & 1 & 2 & 3 & 4 & 5 & 6 & 7 \\
\hline & \multicolumn{8}{|l|}{ Мотив «Инновации и креативность» } \\
\hline 13. & Разработать идею нового продукта или услуги & 1 & 2 & 3 & 4 & 5 & 6 & 7 \\
\hline 14. & Быть на передовом крае образовательных технологий & 1 & 2 & 3 & 4 & 5 & 6 & 7 \\
\hline 15. & Работать так, как я считаю нужным & 1 & 2 & 3 & 4 & 5 & 6 & 7 \\
\hline 16. & Реализовать свое личное ви́дение, понимание & 1 & 2 & 3 & 4 & 5 & 6 & 7 \\
\hline
\end{tabular}




\title{
Подсчет и интерпретация результатов
}

Все утверждения опросника имеют прямую кодировку, поэтому вариант ответа, выбранный респондентом, является его баллом, полученным за соответствующий вопрос (от 1 до 7). Подсчет итоговых баллов происходит отдельно для каждого фактора, поскольку мотивы являются многомерным конструктом: разные мотивы могут иметь разную значимость у одного респондента. Соответственно общий балл по всему опроснику не рассчитывается.

Хавенсон Татьяна Евгеньевна - старший научный сотрудник, лаборатория инноваций в образовании, Институт образования, Национальный исследовательский университет «Высшая школа экономики», $\mathrm{PhD}$ наук об образовании.

Сфера научных интересов: инновации в образовании, измерения в социальных науках,доказательная образовательная политика.

Контакты: tkhavenson@hse.ru

Лукина Анастасия Андреевна - младший научный сотрудник, Центр социологии культуры, Институт образования, Национальный исследовательский университет «Высшая школа экономики».

Сфера научных интересов: измерения в социальных науках, формальные методы изучения культуры, культурсоциология.

Контакты: aalukina@hse.ru

\section{Measuring Motivation for Innovation in Education: Concept Definition and Scale Validation}

\author{
T.E. Khavenson ${ }^{\text {a }}$ A.A. Lukina ${ }^{a}$
}

${ }^{a}$ HSE University, 20 Myasnitskaya Str., Moscow, 101000, Russian Federation

\begin{abstract}
The reasons for innovations inside and outside the education system have attracted much research interest over the past decades. However, there is still a lack of methodological tools to measure motives of actors coming from inside and outside the system to launch their innovative projects. The article describes approaches to measure the construct "motivation for innovative activity," as well as the results of adaptation of the scale aimed at measuring motives for creation of innovative educational projects. The tool is based on the scale, constructed in English, "Reasons to create business projects" (PSED). In this research the scale was translated into Russian, adapted for the group of innovators in education and validated within a classical framework of combining exploratory and confirmatory factor analysis (EFA and CFA, respectively). Additionally, the subscales were evaluated in terms of internal coherence. The Russian and the English version of the scale were compared, and each subscale was interpreted. Adaptation was performed on the sample of innovators in education, that is, the participants of Competition of Innovations in Education $(\mathrm{N}=286)$. The final scale includes 16 statements and allows to evaluate the intensity of four motivational attitudes towards innovative activity: "Social significance," "Innovations and creativity," "Self-realization and achievement," "Finance and autonomy." The
\end{abstract}


identified motives reflect certain endeavors and goals of innovators and determine the content and orientation of their educational projects. The instrument can be used for both research and practice purposes to explore motivation of proactive actors in education, as well as similar groups involved in the development of public social spheres. The full version of the scale is presented in the appendix and contains the instructions for respondents and scoring criteria for four subscales.

Keywords: motivation towards innovations, PSED, scale adaptation, measuring motives of innovative activity.

\section{References}

Ajzen, I. (1991). The theory of planned behavior. Organizational Behavior and Human Decision Processes, 50(2), 179-211.

Ajzen, I. (2002). Perceived behavioral control, self-efficacy, locus of control, and the theory of planned behavior. Journal of Applied Social Psychology, 32(4), 665-683. doi:10.1111/j.15591816.2002.tb00236.x

Attali, M. O., \& Yemini, M. (2017). Initiating consensus: stakeholders define entrepreneurship in education. Educational Reviere, 69(2), 140-157. doi:10.1080/00131911.2016.115345

Battilana, J., Leca, B., \& Boxenbaum, E. (2009). How actors change institutions: Towards a theory of institutional entrepreneurship. The Academy of Management Annals, 3(1), 65-107. doi:10.1080/19416520903053598

Bogatyreva, K., \& Shirokova, G. (2017). From entrepreneurial aspirations to founding a business: The case of Russian students. Foresight and STI Governance, 11(3), 25-36. doi:10.17323/25002597.2017.3.25.36. Retrieved from https://foresight-journal.hse.ru/data/2017/09/27/ 1172894856/Shirokova\%2025-36.pdf

Caringal-Go, J. F., \& Hechanova, M. R. M. (2018). Motivational needs and intent to stay of social enterprise workers. Journal of Social Entrepreneurship, 9(3), 200-214. doi:10.1080/19420676.2018.1468352

Carsrud, A., \& Brännback, M. (2011). Entrepreneurial motivations: What do we still need to know? Journal of Small Business Management, 49(1), 9-26. doi:10.1111/j.1540-627x.2010.00312.x

Carter, N. M., Gartner, W. B., \& Shaver, K. G. (2004). Career reasons. In W. B. Gartner, K. G. Shaver, N. M. Carter, \& P. D. Reynolds (Eds.), Handbook of entrepreneurial dynamics: The process of business creation (pp. 142-152). Thousand Oaks, CA: Sage.

Deci, E. L., \& Ryan, R. M. (1985). Intrinsic motivation and self-determination in human behavior. New York, NY: Plenum.

Douglas, E., \& Prentice, C. (2019). Innovation and profit motivations for social entrepreneurship: A fuzzy-set analysis. Journal of Business Research, 99, 69-79. doi:10.1016/j.jbusres.2019.02.031

Elfving, J. (2008). Contextualizing entrepreneurial intentions: a multiple case study on entrepreneurial cognitions and perceptions. Turku, FI: Åbo Akademi förlag.

Fayolle, A., Liñán, F., \& Moriano, J. A. (2014). Beyond entrepreneurial intentions: values and motivations in entrepreneurship. International Entrepreneurship and Management Journal, 10(4), 679689. doi:10.1007/s11365-014-0306-7 
Frese, M., \& Gielnik, M. M. (2014). The psychology of entrepreneurship. Annual Review of Organizational Psychology and Organizational Behavior, 1(1), 413-438.

Ganguli, I., Huysentruyt, M., \& Le Coq, C. (2018). How do nascent social entrepreneurs respond to rewards? a field experiment on motivations in a grant competition. UMass Amherst Economics Working Papers, 258, 45.

Grice, J. W. (2001). Computing and evaluating factor scores. Psychological Methods, 6(4), 430-450. doi:10.1037/1082-989X.6.4.430

Hellström, T., Hellström, C., \& Berglund, H. (2002). The innovating self: Exploring self among a group of technological innovators. Journal of Managerial Psychology, 17(4), 267-286. doi:10.1108/02683940210428083

International Test Commission. (2017). The ITC guidelines for translating and adapting tests. Version, $1,20-12$.

Jones, J., Seet, P.-S., Acker, T., \& Whittle, M. (2021). Barriers to grassroots innovation: The phenomenon of social-commercial-cultural trilemmas in remote indigenous art centres. Technological Forecasting and Social Change, 164, 119583. doi:10.1016/j.techfore.2019.02.003

Khavenson, T. E., Koroleva, D. O., \& Lukina, A. A. (2018). Aktory obrazovatel'nykh innovatsii: Tsennosti i motivatsiya [Actors of educational innovations: Values and motivation]. Moscow: HSE Publishing House. Retrieved from https://publications.hse.ru/books/227119446 (in Russian)

Koroleva, D. O., Khavenson, T. E., \& Andreeva, A. A. (2017). Landshaft obrazovatel'nykh innovatsii: soderzhanie $i$ struktura [The landscape of educational innovations: the content and structure]. Moscow: HSE Publishing House. (in Russian)

Kuz'minov, Ya. I., \& Frumin, I. D. (Eds.). (2018). Dvenadtsat' reshenii dlya novogo obrazovaniya (Doklad Tsentra strategicheskikh razrabotok i Vysshei shkoly ekonomiki) [Twelve decisions for a new education (A report by the Centre of Strategic Developments and Higher School of Economics]. Mosciow: HSE Publishing House. Retrieved from https://publications.hse.ru/books/218061780 (in Russian)

Muńiz, J., Elosua, P., \& Hambleton, R. K. (2013). International Test Commission Guidelines for test translation and adaptation. Psicothema, 25(2), 151-157.

OECD. (2014). Measuring innovation in education: A new perspective, educational research and innovation. Paris: OECD.

Perikova, E. I., Atamanova, I. V., \& Bogomaz, S. A. (2020). Specific features of psychological readiness for innovative activity (with the main focus on young adults in St. Petersburg and Tomsk). Science for Education Today, 10(1), 62-78. doi:10.15293/2658-6762.2001.04 (in Russian)

Phelps, E. (2018). The dynamism of nations: toward a theory of indigenous innovation. Journal of Applied Corporate Finance, 30(3), 8-26.

Quigley, N. R., Newbert, S. L., \& Clark, K. D. (2015). The motivations underlying small business formation: An overview and empirical examination of self-efficacy and commitment. In S. L. Newbert (Ed.), Small business in a global economy: Creating and managing successful organizations (pp. 21-49). Denver, CO: Praeger.

Schlaegel, C., \& Koenig, M. (2013). Determinants of entrepreneurial intent: A meta-analytic test and integration of competing models. Entrepreneurship Theory and Practice, 38(2), 291-332. doi:10.1111/etap.12087

Seelos, C., \& Mair, J. (2005). Social entrepreneurship: Creating new business models to serve the poor. Business Horizons, 48(3), 241-246. 
Seyfang, D. G., \& Smith, D. A. (2007). Grassroots innovations for sustainable development: Towards a new research and policy agenda. Environmental Politics, 16(4), 584-603. doi:10.1080/09644010701419121

Shapero, A., \& Sokol, L. (1982). The social dimensions of entrepreneurship. In C.A. Kent, D. L. Sexton, \& K. H. Vesper (Eds.), Encyclopedia of entrepreneurship (pp. 72-90). Englewood Cliffs, NJ: Prentice-Hall.

Shirley, D. (2017). Accelerating educational change. Journal of Educational Change, 18(3), 257-262. doi:10.1007/s10833-017-9303-2

Shirokova, G. V., Tsukanova, T. V., \& Bogatyreva, K. A. (2015). University environment and student entrepreneurship: the role of business experience and entrepreneurial self-efficacy. Voprosy Obrazovaniya [Educational Studies Moscow], 3, 171-207. (in Russian)

Teixeira, S. J., Casteleiro, C. M. L., Rodrigues, R. G., \& Guerra, M. D. (2018). Entrepreneurial intentions and entrepreneurship in European countries. International Journal of Innovation Science, 10(1), 22-42. doi:10.1108/IJIS-07-2017-0062

Tortia, E. C., Degavre, F., \& Poledrini, S. (2020). Why are social enterprises good candidates for social innovation? Looking for personal and institutional drivers of innovation. Annals of Public and Cooperative Economics, 91(3), 459-477. doi:10.1111/apce.12265

Xu, Z., Robinson, J. A., Germak, A. J., \& Huang C. (2014, November). For Love or Money? Achievement Orientation, Non-monetary Focus, and the Nascent Social Entrepreneur. Paper presented at the ARNOVA's 43rd Annual Conference, Denver, CO.

Zahra, S. A., Gedajlovic, E., Neubaum, D. O., \& Shulman, J. M. (2009). A typology of social entrepreneurs: Motives, search processes and ethical challenges. Journal of Business Venturing, 24(5), 519-532.

Tatiana E. Khavenson - Associate Professor, Laboratory for Innovations, Institute of Education, HSE University, PhD in education.

Research Area: innovative behavior in education, measurement in social sciences, evidence-based education policy.

E-mail: tkhavenson@hse.ru

Anastasia A. Lukina - Junior Research Fellow, Centre for Cultural Sociology, Institute of Education, HSE University.

Research Area: measurement in social sciences, formal methods of cultural analysis, cultural sociology.

E-mail: aalukina@hse.ru 
Психология. Журнал Высшей школы экономики,

2021. T. 18. № 1. C. 109-128. DOI: 10.17323/1813-8918-2021-1-109-128

\title{
АПРОБАЦИЯ И ВАЛИДИЗАЦИЯ МЕТОДИКИ ВЕРЫ В СВОБОДУ /ДЕТЕРМИНИЗМ (FAD-PLUS) НА РОССИЙСКОЙ ВЫБОРКЕ
}

\author{
А.Н. МОСПАН
}

${ }^{a}$ Национальный исследовательский университет «Высшая школа экономики», 101000, Россия, Москва, ул. Мясницкая, д. 20

\section{Резюме}

Мировоззренческие убеждения, относящиеся к вере в свободу и предопределенность окружающего и внутреннего мира, являются предметом активного обсуждения и исследования в психологической науке. В статье представлены результаты апробации и конструктной валидизации русскоязычной версии методики веры в свободу/детерминизм (FAD-Plus) Д. Полуса и Дж. Кэри. На выборке студентов первого курса факультета психологии московских вузов $(\mathrm{N}=372)$ подтверждена оригинальная четырехфакторная структура опросника, который включает в себя четыре шкалы: Фаталистический детерминизм ( $\alpha$ Кронбаха $0.793)$, Свобода ( $\alpha$ Кронбаха -0.777$)$, Непредсказуемость ( $\alpha$ Кронбаха -0.689$)$, Научный детерминизм ( $\alpha$ Кронбаха -0.675$)$. Для конструктной валидизации опросника были рассмотрены связи методики с параметрами психологического благополучия и мотивации: диспозиционным и атрибутивным оптимизмом, субъективным благополучием и эмоциональным состоянием, осмысленностью жизни и жизненной позицией, психологическими потребностями, персональной ответственностью. Согласно полученным результатам, русскоязычная версия методики веры в свободу/детерминизм обладает хорошими психометрическими характеристиками и может быть использована как качественный исследовательский инструмент. На основании корреляционного анализа была выявлена положительная взаимосвязь между верой в свободу и характеристиками психологического благополучия: удовлетворенностью жизнью, положительными эмоциями, оптимизмом, осмысленностью жизни, тремя аспектами жизненной позиции, удовлетворенностью базовых психологических потребностей, персональной ответственностью и чувствительностью к обратной связи. Остальные виды убеждений показали более слабые связи с психологическими характеристиками. Вера в непредсказуемость отрицательно связана с положительными эмоциями, атрибутивным оптимизмом, осмысленностью жизни, осознанностью жизни, ответственностью и чувствительностью к обратной связи. Вера в научный детерминизм имеет отрицательные корреляции с атрибутивным оптимизмом в ситуации успеха, активностью жизненной позиции, чувствительностью к обратной связи и удовлетворением потребности в компетентности. Вера в фаталистический детерминизм во многом схожа с научным детерминизмом по паттерну корреляционных связей, однако, в отличие от последней, она также положительно коррелирует с удовлетворенностью жизнью и с чувством гармонии с ней.

Ключевые слова: мировоззрение, вера в свободу/детерминизм, FAD-Plus, психологическое благополучие, валидизация методики.

Исследование выполнено при поддержке Российского научного фонда, проект № 16-18-10439 «Системно-динамический анализ регуляции деятельности». 
Вопрос о том, свободен ли человек в своих поступках или же все его действия так или иначе детерминированы, принадлежит к числу основных мировоззренческих дилемм, неизменно входящих в круг центральных дискуссий в философии и теологии на протяжении многих столетий. С 1980-х гг. он становится предметом серьезного анализа также в психологии (см.: Леонтьев, 2000). Дополнительный толчок этим исследованиям придали, с одной стороны, революционные прорывы в естественно-научной картине мира конца прошлого столетия, заставившие пересмотреть имеющиеся представления о естественно-научном детерминизме и его границах (см.: Леонтьев, 2018), с другой стороны, нашумевшие исследования в нейронауках, придавшие дополнительную аргументацию убеждению в детерминированности человеческих действий, в частности, работы, выявившие отставание во времени сознательного решения от реакций на уровне мозговых процессов (Libet et al., 1983) и эффект иллюзии свободной воли (Wegner, 2002); впрочем, даже в нейронауках это убеждение разделяют далеко не все, оставляя место личной ответственности индивида за свои поступки в «детерминированной Вселенной» (см., например: Газзанига, 2017).

В 2000-е гг. наблюдается новая волна теоретических (например: Baer, et al., 2008) и эмпирических (Nichols, 2006) исследований соотношения свободы воли и детерминизма. При этом на передний план постепенно выдвигается не столько онтологический вопрос о реальности человеческой свободы, решение которого выходит за пределы компетенции психологической науки, сколько вопрос об индивидуальных различиях в мировоззренческих представлениях о реальности либо иллюзорности свободы и о тех психологических следствиях, которые имеют те или иные убеждения (например: Baumeister et al., 2009; Vohs, Schooler, 2008). Действительно, еще У. Джеймс (1997) показал в философских трудах, что значимость мировоззренческих убеждений не зависит от их онтологической обоснованности; сами убеждения действуют как «самоосуществляющееся пророчество» (Merton, 2016), порождая те или иные психологические последствия. Безусловно, вера в то, что мы свободны или, напротив, несвободны в своих действиях, относится к наиболее важным из этих убеждений.

Мировоззренческие убеждения, касающиеся свободы/детерминизма, стали в последнее время объектом психологической диагностики и эмпирических исследований. Целью данной статьи является апробация и конструктная валидизация русскоязычной версии одного из наиболее эффективных инструментов этого ряда - методики FAD-Plus Делроя Полуса и Джасмин Кэри (Paulhus, Carey, 2011).

\section{Вера в свободу/детерминизм как объект психологической диагностики}

Одной из первых попыток диагностического подхода была работа У. Вайни, Д. Уолдмана и Ж. Барчилон (Viney et al., 1982), которые разработали шкалу Free Will-Determinism Scale, основанную на философском споре о свободе воли и детерминизме и содержавшую семь биполярных пунктов. 
Понимание вопросов, однако, давалось нелегко: использование этого инструмента потребовало подготовительной лекции о сути противопоставления свободы воли и детерминизма, но и после ее прослушивания студенты колледжа испытывали трудности в понимании пунктов шкалы. Это привело к отказу от использования данного инструмента.

Чтобы раскрыть сложность связи между свободой воли и детерминизмом, С. Стросснер и Ч. Грин (Stroessner, Green, 1990) попытались измерить отношение к свободе воли отдельно от двух форм детерминизма: психосоциального и религиозно-философского. Корреляции между шкалами не были представлены, поэтому окончательные отношения между тремя шкалами неизвестны.

В попытке уйти от концепта свободы воли Й. Келлер (Keller, 2005) разработал шкалу веры в генетический детерминизм, состоящую из 18 пунктов. Он обнаружил, что высокие баллы по шкале связаны с наличием социальных стереотипов и предрассудков. Однако данный подход был односторонним, не учитывал других форм детерминации. Еще один опросник был разработан Р. Ракосом, К. Лорен, С. Скалой и С. Слэйном (Rakos et al., 2008), которые вернулись к более ранней концепции свободной воли и детерминизма как противоположностей.

Растущий интерес к этой теме и отсутствие адекватного измерительного инструмента побудили Д. Полуса и Дж. Кэри (Paulhus, Carey, 2011) разработать многофакторную модель исследования свободы воли и детерминизма. Предварительная неопубликованная версия опросника (FAD-4) состояла из четырех шкал, каждая из которых включала в себя семь пунктов. Как показал анализ этого инструмента, пункты, выражающие веру в свободу воли, группируются отдельно от веры в два типа детерминизма - научный и фаталистический. В отдельную группу выделились пункты, выражающие убежденность в непредсказуемость. Как и С. Стросснер и Ч. Грин (Stroessner, Green, 1990), авторы пришли к выводу, что убеждения о свободе воли и детерминизме не являются взаимоисключающими.

Несмотря на то что FAD-4 не был опубликован, он оказался полезным в ряде исследований. Например, Б. Вестлейк и Д. Полус (Westlake, Paulhus, $2007)$ обнаружили, что вера в свободу воли положительно связана с убеждением в необходимости карать нарушителей закона. К. Вос и Дж. Скулер (Vohs, Schooler, 2008) показали, что вера в свободу воли отрицательно связана с готовностью мошенничать ради корысти. Р. Баумейстер с соавт. (Baumeister et al., 2009) показали, что вера в свободу воли способна предсказать поведенческий аспект альтруизма.

Преодолевая некоторые психометрические недостатки FAD-4, авторы методики разработали новый инструмент - FAD-Plus, с использованием пунктов из предыдущей версии (Paulhus, Carey, 2011). Разработка опросника проходила в три этапа. В первом исследовании авторы провели факторный анализ 23 пунктов, во втором - повысили уровень надежности шкалы за счет увеличения количества пунктов, в третьем - расширили выборку исследования для подтверждения четырехфакторной структуры методики. 
Первый фактор мировоззренческих убеждений авторы описали как Фаталистический детерминизм (например, утверждение «У судьбы для каждого есть свой план»). Второй фактор был интерпретирован как Свобода воли (пункт с наибольшей факторной нагрузкой: «Люди в состоянии преодолеть любые препятствия, если действительно захотят»). Помимо идеи автономии личности, этот фактор также включает в себя утверждения об ответственности индивида за свои действия. Третий выделенный фактор - Непредсказуемость - дает наибольшую факторную нагрузку на пункт ( ЖЖизнь трудно предвидеть, потому что она полна случайностей»). Наконец, четвертый фактор авторы обозначили как Научный детерминизм, так как он включал в себя утверждения о детерминированности человека наследственностью (например: «Биологические свойства людей определяют их таланты и личность») и средой («Наука выяснила, в какой степени ваш интеллект и личность зависят от среды, в которой вы росли»).

Одно из ключевых достоинств методики представляет заложенная в нем идея того, что вера в свободу воли и вера в детерминизм не являются полярно противоположными конструктами. Так, индивид может верить и в свободу и в детерминизм или руководствоваться чем-то одним или третьим.

Важным конструктом в исследовании веры в свободу или детерминизм является локус контроля (Rotter, 1966), т.е. вера в возможность человека влиять на события, происходящие в его жизни, в противовес влияниям случая и внешних, более могущественных факторов (Levenson, 1973). Авторы FAD-Plus решили эту проблему за счет дискриминантной валидности, установив взаимосвязь шкал опросника со стандартной методикой локуса субъективного контроля. Для того чтобы выявить связь шкал с другими личностными характеристиками человека, авторы методики рассмотрели взаимосвязи с личностными факторами Большой пятерки. Последний вариант методики свободы воли и детерминизма FAD-Plus включает 27 прямых пунктов, ответы на которые представлены в виде 5-балльной шкалы, где 1 - полностью не согласен с утверждением, 5 - полностью согласен с утверждением.

Методика FAD-Plus была адаптирована в ряде стран. Авторы польской адаптации (Kondratowicz-Nowak et al., 2018) использовали версию с 16 пунктами, объединив субшкалы фаталистического и научного детерминизма в единый фактор детерминизма. Серия исследований показала положительные корреляции веры в детерминизм с религиозным фундаментализмом и верой в несправедливый мир, а также ряд закономерностей, связанных с эмоциональными переживаниями, в частности, положительные корреляции веры в свободу воли с позитивными эмоциями, отрицательные корреляции веры в детерминизм с позитивными эмоциями и удовлетворенностью жизнью. Во французской адаптации методики была использована полная версия опросника (27 пунктов) (Caspar et al., 2017), а также рассмотрены взаимосвязи субшкал FAD-Plus c религиозными практиками. Авторы исследования обнаружили, что чем больше люди занимаются религиозными практиками, тем больше они верят в предопределенность и неизбежность собственного будущего. В исследовании, проведенном на китайской выборке школьников старших классов 
(Li et al., 2018), было обнаружено, что субшкала веры в свободу воли (из версии опросника 27 пунктов) является важнейшим предиктором настойчивости в достижении долгосрочных целей.

Сразу отметим, что мы солидарны с теми достаточно многочисленными авторами, которые считают старое понятие «свобода воли» дезориентирующим. Во-первых, свобода свойственна человеку в целом, а не отдельной его функции (Фромм, 1992), во-вторых, проблема воли в психологии представляет собой отдельную проблемную область, не совпадающую и лишь ограниченно пересекающуюся с областью психологии свободы, последняя же в большей мере соотносится сегодня с такими конструктами, как автономия и самодетерминация. Поэтому в дальнейшем мы, обсуждая русскоязычную версию, будем называть эту шкалу просто шкалой свободы.

\section{Адаптация русскоязычной версии методики FAD-Plus}

Методика FAD-Plus представляется наиболее удачной по сравнению с аналогами. Она была переведена Д.А. Леонтьевым на русский язык.

Первый этап исследования, направленный на адаптацию и изучение психодиагностических возможностей методики веры в свободу/детерминизм (ВСД), был проведен на объединенной выборке студентов первого курса факультета психологии московских вузов $(\mathrm{N}=372)$. Доля мужчин составила $13 \%(\mathrm{n}=48)$, доля женщин - 87\% ( $\mathrm{n}=324)$, возраст респондентов варьировал от 17 до 28 лет (средний возраст - 18.6 года).

В Приложении приведены описательные статистики пунктов методики по результатам исследования. Почти все пункты имеют нормальное распределение, так как значение эксцесса и асимметрии не превышает 1 по модулю.

Для анализа структуры методики был использован конфирматорный (CFA) факторный анализ. Он показал приемлемое соответствие данным по двум из трех практических индексов соответствия (кроме СFI): $\chi^{2}(318)=888$, $\mathrm{CFI}=0.750, \mathrm{RMSEA}=0.0694, \mathrm{SRMR}=0.0787$. Для исключения эффекта слабых перекрестных нагрузок на показатели модели был применен метод эксплораторного моделирования структурными уравнениями (ESEM), при оценке модели была использована статистика WLSMV для порядковых переменных. В качестве целевой матрицы при вращении со стандартизацией по Кайзерy (Browne, 2001) выступала матрица теоретически ожидаемых нагрузок. Результаты ESEM показали приемлемое соответствие модели по всем показателям $\left(\chi^{2}(249)=528.837, \mathrm{CFI}=0.915, \mathrm{RMSEA}=0.055, \mathrm{SRMR}=0.041\right)$. Полученные факторные нагрузки представлены в таблице 1 . Несмотря на наличие дополнительных факторных нагрузок, теоретически ожидаемые нагрузки переменных оказались наиболее высокими, что свидетельствует в пользу теоретической модели. С целью сохранения совместимости с оригинальной структурой мы

\footnotetext{
${ }^{1}$ Выражаем благодарность автору методики доктору Делрою Полусу за любезное разрешение на ее перевод и адаптацию, а также Евгению Осину за ценные советы по обработке данных исследования.
} 
Таблица 1

Факторная структура методики веры в свободу/детерминизм

\begin{tabular}{|c|c|c|c|c|}
\hline Пункт опросника & Свобода & $\begin{array}{c}\text { Фаталистический } \\
\text { детерминизм }\end{array}$ & $\begin{array}{l}\text { Непредска- } \\
\text { зуемость }\end{array}$ & $\begin{array}{c}\text { Научный } \\
\text { детерминизм }\end{array}$ \\
\hline $\begin{array}{l}\text { 4. Люди полностью контролируют те } \\
\text { решения, которые они принимают }\end{array}$ & 0.512 & -0.108 & & \\
\hline $\begin{array}{l}\text { 8. Люди должны нести полную ответ- } \\
\text { ственность за плохие выборы, которые } \\
\text { они делают }\end{array}$ & 0.648 & & & 0.153 \\
\hline $\begin{array}{l}\text { 12. Люди в состоянии преодолеть } \\
\text { любые препятствия, если действитель- } \\
\text { но захотят }\end{array}$ & 0.641 & & & \\
\hline $\begin{array}{l}\text { 16. Преступники несут полную ответ- } \\
\text { ственность за то плохое, что они делают }\end{array}$ & 0.612 & & & \\
\hline $\begin{array}{l}\text { 21. Люди обладают полной свободой } \\
\text { воли }\end{array}$ & 0.606 & & 0.124 & -0.155 \\
\hline $\begin{array}{l}\text { 23. Люди всегда сами виноваты в своих } \\
\text { дурных поступках }\end{array}$ & 0.736 & & & 0.156 \\
\hline $\begin{array}{l}\text { 26. Сила рассудка всегда может преодо- } \\
\text { леть желания тела }\end{array}$ & 0.580 & & & \\
\hline $\begin{array}{l}\text { 1. Я верю, что будущее уже предопреде- } \\
\text { лено судьбой }\end{array}$ & & 0.825 & & \\
\hline $\begin{array}{l}\text { 5. Как бы вы ни старались, вы не може- } \\
\text { те изменить свою судьбу }\end{array}$ & -0.226 & 0.631 & & \\
\hline 9. У судьбы для каждого есть свой план & 0.232 & 0.936 & & \\
\hline $\begin{array}{l}\text { 13. Что случится, то случится, и мы } \\
\text { мало что можем с этим поделать }\end{array}$ & -0.224 & 0.411 & 0.214 & \\
\hline $\begin{array}{l}\text { 17. Нравится это людям или нет, их } \\
\text { жизнью управляют скрытые силы }\end{array}$ & & 0.599 & & 0.164 \\
\hline $\begin{array}{l}\text { 3. Человеческая история управляется в } \\
\text { основном случайностями }\end{array}$ & -0.164 & -0.141 & 0.472 & 0.198 \\
\hline $\begin{array}{l}\text { 7. Никто не может предвидеть, что про- } \\
\text { изойдет в этом мире }\end{array}$ & & & 0.567 & -0.331 \\
\hline $\begin{array}{l}\text { 11. Жизнь не более предсказуема, чем } \\
\text { кидание монетки или костей }\end{array}$ & 0.118 & & 0.448 & 0.120 \\
\hline 15. Люди непредсказуемы & & 0.134 & 0.325 & -0.257 \\
\hline $\begin{array}{l}\text { 19. Жизнь трудно предвидеть, потому } \\
\text { что она полна случайностей }\end{array}$ & & & 0.688 & \\
\hline $\begin{array}{l}\text { 20. Удача играет большую роль в жизни } \\
\text { людей }\end{array}$ & 0.100 & 0.215 & 0.379 & 0.230 \\
\hline $\begin{array}{l}\text { 25. То, что происходит с людьми, зави- } \\
\text { сит от случая }\end{array}$ & -0.172 & & 0.575 & 0.391 \\
\hline 27. Наше будущее нельзя предвидеть & & & 0.634 & -0.222 \\
\hline $\begin{array}{l}\text { 2. Биологические свойства людей опре- } \\
\text { деляют их таланты и личность }\end{array}$ & -0.138 & 0.132 & & 0.531 \\
\hline $\begin{array}{l}\text { 6. Психологи и психиатры рано или } \\
\text { поздно смогут предсказывать все пове- } \\
\text { дение людей }\end{array}$ & & & -0.298 & 0.414 \\
\hline $\begin{array}{l}\text { 10. Ваши гены определяют ваше буду- } \\
\text { щее }\end{array}$ & -0.165 & & & 0.697 \\
\hline
\end{tabular}


Таблица 1 (окончание)

\begin{tabular}{|l|l|l|l|c|}
\hline $\begin{array}{l}\text { 14. Наука выяснила, насколько ваш } \\
\text { интеллект и личность зависят от среды, } \\
\text { в которой вы росли }\end{array}$ & 0.159 & & $\mathbf{0 . 5 4 2}$ \\
\hline $\begin{array}{l}\text { 18. Поведение людей, как и остальных } \\
\text { животных, всегда подчиняется законам } \\
\text { природы }\end{array}$ & & & $\mathbf{0 . 5 1 6}$ \\
\hline $\begin{array}{l}22 . \text { Характер родителей определяет } \\
\text { характер их детей }\end{array}$ & 0.139 & & $\mathbf{0 . 4 1 8}$ \\
\hline $\begin{array}{l}24 . \text { От среды, в которой вы росли в дет- } \\
\text { сте, зависят ваши успехи во взрослом } \\
\text { возрасте }\end{array}$ & & & 0.155 & $\mathbf{0 . 3 5 4}$ \\
\hline
\end{tabular}

Примечание. Представлены статистически достоверные факторные нагрузки $(p<0.05)$; полужирным шрифтом выделены факторные нагрузки пунктов, входящих в соответствующую шкалу; в таблице не представлены факторные нагрузки менее 0.1 по модулю.

отказались от внесения модификаций в модель. Таким образом, подтверждается исходная четырехфакторная структура опросника, выявленная авторами оригинальной методики FAD-Plus (Paulhus, Carey, 2011).

Большинство шкал демонстрируют достаточно высокую надежность по коэффициенту альфа Кронбаха для исследовательских целей: Свобода $(\alpha=0.777)$, Фаталистический детерминизм $(\alpha=0.793)$, Непредсказуемость $(\alpha=0.689)$, Научный детерминизм $(\alpha=0.675)$. В таблице 2 также представлена корреляционная матрица субшкал тестируемой методики.

Приемлемые в целом, но не идеальные характеристики отдельных пунктов могут использоваться без дальнейших попыток улучшения или подвергнуться доработке. Улучшение факторной нагрузки отдельных пунктов может быть достигнуто только за счет снижения точности перевода и уменьшения текстуальной согласованности русскоязычного и оригинального вариантов методики. Оба варианта имеют свои преимущества и свои издержки. Мы решили пока воздержаться от дополнительных попыток улучшения перевода, тем более что работа над русскоязычной версией методики только началась и,

Таблица 2

Показатели коэффициента корреляции Пирсона между субшкалами методики веры в свободу/детерминизм

\begin{tabular}{|l|c|c|c|c|}
\hline \multicolumn{1}{|c|}{ Субшкала } & Свобода & $\begin{array}{c}\text { Фаталистический } \\
\text { детерминизм }\end{array}$ & Непредсказуемость & $\begin{array}{c}\text { Научный } \\
\text { детерминизм }\end{array}$ \\
\hline Свобода & - & & & \\
\hline $\begin{array}{l}\text { Фаталистический } \\
\text { детерминизм }\end{array}$ & $-0.127^{*}$ & - & & \\
\hline Непредсказуемость & -0.009 & $0.233^{* * *}$ & - & \\
\hline $\begin{array}{l}\text { Научный } \\
\text { детерминизм }\end{array}$ & -0.074 & $0.328^{* * *}$ & 0.110 & - \\
\hline
\end{tabular}

${ }^{*} p<0.05,{ }^{* *} p<0.01,{ }^{* * *} p<0.001$. 
прежде чем вносить коррективы в текст методики, стоит накопить достаточный объем эмпирических данных.

\section{Конструктная валидизация методики ВСД: мировоззренческие убеждения, ресурсы саморегуляции, субъективное благополучие и мотивация}

Второй этап исследования представляет конструктную валидизацию методики веры в свободу/детерминизм на той же выборке студентов факультета психологии московских вузов $(\mathrm{N}=372)$ с использованием корреляционного анализа данных.

\section{Инструменть}

Для анализа были использованы следующие методики (коэффициент надежности альфа Кронбаха указан в скобках):

1. Опросник «Стиль объяснения успехов и неудач (СТОУН)» (Гордеева и др., 2009). Использован краткий вариант опросника, в котором респонденту предлагается представить себя в 5 ситуациях успеха (надежность шкалы оптимизма в ситуации успеха $\alpha=0.86$ ) и 7 ситуациях неудачи (надежность шкалы оптимизма в ситуации неудачи $\alpha=0.8$ ), сформулировать и оценить наиболее вероятную причину каждого события по 3 параметрам атрибутивного стиля: стабильность, глобальность и контролируемость.

2. Тест диспозиционного оптимизма (LOT) (Гордеева и др., 2010) основан на модели поведенческой саморегуляции М. Шейера и Ч. Карвера. Методика применяется для диагностики индивидуальных различий в оптимизме, который представляет обобщенные ожидания относительно будущих событий. Тест включает в себя общий показатель диспозиционного оптимизма $(\alpha=0.89)$, субшкалу позитивных ожиданий $(\alpha=0.79)$ и субшкалу негативных ожиданий $(\alpha=0.87)$.

3. Тест смысложизненных ориентаций в авторской модификации (Леонтьев, 1992) разработан на базе теста «Purpose in Life» Дж. Крамбо и Л. Махолика (Crumbaugh, Maholick, 1981). Методика включает в себя 20 парных утверждений, которые необходимо оценить от 1 до 7 в соответствии со степенью определенности в выборе каждого из утверждений. Тест измеряет общий показатель осмысленности жизни $(\alpha=0.9)$ и содержит 4 дополнительные субшкалы смысложизненных ориентаций: процесс - эмоциональная насыщенность настоящего $(\alpha=0.81)$; цели - наличие осмысленной перспективы будущего $(\alpha=0.84)$; результат - удовлетворенность самореализацией в прошлом $(\alpha=0.78)$; локус контроля - способность влиять на события, происходящие в жизни $(\alpha=0.57)$.

4. Шкала позитивного и негативного аффекта (ШПАНА) (Осин, 2012) состоит из 20 прилагательных, которые описывают эмоциональные состояния индивида по двум шкалам: позитивный $(\alpha=0.89)$ и негативный аффект $(\alpha=0.89)$. В инструкции опросника респондентам предлагалось оценить выраженность своих эмоций за последние две недели. 
5. Сбалансированный опросник психологических потребностей (Balanced Measure of Psychological Needs; Sheldon, Hilpert, 2012) измеряет удовлетворенность базовых потребностей в рамках теории самодетерминации: связность с другими людьми $(\alpha=0.74)$, компетентность в деятельности $(\alpha=0.81)$ и автономию личности $(\alpha=0.72)$. Он состоит из 18 утверждений, которые необходимо оценить по шкале от 1 до 5.

6. Шкала удовлетворенности жизнью Э. Динера измеряет уровень субъективного благополучия жизни в целом (в адаптации Е.Н. Осина и Д.А. Леонтьева, 2020) $(\alpha=0.84)$.

7. Опросник жизненной позиции личности (Леонтьев, Шильманская, 2019), измеряющий отношения личности к собственной жизни, состоит из 12 утверждений, сгруппированных в три шкалы: гармония с жизнью $(\alpha=0.86)$, осознанность жизни (или рефлексивность жизненной позиции) $(\alpha=0.71)$, а также активность (субъектность) в отношении собственной жизни $(\alpha=0.72)$.

8. Шкала чувствительности к обратной связи (ЧОС) (Леонтьев и др., 2019) применяется для диагностики способности человека реагировать на успешность собственных действий и корректировать активность в соответствии с оценкой этой успешности $(\alpha=0.71)$. Методика содержит 10 утверждений, которые предлагается оценить по 5-балльной шкале.

9. Шкала персональной ответственности (Sheldon et al., 2018), состоящая из 8 пунктов, измеряет уровень личной ответственности человека за собственные действия $(\alpha=0.78)$.

Бо́льшая часть перечисленных методик (2-6) относится к методикам диагностики субъективного и психологического благополучия. Они направлены на выявление различных аспектов благополучия и регулярно используются в исследованиях по позитивной психологии для контроля эффектов тех или иных ситуаций или интервенций. Остальные методики $(1,7-9)$ разработаны в самое последнее время и характеризуют различные аспекты саморегуляции и субъектности (самодетерминации). Комплекс методик, использованных для конструктной валидизации, позволяет оценить степень позитивности тех или иных убеждений, относящихся к свободе/детерминизму, под углом зрения их психологических последствий, а также их связь с мерой выраженности личностных механизмов субъектности и самодетерминации.

\section{Результать}

Почти все шкалы методик имеют нормальное распределение, поэтому для корреляционного анализа был использовал коэффициент Пирсона.

Как показано в таблице 3, параметры атрибутивного стиля и диспозиционного оптимизма обнаруживают разную картину взаимосвязей со шкалами методики веры в свободу/детерминизм. Диспозиционный оптимизм описывает стабильную личностную характеристику человека, которая отражает позитивные ожидания субъекта относительно будущего. Единственной шкалой, которая имеет взаимосвязи с диспозиционным оптимизмом, является свобода. Чем больше индивид убежден в том, что человек автономен и ответственен за 
Таблица 3

Показатели коэффициента корреляции Пирсона между шкалами методики ВСД и параметрами оптимизма

\begin{tabular}{|c|c|c|c|c|c|}
\hline \multicolumn{2}{|c|}{$\begin{array}{c}\text { Опросник стиля объяснения } \\
\text { успехов и неудач } \\
\text { (для } \mathbf{N}=317)\end{array}$} & \multirow{2}{*}{$\begin{array}{l}\text { Свобода } \\
0.477^{* * *}\end{array}$} & \multirow{2}{*}{\begin{tabular}{|c}
$\begin{array}{c}\text { Непредска- } \\
\text { зуемость }\end{array}$ \\
$-0.193^{* * *}$
\end{tabular}} & \multirow{2}{*}{$\begin{array}{c}\text { Фаталистический } \\
\text { детерминизм } \\
-0.184^{* *}\end{array}$} & \multirow{2}{*}{$\begin{array}{c}\begin{array}{c}\text { Научный } \\
\text { детерминизм }\end{array} \\
-0.141^{*}\end{array}$} \\
\hline \multirow{4}{*}{$\begin{array}{l}\text { Ситуация } \\
\text { успеха }\end{array}$} & $\begin{array}{l}\text { Общий показа- } \\
\text { тель оптимизма }\end{array}$ & & & & \\
\hline & Стабильность & $0.361^{* * *}$ & $-0.19 * * *$ & $-0.121^{*}$ & -0.09 \\
\hline & Глобальность & $0.437 * * *$ & $-0.13^{*}$ & $-0.151^{* *}$ & $-0.117^{*}$ \\
\hline & Контроль & $0.447 * * *$ & $-0.196^{* * *}$ & $-0.208^{* * *}$ & $-0.163^{* *}$ \\
\hline \multirow{4}{*}{$\begin{array}{l}\text { Ситуация } \\
\text { неудачи }\end{array}$} & $\begin{array}{l}\text { Общий показа- } \\
\text { тель оптимизма }\end{array}$ & $0.25^{* * *}$ & $-0.154^{* *}$ & -0.102 & -0.044 \\
\hline & Стабильность & $0.199 * * *$ & $-0.207 * * *$ & -0.074 & -0.057 \\
\hline & Глобальность & 0.05 & -0.073 & 0.012 & $0.112^{*}$ \\
\hline & Контроль & $0.3^{* * *}$ & -0.036 & $-0.172^{* *}$ & $-0.179 * *$ \\
\hline \multicolumn{2}{|c|}{$\begin{array}{l}\text { Тест диспозиционного } \\
\text { оптимизма (для } \mathrm{N}=205 \text { ) }\end{array}$} & $0.34^{* * *}$ & -0.127 & 0.044 & -0.012 \\
\hline
\end{tabular}

${ }^{*} p<0.05,{ }^{* *} p<0.01,{ }^{* * *} p<0.001$.

свои действия, тем больше позитивных ожиданий у него относительно будущего. Вера в детерминизм или непредсказуемость связана с диспозиционным оптимизмом незначимо.

Субшкалы опросника стиля объяснения успехов и неудач имеют взаимосвязи со всеми шкалами методики ВСД. Оптимистический атрибутивный стиль отражает то, как индивид объясняет произошедшие благоприятные и неудачные события, т.е. ориентирован на контекст прошлого или настоящего. Таким образом, в случае ожиданий будущего срабатывают только убеждения, касающиеся свободы человека, а в контексте объяснения причин конкретных жизненных ситуаций - всех шкал методики. На основании положительных корреляций шкалы свободы с различными параметрами оптимизма можно сделать вывод о том, что убеждения относительно свободы как части природы человека благоприятно влияют на атрибутивный стиль. При этом вера в непредсказуемость мира, а также убеждения в скрытых и судьбоносных силах и научном детерминизме, напротив, связаны преимущественно с пессимизмом, особенно при атрибуции успеха; для атрибуции неудачи большинство этих связей незначимы. Интересным наблюдением является смена направленности взаимосвязи шкалы научного детерминизма с глобальностью причины в зависимости от благоприятности ситуации. В случае успеха человек с убеждениями в биологической и средовой причинности мира имеет склонность конкретизировать причину ситуации, а в случае неудачи, наоборот, делать акцент на универсальности. В целом убеждения в свободе воли и 
детерминизме играют большую роль в ситуации успеха, тогда как в ситуации неудачи большинство связей с параметрами оптимизма более слабые.

В таблице 4 приведены результаты корреляционного анализа методики ВСД с параметрами общей удовлетворенности жизнью и эмоционального состояния за последние две недели. Шкала свободы имеет прямую взаимосвязь с позитивным эмоциональным состоянием индивида и отрицательную корреляцию с негативными аффектами, тогда как убеждения в принципиальной непредсказуемости мира отрицательно коррелируют с позитивным аффектом. Высокий уровень удовлетворенности жизнью связан с убеждениями в автономии и ответственности личности за принятые решения и фаталистическим детерминизмом, т.е. верой в скрытые силы и судьбу. Таким образом, субъективное благополучие человека может быть равно связано с убеждениями как в активности и автономии личности, так и в невозможности индивида повлиять на судьбу.

Обнаруживаются положительные взаимосвязи параметров осмысленности и жизненной позиции со шкалой свободы, которая, очевидно, во многом определяет психологическое благополучие личности (таблица 5). Убеждения в принципиальной непредсказуемости мира, напротив, имеют обратные корреляции с осознанностью своей жизни как единого целого и общим показателем осмысленности. При этом индивид с верой в непредсказуемость жизни обладает низкой эмоциональной насыщенностью настоящего и не видит себя способным повлиять на события. Вера в обусловленность жизни биологическими и средовыми факторами (научный детерминизм) блокирует активность индивида в отношении собственной жизни. Шкала фаталистического детерминизма имеет неоднозначные взаимосвязи с жизненной позицией. Несмотря на то что она демонстрирует значимые положительные корреляции с гармонией, она в то же время соотносится с низкими показателями осознанности и активности индивида, а также блокирует его локус контроля.

Рассмотрим взаимосвязи методики ВСД с параметрами саморегуляции (таблица 6). Наиболее высокие значимые корреляции предсказуемо обнаружены у шкалы свободы с удовлетворенностью всех трех базовых психологических

Таблица 4

Показатели коэффициента корреляции Пирсона между шкалами методики ВСД и параметрами субъективного благополучия и эмоционального состояния

\begin{tabular}{|l|c|c|c|c|}
\hline $\begin{array}{l}\text { Шкала позитивного и } \\
\text { негативного аффекта } \\
\text { (для N = 371) }\end{array}$ & Свобода & Непредсказуемость & $\begin{array}{c}\text { Фаталистический } \\
\text { детерминизм }\end{array}$ & $\begin{array}{c}\text { Научный } \\
\text { детерминизм }\end{array}$ \\
\hline Позитивный аффект & $0.26^{* * *}$ & $-0.123^{*}$ & -0.031 & -0.001 \\
\hline Негативный аффект & $-0.147^{* *}$ & 0.074 & -0.088 & 0.003 \\
\hline $\begin{array}{l}\text { Шкала удовлетворен- } \\
\text { ности жизнью } \\
\text { (для N = 261) }\end{array}$ & $0.14^{*}$ & 0.013 & $0.179^{* *}$ & 0.02 \\
\hline
\end{tabular}


Таблица 5

Показатели коэффициента корреляции Пирсона шкал методики ВСД с показателями осмысленности жизни и жизненной позиции

\begin{tabular}{|l|c|c|c|c|}
\hline $\begin{array}{c}\text { Жизненная позиция } \\
\text { (для N = 371) }\end{array}$ & Свобода & Непредсказуемость & $\begin{array}{c}\text { Фаталистический } \\
\text { детерминизм }\end{array}$ & $\begin{array}{c}\text { Научный } \\
\text { детерминизм }\end{array}$ \\
\hline Гармония & $0.28^{* * *}$ & -0.091 & $0.121^{*}$ & -0.041 \\
\hline Осознанность & $0.401^{* * *}$ & $-0.132^{*}$ & $-0.158^{* *}$ & -0.062 \\
\hline Активность & $0.456^{* * *}$ & -0.068 & $-0.27^{* * *}$ & $-0.166^{* *}$ \\
\hline $\begin{array}{l}\text { Общий показатель } \\
\text { СЖО (для N = 208) }\end{array}$ & $0.338^{* * *}$ & $-0.171^{*}$ & -0.073 & -0.082 \\
\hline Процесс & $0.218^{* *}$ & -0.107 & 0.002 & -0.078 \\
\hline Цель & $0.334^{* * *}$ & $-0.223^{* *}$ & -0.121 & -0.092 \\
\hline Результат & $0.195^{* *}$ & -0.101 & -0.004 & -0.034 \\
\hline Локус контроля & $0.383^{* * *}$ & $-0.185^{* *}$ & $-0.198^{* *}$ & -0.099 \\
\hline
\end{tabular}

${ }^{*} p<0.05,{ }^{* *} p<0.01,{ }^{* * *} p<0.001$.

Таблица 6

Показатели коэффициента корреляции Пирсона между шкалами методики ВСД и параметрами саморегуляции

\begin{tabular}{|l|c|c|c|c|}
\hline $\begin{array}{c}\text { Сбалансированный } \\
\text { опросник психологи- } \\
\text { ческих потребностей } \\
\text { (для N = 371) }\end{array}$ & Свобода & Непредсказуемость & $\begin{array}{c}\text { Фаталистический } \\
\text { детерминизм }\end{array}$ & $\begin{array}{c}\text { Научный } \\
\text { детерминизм }\end{array}$ \\
\hline Отношения & $0.124^{*}$ & -0.024 & 0.011 & -0.029 \\
\hline Компетентность & $0.286^{* *}$ & -0.052 & 0.005 & $-0.106^{*}$ \\
\hline Автономия & $0.211^{* * *}$ & -0.026 & -0.026 & -0.055 \\
\hline $\begin{array}{l}\text { Чувствительность к } \\
\text { обратной связи } \\
\text { (для N = 262) }\end{array}$ & $0.329^{* * *}$ & $-0.137^{*}$ & $-0.241^{* * *}$ & $-0.124^{*}$ \\
\hline $\begin{array}{l}\text { Персональная ответ- } \\
\text { ственность } \\
\text { (для N = 372) }\end{array}$ & $0.313^{* * *}$ & $-0.116^{*}$ & 0.045 & -0.037 \\
\hline
\end{tabular}

$$
{ }^{*} p<0.05,{ }^{* *} p<0.01,{ }^{* * *} p<0.001 \text {. }
$$

потребностей, персональной ответственностью, а также со способностью человека реагировать на успешность деятельности и ее корректировку. Чувствительность к обратной связи активируется только в случае веры в свободу человека; остальные три типа мировоззренческих убеждений снижают эту чувствительность. Вера в непредсказуемость обратно связана с личной ответственностью, в то время как вера в детерминизм коррелирует с ответственностью незначимо. Неожиданной оказалась отрицательная корреляция 
веры в научный детерминизм с удовлетворенностью потребности в компетентности. Это можно объяснить тем, что когнитивная установка на средовые и биологические факторы повышает чувствительность индивида в отношении своих знаний и навыков, необходимых для эффективной деятельности.

\section{Обсуждение}

Как следует из представленных результатов, русскоязычный перевод методики веры в свободу/детерминизм обнаруживает хорошие психометрические характеристики, что проявляется в параметрах структурной модели при допущении о взаимосвязи ее шкал между собой, а также в показателях внутренней согласованности шкал (альфа Кронбаха). Оригинальная структура методики хорошо воспроизводится, что позволяет говорить о методике как о качественном исследовательском инструменте, по крайней мере, для использования в исследовательских целях. Формулировка ряда пунктов методики может быть улучшена, что повысит консистентность шкал, но их актуальные параметры позволяют использовать методику и в нынешнем виде, без дополнительных текстуальных изменений.

Проделанный анализ не только подтверждает конструктную валидность методики, но и подводит к интересным содержательным выводам. Наши данные подтверждают сделанные зарубежными авторами выводы о конструктивном характере веры в свободу человека как «самоосуществляющемся пророчестве». Действительно, вера в свободу значимо положительно коррелирует практически со всеми переменными, так или иначе отражающими характеристики психологического благополучия и личностных ресурсов: с удовлетворенностью жизнью, положительными эмоциями, диспозиционным и атрибутивным оптимизмом, осмысленностью жизни и всеми ее составляющими, всеми тремя аспектами жизненной позиции, удовлетворенностью всех трех базовых психологических потребностей (согласно модели теории самодетерминации), а также персональной ответственностью и чувствительностью к обратной связи. Эта центральная роль веры в свободу хорошо согласуется с опубликованными данными многолетнего всемирного мониторингового проекта изучения ценностей (Inglehart et al., 2008), в котором было обнаружено, что ощущение свободы выбора опосредует влияние большого количества макросоциальных индикаторов на страновом уровне на субъективное благополучие, объясняя около $30 \%$ дисперсии последнего.

Другие три вида убеждений, относящихся к свободе/детерминизму, гораздо меньше и слабее связаны с психологическими характеристиками. Так, вера в непредсказуемость значимо отрицательно связана с положительными эмоциями (незначимо - с отрицательными), атрибутивным (но не диспозиционным) оптимизмом, осмысленностью жизни, осознанностью жизни, ответственностью и чувствительностью к обратной связи, незначимо - с удовлетворенностью жизнью, удовлетворением базовых потребностей, активностью и гармонией в структуре жизненной позиции. По-видимому, эта вера связана со сравнительно слабой склонностью анализировать и понимать окружающий 
мир; ее выраженность не служит признаком проблем, но, возможно, несколько снижает эмоциональную насыщенность и полноту жизни. Вера в научный детерминизм значимо (отрицательно) коррелирует лишь с атрибутивным оптимизмом в ситуации успеха, активностью жизненной позиции, чувствительностью к обратной связи и удовлетворением потребности в компетентности; вероятно, она снижает активность и целеустремленность личности. Наиболее неоднозначной выглядит вера в фаталистический детерминизм. С одной стороны, она значимо отрицательно коррелирует с атрибутивным оптимизмом в ситуации успеха, активностью и осознанностью жизненной позиции, чувствительностью к обратной связи, что похоже на паттерн корреляционных связей веры в научный детерминизм. С другой стороны, в отличие от последней, она также положительно коррелирует с удовлетворенностью жизнью и с чувством гармонии с ней. Эти данные хорошо согласуются с представлениями об амбивалентных психологических следствиях религиозной веры: в наиболее распространенном варианте она представляет собой принятие божественной причинности как отказ от субъектности в обмен как раз на чувство гармонии и удовлетворенности.

Перспективой дальнейших исследований может стать анализ взаимосвязей рассмотренных верований не только с личностными характеристиками, но и с другими убеждениями, например, верой в справедливый или опасный мир.

Проделанная работа привела к пополнению арсенала доступных русскоязычным психологам методических средств новым инструментом для изучения внутреннего мира и мировоззренческих убеждений личности.

\section{Литература}

Газзанига, М. (2017). Кто за главного? Свобода воли с точки зрения нейробиологии. М.: ACT/Corpus.

Гордеева, Т. О., Осин, Е. Н., Шевяхова, В. Ю. (2009). Диагностика оптимизма как стиля объяснения успехов и неудач: опросник СТОУН. М.: Смысл.

Гордеева, Т. О., Сычев, О. А., Осин, Е. Н. (2010). Разработка русскоязычной версии теста диспозиционного оптимизма (LOT). Психологическая диагностика, 2, 36-64.

Джеймс, У. (1997). Воля к вере. М.: Республика.

Леонтьев, Д. А. (1992). Тест смысложизненных ориентаций. М.: Смысл.

Леонтьев, Д. А. (2000). Психология свободы: к постановке проблемы самодетерминации личности. Психологический журнал, 21(1), 15-25.

Леонтьев, Д. А. (2018). Илья Пригожин и психология ХХІ века. Психологический журнал, 39(3), 5-14. doi:10.7868/S0205959218030017

Леонтьев, Д. А., Моспан, А. Н., Митина, О. В. (2019). Разработка и валидизация шкалы чувствительности к обратной связи. Психологические исследования: электронный научный журнал, 12(63). Режим доступа: http://psystudy.ru

Леонтьев, Д. А., Шильманская, А. Е. (2019). Жизненная позиция личности: от теории к операционализации. Вопросы психологии, 1, 90-100. 
Осин, Е. Н. (2012). Измерение позитивных и негативных эмоций: разработка русскоязычного аналога методики PANAS. Психология. Журнал Высшей школы экономики, 9(4), 91-110.

Осин, Е. Н., Леонтьев, Д. А. (2020). Краткие русскоязычные шкалы диагностики субъективного благополучия: психометрические характеристики и сравнительный анализ. Мониторинг общественного мнения: Экономические и социальнье перемены, 1, 117-142. doi:10.14515/monitoring.2020.1.06

Фромм, Э. (1992). Душа человека. Ее способность к добру и злу. М.: Республика.

Ссылки на зарубежные источники см. в разделе References после англоязычного блока.

Пункты методики ВСД и их психометрические показатели

Приложение

\begin{tabular}{|l|c|c|c|c|c|c|}
\hline & Среднее & $\begin{array}{c}\text { Стандартная } \\
\text { ошибка } \\
\text { среднего }\end{array}$ & $\begin{array}{c}\text { Стандартное } \\
\text { отклонение }\end{array}$ & Дисперсия & Асимметрия & Эксцесс \\
\hline $\begin{array}{l}\text { 1. Я верю, что будущее уже } \\
\text { предопределено судьбой. }\end{array}$ & 2.22 & 0.0558 & 1.070 & 1.150 & 0.549 & -0.447 \\
\hline $\begin{array}{l}\text { 2. Биологические свойства } \\
\text { людей определяют их } \\
\text { таланты и личность. }\end{array}$ & 2.79 & 0.0486 & 0.938 & 0.879 & 0.080 & -0.266 \\
\hline $\begin{array}{l}\text { 3. Человеческая история } \\
\text { управляется в основном } \\
\text { случайностями. }\end{array}$ & 2.79 & 0.0533 & 1.030 & 1.050 & 0.210 & -0.522 \\
\hline $\begin{array}{l}\text { 4. Люди полностью конт- } \\
\text { ролируют те решения, } \\
\text { которые они принимают. }\end{array}$ & 3.31 & 0.0526 & 1.010 & 1.030 & -0.117 & -0.745 \\
\hline $\begin{array}{l}\text { 5. Как бы вы ни старались, } \\
\text { вы не можете изменить } \\
\text { свою судьбу. }\end{array}$ & 1.83 & 0.0498 & 0.960 & 0.921 & 1.350 & 1.780 \\
\hline $\begin{array}{l}\text { 6. Психологи и психиатры } \\
\text { рано или поздно смогут } \\
\text { предсказывать все поведе- } \\
\text { ние людей. }\end{array}$ & 2.3 & 0.0603 & 1.160 & 1.350 & 0.614 & -0.469 \\
\hline $\begin{array}{l}\text { 7. Никто не может предви- } \\
\text { деть, что произойдет в } \\
\text { этом мире. }\end{array}$ & 3.46 & 0.0575 & 1.110 & 1.220 & -0.374 & -0.639 \\
\hline $\begin{array}{l}\text { 8. Люди должны нести } \\
\text { полную ответственность за } \\
\text { плохие выборы, которые } \\
\text { они делают. }\end{array}$ & 3.81 & 0.0528 & 1.020 & 1.040 & -0.685 & -0.005 \\
\hline $\begin{array}{l}\text { 9. У судьбы для каждого } \\
\text { есть свой план. }\end{array}$ & 2.39 & 0.0654 & 1.260 & 1.580 & 0.478 & -0.886 \\
\hline $\begin{array}{l}\text { 10. Ваши гены определяют } \\
\text { ваше будущее. }\end{array}$ & 2.36 & 0.0509 & 0.982 & 0.965 & 0.319 & -0.613 \\
\hline $\begin{array}{l}\text { 11. Жизнь не более пред- } \\
\text { сказуема, чем кидание } \\
\text { монетки или костей. }\end{array}$ & 2.95 & 0.0577 & 1.110 & 1.240 & -0.129 & -0.874 \\
\hline
\end{tabular}




\begin{tabular}{|c|c|c|c|c|c|c|}
\hline $\begin{array}{l}\text { 12. Люди в состоянии пре- } \\
\text { одолеть любые препят- } \\
\text { ствия, если действительно } \\
\text { захотят. }\end{array}$ & 4.05 & 0.0506 & 0.976 & 0.952 & -0.920 & 0.284 \\
\hline $\begin{array}{l}\text { 13. Что случится, то слу- } \\
\text { чится, и мы мало что } \\
\text { можем с этим поделать. }\end{array}$ & 2.3 & 0.0513 & 0.989 & 0.978 & 0.569 & -0.084 \\
\hline $\begin{array}{l}\text { 14. Наука выяснила, } \\
\text { насколько ваш интеллект } \\
\text { и личность зависят от } \\
\text { среды, в которой вы росли. }\end{array}$ & 3.22 & 0.0554 & 1.070 & 1.140 & -0.224 & -0.633 \\
\hline 15. Люди непредсказуемы. & 3.25 & 0.0523 & 1.010 & 1.010 & -0.034 & -0.698 \\
\hline $\begin{array}{l}\text { 16. Преступники несут } \\
\text { полную ответственность за } \\
\text { то плохое, что они делают. }\end{array}$ & 3.73 & 0.0519 & 0.999 & 0.997 & -0.699 & 0.004 \\
\hline $\begin{array}{l}\text { 17. Нравится это людям } \\
\text { или нет, их жизнью управ- } \\
\text { ляют скрытые силы. }\end{array}$ & 2.13 & 0.0552 & 1.070 & 1.140 & 0.710 & -0.204 \\
\hline $\begin{array}{l}\text { 18. Поведение людей, как } \\
\text { и остальных животных, } \\
\text { всегда подчиняется зако- } \\
\text { нам природы. }\end{array}$ & 2.46 & 0.0536 & 1.030 & 1.070 & 0.499 & -0.149 \\
\hline $\begin{array}{l}\text { 19. Жизнь трудно предви- } \\
\text { деть, потому что она полна } \\
\text { случайностей. }\end{array}$ & 3.55 & 0.0523 & 1.010 & 1.020 & -0.638 & -0.075 \\
\hline $\begin{array}{l}\text { 20. Удача играет большую } \\
\text { роль в жизни людей. }\end{array}$ & 3.6 & 0.0485 & 0.933 & 0.870 & -0.487 & 0.096 \\
\hline $\begin{array}{l}\text { 21. Люди обладают полной } \\
\text { свободой воли. }\end{array}$ & 3.24 & 0.0527 & 1.010 & 1.020 & -0.264 & -0.542 \\
\hline $\begin{array}{l}\text { 22. Характер родителей } \\
\text { определяет характер их } \\
\text { детей. }\end{array}$ & 3.05 & 0.0514 & 0.991 & 0.981 & -0.086 & -0.584 \\
\hline $\begin{array}{l}\text { 23. Люди всегда сами } \\
\text { виноваты в своих дурных } \\
\text { поступках. }\end{array}$ & 3.35 & 0.0523 & 1.010 & 1.020 & -0.201 & -0.445 \\
\hline $\begin{array}{l}\text { 24. От среды, в которой вы } \\
\text { росли в детстве, зависят } \\
\text { ваши успехи во взрослом } \\
\text { возрасте. }\end{array}$ & 3.4 & 0.0491 & 0.946 & 0.894 & -0.352 & -0.266 \\
\hline $\begin{array}{l}\text { 25. То, что происходит с } \\
\text { людьми, зависит от случая. }\end{array}$ & 2.78 & 0.0447 & 0.862 & 0.743 & 0.252 & -0.206 \\
\hline $\begin{array}{l}\text { 26. Сила рассудка всегда } \\
\text { может преодолеть жела- } \\
\text { ния тела. }\end{array}$ & 3.58 & 0.0569 & 1.100 & 1.200 & -0.534 & -0.441 \\
\hline $\begin{array}{l}\text { 27. Наше будущее нельзя } \\
\text { предвидеть. }\end{array}$ & 3.42 & 0.0529 & 1.020 & 1.040 & -0.165 & -0.499 \\
\hline Стандартная ошибка & & & & & 0.127 & 0.253 \\
\hline
\end{tabular}


Моспан Анастасия Никитична - младший научный сотрудник, Международная лаборатория позитивной психологии личности и мотивации, Национальный исследовательский университет «Высшая школа экономики».

Сфера научных интересов: психология личности, экзистенциальная психология, совладание с неопределенностью.

Контакты: amospan@hse.ru

Леонтьев Дмитрий Алексеевич - профессор, департамент психологии, факультет социальных наук; заведующий лабораторией, Международная лаборатория позитивной психологии личности и мотивации, Национальныи исследовательскии университет «Высшая школа экономики», доктор психологических наук.

Сфера научных интересов: психология мотивации, психодиагностика, философская антропология, психология личности.

Контакты: dleontiev@hse.ru

\title{
Approbation and Validation of the Freedom/Determinism Beliefs Inventory (FAD-Plus) in the Russian Sample
}

\author{
A.N. Mospan ${ }^{\mathrm{a}}$, D.A. Leontiev ${ }^{\mathrm{a}}$ \\ ${ }^{a}$ HSE University, 20 Myasnitskaya Str., Moscow, 101000, Russian Federation
}

\begin{abstract}
Worldview beliefs related to freedom vs. determinacy in the surrounding and inner world are the focus of active discussion and research in psychological science. The paper presents the results of approbation and construct validation of the Russian-language version of the freedom/determinism beliefs inventory FAD-Plus by D. Paulhus and J. Carey. The results of the research on the sample of first-year psychology students from Moscow universities $(\mathrm{N}=372)$ confirmed the original four-factor structure of the questionnaire, which embraces four scales: Fatalistic Determinism (Cronbach's $\alpha=.793$ ), Freedom (Cronbach's $\alpha=.777$ ), Unpredictability (Cronbach's $\alpha=.689$ ), Scientific Determinism (Cronbach's $\alpha=.675$ ). For the construct validation of the questionnaire, correlations of the inventory scales with a number of variables referring to well-being, motivation and self-regulation were considered, including dispositional and attributional optimism, subjective well-being and emotional state, meaningfulness of life and attitudes to one's life, psychological needs satisfaction, personal responsibility. The results suggest that the Russian-language version of the freedom/determinism beliefs inventory has good psychometric properties and can be used as a helpful research instrument. Correlation analysis revealed positive relations between the belief in freedom and multiple characteristics of wellbeing: satisfaction with life, positive emotions, optimism, meaningfulness of life, attitudes to one's life, satisfaction of basic psychological needs, personal responsibility and sensitivity to feedback. Other types of beliefs showed weaker correlations with psychological characteristics. The belief in unpredictability was negatively associated with positive emotions, attributive optimism, meaningfulness of life, awareness of life, responsibility and sensitivity to feedback. The belief in scientific determinism had negative correlations with attributional optimism in a situation of
\end{abstract}


success, activity regarding one's life, sensitivity to feedback and satisfaction of the need for competence. Belief in fatalistic determinism is in many ways similar to scientific determinism in terms of correlations, but unlike the latter, it also positively correlated with satisfaction with life and a sense of harmony with one's life.

Keywords: worldview, freedom/determinism beliefs, FAD-Plus, well-being, test validation.

\section{References}

Baer, J., Kaufman, J. C., \& Baumeister, R. F. (Eds.). (2008). Are we free? Psychology and free will. New York, NY: Oxford University Press.

Baumeister, R. F., Masicampo, E. J., \& DeWall, C. N. (2009). Prosocial benefits of feeling free: Disbelief in free will increases aggression and reduces helpfulness. Personality and Social Psychology Bulletin, 35(2), 260-268. doi:10.1177/0146167208327217

Browne, M. W. (2001). An overview of analytic rotation in exploratory factor analysis. Multivariate Behavioral Research, 36(1), 111-150.

Caspar, E. A., Verdin, O., Rigoni, D., Cleeremans, A., \& Klein, O. (2017). What do you believe in? French translation of the FAD-Plus to assess beliefs in free will and determinism and their relationship with religious practices and personality traits. Psychologica Belgica, 57(1), 1-16. doi:10.5334/pb.321

Crumbaugh, J. C., \& Maholick, L. T. (1981). PIL [Purpose in Life Test]. Viktor Frankl Institute of Logotherapy.

Fromm, E. (1992). Dusha cheloveka. Ee sposobnost' $k$ dobru i zlu [The heart of man: Its genius for good and evil]. Moscow: Respublica. (in Russian; trans. of: Fromm, E. (1964). The heart of man: Its genius for good and evil. Harper \& Row.)

Gazzaniga, M. (2017). Kto za glavnogo? Svoboda voli s tochki zreniya neirobiologii [Who's in charge? Free will and the science of the brain]. Moscow: AST/Corpus. (in Russian; trans. of: Gazzaniga, M. S. (2011). Who's in charge? Free will and the science of the brain. New York, NY: Ecco.)

Gordeeva, T. O., Osin, E. N., \& Shevyakhova V. Yu. (2009). Diagnostika optimizma kak stilya obyasneniya uspekhov i neudach: Oprosnik STOUN [The diagnostics of optimism as an explanatory style of success and failure: STOUN questionnaire]. Moscow: Smysl. (in Russian)

Gordeeva, T. O., Sychev, O. A., \& Osin, E. N. (2010). Razrabotka russkoyazychnoi versii testa dispozitsionnogo optimizma (LOT) [Development of a Russian-language version of the dispositional optimism test (LOT)]. Psikhologicheskaya Diagnostika, 2, 36-64. (in Russian)

Inglehart, R., Foa, R., Peterson, C., \& Welzel, C. (2008). Development, freedom, and rising happiness: A global perspective (1981-2007). Perspectives on Psychological Science, 3(4), 264-285.

James, W. (1997). Volya k vere [The will to believe]. Moscow: Respublica. (in Russian)

Keller, J. (2005). In genes we trust: the biological component of psychological essentialism and its relationship to mechanisms of motivated social cognition. Journal of Personality and Social Psychology, 88(4), 686-702. doi:10.1037/0022-3514.88.4.686

Kondratowicz-Nowak, B., Duda, J., Wierzbicki, J., \& Zawadzka, A. M. (2018). The Free Will and Determinism Plus (FAD-Plus) scale: The validity and reliability of the Polish adaptation. Roczniki Psychologiczne, 21(4), 345-364.

Leontiev, D. A. (1992). Test smyslozhiznennykh orientatsii [Life-Purpose Orientations Test]. Moscow: Smysl. (in Russian) 
Leontiev, D. A. (2000). The psychology of freedom: Toward the investigation of person's self-determination. Psikhologicheskii Zhurnal, 21(1), 15-25. (in Russian)

Leontiev, D. A. (2018). Ilya Prigogine and the psychology of XXI century. Psikhologicheskii Zhurnal, 39(3), 5-14. doi:10.7868/S0205959218030017 (in Russian)

Leontiev, D. A., \& Shilmanskaya, A. E. (2019). Personal life position: Making theoretical notions operational. Voprosy Psikhologii, 1, 90-100. (in Russian)

Leontiev, D. A., Mospan, A. N., \& Mitina, O. V. (2019). Elaboration and validation of the feedback sensitivity scale. Psikhologicheskie Issledovaniya, 12(63). Retrieved from http://psystudy.ru (in Russian)

Levenson, H. (1973). Multidimensional locus of control in psychiatric patients. Journal of Consulting and Clinical Psychology, 41(3), 397-404. doi:10.1037/h0035357

Li, J., Zhao, Y., Lin, L., Chen, J., \& Wang, S. (2018). The freedom to persist: Belief in free will predicts perseverance for long-term goals among Chinese adolescents. Personality and Individual Differences, 121, 7-10.

Libet, B., Wright Jr, E. W., \& Gleason, C. A. (1983). Preparation-or intention-to-act, in relation to preevent potentials recorded at the vertex. Electroencephalography and Clinical Neurophysiology, 56(4), 367-372. doi:10.1016/0013-4694(83)90262-6

Merton, R. K. (2016). The self-fulfilling prophecy. The Antioch Reviere, 74(3), 504-521. doi:10.7723/antiochreview.74.3.0504

Nichols, S. (2006). Folk intuitions on free will. Journal of Cognition and Culture, 6(1-2), 57-86. doi:10.1163/156853706776931385

Osin, E. N. (2012). Measuring positive and negative affect: Development of a Russian-language analogue of PANAS. Psychology. Journal of Higher School of Economics, 9(4), 91-110. (in Russian)

Osin, E. N., \& Leontiev, D. A. (2020). Brief Russian-language instruments to measure subjective wellbeing: Psychometric properties and comparative analysis. Monitoring of Public Opinion: Economic and Social Changes Journal (Public Opinion Monitoring), 1, 117-142. doi:10.14515/monitoring.2020.1.06 (in Russian)

Paulhus, D. L., \& Carey, J. M. (2011). The FAD-Plus: Measuring lay beliefs regarding free will and related constructs. Journal of Personality Assessment, 93(1), 96-104. doi:10.1080/00223891.2010.528483

Rakos, R. F., Laurene, K. R., Skala, S., \& Slane, S. (2008). Belief in free will: Measurement and conceptualization innovations. Behavior and Social Issues, 17(1), 20-40. doi:10.5210/bsi.v17i1.1929

Rotter, J. B. (1966). Generalized expectancies for internal versus external control of reinforcement. Psychological Monographs: General and Applied, 80(1), 1-28. doi:10.1037/h0092976

Sheldon, K. M., \& Hilpert, J. C. (2012). The balanced measure of psychological needs (BMPN) scale: An alternative domain general measure of need satisfaction. Motivation and Emotion, 36(4), 439451. doi:10.1007/s11031-012-9279-4

Sheldon, K. M., Gordeeva, T., Leontiev, D., Lynch, M. F., Osin, E., Rasskazova, E., \& Dementiy, L. (2018). Freedom and responsibility go together: Personality, experimental, and cultural demonstrations. Journal of Research in Personality, 73, 63-74. doi:10.1016/j.jrp.2017.11.007

Stroessner, S. J., \& Green, C. W. (1990). Effects of belief in free will or determinism on attitudes toward punishment and locus of control. The Journal of Social Psychology, 130(6), 789-799. doi:10.1080/00224545.1990.9924631

Viney, W., Waldman, D. A., \& Barchilon, J. (1982). Attitudes toward punishment in relation to beliefs in free will and determinism. Human Relations, 35(11), 939-949. doi:10.1177/001872678203501101 
Vohs, K. D., \& Schooler, J. W. (2008). The value of believing in free will: Encouraging a belief in determinism increases cheating. Psychological Science, 19(1), 49-54. doi:10.1111/j.14679280.2008.02045.x

Wegner, D. M. (2002). The illusion of conscious will. The MIT Press.

Westlake, B., \& Paulhus, D. L. (2007, June). Crime and punishment: personality and mitigating factors. Poster Presented at the Meeting of the Canadian Psychological Association, Ottawa, ON, Canada.

Anastasia N. Mospan - Junior Research Fellow, International Laboratory of Positive Psychology of Personality and Motivation, HSE University.

Research Area: psychology of personality, existential psychology, coping with uncertainty.

E-mail: amospan@hse.ru

Dmitry A. Leontiev - professor, School of Psychology, Faculty of Social Sciences; Head, International Laboratory of Positive Psychology of Personality and Motivation, HSE University.

Research Area: psychology of motivation, psychodiagnostics, philosophical anthropology, psychology of personality.

E-mail: dleontiev@hse.ru 
Психология. Журнал Высшей школы экономики.

2021. T. 18. № 1. C. 129-144. DOI: 10.17323/1813-8918-2021-1-129-144

\title{
Cmambu
}

\section{ИНТЕЛЛЕКТ РЕГИОНОВ РОССИИ СКВОЗЬ ПРИЗМУ СОЦИАЛЬНЫХ СЕТЕЙ}

\author{
Е.А. ВАЛУЕВА ${ }^{\text {a }}$ Е.М. ЛАПТЕВА ${ }^{\mathrm{a}}$, А.А. ГРИГОРЬЕВ
}

а ФГБУН «Институт психологии Российской академии наук», 129366, Москва, ул. Ярославская, д. $13, \kappa .1$

\section{Резюме}

В работе исследуются связи характеристик текстовых сообщений пользователей социальной сети ВКонтакте с интеллектом. Анализ проводится на региональном уровне: единицами анализа являются регионы Российской Федерации, сопоставляются усредненные показатели сообщений пользователей, проживающих в регионах, с оценками интеллектуального потенциала регионов. Рассмотренные характеристики сообщений включали формальные и грамматические показатели, а также эмоциональные компоненты сообщений. Оценки интеллектуального потенциала регионов были получены путем усреднения региональных результатов тестирования интеллекта мужчин, желающих поступить на военную службу по контракту, и данных об образовательных достижениях регионов (средний результат ЕГЭ лиц, поступивших в российские вузы в 2018 г.). Анализ показал, что четыре формальных и грамматических показателя (средняя длина слова, относительное количество вводных слов и словосочетаний, относительное количество простых непроизводных предлогов и средняя длина предложения), которые могут рассматриваться как маркеры когнитивной сложности текста, вносят независимый вклад в предсказание регионального интеллекта и в совокупности объясняют $60 \%$ его дисперсии. Эмоциональные компоненты сообщений не вносят независимого от маркеров когнитивной сложности текста вклада в предсказание регионального интеллекта. Кроме того, была показана связь регионального интеллекта с активностью и грамотностью пользователей социальной сети ВКонтакте. Значение полученных результатов заключается в том, что они ведут к созданию средств оценки интеллекта по тексту, которые будут иметь, можно полагать, определенные преимущества перед традиционными психометрическими методами его измерения в исследованиях региональных различий интеллекта и его изменения во времени.

Ключевые слова: интеллект, цифровые следы, социальная сеть, ВКонтакте, когнитивная сложность, автоматический анализ текста, эмоциональная окраска текста, регионы России.

Работа выполнена при поддержке РФФИ, проект № 17-29-09155 офи_м. 


\section{Введение}

В последнее время все больший интерес в психологии вызывает исследование активности пользователей в социальных сетях. Привлекательность этого материала заключается в его несомненной экологической валидности: общение и самовыражение в интернет-пространстве происходят естественным образом, поэтому могут считаться идеальным объектом для психологического исследования. На настоящий момент показано, что цифровые следы человека (т.е. совокупность его действий в сети Интернет) могут быть в достаточной степени хорошими предикторами личностных черт Большой пятерки (в особенности - экстраверсии и открытости опыта), а также некоторых эмоциональных состояний - тревоги, депрессии (Латынов, Овсянникова, 2020). При этом наиболее часто анализируется лексика текстовых сообщений пользователей, «лайки», а также визуальный материал - аватарки (фото пользователей) и размещаемые в постах фото или картинки. Обращает на себя внимание тот факт, что в исследованиях цифровых следов человека не очень популярно направление, связанное с изучением когнитивных способностей. Лишь в одной из работ М. Косински с соавт. было показано, что интеллект пользователей Фейсбука может быть предсказан лайками определенных категорий (например, люди с высоким интеллектом лайкают категории «Властелин колец», а с низким - «Харлей Дэвидсон») (Kosinski et al., 2013). Некоторое время назад также были популярны работы, в которых изучались текстовое поведение в социальных сетях, а именно использование текстизмов (например, «4 you», «2 you», «2 B or not to be»), и связь текстового поведения с навыками чтения, грамотностью и т.д. Было показано, что, несмотря на популярность в англоязычных СМИ мнения об увлечении текстизмами как об опасной тенденции для литературного развития и грамотности детей, исследования не подтверждают эту точку зрения (Wood et al., 2014). Результаты показывают, что дети, использующие больше текстизмов, демонстрируют лучшие способности в вербальных рассуждениях и орфографии, лучше читают, имеют больший словарный запас (Plester et al., 2008, 2009). Стоит отметить, однако, что исследования на других возрастных группах (подростки, взрослые) не дают столь однозначной картины (Waldron et al., 2015).

Исследования, имеющие истоки в психолингвистике, демонстрируют, что тексты могут быть охарактеризованы с точки зрения их когнитивной сложности, которая, в свою очередь, может предсказывать уровень интеллектуальных способностей как читателя, для которого этот текст создан (Валуева и др., 2017), так и самого автора (Smirnov, 2017). В работе И. Смирнова в качестве единственного показателя сложности текста была взята средняя длина слова в текстовых сообщениях пользователей ВКонтакте. Средняя длина слова хорошо дифференцировала выпускников высоко- и низкорейтинговых школ Санкт-Петербурга и коррелировала с возрастом пользователя в момент написания поста.

В работе Валуевой с соавт. был выявлен целый ряд показателей, отражающих когнитивную сложность текстов детской художественной литературы. 
Среди них были формальные показатели, характеризующие объем текста (длина слов, длина предложений, количество запятых и т.д.), а также морфологические (использование разных типов слов и частей речи) и синтаксические компоненты (типы предложений), позволяющие проанализировать изменения, происходящие с текстом по мере взросления читательской аудитории.

Упомянутые работы И. Смирнова (2017) и Е. Валуевой с соавт. (2017) являются примером принципиально нового подхода к исследованию связи когнитивных способностей и особенностей текстов. Связи показателей в них изучаются не на индивидуальном, а на групповом уровне. Начало интенсивным исследованиям в этом направлении положила первая книга Р. Линна и T. Ванханена «IQ и благосостояние наций» (Lynn, Vanhanen, 2002), в которой было показано, что интеллект страны (национальный IQ) коррелирует со множеством социально-экономических показателей, характеризующих благосостояние стран. В значительной части работ по поиску социально-экономических коррелятов интеллекта сравниваются показатели стран между собой. Однако существуют и работы на уровне регионов одной страны, демонстрирующие сходные результаты. Подобные исследования проведены по регионам Франции, США, Италии, Португалии, Испании, Китая, Японии, Финляндии, Индии, Турции, России (см.: Grigoriev et al., 2016).

Настоящее исследование также основано на изучении больших групп населения. В нашем случае единицами анализа являются регионы Российской Федерации. Цель работы состояла в том, чтобы изучить взаимосвязь особенностей текстового поведения пользователей социальной сети ВКонтакте с интеллектуальным потенциалом регионов России.

\section{Методика}

\section{Сбор данных из сочцильной сети ВКонтакте}

Данные для анализа были загружены из популярной в России социальной сети ВКонтакте, которая предоставляет программный интерфейс (API) для взаимодействия и загрузки ресурсов на программном уровне. Загружались сообщения пользователей, которые указали в профиле возраст от 18 лет и хотя бы одно учебное заведение, а также имеют хотя бы одного друга из указанного учебного заведения. Последнее требование было сформулировано для того, чтобы по возможности отсеять «фейковые» аккаунты (Смирнов и др., 2016). Алгоритм сбора обращался к сайту vk.com с запросом, содержащим название региона и города, и выбирал случайным образом пользователей, имеющих не менее 10 общедоступных публикаций, начиная отсчет от самых свежих публикаций (2019) и до начала 2012 г. Считались только публикации, содержащие текст (т.е. исключались записи с приложениями без комментариев от владельца исследуемого профиля) и не содержащие ссылку на приложение ВКонтакте. Сбор данных по региону останавливался, когда для региона было набрано 3200 пользователей, либо раньше, если исчерпывались доступные профили пользователей, соответствующие условиям. 
Помимо самих текстов сообщений (постов), для каждого пользователя были также загружены данные о возрасте, поле, числе друзей, а для каждого сообщения - тип приложения (нет, фото, аудио, видео и т.д.) и количество его просмотров (для записей начиная с 1 января 2017 г.).

\section{Предварительная обработка данных}

Первоначально были загружены сообщения 315441 пользователей старше 18 лет из 85 регионов России, всего 5457945 непустых (т.е. содержащих какой-либо текст) сообщений (постов).

Часть сообщений имела признаки автоматического генерирования приложениями ВКонтакте или посторонними сайтами. Например, «Нажми на ссылку, чтобы вступить в мой клан...», «Клевер - ежедневная онлайн-викторина...», «У меня новый Уровень Азарта и куча бонусов...» и т.д. Часть сообщений содержала только гиперссылку, без каких-либо пояснений пользователя. Такие сообщения мы исключили из анализа (всего было установлено около 150 различных признаков, по которым сообщения исключались из анализа). Также были исключены данные пользователей, отметивших в профиле возраст более 70 лет. Анализ данных этих профилей показал, что тексты сообщений демонстрируют случайным образом распределенные результаты всех показателей. Мы предположили, что эти пользователи в большинстве своем являются школьниками, которым ВКонтакте не позволяет указать свой реальный возраст.

В результате в анализ вошли данные 298806 пользователей и 4600023 сообщений этих пользователей. На каждого пользователя приходится от 1 до 333 записей с медианой 8 записей у пользователя. Общее число слов в записях пользователя варьировало от 1 до 146729 (медиана - 55).

Для дальнейшего анализа данные всех пользователей из региона были объединены в один массив. Все показатели для каждого региона вычислялись на основе этого объединенного массива. Количество постов, вошедших в массив, варьировало в зависимости от региона от 8197 (Чукотский автономный округ) до 150379 (г. Москва).

\section{Анализируемые показатели}

\section{Показатели текстовых сообщений}

Анализ данных проводился при помощи кода, написанного на языке R.

В сообщениях пользователей было выделено несколько частей:

1. Словесная часть. Под словом понимался набор кириллических или латинских букв (и дефиса), идущих непрерывно.

2. Эмотиконы (смайлы), т.е. набор типографических знаков, изображающих эмоцию. 
3. Хештеги, т.е. набор символов (одно или несколько слов, идущих непрерывно), начинающийся со знака \#. Хештеги были удалены из текста и не использовались в дальнейшем анализе.

Хештеги и неэмотиконы из категории Юникода «Other symbol» были удалены из текста и не использовались в дальнейшем анализе.

\section{Словесная часть}

В словесной части сообщений была произведена оценка нескольких показателей. За основу были взяты показатели, которые использовались в статье Е.А. Валуевой с соавт. (Валуева и др., 2017), однако специфика текстов в социальных сетях не позволила абсолютно точно воспроизвести все переменные. Анализировались следующие характеристики.

I Формальные характеристики, связанные с общим объемом текстовой продукции:

1) число слов в одной записи (медиана по региону от среднего числа слов по записям пользователя), далее - средняя длина поста;

2) длина слова (медиана по региону от средней длины слова у пользователя);

3) количество точек в тексте (по отношению к общему количеству слов). Мы полагаем, что данный показатель, хотя и весьма приблизительно в случае с текстами в социальных сетях, отражает среднюю длину предложения (чем больше точек на слово, тем меньше длина предложения). Приблизительность оценки длины предложения связана с тем, что, как правило, пользователи не ставят точки (и не используют заглавных букв), если пишут одно короткое предложение, или могут применять эмотиконы и/или хештеги вместо знаков препинания;

4) количество запятых в тексте (по отношению к общему количеству слов).

\section{II Морфологические компоненты:}

5) количество вводных слов и словосочетаний (относительно общего количества слов в тексте). Примерами вводных слов являются такие, как «вероятно», «конечно», «видимо» и т.д. Предполагается, что вводные слова имеют множество особенностей и функций, усложняющих структуру высказывания;

6) количество компаративов, т.е. прилагательных и наречий в сравнительной степени (относительно общего количества слов в тексте), например: «дальше», «ближе», «веселее», «проще» и т.д. Слова, выражающие степень сравнения, вносят дополнительное логическое звено в характеристику объектов действительности, требуют осознания непростых взаимоотношений между ними, поэтому могут служить маркерами усложнения когнитивной организации;

7) количество простых непроизводных предлогов (относительно общего количества слов в тексте), например: «в», «за», «на», «под», «перед» и т.д. Грамматически предлоги отвечают за бо́льшую детализацию и визуализированность текста по сравнению с элементарными субъектно-предикатными 
предложениями типа «Мама мыла раму», поэтому их наличие может рассматриваться как маркер усложнения текста;

8) количество модальных частиц (относительно общего количества слов в тексте), например: «же», «неужели», «разве» и т.д. Модальные частицы вносят в предложение эмоционально-оценочные, вопросительные, уступительные и другие семантические оттенки, поэтому могут являться маркерами когнитивного усложнения текста.

\section{III Синтаксические компоненты:}

9) количество вопросительных и 10) количество восклицательных предложений (относительно общего количества слов в тексте). Количество восклицательных предложений оценивалось по количеству восклицательных знаков. Количество вопросительных предложений рассчитывалось как среднее zзначений двух показателей (коррелирующих на уровне 0.36) - количество знаков вопроса и количество вопросительных слов («какой», «куда», «откуда», «насколько» и т.д.).

\section{IV Эмоциональная окраска слов}

Для оценки эмоциональной окраски слов была использована база данных ENRuN (Люсин, Сысоева, 2017), содержащая 378 существительных русского языка, оцененных по эмоциональным категориям «радость», «грусть», «злость», «страх» и «отвращение». Четыре слова были исключены из анализа, поскольку их словоформы совпадали с другими словами (например, «горе» может означать название чувства, а может быть падежной формой слова «гора»). Был произведен поиск слов из словаря ENRuN (с учетом всех словоформ) в сообщениях пользователей ВКонтакте, и на основе этих совпадений был вычислен средний балл эмоциональной окраски слов по пяти категориям. Так как оценки по категориям высоко коррелировали между собой (факторный анализ продемонстрировал наличие одного фактора, объясняющего более $90 \%$ дисперсии), в качестве общего показателя были взяты факторные оценки по первому фактору. Оценки были инвертированы (умножены на -1) так, чтобы высокие значения соответствовали позитивной окрашенности слов, а низкие - негативной.

\section{Эмотиконы}

На сайте https://unicode-table.com/ были выбраны эмотиконы из основного набора. Выбранные эмотиконы мы разделили на три категории:

1) позитивные $(\mathrm{N}=25)$ - эмотиконы с различными вариантами улыбок;

$2)$ негативные $(\mathrm{N}=30)$ - эмотиконы с прямыми или опущенными уголками «губ», оскалом или круглым ртом, с графическими признаками страха;

3) жестовые $(\mathrm{N}=16)$ - изображения действий - губы, сложенные в поцелуй, руки в положении мольбы, закрытый руками рот, аплодисменты и т.д. 


\section{Показатели интеллектуального потенциала регионов РФ}

Для подсчета показателя интеллектуального потенциала регионов России (регионального интеллекта) были использованы две переменные. Во-первых, из работы К. Сугоняева с соавт. (Sugonyaev et al., 2018) были взяты оценки интеллекта регионов, полученные путем тестирования интеллекта мужчин, желающих поступить на военную службу по контракту (тестирование проводилось на сайте Министерства обороны РФ, выборка составила 238619 человек). Во-вторых, на основе данных, представленных на сайте Высшей школы экономики (https://ege.hse.ru/stata_2018), была произведена оценка интеллекта регионов по среднему баллу ЕГЭ лиц, поступивших в российские вузы в 2018 г. Оценка производилась следующим образом. В данных, представленных на сайте Высшей школы экономики, сообщены средние баллы ЕГЭ поступивших в каждый вуз на обучение по каждой специальности. Первым шагом было усреднение внутри регионов оценок лиц, поступивших на обучение по данной специальности, по вузам, со взвешиванием на численность поступивших. Таким образом, были получены средние оценки лиц, поступивших в данном регионе на обучение по данной специальности. Специальности различались по престижности. Например, в Алтайском крае средний балл ЕГЭ поступивших на обучение по специальности «Государственное и муниципальное управление» был 76.2, а поступивших на обучение по специальности «Вооружение» - всего 52.3; в Волгоградской области средний балл поступивших на эти две специальности составил 73.6 и 57.1 соответственно. Между тем вузы, обучающие по тем или иным специальностям, распределены по регионам неравномерно. Чтобы исключить этот источник вариации, на втором шаге баллы ЕГЭ были стандартизированы внутри специальностей. На третьем шаге стандартизированные оценки были усреднены по специальностям, в результате были получены региональные оценки интеллекта.

Так как два показателя достаточно высоко коррелировали между собой $(r=0.62)$, в качестве значения регионального интеллекта было взято среднее z-оценок по этим показателям. Лишь для одного из 85 регионов РФ (Ненецкий $\mathrm{AO}$ ) не была представлена ни одна из оценок (в регионе отсутствуют вузы, а прошедших тестирование на сайте Министерства обороны оказалось слишком мало (менее 100 человек), чтобы надежно оценить уровень интеллекта в регионе). В связи с этим весь анализ взаимосвязей регионального интеллекта с особенностями сообщений в ВКонтакте проводился для 84 регионов РФ.

\section{Результаты}

В таблице 1 приведены корреляции регионального интеллекта с выделенными показателями текстовых сообщений ВКонтакте.

Перечисленные показатели можно объединить в две большие группы показатели когнитивной сложности сообщений и показатели эмоциональной 
Корреляции регионального интеллекта с показателями текстовых сообщений ВКонтакте (коэффициенты корреляции Пирсона)

\begin{tabular}{|l|r|c|}
\hline \multicolumn{1}{|c|}{ Показатель } & $\boldsymbol{r}$ & \multicolumn{1}{c|}{$\boldsymbol{p}$} \\
\hline Среднее количество слов в посте & 0.39 & 0.000 \\
\hline Средняя длина слова & 0.64 & 0.000 \\
\hline Количество точек (длина предложений) & -0.23 & 0.034 \\
\hline Количество запятых & 0.24 & 0.032 \\
\hline Вводные слова & 0.44 & 0.000 \\
\hline Компаративы & 0.44 & 0.000 \\
\hline Непроизводные предлоги & 0.62 & 0.000 \\
\hline Частицы & 0.09 & 0.434 \\
\hline Вопросительные предложения & -0.23 & 0.033 \\
\hline Восклицательные предложения & 0.39 & 0.000 \\
\hline Эмоциональная окраска слов & 0.58 & 0.000 \\
\hline Позитивные эмотиконы & 0.06 & 0.599 \\
\hline Негативные эмотиконы & 0.25 & 0.021 \\
\hline Эмотиконы-жесты & 0.52 & 0.000 \\
\hline
\end{tabular}

составляющей сообщений пользователей ВКонтакте. Результаты будут представлены по каждой группе показателей отдельно.

\section{Связь регионального интеллекта с особенностями когнитивной составляющей сообщений пользователей ВКонтакте}

Из таблицы 1 видно, что показатели регионального интеллекта демонстрируют значимые и достаточно высокие корреляции с формальными и морфологическими характеристиками сообщений пользователей ВКонтакте. Наиболее высокая корреляция наблюдается со средней длиной слова (0.64), что неудивительно, так как длина слова является традиционной мерой сложности текста (Smirnov, 2017; Yasseri et al., 2012). Также положительные корреляции с региональным интеллектом наблюдаются для среднего количества слов в посте $(0.39)$, количества запятых $(0.24)$ и точек $(-0.24)^{1}$, вводных слов (0.44), компаративов (0.44) и непроизводных предлогов (0.62). Единственным показателем из словесной части сообщений, который, вопреки нашим ожиданиям, оказался не связанным с региональным интеллектом, явилось количество употребляемых частиц (0.09). Прямой пошаговый регрессионный анализ показал, что четыре показателя (длина слов, вводные слова, непроизводные предлоги и длина предложений) в совокупности объясняют $60 \%$ дисперсии регионального интеллекта (таблица 2). Остальные предикторы (количество слов в посте, количество запятых, компаративы) не вносили значимого вклада в регрессионную модель.

\footnotetext{
${ }^{1}$ Отрицательная корреляция свидетельствует о том, что более высокий интеллект связан с порождением более длинных предложений.
} 
Таблица 2

Результаты регрессионного анализа (зависимая переменная - региональный интеллект, независимые переменные - формальные и морфологические особенности сообщений пользователей)

\begin{tabular}{|l|r|r|r|r|c|c|}
\hline \multicolumn{1}{|c|}{ Предикторы } & \multicolumn{1}{c|}{ B } & Std. Error & $\boldsymbol{\beta}$ & $\boldsymbol{t}$ & $\boldsymbol{p}$ & $\mathbf{R}^{2}$ change $^{*}$ \\
\hline (Соnstant) & -40.73 & 5.86 & & -6.96 & 0.000 & \\
\hline Длина слов & 6.88 & 1.26 & 0.46 & 5.46 & 0.000 & 0.41 \\
\hline Вводные слова & 711.48 & 185.35 & 0.28 & 3.84 & 0.000 & 0.13 \\
\hline $\begin{array}{l}\text { Непроизводные } \\
\text { предлоги }\end{array}$ & 72.62 & 24.02 & 0.26 & 3.02 & 0.003 & 0.05 \\
\hline $\begin{array}{l}\text { Количество точек } \\
\text { (длина предложений) }\end{array}$ & -65.24 & 25.76 & -0.18 & -2.53 & 0.013 & 0.03 \\
\hline
\end{tabular}

* Изменение $\mathrm{R}^{2}$ указано для последовательных моделей, включающих в себя соответствующую переменную.

Из таблицы 1 также следует, что количество вопросительных предложений отрицательно коррелирует с интеллектом, а количество восклицательных предложений - положительно. Это противоречит результатам, полученным в исследовании Е.А. Валуевой с соавт. (Валуева и др., 2017), где было показано, что по мере роста когнитивных способностей предполагаемой читательской аудитории текста увеличивается количество вопросительных предложений и уменьшается количество восклицательных. Так как процитированные данные получены на принципиально другом материале (тексты детской художественной литературы), можно предположить, что вопросительные и восклицательные знаки в сообщениях социальных сетей не являются характеристикой когнитивной сложности текста, а отражают эмоциональную составляющую сообщения. Это предположение будет проверено в следующем разделе.

\section{Эмоциональная составляющая сообщений пользователей ВКонтакте и ее связь с региональным интеллектом}

В таблице 1 показано, что эмоциональная окраска используемых слов коррелирует с региональным интеллектом на достаточно высоком уровне (0.58). Также с региональным интеллектом коррелируют, как уже было сказано, использование вопросительных (-0.23) и восклицательных (0.39) знаков, негативных (0.25) и жестовых (0.52) эмотиконов. Использование позитивных эмотиконов (улыбающихся рожиц) никак не связано с интеллектом. В таблице 3 представлена корреляционная матрица «эмоциональных» переменных. Можно заметить, что паттерн корреляций данного набора переменных с эмоциональной окраской слов сходен с паттерном корреляций этих переменных с региональным интеллектом (отрицательная корреляция вопросительных предложений, отсутствие корреляции с позитивными эмотиконами, положительные корреляции - со всеми остальными). 
Таблица 3

Корреляционная матрица эмоциональных компонентов

\begin{tabular}{|l|c|c|c|c|c|}
\hline & $\begin{array}{c}\text { Эмоциональ- } \\
\text { ная окраска } \\
\text { слов }\end{array}$ & $\begin{array}{c}\text { Вопроси- } \\
\text { тельные } \\
\text { предложения }\end{array}$ & $\begin{array}{c}\text { Восклица- } \\
\text { тельные } \\
\text { предложения }\end{array}$ & $\begin{array}{c}\text { Позитивные } \\
\text { эмотиконы }\end{array}$ & $\begin{array}{c}\text { Негативные } \\
\text { эмотиконы }\end{array}$ \\
\hline $\begin{array}{l}\text { Вопросительные } \\
\text { предложения }\end{array}$ & $-0.429^{* *}$ & - & & & \\
\hline $\begin{array}{l}\text { Восклицательные } \\
\text { предложения }\end{array}$ & $0.728^{* *}$ & $-0.213^{*}$ & - & & \\
\hline $\begin{array}{l}\text { Позитивные } \\
\text { эмотиконы }\end{array}$ & 0.151 & 0.052 & -0.060 & - & - \\
\hline $\begin{array}{l}\text { Негативные } \\
\text { эмотиконы }\end{array}$ & $0.424^{* *}$ & -0.181 & 0.033 & $0.354^{* *}$ & - \\
\hline $\begin{array}{l}\text { Эмотиконы- } \\
\text { жесты }\end{array}$ & $0.639^{* *}$ & $-0.359^{* *}$ & $0.356^{* *}$ & 0.200 & $0.681^{* *}$ \\
\hline
\end{tabular}

${ }^{*} p<0.05,{ }^{* *} p<0.01$.

Таблица 4

Результаты регрессионного анализа (зависимая переменная - региональный интеллект, независимые переменные - эмоциональные компоненты сообщений пользователей)

\begin{tabular}{|l|c|c|c|c|c|c|}
\hline \multicolumn{1}{|c|}{ Предикторы } & $\mathbf{B}$ & Std. Error & $\boldsymbol{\beta}$ & $\boldsymbol{t}$ & $\boldsymbol{p}$ & $\mathbf{R}^{2}$ change $^{*}$ \\
\hline (Constant) & -0.547 & 0.261 & & -2.100 & 0.039 & \\
\hline $\begin{array}{l}\text { Эмоциональная окраска } \\
\text { слов }\end{array}$ & 0.383 & 0.105 & 0.418 & 3.643 & 0.000 & 0.333 \\
\hline Эмотиконы-жесты & 5.176 & 2.381 & 0.249 & 2.174 & 0.033 & 0.037 \\
\hline
\end{tabular}

* Изменение $\mathrm{R}^{2}$ указано для последовательных моделей, включающих в себя соответствующую переменную.

Прямой пошаговый регрессионный анализ показал, что две переменные (эмоциональная окраска слов и эмотиконы-жесты) объясняют 36\% дисперсии регионального интеллекта (см. таблицу 4), а все остальные переменные (вопросительные и восклицательные предложения, негативные эмотиконы) не вносят в модель значимого вклада.

По всей видимости, интеллект связан с эмоциональностью текстов и в силу этого - с использованием восклицательных и вопросительных предложений (знаков) как с дополнительными средствами выражения эмоций, помимо окраски слов. При этом примечательно, что восклицательные предложения передают позитивные эмоциии, а вопросительные - с негативные.

Затем мы проверили, вносят ли эмоциональные компоненты сообщений пользователей дополнительный вклад (по сравнению с когнитивными компонентами) в объяснение региональных различий в интеллекте. Результаты регрессионного анализа показали, что при контроле когнитивных компонентов вклад эмоциональных не значим $(p(\mathrm{~F}$ change $)=0.515)$ (таблица 5$)$. 
Таблица 5

Результаты регрессионного анализа (зависимая переменная - региональный интеллект, независимые переменные - когнитивные и эмоциональные компоненты сообщений пользователей)

\begin{tabular}{|l|r|c|c|c|c|}
\hline \multicolumn{1}{|c|}{ Предикторы } & \multicolumn{1}{c|}{ B } & Std. Error & $\boldsymbol{\beta}$ & $\boldsymbol{t}$ & $\boldsymbol{p}$ \\
\hline (Constant) & -36.93 & 6.76 & & -5.46 & 0.000 \\
\hline Длина слов & 6.24 & 1.38 & 0.41 & 4.51 & 0.000 \\
\hline Вводные слова & 689.02 & 187.51 & 0.27 & 3.67 & 0.000 \\
\hline Непроизводные предлоги & 60.68 & 26.31 & 0.22 & 2.31 & 0.024 \\
\hline Количество точек (длина предложений) & -5.38 & 27.78 & -0.15 & -1.99 & 0.050 \\
\hline Эмоциональная окраска слов & 0.08 & 0.10 & 0.08 & 0.80 & 0.427 \\
\hline Эмотиконы-жесты & 0.91 & 2.02 & 0.04 & 0.45 & 0.653 \\
\hline
\end{tabular}

Связь срегионального интеллекта с общей активностью и грамотностью пользователей ВКонтакте

Алгоритм загрузки данных позволил нам оценить параметр, который мы назвали общей активностью пользователей. Как было указано выше, для каждого пользователя загружались сообщения, начиная с самых новых и заканчивая хронологически более ранними. На основании даты публикации каждого сообщения нами был посчитан средний год публикации. Этот показатель (средний год публикации сообщений в периоде с 2012 по 2019 г.) свидетельствует об общей активности пользователей в социальной сети, так как наиболее активные пользователи будут иметь большее количество более свежих записей по сравнению с менее активными. Корреляция регионального интеллекта со средним годом публикации составила $0.77(p<0.0001)$. Частично эту связь можно объяснить увеличением длины слов в сообщениях, происходящим с течением времени (Smirnov, 2017), однако даже парциальная корреляция интеллекта с активностью пользователей при контроле длины слов осталась достаточно высокой и значимой $(r=0.58, p<0.0001)$.

Еще один параметр, который мы косвенно смогли оценить на основе полученных данных, - это грамотность пользователей. При оценке эмоциональной окраски сообщений мы производили подсчет частоты встречаемости слов из словаря ENRuN в сообщениях пользователей. Количество совпадений слов в сообщении со словами из словаря может рассматриваться как косвенная мера грамотности пользователей. Если слово не совпадает со словарем, это может быть связано как с тем, что его нет в тексте в принципе, так и с тем, что оно написано неправильно. В силу того что у нас нет особых оснований полагать, что распределение встречаемости слов, фиксируемых словарем ENRuN, не является равномерным в регионах, мы считаем, что разброс по этой переменной обусловлен правильным или неправильным написанием слов (т.е. грамотностью 
пользователей). Корреляция общего количества совпадений с эмоциональным словарем (при контроле общего количества слов в регионе) составила $0.41(p<0.0001)$.

\section{Обсуждение}

Первый момент, на который хотелось бы обратить внимание в обсуждении, - это вопрос о пригодности данных из социальных сетей для автоматического анализа.

Алгоритм сбора данных на этапе загрузки сообщений отфильтровывал пользователей по следующим параметрам: 1) пользователи, зарегистированные в одном из 85 регионов РФ; 2) пользователи, имеющие общедоступный профиль; 3) пользователи старше 18 лет; 4) пользователи, у которых указано хотя бы одно учебное заведение (школа или вуз); 5) пользователи, имеющие хотя бы одного друга из указанного учебного заведения; 6) пользователи, имеющие хотя бы одно непустое текстовое сообщение на своей странице. Чтобы собрать нашу выборку (315 441 пользователей), пришлось отсеять около 85 млн пользователей, которые не соответствовали перечисленным критериям отбора. Это составляет примерно $1 / 7$ всех пользователей ВКонтакте (на момент написания статьи общее количество зарегистрированных пользователей ВКонтакте составляло примерно 592.4 млн). На этапе обработки данных мы отсеяли еще около 1/5 собранных постов, которые оказались не пригодны для нашего анализа (автоматически сгенерированные ссылки и тексты, посты, состоящие из 1 буквы, хештеги и т.д.).

Однако, несмотря на использование достаточно строгих критериев отбора, удалось собрать выборку, в которой были хорошо представлены все регионы страны. Таким образом, получение валидных данных из социальных сетей возможно, но требует организации правильной процедуры автоматического отбора.

Во-вторых, центральным в данном исследовании является вопрос о пригодности данных из социальных сетей для оценки интеллекта населения регионов РФ. Значимые корреляции между рядом показателей текстовых сообщений и оценками интеллекта дают основания для положительного ответа на этот вопрос. Это укрепляет оптимизм, который вселяют результаты недавних исследований (Валуева и др., 2017; Woodley of Menie et al., 2015), относительно перспектив создания средств оценки интеллекта, в частности группового, по текстам. Важность появления таких средств трудно переоценить. Во-первых, не секрет, что оценивание регионального интеллекта, его динамики с помощью психометрических тестов зачастую связано с большими организационными трудностями. Психологам нередко приходится полагаться на результаты исследований образовательных достижений, которые не везде бывают легко доступны и могут быть далеко не столь валидной мерой регионального интеллекта, как это принять думать. Появление средств диагностики интеллекта по легко доступному материалу - текстам, нужные параметры выборок которого исследователи смогут обеспечить, позволит резко 
увеличить количество и улучшить качество оценок регионального интеллекта. Во-вторых, как отмечают М. Вудли оф Мени с соавт. (Woodley of Menie et al., 2015), частота правильных ответов на пункты психометрических тестов с вариантами ответа (а таких большинство) увеличивается за счет использования респондентами тактик угадывания. Из текстов же можно извлечь более экологически валидные данные о изменении интеллекта во времени (Ibid.), что обуславливает значение разработки средств оценки интеллекта по текстам для исследований эффекта Флинна.

Полученные результаты довольно близко подводят к созданию одного из средств оценки интеллекта по тексту - опирающегося на формальные и грамматические показатели текста. Четыре таких показателя (средняя длина слова, количество вводных слов и словосочетаний относительно общего количества слов в тексте, количество простых непроизводных предлогов относительно общего количества слов в тексте и средняя длина предложения, оцениваемая по количеству точек по отношению к общему количеству слов) в совокупности объяснили $60 \%$ дисперсии регионального интеллекта. Эти показатели могут рассматриваться как маркеры когнитивной сложности текста, что и обусловило их использование в данном исследовании. Дальнейшая работа в этом направлении будет заключаться, во-первых, в оптимизации состава таких показателей, а во-вторых, в сопоставлении оценок регионального интеллекта с социально-экономическими показателями регионов РФ.

Проведенное исследование показало также неэффективность эмоциональных компонентов сообщений как независимых от маркеров когнитивной сложности текста предикторов регионального интеллекта. Этот негативный результат, однако, ставит вопрос об источниках корреляций этих компонентов с региональным интеллектом. Кроме того, показана связь активности и грамотности пользователей социальной сетью ВКонтакте с региональным интеллектом. Связь с активностью представляет собой, вероятно, одну из труднообъяснимых связей интеллекта (другим примером является его связь с политическими ориентациями), что же касается связи с грамотностью, то этот результат, не являясь, напротив, неожиданным (см., например: Григорьев и др., 2015), нуждается в дальнейшей проверке.

\section{Выводы}

По результатам проведенного исследования можно сделать следующие выводы.

1. Социальные сети являются источником пригодных для автоматического анализа данных.

2. Формальные и грамматические показатели текста целесообразно использовать при создании средств оценки регионального интеллекта по текстам.

3. Эмоциональные компоненты сообщений нецелесообразно использовать для оценки регионального интеллекта по текстам. 


\section{Литература}

Валуева, Е. А., Данилевская, Н. М., Лаптева, Е. М., Ушаков, Д. В. (2017). Когнитивная сложность художественных текстов для детей: квантитативные методы оценки. Вопросы психолингвистики, 31(1), 42-61.

Григорьев, А. А., Лаптева, Е. М., Ушаков, Д. В. (2015). Образовательные достижения районов Московской области воспроизводят уровень грамотности в ХІХ в. Сибирский психологический журнал, 56, 69-85.

Латынов, В. В., Овсянникова, В. В. (2020). Прогнозирование психологических характеристик человека на основании его цифровых следов. Психология. Журнал Высшей школы экономики, $17(1), 166-180$.

Люсин, Д. В., Сысоева, Т. А. (2017). Эмоциональная окраска имен существительных: база данных ENRuN. Психологический журнал, 38(2), 122-131.

Смирнов, И. Б., Сивак, Е. В., Козьмина, Я.Я. (2016). В поисках утраченных профилей: достоверность данных «ВКонтакте» и их значение для исследований образования. Вопросы образования, 4, 106-122.

Ссылки на зарубежные источники см. в разделе References после англоязычного блока.

Валуева Екатерина Александровна - научный сотрудник, лаборатория психологии и психофизиологии творчества, ФГБУН «Институт психологии Российской академии наук», кандидат психологических наук.

Сфера научных интересов: когнитивная психология, интеллект, творчество.

Контакты: ekval@list.ru

Лаптева Екатерина Михайловна - научный сотрудник, лаборатория психологии и психофизиологии творчества, ФГБУН «Институт психологии Российской академии наук», кандидат психологических наук.

Сфера научных интересов: кристаллизованный интеллект, потребность в познании, когнитивные и мотивационные механизмы кристаллизованного интеллекта.

Контакты: ek.lapteva@gmail.com

Григорьев Андрей Александрович - ведущий научный сотрудник, лаборатория психологии и психофизиологии творчества, ФГБУН «Институт психологии РАН», доктор филологических наук, доцент.

Сфера научных интересов: интеллект, индивидуальные различия, психолингвистика.

Контакты: andrey4002775@yandex.ru 


\title{
Regional IQ Differences in Russia through the Prism of Social Media
}

\author{
E.A. Valueva ${ }^{a}$, E.M. Lapteva ${ }^{a}$, A.A. Grigoriev ${ }^{a}$ \\ ${ }^{a}$ Institute of Psychology, Russian Academy of Sciences, 13 build. 1, Yaroslavskaya Str., Moscow, 129366, \\ Russian Federation
}

\begin{abstract}
The article examines the relationship between characteristics of text messages, composed by users of social network (VKontakte), and intelligence. The analysis is conducted on the regional level: we compared the regional IQ with the text parameters averaged over the users living in one region. The text parameters include formal, grammatical and emotional indexes. The regional IQ is computed as an average z-score of the Unified State Examination score (high school entrants, 2018) and IQ score of the attendees to the volunteer military service. Four text parameters that can be considered as markers of the text cognitive complexity (mean word length, mean sentence length, percent of the parenthetic words and phrases, percent of the simple propositions) predicted regional IQ independently and explained $60 \%$ of its variance. Emotional index correlates with regional IQ, but does not predict regional IQ independently of cognitive complexity markers. Moreover, we revealed correlations between regional IQ and literacy of VKontakte users. The significancy of these results is creating the new IQ measure, which allows evaluating regional IQ and its dynamics by means of text analysis. The method has an advantage over the traditional psychometric IQ measures in this field of research.
\end{abstract}

Keywords: intelligence, digital footprints, social media, VKontakte, cognitive complexity, text automatic analysis, text sentiment analysis, regions of Russia.

\section{References}

Grigoriev, A. A., Lapteva, E. M., \& Ushakov, D. V. (2015). Educational performance of Moscow region districts reproduce their literacy level in the XIX century: mechanisms of the "cultural genetics". Siberian Journal of Psychology, 56, 69-85. (in Russian)

Grigoriev, A., Ushakov, D., Valueva, E. A., Zirenko, M., \& Lynn, R. (2016). Differences in educational attainment, socio-economic variables and geographical location across 79 provinces of the Russian Federation. Intelligence, 58, 14-17.

Kosinski, M., Stillwell, D., \& Graepel, T. (2013). Private traits and attributes are predictable from digital records of human behavior. Proceedings of the National Academy of Sciences of the United States of America, 110(15), 5802-5805.

Latyunov, V. V., \& Ovsyannikova, V. V. (2020). Predicting psychological characteristics from digital footprints. Psychology. Journal of Higher School of Economics, 17(1), 166-180. (in Russian)

Lynn, R., \& Vanhanen, T. (2002). IQ and the wealth of nations. Westport, CT: Praeger.

Lyusin, D. V., \& Sysoeva, T. A. Emotional norms for nouns: The database ENRuN. Psikhologicheskii Zhurnal, 38(2), 122-131. (in Russian) 
Plester, B., Wood, C., \& Bell, V. (2008). Txt msg n school literacy: does texting and knowledge of text abbreviations adversely affect children's literacy attainment? Literacy, 42(3), 137-144.

Plester, B., Wood, C., \& Joshi, P. (2009). Exploring the relationship between children's knowledge of text message abbreviations and school literacy outcomes. The British Journal of Developmental Psychology, 27(1), 145-161.

Smirnov, I. (2017). The digital Flynn effect: Complexity of posts on social media increases over time. Lecture Notes in Computer Science, 10540, 24-30. doi:10.1007/978-3-319-67256-4_3

Smirnov, I., Sivak, E., \& Kozmina, Y. (2016). In search of lost profiles: The reliability of VKontakte data and its importance in educational research. Educational Studies Moscow, 4, 106-122. (in Russian)

Sugonyaev, K., Grigoriev, A., \& Lynn, R. (2018). A new study of differences in intelligence in the provinces and regions of the Russian Federation and their demographic and geographical correlates. Mankind Quarterly, 59(1), 31-37.

Valueva, E. A., Danilevskaya, N. M., Lapteva, E. M., \& Ushakov, D. V. (2017). Cognitive complexity of children fiction: quantitative methods of evaluation. Journal of Psycholinguistics, 31(1), 42-61. (in Russian)

Waldron, S., Kemp, N., Plester, B., \& Wood, C. (2015). Texting behavior and language skills in children and adults. In L. D. Rosen, N. A. Cheever, \& L. M. Carrier (Eds.), The Wiley handbook of psychology, technology, and society (pp. 232-240). John Wiley \& Sons, Ltd.

Wood, C., Kemp, N., Waldron, S., \& Hart, L. (2014). Grammatical understanding, literacy and text messaging in school children and undergraduate students: A concurrent analysis. Computers and Education, 70, 281-290.

Woodley of Menie, M. A., Fernandes, H. B. F., Figueredo, A. J., \& Meisenberg, G. (2015). By their words ye shall know them: Evidence of genetic selection against general intelligence and concurrent environmental enrichment in vocabulary usage since the mid 19th century. Frontiers in Psychology, 6, 361. doi:10.3389/fpsyg.2015.00361

Yasseri, T., Kornai, A., \& Kertész, J. (2012). A practical approach to language complexity: A Wikipedia case study. PLoS ONE, 7(11), e48386.

Ekaterina A. Valueva - Research Fellow, Institute of Psychology, Russian Academy of Sciences, $\mathrm{PhD}$ in Psychology.

Research Area: cognitive psychology, intelligence, creativity.

E-mail: ekval@list.ru

Ekaterina M. Lapteva - Research Fellow, Institute of Psychology, Russian Academy of Sciences, PhD in Psychology.

Research Area: crystalized intelligence, need for cognition, cognitive and motivational mechanisms of crystallized intelligence.

E-mail: ek.lapteva@gmail.com

Andrei A. Grigoriev - Leading Research Fellow, Institute of Psychology of Russian Academy of Sciences, DSc in Philology, Associate Professor.

Research Area: intelligence, individual differences, psycholinguistics.

E-mail: andrey4002775@yandex.ru 
Психология. Журнал Высшей школы экономики,

2021. T. 18. № 1. C. 145-166. DOI: 10.17323/1813-8918-2021-1-145-166

\title{
MATHEMATISCHE PSYCHOLOGIE: ИСТОРИЯ КОНФЛИКТА
}

\begin{abstract}
C.B. MOPO3OBA ${ }^{\mathrm{a}}$
${ }^{a}$ Санкт-Петербургский государственный университет; 199034, Россия, Санкт-Петербург, наб. Макарова, д. 6

Резюме

В исследовании рассматривается роль математической психологии (mathematische Psychologie) в немецком философском дискурсе XIX - начала XX в. История математической психологии рассматривается с позиций дисциплинарного подхода в историографии. Автор акцентирует внимание на реконструкции социальных механизмов определения и поддержания границ содержания дисциплины, их связи со структурой и особенностями функционирования университетов и научных учреждений, а также академических корпораций. Автор показывает, как математическая психология несколько раз оказывалась в центре дисциплинарных конфликтов. Сначала она была предметом полемики между гербартарианцами и неокантианцами. В середине века, после публикации «Элементов психофизики» Фехнера, физиологическое направление психологии представителями академической философии воспринималось как «математическая психология». К концу XIX в., уже после расцвета психофизики, во время подъема новой волны неокантианства гербартовские психология и психофизика стали предметом полемики Дильтея и Эббингауза о пересмотре методологических оснований психологии. Дискуссия начала ХХ в. об исключении экспериментальной психологии из состава философских дисциплин подводит итог обращению к математической психологии для определения дисциплинарных границ. История математической психологии показала, что даже в том случае, когда речь шла о математике как о методе, в философских дисциплинах разворачивались настоящие баталии, в которых представители разных методологических лагерей пытались отстоять свою независимость. Начавшись как философский спор, полемика постепенно приобрела иное значение. Негативное отношение к математической психологии стало восприниматься как признак всего методологически отсталого и потерявшего свою актуальность.
\end{abstract}

Ключевые слова: mathematische Psychologie, математическая психология, история психологии, дисциплинарный конфликт, академическая политика.

В немецких университетах XIX в. были заложены основы современной научной психологии. Именно в университетских стенах развернулись бои за определение места научной психологии и сохранение дисциплинарных границ философии. Традиционно этот процесс рассматривается исследователями истории психологии с точки зрения формирования экспериментальной психологии. Однако de facto он охватывает все философские дисциплины,

Исследование выполнено при финансовой поддержке РФФИ в рамках научного проекта № 19-013-00279. 
причем в связи с пересмотром их места в общей классификации наук. Вероятно, кризис немецкой науки начала XX в. и обсуждение предмета и места психологии в немецких университетах напрямую повлияли на специфику дальнейшего развития научной психологии.

Настоящее исследование было предпринято с целью анализа истории одной из ключевых психологических дисциплин XIX в. - «математической психологии». Мы попытались определить, какие факторы в XIX - начале XX в. оказали влияние на специфику отношения научного сообщества к применению количественных методов в психологических исследованиях. В процессе работы с немецкими источниками стало очевидно, что историю этого понятия невозможно рассматривать вне общего контекста дисциплинарной политики немецких университетов. Поэтому отдельный интерес для нас представляет дискурсивный аспект использования понятия «математическая психология» (mathematische Psychologie) немецкими психологами в указанный период.

Анализ существующей на данный момент историографии немецкой психологии и философии XIX - начала XX в. позволяет сделать вывод о том, что интерпретация происходивших событий сформировалась к 1970-м гг. и с тех пор значительных изменений не претерпела. История немецкой психологии и философии - это в первую очередь история «кризиса» психологии и философии. Авторы, изучавшие этот период, строили свое повествование, ведя читателя от политического контекста и специфики академических свобод немецких университетов к разрушению научных основ психологии и идеологическому триумфу «немецкого духа» (Поппер, 1992; Рингер, 2008; Kusch, 1995; Ash, 1980a). Современные авторы продолжают сложившуюся традицию (Mülberger, 2012) и/или пытаются переосмыслить историографию «кризиса». В последнем случае они абстрагируются от политического и идеологического контекста, что позволяет более гибко интерпретировать дискуссии о «кризиcе» (Sturm, 2012; Sturm, Mülberger, 2012; Юдин, 2015). Впрочем, встречаются и варианты политически нейтрального описания немецкой психологии и философии (Danziger, 1998; Hatfield, 2003). Чаще всего это англоязычные авторы, задача которых сводится к констатации факта: американская (английская, русская и т.д.) научная психология (new psychology) корнями уходит в немецкую экспериментальную психологию.

Мы видим свою задачу в описании процесса дисциплинарного становления психологии, свободного от поиска ростков нацистской науки в «науках о духе» XIX в. Во-первых, в связи с этим хронологические рамки исследования определяются XIX - началом XX в. Мы не рассматривали историю немецкой психологии веймарского периода. Во-вторых, комплекс интересующих нас источников был ограничен научными трудами и полемическими текстами ключевых философов указанного периода, писавших о методологии психологии. К материалам дискуссий о кризисе в немецкой психологии и философии мы обращались лишь в тех случаях, когда это непосредственно касается предмета нашего исследования.

С нашей точки зрения, историю математической психологии целесообразно описывать как историю научной дисциплины. Такой подход позволяет 
максимально полно осветить процесс становления научной психологии в Германии. В исследованиях, выполненных в парадигме дисциплинарного подхода, реконструируются социальные механизмы определения и поддержания границ содержания дисциплин, их связи со структурой и особенностями функционирования университетов и научных учреждений, академических корпораций (Backhouse, Fontaine, 2010; Дмитриев, Савельева, 2015).

\section{Научные дисциплины и немецкие университеты}

К моменту появления притязаний психологии на статус самостоятельной дисциплины в немецких университетах гумбольдтовская модель в течение уже многих десятилетий определяла характер поля философского знания и академическое оформление его границ. Немецкие университеты, согласно этой модели, были наделены внутренней независимостью, но при этом право назначать профессоров принадлежало государству. Кафедральная структура факультетов была внутренним делом университета, хотя профессорский штат определялся правительством.

Гумбольдтовская университетская модель повлияла на завершение процесса профессионализации исследовательской деятельности. Преподаватель обязан был быть исследователем. В поисках научной истины преподаватель и студент имели равный статус. Студенты свободно выбирали университеты, профессоров и академические курсы, которые хотели прослушать. Так реализовывался принцип «академической свободы». Особый статус выпускников университетов был закреплен на уровне системы государственных экзаменов и профессиональных привилегий. Студентами университета могли стать только выпускники гимназий (Андреев, 2009).

Так как немецкая университетская модель объединила научные исследования и обучение, процесс формирования новой науки неизбежно включал борьбу за дисциплинарные атрибуты: открытие лабораторий и кафедр, распределение профессорских ставок, право присуждения научных степеней и введение государственного экзамена по соответствующей специальности. В немецких университетах XIX в. выпускники после защиты диссертации могли претендовать на право чтения лекций и получение должности приват-доцента, а затем и профессора. Приват-доцентура не оплачивалась из средств казны и обеспечивалась только гонорарами слушателей лекций. Финансовая независимость имела и свои плюсы: приват-доценты могли самостоятельно выбирать темы научных исследований. В результате лаборатории немецких университетов стали мировыми научными центрами (Сокулер, 2001).

К середине XIX в. вся немецкая наука практически полностью была представлена университетскими преподавателями и студентами. Исследовательские группы обыкновенно состояли из учителя и нескольких учеников. К концу века стали появляться исследовательские институты экспериментальных наук, которые имели официальный штат научных сотрудников и лаборатории (Бен-Дэвид, 2014). Одним из таких исследовательских институтов стал Институт экспериментальной психологии В. Вундта. 
В результате гумбольдтовской реформы философские факультеты стали занимать центральное место в структуре немецких университетов. Они объединяли все теоретические науки, в том числе естественные (Шнедельбах, 2002). Философия получила особый статус в классификации наук. Тогда же была заложена идея о философском факультете как средстве воспитания немецкой нации (Демин, 2013).

Вследствие этого характерной чертой немецкой науки до 1830-х гг. включительно стало предпочтение спекулятивных методов эксперименту и количественному анализу. Лишь к середине века строгая модель науки, построенной по образцу физики, стала набирать популярность среди ученых. Д. Бен-Дэвид считает, что развитие естествознания в немецких университетах в первой половине века происходило вопреки реформе и господству философского метода в науке как ответная реакция на смену академических элит (Бен-Дэвид, 2014).

Психология традиционно воспринималась академическим сообществом как философская дисциплина. Более того, в немецкой философии второй половины XIX в. наблюдались тенденции пересмотра системы философских наук на базе психологии («психологизм» в философии) (Kusch, 1995). Это не удивительно, ведь психология, согласно учебным планам, уже к середине 1870-х гг. была одной из ведущих философских дисциплин и соперничала лишь с историей философии (Wundt, 1877).

Однако с 1880-х гг. стало появляться все больше философов, специализирующихся в области экспериментальной психологии, и возрастать количество психологических публикаций. Эта тенденция привела в начале XX в. к попыткам определить психологию как самостоятельную научную дисциплину. Ситуацию обострило стремительное развитие естественных наук в середине XIX в. Вследствие смены научных ориентиров спекулятивная философия начала терять ведущие позиции в системе немецких наук (Бен-Дэвид, Коллинз, 2002).

В целом к началу XX в. можно констатировать дисциплинарный конфликт внутри философских дисциплин. С одной стороны, происходил естественный процесс формирования экспериментальной психологии как новой научной дисциплины, что привело к ее притязаниям на академический статус. С другой стороны, этот процесс тормозился академическими и политическими реалиями. Более того, к началу XX в. сложилась такая ситуация, когда профессорскую должность на философском факультете можно было получить через приказ министерства вопреки желаниям администрации университета и коллег. Примером может служить назначение Э. Гуссерля экстраординарным профессором в Геттинген (Куренной, 2005).

\section{Математическая психология как дисциплина}

История «математической психологии» (mathematische Psychologie) берет начало в работах И. Канта. Он указывает на две основные проблемы применения математики в психологии: человеческая психика обладает только временны́ми, 
но не пространственными характеристиками, поэтому психические явления нельзя измерить; психику нельзя исследовать экспериментальным методом (Кант, 1994). По сути, вся дальнейшая история психологии, в особенности история немецкой психологической мысли XIX в., так или иначе связана с преодолением этих двух фундаментальных проблем.

После выхода в свет «Метафизических начал естествознания» события развивались закономерным образом. Каждый новый ниспровергатель кантовского скептицизма считал себя обязанным заявить об «историческом значении» трудов своего предшественника. Первым автором, труды которого уже в середине XIX в. стали иметь историческое значение, стал основатель математической психологии И.Ф. Гербарт.

Важно отметить, что свое повествование в программных сочинениях Гербарт строил по полемическому принципу. Сначала он возражает на тезисы Канта о невозможности применения математики в психологии и измерения психических явлений и лишь после этого приступает к изложению собственной позиции (Гербарт, 2007a). Полемизируя с Кантом, он заявлял, что нет препятствий к построению математической модели психики еще до измерений: «Можно вычислять изменяемость известных величин и их самих, поскольку они изменяемы, не определяя их вполне; на этом основывается весь анализ бесконечного. Далее, можно гипотетически принять законы изменения величин и, вычислив следствия, вытекающие из этих гипотез, сравнивать их с опытом» (Гербарт, 2007б, с. 64). Гербарт видел свою задачу прежде всего в формулировке метода применения математики в психологии. По образцу естественных наук он считал необходимым описать каузальные связи психических явлений, рассуждал о статике и механике духа, пытался выявить суммы простых душевных сущностей, далее неделимых, которые могут быть подвергнуты математическому анализу. Решение проблемы психического времени и пространства Гербарт видел в создании учения о механике духа. Не проводя полной аналогии между движением физических тел в пространстве и психических явлений в душе, он тем не менее говорил о представлениях, которые могут «погружаться» и «подниматься», достигая «механического порога» сознания, т.е. использовал пространственную риторику для описания интенсивности представлений. С его точки зрения, наши представления, чувства и аффекты в каждую единицу времени бывают больше или меньше, сильнее или слабее. Следовательно, можно говорить о количественных характеристиках психических явлений: о напряженности каждого единичного представления, степени задержки между какими-нибудь двумя представлениями, степени связи между несколькими представлениями (ассоциации идей) и др. Но, как известно, эмпирических исследований Гербарт не проводил.

Дальнейшее развитие математическая психология получила в трудах М.-В. Дробиша. В предисловии к работе 1850 г. он писал, что математическая часть гербартовской психологии не угодила ни психологам, ни математикам. Его психология - только абстрактная подготовка к будущей математической психологии. Но работа Гербарта «является памятником завидной прозорливости и редкой настойчивости» (Drobisch, 1850, S. vi). Дробиш оспаривал 
тезис о невозможности измерить психические явления, предлагая видеть в проблеме теоретическую и практическую измеримость. Вопрос о том, как можно решить проблему несоизмеримости психических явлений на практике, остается открытым. Но, добавлял он, возможно, определенные результаты в этом направлении можно было бы ожидать со стороны физиологии. В целом аргументация Дробиша постоянно отсылает к опыту физических наук.

В 1851 г. Г. Фехнер заявил, что в основе математической психологии должны лежать измерения не психических, а физиологических явлений, что подход Гербарта неубедителен. Фехнер сформулировал основные принципы психофизики, дав свой ответ на тезисы Канта. Он предложил косвенное измерение психических параметров через физические, которые, в отличие от психических, обладают всеми необходимыми характеристиками для применения к ним метрических шкал. Фехнер исходил из того, что любой психический акт есть совокупность возбуждений, а возбуждение, по его мнению, пропорционально логарифму от силы любого внешнего события (Fechner, 1987).

В 1860 г. Фехнер опубликовал »Элементы психофизики». По традиции, в предисловии к первому тому дается определение исторического значения трудов Гербарта: «Заслуга Гербарта всегда останется не только в том, что он впервые высказал возможность математического взгляда на [психологические] связи, но прежде всего в том, что он первый осуществил остроумную попытку разработать такой взгляд; и все, кто после него, будут лишь последователями» (Fechner, 1860, S. х).

Наиболее важной частью концепции Фехнера являются разработанные им психофизические методы измерения, которые позволили экспериментально проверить закон Вебера. Суть этого закона сводится к тому, что существует пропорциональная зависимость между логарифмом силы физического раздражителя и силой ощущения. В современной психофизиологии хорошо известно, что в случаях, когда производятся косвенные измерения психических характеристик через физические величины, например, время реакции или КГР (см.: Суходоев, б.г.), мы получаем переменную, значения которой имеют логнормальное распределение. Процедура логарифмирования приводит к тому, что распределение значений такой переменной становится близким к нормальному.

Фехнер предложил методы для измерения ощущений, точнее, он систематизировал методы, которые были разработаны Вебером и др. Измерять ощущения он предлагал в интервальной шкале. Согласно закону Вебера-Фехнера, приращения ощущений равны $\mathrm{g}=\mathrm{k}\left(\log \mathrm{b} / \mathrm{b}_{0}\right)$, где $\mathrm{g}$ - величина ощущения, $\mathrm{b}-$ величина раздражителя, $\mathrm{b}_{0}$ - пороговое значение раздражителя. Шкала ощущений не имеет абсолютного нуля, но существует значение, которому соответствует начало и окончание ощущения раздражителя (нижний и верхний абсолютный пороги чувствительности). Для обнаружения абсолютных порогов Фехнер использовал метод границ и метод постоянных раздражителейํ․ㄹ.

\footnotetext{
${ }^{1}$ Метод границ и метод постоянных раздражителей являются модификациями методов едва заметных различий и истинных и ложных случаев соответственно.
} 
Существует значение, при котором увеличение силы раздражения уже не приводит к различению двух отличающихся по силе раздражителей (дифференциальный порог). При этом если два стимула не различаются, то, согласно закону, получается $0=\log 1$ (по формуле g - g' = k(logb/b'), где g - g' - разность ощущений, b - величина приращенного раздражителя, b' - величина исходного раздражителя).

Проблему отрицательных значений ощущений Фехнер решал следующим образом. Он полагал положительные ощущения осознанными, а отрицательные неосознанными (подпороговыми). Для измерения дифференциального порога было предложено три метода измерения дифференциальной чувствительности: метод едва заметных различий, метод истинных и ложных случаев и метод средней ошибки.

Параллельно с Фехнером над проектами изучения психики через физиологию работали Р. Лотце и В. Вундт. Работу, изданную в 1852 г., Лотце посвящает проблемам исследования простых ощущений, чувств, движений, инстинктов и др. Ссылаясь на работу Фехнера 1851 г., он отмечает, что подтверждение логарифмической зависимости было бы прекрасно, но на самом деле мы можем измерить лишь силу раздражений, но не ощущений. И тем не менее он видит в формулах Фехнера надежду на то, что в психологии будут найдены математические законы, которые позволят найти новые явления и объяснить уже известным (Lotze, 1852).

Еще один физиологический по своему эмпирическому основанию проект психологии берет свое начало в работах В. Вундта. Уже в 1862 г. Вундт попытался найти физиологические основания для психологической теории. Он предположил, что закон Вебера-Фехнера применим для описания характера взаимосвязи не только между ощущением и раздражением, но и между ощущением и восприятием. Вундт высказал идею о том, что психофизический закон остается в силе и при описании высшей психической деятельности (Wundt, 1862).

В 1874 г. выходит первое издание «Оснований физиологической психологии» В. Вундта. В предисловии Вундт по традиции оспаривает кантовские тезисы: «Первый из этих доводов ошибочен, второй, по меньшей мере, односторонен» (Вундт, 1880, с. 6) Идея неизмеримости психических явлений неверна постольку, поскольку психика обладает не одним измерением. Однако если бы Кант был прав, то, исходя из понятия величины ${ }^{2}$, измерить психику действительно было бы невозможно. В реальности наши ощущения не только распределены во времени, но и различны по интенсивности. Следовательно, интенсивность ощущений является вторым измерением. Односторонность идеи неприменимости экспериментального метода к психическим явлениям Вундт видит в следующем. Если между психическими и физическими или психическими и психическими явлениями установить причинно-следственные связи, то далее можно судить о причинах по следствиям или, наоборот, о следствиях по причинам. В случае психофизических методов как раз судят о следствиях по причинам, т.е. об ощущениях по раздражениям.

\footnotetext{
${ }^{2}$ Вундт имеет в виду физическое определение величины как объема, протяженности предмета.
} 
Тем не менее он признает, что непосредственно измерить психические явления экспериментальным путем не представляется возможным.

Как известно, при переиздании своих произведений Вундт вносил в них многочисленные поправки. Более того, с течением времени его взгляды на психологию претерпели весьма серьезные изменения. Что касается переизданий «Оснований физиологической психологии», то в первых трех изданиях прямая связь психофизики Фехнера с психологией Гербарта и тезисами Канта явно не высказывается. Но в пятом (1902-1903) и шестом (1908-1911) изданиях появляется вставка, в которой Вундт говорит об этой связи: «Фехнер имеет заслугу в том, что первым последовал тем путем, который в известных границах фактически реализовал возможность “математической психологии": этот путь указывает на экспериментальное влияние сенсорных стимулов на сознание» (Wundt, 1908, S. 40). Но далее Вундт критикует Фехнера за то, что он пытается решать не психологические, а метафизические проблемы. И в завершение определяет историческое значение Фехнера и Гербарта: «Тем не менее неизменной останется его слава как первого, кто начал реализовывать проект “строгой психологии” [“exakten Psychologie”], которую нащупал Гербарт» (Ibid.).

За десятилетие до выхода «Оснований физиологической психологии» Дробиш опубликовал статью, в которой рассматриваются ранние произведения Вундта (Drobisch, 1864). Он упрекает автора в поверхностном знании математической психологии Гербарта и психофизики Фехнера. Вундт критикует Гербарта за метафизические основания его подхода. В особенности он выступает против неизменности суммы существующих в сознании представлений, в то время как на самом деле Гербарт имел в виду то, что сумма осознанных представлений стремится оставаться стабильной. Далее, если Вундт считает неуместным говорить о «статике» и «механике» духа, которые автор использовал в метафорическом смысле, то по той же причине не стоит использовать и гербартовское понятие «порог сознания», позаимствованное Фехнером. Также возмущает Дробиша широкая трактовка закона ВебераФехнера. Он говорит о логическом, но не математическом выводе о возможности расширения закона в зону восприятия. В общем он пытается убедить читателей в том, что вундтовская попытка реформирования психологии «радикальная» и «незрелая».

Психология Гербарта, как позднее и психофизика Фехнера, вызывала критические возражения не только у его последователей и Вундта. В лучшем случае ее упрекали, например, как Лотце в «Метафизике» (Lotze, 1841), в механистическом характере, но при этом выражали надежду на то, что предложенная исследовательская программа в будущем приведет к прогрессу психологии (Ibid.).

Наиболее радикальные высказывания в адрес математической психологии принадлежат представителям неокантианства. Один из лидеров этого движения Ф.А. Ланге неоднократно выступал с критическими замечаниями в адрес математической психологии, вплоть до ее полного отрицания: «Математическая психология для нас не существует, а только мы могли бы найти в ней 
основание вникнуть еще раз точнее в метафизическую основу психологии по Канту» (Ланге, 1883, с. 331).

В 1865 г., во время работы над «Историей материализма», Ланге публикует критическое произведение о психологии Гербарта и Дробиша в ответ на рассмотренную выше статью Дробиша о психологии как естественной науке. Он говорит о том, что математическая психология пользуется хорошей репутацией в широких кругах, несмотря на фундаментальную ошибку учения Гербарта, которую унаследовали и труды Дробиша. Суть претензий сводилась к критике гербартовского подхода к выявлению суммы простых душевных сущностей, совокупность которых можно подвергнуть математическим подсчетам. Если душа является абсолютно простым образованием, то она не может видоизменяться, так как изменение можно представить только через смену порядка частей. Из математической психологии следует исключить спекулятивное утверждение о торможении суммы идей и связанные с нею пороговые формулы (Lange, 1865).

Через год выходит фундаментальный труд Ланге «История материализма и критика его нынешнего значения», в котором он резко отзывается о математической психологии в разделе «Естественнонаучная психология»: «И ведь существует целый ряд разумных и почтенных людей, которые серьезно полагают, что Гербарт своими дифференциальными уравнениями так основательно объяснил мир представлений, как Коперник и Кеплер - мир небесных тел. Это, конечно, такое же жестокое самообольщение, как френология; а что касается психологии как естественной науки, то этим прекрасным названием до такой степени злоупотребляли, что легко можно подвергнуться опасности выбросить ребенка вместе с водой из ванны» (Ланге, 1883, с. 329).

Однако в целом Ланге, как ни странно, проявляет оптимизм, говоря, что естественнонаучная психология в Германии существует, хоть и в зачаточном состоянии, еще не освободившаяся от метафизики, и в ее основе лежит именно школа Гербарта. К психофизике он оказывается более благосклонен: «Но ценность исследований Фехнера для математической психологии, конечно, не настолько низка, чтобы можно было предпочесть им даже полностью гипотетическую теорию» (Lange, 1865, S. 28). Любопытно, что при этом он считает веберовскую формулу психофизики Фехнера эмпирическим свидетельством против математической психологии!

Позднее в «Истории материализма» он высказывается более сдержанно: «Между скудными зачатками будущей научной психологии есть положение, которое учит, что - в обыкновенных пределах - ощущение возрастает как логарифм соответствующего раздражения: формула $\mathrm{x}=\log (\mathrm{y})$, которую Фехнер положил как “закон Вебера” в основание своей психофизики. Но невероятно, что этот закон имеет основание в самом сознании, а не в тех психофизических процессах, которые совершаются между внешним (физическим) раздражением и актом начала сознания» (Ланге, 1883, с. 41). В примечании Ланге добавляет, что новейшие исследования свидетельствуют в пользу того, что логарифмическая зависимость объясняется спецификой физиологии нервных окончаний. 
Действительно, психофизика Фехнера подверглась большой критике почти сразу же после выхода «Элементов психофизики» (Рибо, 1895). Вопервых, выяснилось, что закон Вебера-Фехнера верен только в известных пределах, при очень слабой и очень сильной стимуляции логарифмическая зависимость нарушается. Во-вторых, предпринимались попытки найти другую формулу, более точно описывающую связь между раздражениями и ощущениями (Stevens, 1957). В-третьих, ставился вопрос о свойствах шкалы, в которой измерялись ощущения: действительно ли это шкала равных интервалов? Отдельного внимания были удостоены «отрицательные ощущения» и корректность математического преобразования формулы Вебера в формулу Фехнера. Как показал Г. Эббингауз, Фехнер действительно допускает неоправданное допущение (Эббингауз, 1912, с. 91-94).

Особый интерес для нашей темы представляет то, как в психофизической полемике был решен вопрос об измерительных шкалах. Сам Фехнер указывал на то, что проблемы со шкалой равных интервалов нет, поскольку в ней измерялись не сами ощущения, а разности между ощущениями, которые равны между собою. Собственно, если бы формула Фехнера не имела ограничений в применении к результатам экспериментов, то можно было бы согласиться с тем, что разности ощущений действительно измеряются в шкале равных интервалов. Однако, как показал, например, Гельмгольц, это не соответствует действительности (Helmholtz, 1867).

После сомнительного успеха психофизики, спустя полвека наконец была сделана первая попытка экспериментально проверить идею Гербарта о связях идей (Boudewijnse, Murray, 2001). Г. Эббингауз в своих экспериментальных исследованиях памяти использовал для этого разработанную им методику бессмысленных слогов. При описании дизайна одного из экспериментов на воспроизведение серий бессмысленных слогов он прямо указывает на то, что идея заимствована у Гербарта. Более того, он даже цитирует пассаж из его работы, призванный проиллюстрировать теоретическую интуицию математического психолога (Ebbinghaus, 1913). В эксперименте Эббингауз оценивал последовательное воспроизведение всех стимулов, которые предъявлялись для заучивания в определенной последовательности. Силу связи элементов стимульного ряда он предложил оценивать по времени, которое проходит меду воспроизведением двух слогов, и по количеству слогов, которые вставляет испытуемый между ними (если это происходит). Вторая переменная, как бы мы сейчас сказали, отражала степень удаленности слогов друг от друга в семантическом пространстве. Тем самым Эббингауз смог измерить временнб́е и пространственные характеристики психического явления (памяти). Полученные данные свидетельствовали в пользу истинности идеи Гербарта. В попытке объяснить, почему одни идеи удерживаются на уровне сознания, а другие вытесняются, он обратился за помощью к дифференциальным уравнениям.

По поводу Фехнера и психофизики Эббингауз настроен весьма скептически. Он полагает, что главная заслуга Фехнера состоит в том, что он систематизировал методы психофизики, т.е. он видел в нем в первую очередь методолога. Что касается логарифмической зависимости между раздражениями и 
ощущениями, то, рассмотрев основные критические замечания по этому поводу, Эббингауз завершает свое повествование следующим пассажем: «Отрицательные же ощущения Фехнера представляют и будут представлять для психологии только один интерес: они показывают, какие заблуждения, противные простому здравому смыслу, возможны даже у выдающихся мыслителей, когда они вызваны значительным поводом, вроде, например, красоты цельной на вид системы, или когда они прикрыты авторитетом крупного имени» (Эббингауз, 1912, с. 94).

Мы не затронули такого важного психологического применения прикладной математики, как моральная статистика ${ }^{3}$ и социальная физика А. Кетле (Кетле, 1866, 1911). Также мы не рассмотрели реакцию на нее немецких философов. Эти вопросы освещаются в ряде трудов (Дробиш, 1867; Ланге, 1883; Лотце, 1867; Wundt, 1862). Для нас сейчас важен лишь тот факт, что моральная статистика не воспринималась в Германии как бельгийская разновидность математической психологии.

Не обсуждается здесь эмпириокритицизм Р. Авенариуса, хотя по своей сути «Критика чистого опыта» является прямым следствием математической психологии Гербарта, сам он на это прямых указаний не дает (Авенариус, 1907-1908) Не случайно Вундт, давая оценку математической стороне его работы, заявил о спекулятивном характере попытки Авенариуса применить «анализ функций» к описанию человеческой психики (Вундт, 1910). Прямого влияния на дальнейшее развитие применения математики в психологии «Критика чистого опыта» не оказала. Впрочем, эмпириокритицизм способствовал переопределению предмета психологии (Авенариус, 2003; Кюльпе, 2007).

Выше мы рассмотрели основные вехи развития математической психологии и реакцию научной общественности на попытки применить математику к психологическим явлениям. Можно видеть, что с течением времени математическая психология превратилась из спекулятивной науки, тесно связанной с метафизикой, в самостоятельную научную дисциплину на границе психологии и физиологии (Липпс, 2012). В целом к началу XX в. сформировалась традиция понимать психофизику как часть математической психологии. С одной стороны, она восходила к ранним работам Фехнера, поддержанным Ланге и Вундтом (в его последних изданиях «Оснований физиологической психологии»), с другой стороны, восприятию этой науки как части экспериментальной

\footnotetext{
${ }^{3} \mathrm{C}$ темой моральной статистики тесно связаны дискуссии о свободе воли. Статистика преступности и самоубийств, выраженная в терминах вероятности, исходит из идеи эмпирической обусловленности и причинности человеческих действий. Следовательно, о свободе воли речь идти не может. Впрочем, психофизический закон противоречит положению о человеческом волеизъявлении. Суть сводится к тому, что если мы полагаем причинно-следственную связь между физическим миром и психическими реакциями, то эти реакции оказываются неизбежными. Обширные дискуссии на тему свободы воли не имеют прямого отношения к теме нашего исследования, хотя и касаются оппозиции метафизики и психологии, поэтому здесь мы считаем достаточным дать лишь краткую справку об этой философской проблеме.
} 
психологии, идущему от Вундта. Такая двойственность связей психофизики обусловила специфическую роль математической психологии в дисциплинарном конфликте конца XIX - начала XX в., так как позволила приравнять математическую психологию к экспериментальной. Смешение математической психологии с экспериментальной психологией довершил Эббингауз в экспериментальных исследованиях памяти.

\section{Дисциплинарный конфликт и границы допустимого}

Возможность пересмотра традиционных дисциплинарных границ психологии обсуждалась начиная с момента появления математической психологии. С самого начала этот процесс сопровождался попытками отнести психологию к «объяснительным» и/или «описательным» наукам. В результате к концу XIX в. дискуссии о месте психологии в классификации наук и ее независимости от философии будут вестись с использованием именно этой терминологии. Соответственно, наша задача состоит в анализе вариантов, способов определения и защиты ее дисциплинарных границ.

Уже в 1842 г. Дробиш в «Эмпирической психологии, согласно научному методу» поставил вопрос о возможности классифицировать психологию как естественную науку и вывести ее из числа философских наук. Психология, с его точки зрения, руководствуется тремя методами исследования: описательным, классифицирующим и объяснительным. По мнению Дробиша, под объяснительной психологией традиционно понимают психологию, образцом для которой послужила физическая наука (Drobisch, 1842).

Внутренняя методологическая расщепленность академической психологии усугубилась с началом применения экспериментального метода к исследованию психических явлений. В одной из своих ранних работ Вундт писал, что психологии необходимо перестать находиться под влиянием метафизики и начать формулировать собственные законы (Wundt, 1862).

Глава баденской школы неокантианства В. Виндельбандт в 1876 г. по случаю вступления в должность профессора философии в Цюрихе выступил с речью о связи философии с эмпирическими науками, в первую очередь с психологией. Он говорил о том, что, с одной стороны, все привыкли, что психология входит в состав философских дисциплин, но, с другой стороны, она все дальше удаляется от своих метафизических основ и все больше обращается к эмпирическим методам исследования. Виндельбандт считал, что недалеко то время, когда психология полностью потеряет связь с метафизикой и превратится, как считал Ланге, в «психологию без души». «Обоснование и закрепление эмпирического метода в психологии поэтому самым тесным образом связано с ее освобождением от оков метафизики» (Windelband, 1876, S. 6). Развитие эмпирической психологии он ставил в заслугу «разрушительной критике

\footnotetext{
${ }^{4}$ «Если иметь в виду главным образом самостоятельность метода, то нашу науку (физиологическую психологию.) - C.M. можно назвать экспериментальной психологией, в отличие от психологии, основанной исключительно на самонаблюдении» (Вундт, 1880, с. 2).
} 
Гербарта». Далее Виндельбандт делал вывод о возможности открытия самостоятельных кафедр психологии. В завершение он отмечал, что для успешного применения математики в этой науке необходимо выработать свою четкую систему понятий.

В это же время в немецкой философии был популярен психологизм. Его основная идея была противоположна сепаратистским настроениям, она сводилась к попыткам создать проект философии на фундаменте психологии. К представителям этого течения можно отнести В. Дильтея с его описательной психологией и др. Основная проблема психологистических проектов состояла в том, чтобы четко определить, какой должна быть психология, на фундаменте которой можно основать знание наук о духе.

Острые дискуссии об описательной и объяснительной психологии, возможно, никогда бы и не возникли, так как оба направления методологически слишком далеки друг от друга, если бы не Дильтей. Он попытался не просто предложить свой вариант описательной психологии, но и заменить им естественно-научное направление психологии. В 1894 г. Дильтей опубликовал «Идеи к описательной и расчленяющей психологии», которые вызвали острую критику со стороны Эббингауза. Его труд посвящен критическому анализу объяснительной и описательной психологии. К объяснительной психологии он отнес математическую психологию, психофизику, экспериментальную психологию. Ярчайшим ее представителем, на которого была обрушена вся дильтеевская критика, является Гербарт. Анализ математической психологии привел автора к мысли, что в психологии невозможно формулировать гипотезы и затем проверять их истинность. Однако развитие психофизических методов в экспериментальной психологии вызвало популярность естественно-научной методологии в науке о психических явлениях. Но господство объяснительной психологии, в частности психофизики, вредно для развития наук о духе. Альтернативой такой психологии может стать описательная психология, которая составила бы ей прочную опору в теории и системе психологических понятий (Дильтей, 1996).

Оппонентом Дильтея стал Эббингауз, который показал, что математическая психология и современная ему экспериментальная психология - это две разные дисциплины. Он обвинил Дильтея в том, что тот не знает современного состояния психологии и опирается в своей критике на работы полувековой давности. Большинство упреков, которые предъявлены объяснительной психологии, на самом деле относятся только к учению Гербарта. Эббингауз особенно подчеркивал независимость современной эмпирической психологии от него: «Гербарт, конечно, приобрел значение в пределах Германии. Но его метафизическая изощренность, его необоснованные фикции, его мифологемы всегда служили ему преградой для выхода за ее пределы. <...> Более того, если обозреть живую психологическую исследовательскую работу современности во всей широте и объеме, то обнаружится, что она ни от кого не была дальше умственно отделена так, как именно от Гербарта» (Эббингауз, 2014, с. 164). Мало того, Дильтей также не ориентировался в работах современной «описательной психологии». В целом его работа отличалась бессодержательностью, 
а размышления о неприменимости гипотез к психическим явлениям, которые использовались как главный аргумент против объяснительной психологии, необоснованностью. Критика Эббингауза оказалась настолько жесткой, что Дильтей так и не смог ответить на нее (Куренной, 2014).

Мы можем видеть, что в поздней критике математической психологии изменились акценты. Дильтей обращал внимание не только на механистичность гербартовского подхода, но в первую очередь на способ построения знания через выдвижение научных гипотез. Напротив, Эббингауз указывал на важность гипотез в научном знании. Он говорил о том, что психологическая теория содержит в себе не абсолютные истины, ее положения могут быть эмпирически опровергнуты. Особенно возможности верификации возросли после «глубокой по своим последствиям революции» - введения в методологию психологии экспериментального метода. В этом отношении психология не отличается от других естественных и точных наук. Здесь важно подчеркнуть, что Дильтей не выступал категорически против экспериментов в психологии (Ash, 1980b).

Дильтей и позднее другие представители немецкой философии рубежа веков все более отчетливо осознавали тот факт, что современная им психология со всеми ее экспериментами и измерениями не может оказаться полезной при разработке методологии гуманитарных дисциплин, которые представляли для них основной интерес. Так, Риккерт в «Науках о природе и науках о культуре» приветствовал психологические идеи Дильтея (Риккерт, 1998). В итоге это привело представителей неокантианства к идее, что «объяснительная психология» должна быть независима от философии, причем дисциплинарно. П. Наторп, инициатор открытого движения за академическое оформление разделения психологии и философии, писал: «Поручить философу университетское преподавание психологии или психологу - философии имело бы не больше оснований, нежели поручить философу преподавать также математику, или биологию, или...» (Наторп, 2006, с. 39).

Определенную роль в радикальных настроениях академических философов на рубеже веков сыграла идея о кризисе немецкой науки. Тема кризиса достаточно хорошо раскрыта Ф. Рингером в «Закате немецких мандаринов» (Рингер, 2008). Первым о методологическом кризисе заговорили Р. Авенариус и Э. Мах, причем кризисе не только психологии, но и науки в целом (Авенариус, 1907-1908; Mülberger, 2012). В истории математической психологии дискуссии о методологическом кризисе играют второстепенную роль, поэтому подробно останавливаться на них мы не будем. В целом общие кризисные настроения в среде психологов и философов все более и более усиливались начиная с конца 1890-х гг.

С нашей точки зрения, кризис в немецкой психологии в первую очередь был вызван особенностями академической политики и государственного финансирования научных исследований. Как известно, с открытием экспериментальной лаборатории в Лейпциге в 1879 г. началась новая эра научной психологии. В конце XIX в. в Германии насчитывалось уже четыре психологические лаборатории (института): вундтовская в Лейпциге, а также в 
Берлине, Вюрцбурге и Геттингене. Однако институциализация экспериментальной психологии проходила медленно. Официальное признание от университета Психологический институт Вундта получил в 1883 г., но регулярные государственные субсидии на него стали выделяться только с середины 1890-х гг. Не менее драматично обстояли дела с Берлинским институтом Штумпфа. Начиная с конца 1890-х гг. он неоднократно был вынужден просить германское правительство увеличить штат сотрудников института, предоставить новые помещения для лабораторий и субсидии. Об общем состоянии академических штатов и лабораторий можно судить по данным, которые приводит М. Аш (Ash, 1980a, p. 273).

Скромное финансирование академической психологии не смогло остановить процесс роста количества психологов в академической среде. Возникало все больше социальных институций, утверждающих дисциплинарный статус психологии. В конце века появились немецкоязычные специализированные журналы по психологии, психологические общества, стали проводиться конференции. В 1890 г. Эббингауз и А. Кениг начали издавать «Журнал по психологии и физиологии органов чувств». С 1903 г. Э. Мойман издавал «Архив общей психологии». В 1904 г. было основано Общество экспериментальной психологии.

На открытии V съезда Общества экспериментальной психологии в 1912 г. часть участников прямо выступали за создание психологических кафедр и профессорских должностей по психологии (Ash, 1980a). Через два года на VI съезде Общества экспериментальной психологии Мюллер жаловался на отсутствие финансирования экспериментальной психологии и трудности в работе Психологического института в Геттингене (Ash, 1980b).

Здесь стоит уточнить, что на самом деле количество психологов с академической аккредитацией значительно возросло: в 1892 г. психологи занимали три ординарные профессорские кафедры, а в 1910 г. уже десять (Куш, 2002). Но конкуренция за профессорские ставки все равно оставалась слишком жесткой. Что касается финансирования, то оно в разы уступало материальной поддержке в Германии, например, физических наук (Ash, 1980b).

В 1912 г. Кюльпе опубликовал статью «Психология и медицина». В ней он предлагал в каждом немецком университете открыть психологические институты, а также ввести психологию в качестве обязательного предмета для медиков, в связи с этим открыть кафедры психологии на медицинских факультетах. Обоснование своей позиции он видел в том, что молодые психологи нередко специализируются именно в психологии, поверхностно осваивая философские дисциплины (Külpe, 1912). Но после выхода в свет статья не имела общественного резонанса, поэтому в 1914 г. Кюльпе внес новое предложение о выделении психологии в качестве самостоятельной научной дисциплины в рамках философского факультета (Ash, 1980b).

Вскоре ситуация вышла за пределы академического мира. В 1912 г. Наторп выступил в ведущей франкфуртской газете с заявлением, в котором опротестовал получение экспериментальным психологом Э. Йеншем вместо неокантианца Когена профессорского звания на философском факультете 
Марбургского университета. В начале 1913 г. Гуссерль, Наторп, Риккерт и другие ученые составили заявление, адресованное всем немецкоязычным университетам и министерствам образования: «Экспериментальная психология, следовательно, должна быть поддержана только через введение должностей профессоров психологии, и везде, где предварительно должности профессоров философии заняты [психологами], должны быть учреждены новые кафедры философии» (Kusch, 1995, p. 188). Анализ заявления позволяет сделать вывод о том, что авторы явно позаимствовали аргументы из рассмотренной выше речи Виндельбандта и статьи о психологии и медицине Кюльпе, усилив свою аргументацию ссылкой на «кризисное» состояние немецкой философии и повышение интереса студентов к философии жизни, одним из основателей которой считается Дильтей. Особенно важно для нас то, что нападкам подверглись именно экспериментальные психологи, а не представители «объяснительной психологии» и тем более математической психологии. После полемики Эббингауза с Дильтеем математическая психология оказалась дисциплиной прошлого, потерявшей свою актуальность.

Заявление имело большой резонанс в печати. Его подписали 107 философов из Германии, Австрии и Швейцарии. Со стороны психологов оно вызвало резко негативную реакцию, так как выходило за рамки академической полемики. Однако по поводу дисциплинарной независимости существовали разные мнения. Так, Вундт в статье «Психология в борьбе за существование» выступил против исключения психологии из состава философии. Он считал, что потеря психологией философских корней равносильна смерти дисциплины (Вундт, 1913).

C началом Первой мировой войны дисциплинарная борьба за независимость немецкой психологии фактически закончилась. Кроме военного положения, причиной тому послужило смещение акцента с неокантианства в сторону феноменологии Э. Гуссерля. Попытки обороняться от «нападения» психологии на философию прекратились (Куш, 2004). Гуссерль объявил полемическое эссе Дильтея первой атакой на «натуралистическую психологию», гениальной по своей интуиции. Конечно, экспериментальная психология поначалу смогла отбиться, но ее главный недостаток - неспособность объяснить факты духовной жизни, а следовательно, и оказаться полезной для наук о духе (Гуссерль, 2014).

Еще Гербарт в 1822 г. предупреждал: «Математика - господствующая наука нашего времени. Ее завоевания возрастают ежедневно, хотя и без шума. Кто не имеет ее за себя, тот некогда будет иметь ее против себя» (Гербарт, 2007a, с. 53). История математической психологии показала, что даже в том случае, когда речь шла лишь о математике как о методе, в философских дисциплинах разворачивались настоящие баталии, в которых представители разных методологических лагерей пытались отстоять свою независимость. 


\section{Литература}

Авенариус, Р. (1907-1908). Критика чистого опыта. СПб.: И.В. Шестаковский и И.П. Федоров. Авенариус, Р. (2003). О предмете психологии. М.: Едиториал УРСС.

Андреев, А. Ю. (2009). Российские университеты XVIII - первой половины XIX века в контексте университетской истории Европы. М.: Знак.

Бен-Дэвид, Д. (2014). Роль ученого в обществе. М.: Новое литературное обозрение.

Бен-Дэвид, Д., Коллинз, Р. (2002). Социальные факторы при возникновении новой науки: случай психологии. Логос, 35(5-6), 1-30.

Вундт, В. (1880). Основания физиологической психологии. М.: Н.А. Абрикосов.

Вундт, В. (1910). О наивном и критическом реализме. Имманентная философия и эмпириокритииизм. М.: Издание М. и С. Сабашниковых.

Вундт, В. (1913). Психология в борьбе за существование. В кн. Новые идеи в философии: Сб. 10. Методы психологии (с. 91-131). СПб.: Изд-во «Образование».

Гербарт, И. Ф. (2007, а). О возможности и необходимости применять в психологии математику. В кн. И. Ф. Гербарт, Психология (с. 39-56). М.: Издательский дом «Территория будущего».

Гербарт, И. Ф. (2007, б). Психология как наука, вновь обоснованная на опыте, метафизике и математике. В кн. И. Ф. Гербарт, Психология (с. 58-116). М.: Издательский дом «Территория будущего».

Гуссерль, Э. (2014). Введение к лекциям по феноменологической психологии (1925). Логос, 100(4), 187-214.

Демин, М. (2013). Немецкий университет XIX века и дисциплинарная специализация философии. Логос, 91(1), 240-261.

Дильтей, В. (1996). Описательная психология (2-е изд.). СПб.: Алетейя/Кренов.

Дмитриев, А. Н., Савельева, И. М. (ред.). (2015). Науки о человеке: история дисииплин. М.: ИД Высшей школы экономики.

Дробиш, М. (1867). Нравственная статистика. СПб.: Издание Н.И. Ламанского.

Кант, И. (1994). Метафизические начала естествознания. В кн. И. Кант, Сочинения (т. 4, с. $247-$ 372). М.: ЧОРО.

Кетле, Л. А. Ж. (1866). Социальная система и законы, ею управляющие. СПб.: Н. Поляков и К․

Кетле, Л. А. Ж. (1911). Социальная физика, или Опьт исследования о развитии человеческих способностей (т. 1). Киев: Типография И.И. Чоколова.

Куренной, В. (2005). К вопросу о возникновении феноменологического движения. Логос, 5(50), $247-275$.

Куренной, В. (2014). Полемика профессионалов: конкуренция и опровержение исследовательских программ в современной философии. Логос, 100(4), 105-146.

Куш, М. (2002). Социология философского знания: конкретное исследование и защита. Логос, $5-6(35), 1-31$.

Куш, М. (2004). Победителю достается все: Философия жизни и триумф феноменологии. Логос, 3(43), 167-200.

Кюльпе, О. (2007). Введение в философию. М.: Изд-во ЛКИ.

Ланге, Ф. А. (1883). История материализма и критика его значения в настоящее время: T. 2. История материализма после Канта. СПб.: Издание Л.Ф. Пантелеева.

Липпс, Г. Ф. (2012). Основы психофизики. М.: КомКнига.

Лотце, Р. Г. (1867). Микрокозм: Мысли о естественной и бытовой истории человечества: Опыт антропологии (ч. 3). М.: Издание К. Солдатенкова. 
Наторп, П. (2006). Философия и психология. В кн. П. Наторп, Избранные работы (с. 25-54). М.: Издательский дом «Территория будущего».

Поппер, К. Р. (1992). Открытое общество и его враги: Т. 2. Время лжепророков: Гегель, Маркс и другие оракулы. М.: Феникс/Международный фонд «Культурная инициатива».

Рибо, Т. (1895). Современная германская психология. Опьтная школа. СПб.: Паровая скоропечатня А. Пороховщикова.

Риккерт, Г. (1998). Науки о природе и науки о культуре. В кн. Г. Риккерт, Науки о природе и науки о культуре (с. 43-128). М.: Республика.

Рингер, Ф. (2008). Закат немеиких мандаринов: Академическое сообщество в Германии, 18901933. М.: Новое литературное обозрение.

Сокулер, 3. А. (2001). Знание и власть: наука в обществе модерна. СПб.: РХГИ.

Суходоев, В. В. (б.д.). Модифицированная методика измерений и оценки кожно-гальванических реакиий человека. Режим доступа: http://www.ipras.ru/cntnt/rus/media/on-laynbibliote/otdelnie-stati-s/publikacii/stati_sotr/vvsuhodeev.html

Шнедельбах, Г. (2002). Университет Гумбольдта. Логос, 5-6(35), 1-14.

Эббингауз, Г. (1912). Основы психологии (т. 1, вып. 2). СПб.: Издание товарищества «Общественная Польза».

Эббингауз, Г. (2014). Об объясняющей и описательной психологии. Логос, 100(4), 147-186.

Юдин, Г. (2015). Наукоучение Эдмунда Гуссерля и кризис теории разделения наук. В кн. А. Н. Дмитриев, И. М. Савельева (ред.), Науки о человеке: история дисциплин (с. 240-262). М.: ИД Высшей школы экономики.

Ссылки на зарубежные источники см. в разделе References после англоязычного блока.

Морозова Светлана Васильевна - старший преподаватель, кафедра общей психологии, факультет психологии, Санкт-Петербургский государственный университет, кандидат психологических наук.

Сфера интересов: количественная психология, история психологии, экспериментальная психология.

Контакты: svmpsy@gmail.com

\title{
Mathematische Psychologie: History of Conflict
}

\author{
S.V. Morozova ${ }^{a}$ \\ ${ }^{a}$ Saint Petersburg State University, 6 Makarova emb., Saint Petersburg, 199034, Russian Federation
}

\begin{abstract}
The article describes the role of the mathematische Psychologie in the German philosophical discourse of the 19th - early 20th centuries. The history of mathematical psychology is viewed from the standpoint of the disciplinary approach in historiography. The author focuses on the reconstruction of social mechanisms that determine the content of the discipline, its relationship
\end{abstract}


with the structure and specifics of the functioning of universities and academic institutions, as well as academic corporations. The author shows that several times mathematical psychology had been in the center of disciplinary conflicts. At first, it was a subject of controversy between the Herbartarians and the Neo-Kantians. After the publication of Fechner's Elements of Psychophysics, academic philosophers perceived physiological psychology as "mathematical psychology". By the end of the 19th century, after the heyday of psychophysics, during the rise of a new wave of Neo-Kantianism, the psychology of Herbart and psychophysics became the subject of a polemic between Dilthey and Ebbinghaus about the revision of the methodological bases of psychology. The discussion of the early 20th century on the exclusion of experimental psychology from the list of philosophical disciplines completes the process of turning to mathematical psychology as an argument for defining the disciplinary boundaries. The history of mathematische Psychologie showed that even when it was only a question of mathematics as a method, real battles took place in philosophical disciplines, in which representatives of different methodological camps tried to defend their independence. Started as a philosophical argument, the debate on the mathematische Psychologie gradually turned into a branding of the methodologically backward and outdated.

Keywords: mathematische Psychologie, mathematical psychology, history of psychology, disciplinary conflict, academic policy.

\section{References}

Andreev, A. Yu. (2009). Rossiiskie universitety XVIII - pervoi poloviny XIX veka v kontekste universitetskoi istorii Evropy [Russian universities of the $18^{\text {th }}-$ early $19^{\text {th }}$ century in the context of university history of Europe]. Moscow: Znak. (in Russian)

Ash, M. G. (1980, a). Academic politics in the history of science: experimental psychology in Germany, 1879-1941. Central European History, 13(3), 255-286.

Ash, M. G. (1980, b). Experimental psychology in Germany before 1914: aspects of an academic identity problem. Psychological Research, 42, 75-86.

Avenarius, R. (1907-1908). Kritika chistogo opyta [Critique of pure experience]. Saint Petersburg: I.V. Shestakovskii i I.P. Fedorov. (in Russian)

Avenarius, R. (2003). O predmete psikhologii [On the subject of psychology]. Moscow: Editorial URSS. (in Russian)

Backhouse, R. E., \& Fontaine, P. (Eds.). (2010). The history of social sciences since 1945. Cambridge: Cambridge University Press.

Ben-David, J. (2014). Rol' uchenogo v obshchestve [The scientist's role in society]. Moscow: Novoe literaturnoe obozrenie. (in Russian; trans. of: Ben-David, J. (1971). The scientist's role in society. A comparative study. Englewood Cliffs, NJ/London: Prentice-Hall.)

Ben-David, J., \& Collins, R. (2002). Sotsial'nye faktory pri vozniknovenii novoi nauki: sluchai psikhologii [Social factors in the origins of a new science: The case of psychology]. Logos, 35(5-6), 1-30. (in Russian; trans. of: Ben-David, J., \& Collins, R. (1966). Social factors in the origins of a new science: The case of psychology. American Sociological Review, 31(4), 451-465.)

Boudewijnse, G.-J. A., \& Murray, D. J. (2001). The fate of Herbart's mathematical psychology. History of Psychology, 4(2), 107-132. 
Danziger, K. (1998). Constructing the Subject: historical origins of psychological research. Feminisms Redux. Cambridge: Cambridge University Press.

Demin, M. (2013). Nemetskii universitet XIX veka i distsiplinarnaya spetsializatsiya filosofii [German university of the $19^{\text {th }}$ century and disciplinary specialization of philosophy]. Logos, 91(1), 240-261. (in Russian)

Dilthey, W. (1996). Opisatel'naya psikhologiya [Descriptive psychology] (2nd ed.). Saint Petersburg: Aleteiya/Krenov. (in Russian)

Dmitriev, A. N., \& Savelieva, I. M. (Eds.). (2015). Nauki o cheloveke: istoriya distsiplin [Sciences of man: History of the disciplines]. Moscow: HSE Publishing House. (in Russian)

Drobisch, M. W. (1842). Empirische Psychologie nach naturwissenschaftlicher Methode [Empirical psychology on the natural scientific method]. Leipzig. (in German)

Drobisch, M. W. (1850). Erste Grundlehren der mathematischen Psychologie. Mit einer Figurentafel [The first basic teachings of the mathematical psychology. With the figure panel]. Leipzig. (in German)

Drobisch, M. W. (1864). Ueber den neuesten Versuch die Psychologie naturwissenschaftlich zu begründen [On the latest attempt to explain psychology in scientific terms]. Zeitschrift für exacte Philosophie, 4, 313-348. (in German)

Drobisch, M. (1867). Nravstvennaya statistika [Moral statistics]. Saint Petersburg: Izdanie N.I. Lamanskogo. (in Russian)

Ebbinghaus, H. (1912). Osnovy psikhologii [Principles of psychology] (Vol. 1, iss. 2). Saint Petersburg: Izdanie tovarishchestva "Obshchestvennaya Pol'za". (in Russian)

Ebbinghaus, H. (1913). Memory: a contribution to experimental psychology. New York, NY: Teachers College, Columbia University.

Ebbinghaus, H. (2014). Ob ob»yasnyayushchei i opisatel'noi psikhologii [On the explanatory and descriptive psychology]. Logos, 100(4), 147-186.

Fechner, G. T. (1860). Elemente der Psychophysik [Elements of psychophysics] (Erster Theil). Leipzig: Breitkopf und Hдrtel. (in German)

Fechner, G. T. (1987). Outline of a new principle of mathematical psychology (1851). Psychological Research, 49(4), 203-207. doi:10.1007/BF00309027

Hatfield, G. (2003). Psychology: old and new. In T. Baldwin (Ed.), The Cambrige history of philosophy: 1870-1945 (pp. 93-106). Cambridge: Cambridge University Press.

Helmholtz, H., von. (1867). Handbuch der physiologischen Optik [The manual on the physiological Optics]. Leipzig: Leopold Voss. (in German)

Herbart, J. F. (2007, a). O vozmozhnosti i neobkhodimosti primenyat' v psikhologii matematiku [On the possibility and necessity to apply mathematics in psychology]. In J. F. Herbart, Psikhologiya [Psychology] (pp. 39-56). Moscow: Izdatel'skii dom "Territoriya budushchego". (in Russian)

Herbart, J. F. (2007, b). Psikhologiya kak nauka, vnov' obosnovannaya na opyte, metafizike i matematike [Psychology as a science, which is based on experience, metaphysics and mathematics]. In J. F. Herbart, Psikhologiya [Psychology] (pp. 58-116). Moscow: Izdatel'skii dom "Territoriya budushchego". (in Russian)

Husserl, E. (2014). Vvedenie k lektsiyam po fenomenologicheskoi psikhologii [Introduction to the lectures on phenomenological psychology] (1925). Logos, 100(4), 187-214. (in Russian)

Kant, I. (1994). Metafizicheskie nachala estestvoznaniya [Metaphysical foundations of natural science]. In I. Kant, Sochineniya [Writings] (Vol. 4, pp. 247-372). Moscow: ChORO. (in Russian)

Külpe, O. (1912). Psychologie und medizing [Psychology and medicine]. Zeitschrift für Pathopsychologie, 1, 187-267. (in German)

Külpe, O. (2007). Vvedenie v filosofiyu [Introduction to philosophy]. Moscow: Izdatel'stvo LKI. (in Russian) 
Kurennoy, V. (2005). K voprosu o vozniknovenii fenomenologicheskogo dvizheniya [On the issue of the rise of phenomenological movement]. Logos, 5(50), 247-275. (in Russian)

Kurennoy, V. (2014). Polemika professionalov: konkurentsiya i oproverzhenie issledovatel'skikh programm $\mathrm{v}$ sovremennoi filosofii [Polemics of the professionals: competition and refutation of research programs in contemporary philosophy]. Logos, 100(4), 105-146. (in Russian)

Kusch, M. (1995). Psychologism: A case study in the sociology of philosophical knowledge. London/New York, NY: Routledge.

Kusch, M. (2002). Sotsiologiya filosofskogo znaniya: konkretnoe issledovanie i zashchita [Sociology of philosophical knowledge: a case study and a defense]. Logos, 5-6(35), 1-31. (in Russian)

Kusch, M. (2004). Pobeditelyu dostaetsya vse: Filosofiya zhizni i triumf fenomenologii [The winner gets it all: Philosophy of life and the triumph of phenomenology]. Logos, 3(43), 167-200. (in Russian)

Lange, F. A. (1865). Die Grundlegung der mathematischen Psychologie. Ein Versuch zur Nachweisung des fundamentalen Fehlers bei Herbart und Drobisch [The foundation of mathematical psychology. An attempt to prove the fundamental error of Herbart and Drobisch]. Duisburg: Verlag von W. Falk \& Volmer. (in German)

Lange, F. A. (1883). Istoriya materializma i kritika ego znacheniya v nastoyashchee vremya: T. 2. Istoriya materializma posle Kanta [The history of materialism and critique of its significance today. Vol. 2. History of materialism after Kant]. Saint Petersburg: Izdanie L.F. Panteleeva. (in Russian)

Lipps, G. F. (2012). Osnovy psikhofiziki [Foundations of psychophysics]. Moscow: KomKniga. (in Russian)

Lotze, H. (1841). Metaphysik [Metaphysics]. Leipzig: Weidmann'sche buchhandlung. (in German)

Lotze, H. (1852). Medicinische Psychologie, oder Physiologie der Seele [Medical psychology, or the psychology of soul]. Leipzig: Weidmann'sche buchhandlung. (in German)

Lotze, R. H. (1867). Mikrokozm: Mysli o estestvennoi i bytovoi istorii chelovechestva: Opyt antropologii [Microcosm: Thoughts on the natural and common history of mankind: An experience in anthropology] (Pt. 3). Moscow: Izdanie K. Soldatenkova. (in Russian)

Mülberger, A. (2012). Wundt contested: The first crisis declaration in psychology. Studies in History and Philosophy of Biological and Biomedical Sciences, 43, 434-444.

Natorp, P. (2006). Filosofiya i psikhologiya [Philosopy and psychology]. In P. Natorp, Izbrannye raboty [Selected works] (pp. 25-54). Moscow: Izdatel'skii dom "Territoriya budushchego". (in Russian)

Popper, K. R. (1992). Otkrytoe obshchestvo i ego vragi: T. 2. Vremya lzheprorokov: Gegel', Marks i drugie orakuly [Open society and its enemies: Vol. 2. The time of false prophets: Hegel, Marx and other oracles]. Moscow: Feniks/Mezhdunarodnyi fond "Kul'turnaya initsiativa". (in Russian)

Quetelet, L.-A.-J. (1866). Sotsial'naya sistema i zakony, eyu upravlyayushchie [Social system and laws that govern it]. Saint Petersburg: N. Polyakov i K०. (in Russian)

Quetelet, L.-A.-J. (1911). Sotsial'naya fizika, ili Opyt issledovaniya o razvitii chelovecheskikh sposobnostei [Social physics, or the Effort of research on the development of human abilities] (Vol. 1). Kiev: Tipografiya I.I. Chokolova. (in Russian)

Ribot, T. (1895). Sovremennaya germanskaya psikhologiya. Opytnaya shkola [Modern German psychology. School of experience]. Saint Petersburg: Parovaya skoropechatnya A. Porokhovshchikova. (in Russian)

Rickert, H. (1998). Nauki o prirode i nauki o kul'ture [The natural sciences and the cultural sciences]. In H. Rickert, Nauki o prirode i nauki o kul'ture [The natural sciences and the cultural sciences] (pp. 43-128). Moscow: Respublika. (in Russian)

Ringer, F. (2008). Zakat nemetskikh mandarinov: Akademicheskoe soobshchestvo v Germanii, 18901933 [The decline of the German mandarins: the German academic community, 1890-1933]. 
Moscow: Novoe literaturnoe obozrenie. (in Russian; trans. of: Ringer, F. (2008). The decline of the German mandarins: the German academic community, 1890-1933. Cambridge: Harvard Unviversity Press.)

Schnädelbach, P. (2002). Universitet Gumbol'dta [Humboldt university]. Logos, 5-6(35), 1-14. (in Russian)

Sokuler, Z. A. (2001). Znanie i vlast': nauka v obshchestve moderna [Knowledge and power: Science in the modern society]. Saint Petersburg: RKhGI. (in Russian)

Stevens, S. S. (1957). On the psychophysical law. Psychological Review, 64(3), 153-181. doi:10.1037/h0046162

Sturm, T. (2012). Bühler and Popper: Kantian therapies for the crisis in psychology. Studies in History and Philosophy of Biological and Biomedical Sciences, 43(2), 462-72. doi:10.1016/j.shpsc.2011.11.006

Sturm, T., \& Mülberger, A. (2012). Crisis discussions in psychology - New historical and philosophical perspectives. Studies in History and Philosophy of Biological and Biomedical Sciences, 43(2), 42533. doi:10.1016/j.shpsc.2011.11.001

Sukhodoev, V. V. (s. d.). Modifitsirovannaya metodika izmerenii i otsenki kozhno-gal'vanicheskikh reaktsii cheloveka [Modified technique of measurement and assessment of galvanic skin reaction of a man]. Retrieved from http://www.ipras.ru/cntnt/rus/media/on-layn-bibliote/otdelnie-statis/publikacii/stati_sotr/vvsuhodeev.html (in Russian)

Windelband, W. (1876). Über den gegenwärtigen Stand der psychologischen Forschung: Rede zum Antritt der ordentlichen Professur der Philosophie an der Hochschule zu Zürich am 20. Mai 1876 gehalten [On the current state of psychological research: Speech at the inauguration of the full professorship of philosophy at the University of Zurich on May, 20, 1876]. Leipzig: Drück und Verlag von Breitkopf \& Härtel. (in German)

Wundt, W. (1862). Beiträge zur Theorie der Sinneswahrnehmung [Contributions to the theory of sensory perception]. Leipzig/Heidelberg: C. F. Winter'sche Verlagshandlung. (in German)

Wundt, W. (1877). Philosophy in Germany. Mind, 2(8), 493-518.

Wundt, W. (1880). Osnovaniya fiziologicheskoi psikhologii [Principles of physiological psychology]. Moscow: N.A. Abrikosov. (in Russian)

Wundt, W. (1908). Grundzüge der physiologischen Psychologie [Principles of physiological psychology] (Erster Band). Leipzig: Verlag von Wilhelm Engelmann. (in German)

Wundt, W. (1910). O naivnom i kriticheskom realizme. Immanentnaya filosofiya i empiriokrititsizm [On the naive and critical realism. The immanent philosophy and empirio-criticism]. Moscow: Izdanie M. i S. Sabashnikovykh. (in Russian)

Wundt, W. (1913). Psikhologiya v bor'be za sushchestvovanie [Psychology in the struggle for existence]. In Novye idei v filosofii: Sb. 10. Metody psikhologii [New ideas in philosophy: Digest 10. Psychological methods] (pp. 91-131). Saint Petersburg: Obrazovanie. (in Russian)

Yudin, G. (2015). Naukouchenie Edmunda Gusserlya i krizis teorii razdeleniya nauk [The science teaching by Edmund Husserl and the crisis of theory division of sciences]. In A. N. Dmitriev \& I. M. Savelieva (Eds.), Nauki o cheloveke: istoriya distsiplin [Sciences of man: History of disciplines] (pp. 240-262). Moscow: HSE Publishing House. (in Russian)

Svetlana V. Morozova - Senior Lecturer, Faculty of Psychology, Saint Petersburg State University, PhD in Psychology.

Research Area: quantitative psychology, history of psychology, experimental psychology.

E-mail: svmpsy@gmail.com 
Психология. Журнал Высшей школы экономики,

2021. T. 18. № 1. C. 167-181. DOI: 10.17323/1813-8918-2021-1-167-181

\title{
ЯВЛЯЕТСЯ ЛИ РЕАЛИЗАЦИЯ СИСТЕМНО-ИНФОРМАЦИОННОГО ПОДХОДА В.М. ПЕТРОВА СПОСОБОМ ПРЕОДОЛЕНИЯ КРИЗИСА В ПСИХОЛОГИИ И ДРУГИХ ГУМАНИТАРНЫХ НАУКАХ?
}

\begin{abstract}
В.М. РОЗИН
${ }^{a}$ Федеральное государственное бюджетное учреждение науки Институт философии Российской академии наук, 109240, Россия, Москва, ул. Гончарная, д. 12, стр. 1

\section{Резюме}

Автор анализирует статью В.М. Петрова, опубликованную в журнале «Мир психологии», в которой на основе системно-информационного подхода предложена перестройка гуманитарных наук. Автор сравнивает это предложение с близкой по идеям программой Л.С. Выготского 1927 г., изложенной в работе «Исторический смысл психологического кризиса. Методологическое исследование». Автор старается показать, что системный подход нужно понимать иначе, чем это делает Петров, а именно не как предельную онтологию, а как превращенную форму методологии. Кроме того, с опорой на системные разработки Г.П. Щедровицкого, а также реконструкцию истории естественных наук предлагается гипотеза, согласно которой реализация системного подхода предполагает построение двух скоординированных между собой языков - «системно-структурного» и «предметносистемного». Для Щедровицкого второй язык - это язык теории деятельности, где деятельность истолкована как система, для Петрова, вероятно, - теория информации. Автор иначе, чем Петров, представляет главные задачи реформирования психологии: это необходимость конвергенции естественно-научного и гуманитарного подходов, переосмысление связи психологической науки и практики, а также самой психологической науки, осмысление нового статуса и природы человека, попавшего в процессы перехода и сложную реальность постмодерна (посткультуры). Обсуждаются условия, необходимые для решения этих задач. В их число входит авторская концепция науки, учет двух этапов развития психологии и особенностей психологической науки, некоторых характеристик современного состояния культуры. Автор приходит к выводу, что системный подход помогает в изучении психики в рамках отдельной науки (концепции), но не реагирует на различие парадигм, кроме того, разнообразие типов человека и личности осмысляется в психологическом знании и науке в форме множества психологических концепций, теорий и практик, что совершенно нормально и вовсе не требует реформирования. Но методологическая культура психологов нуждается в совершенствовании.
\end{abstract}

Ключевые слова: система, системный подход, предмет, дисциплина, наука, схемы, идеальные объекты, концепция, реконструкция, практика.

Исследование проведено при финансовой поддержке гранта Министерства науки и высшего образования РФ («Новейшие тенденции развития наук о человеке и обществе в контексте процесса цифровизации и новых социальных проблем и угроз: междисциплинарный подход», проект № 075-15-2020-798). 


\section{Возвращение к обсуждению кризиса в психологии и гуманитарных науках}

В качестве преамбулы я бы сформулировал цель данной статьи и разговора как постановку некоторых проблем, касающихся дальнейшего развития психологии. Делаю это, обсуждая интересную работу В.М. Петрова, который склоняет читателя к научной полемике, что в настоящее время встречается нечасто.

В журнале «Мир психологии» опубликована статья В.М. Петрова «Предстоящая “перезагрузка” гуманитарных наук: вызов времени» (Петров, 2019). Он пишет не о преодолении кризиса, а о «перезагрузке» гуманитарных наук как актуальном вызове времени, но, по сути, это та же самая проблема, которую еще в 1920-е гг. обсуждал Л.С. Выготский в своей интересной работе «Исторический смысл психологического кризиса (методологическое исследование)». Если у Выготского единицами анализа ситуации в психологии выступают понятия «идея», «дисциплина», «наука», «система наук», то у Петрова - это «парадигмы». На мой взгляд, большой разницы нет, просто Выготский по понятным причинам еще не читал «Структуру научных революций» Томаса Куна. Вызов времени оба автора видят примерно в одном множестве несовпадающих представлений об изучаемой реальности (психике и других объектах гуманитарной науки), отсутствии единой системь науки, отставании методологии науки. И ответ на этот вызов очень близкий - вместо множества противоречивых представлений (дисциплин, наук) нужно построить единую науку, основанную на строгой иерархической организации и центральном правильном понятии, схватывающем пусть и на достаточно абстрактном уровне, но все же сущность изучаемого явления. Сравним.

«Современная научная психология переживает глубочайший кризис своих методологических основ <..> ...отсутствие общепризнанной системы науки. Каждое изложение психологии у виднейших авторов построено по совершенно иной системе. Все основные понятия и категории толкуются по-разному... $<$...> Единство отдельных психологических предметов и дисциплин в «общей психологии», которую предстоит построить, достигается путем подчинения, господства, путем отказа отдельных дисциплин от суверенитета в пользу общей науки. Внутри нового целого образуется не сосуществование отдельных дисциплин, но их иерархическая система, имеющая главный и вторичный центры, как Солнечная система... <... . ..даже самому отвлеченному, последнему понятию соответствует какая-то черта действительности» (Выготский, 1982, с. $300,312,370,373)$.

«...Имеются конкретные знания о множестве частных фактов (например, относящихся к сфере творчества), известно небольшое количество более или менее достоверных закономерностей (скажем, относящихся к психофизике), но практически нет единой принятой научным сообществом целостной концепчии ментальной жизни человека... <..> Стало быть, если поставить в качестве первого (самого предварительного) ориентира исследования выбор оптимальной парадигмь, то следует сосредоточиться на ее возможньх очертаниях... 
<..> Словом, единую модель гуманитарной сферь, включающую ее ядро ментальные процессы, еще только предстоит построить! И именно в этом заключается ВЫЗОВ ВРЕМЕНИ: без такой модели мы обречены на бесплодное блуждание в мире частностей < ..> нас может ждать весьма печальная перспектива - при отсутствии единой системной иерархически организованной модели гуманитарного знания <...> следует ориентироваться на парадигмы максимально общего характера... В такой “раскладке” главная, центральная парадигма обеспечивает принципиальную правильность (либо, наоборот, неправильность) “общего хода” всех рассуждений, тогда как некие частные парадигмы дают решения для множества конкретных моделей - ситуаций, складывающихся в каждой области <...> Только тогда есть надежда прибегнуть к помощи вышеописанного феномена централизащии - связать друг с другом разных “абонентов” через некую надстроенную над ними всеми “обобщающую” (“центральную”) парадигму...» (Петров, 2019, с. 223, 226, 227-228). Почти через сто лет В.М. Петров воспроизводит структуру мысли Л.С. Выготского. Выготский видел решение поставленных им проблем на путях реализации в психологии естественно-научного подхода (хотя сам скорее действовал как гуманитарий). Точнее, что видно по многим его работам: он сидел на двух, если не на трех, стульях. Например, в книге «Язык и мышление» Выготский, с одной стороны, заявляет, что он будет вести исследования, ориентируясь на методы Френсиса Бэкона, с другой стороны, анализирует мышление подобно гуманитарию, в духе В. Дильтея, с третьей стороны, пытается представить развитие мышления, беря в образец генезис в «Капитале» Маркса.

В. Петров считает, что будущее скорее за системным (системно-информационным) подходом. «Дело в том, - пишет он, - что именно этот подход инвариантен относительно конкретной области “материальной природы” любых научных областей (и поэтому позволяет интегрировать их совокупность в единую системную целостность...)» (Там же, с. 220).

\section{Онтологический и методологический аспекты системного подхода}

Вероятно, Петров не знает или не хочет знать, что в целом психология не пошла за Выготским (исключение - теория деятельности А.Н. Леонтьева и его последователей): общую психологию никто не построил, а количество психологических наук, по-разному истолковывающих психику, в сравнении со временем написания работы Выготского возросло на порядок, если не больше. Как известно, не оправдались и ожидания сторонников системного подхода, утверждавших в 1960-1970-е гг., что системный подход заменит собой методологию и философию и станет универсальным языком науки. Но этот аргумент очень общий, необходим анализ конкретной ситуации, которую обсуждает Петров (Бог, как известно, в деталях). Поэтому обсудим. Начну с проблемы демаркации системного подхода и методологии.

Обратите внимание на фразу Петрова «центральная парадигма обеспечивает принципиальную правильность (либо, наоборот, неправильность) “общего хода” всех рассуждений», т.е. получается, что системный подход - это 
методология, т.е. предписания, обеспечивающие правильность мышления. Но обычно системный подход понимается иначе, скорее как «предельная онтология»: система хотя и не объект, но что-то вроде него - особая онтология, в рамках которой можно правильно помыслить (и конструировать) любой сложный объект (например, психику), правильно его анализировать и синтезировать. А методология вроде бы отличается от онтологии; скажем, по Г.П. Щедровицкому, это знания и проекты мышления и деятельности. «Итак, методолог, - пишет Щедровицкий, - (в отличие от ученого) - это человек, который работает над собственной деятельностью и собственным мышлением, меняя их, трансформируя, создавая новые формы - сначала в мысли, а потом в реализации» (На досках, 2004, с. 131, 184-185). Создание новых видов деятельности и мышления Щедровицкий мыслит проектно и нормативно, «и этим же, - пишет он, - определяется основная функция методологии: она обслуживает весь универсум человеческой деятельности прежде всего проектами и предписаниями» (Там же, с. 95).

Если принять подобное противопоставление, то спрашивается: системный подход - это онтология или методология? Думаю, это особый, странный вариант методологии, когда процедуры мысли и деятельности не заданы явно, именно как процедуры, а указаны, так сказать, латентно, посредством онтологии (кстати, примерно так же устроены философские категории). Ведь что такое система? В качестве образа, схемы - это определенное построение, и в этом смысле объект (целое, подсистемы, элементы, связи и отношения, иерархическая организация и пр.). Но посредством этих схем и образов задаются процедуры правильного системного мышления: определяем, нащупываем целое, противопоставляем его среде или другим целым; мыслим части и подсистемы как обусловленные этим целым, а целое - как составленное из этих частей; определяем единицы (элементы, подсистемы) как самостоятельные образования и одновременно как зависимые от других единиц и пр. и пр.

Системный подход - это, так сказать, «превращенная форма методологии», методология в форме онтологии. В этом его преимущество, но и недостаток. Кстати, первоначально в философии античной культуры и Средних веков методология чаще всего существовала именно в форме онтологии, только в Новое время, когда в центр философской мысли было поставлено мышление (Ф. Бэкон, Р. Декарт, И. Кант) и сформировалась специфическая рефлексия деятельности, в начале XX столетия методология была выделена сначала как самостоятельный жанр (Л.С. Выготский, С. Франк), затем философская дисциплина.

Как онтология система воспринимается предметником (ученым или философом) в виде обобщенной модели изучаемого явления («следует, - замечает Карпов, - ориентироваться на парадигмы максимально общего характера»). Но поскольку процедуры здесь заданы неявно, их, во-первых, можно толковать субъективно, что и происходит в практике исследования и конструирования сложных явлений, во-вторых, многие реальные процедуры не укладываются в образ и схемы системы, ведь системный подход - это хотя и важный, но только один вариант методологии. Именно такой, где исследователю или 
инженеру приходится иметь дело с «многими знаниями и предметами», которые только в совокупности должны задавать сложное явление, поэтому приходится решать задачи синтеза и анализа, определения целого и частей, действия по логике обусловленности и зависимости и пр. Но существуют и другие стратегии «мыследействия», не требующие системного подхода, они поддерживаются другими подходами, например, феноменологическим, семиотическим, гуманитарным, культурно-историческим. Скажем, в феноменологии тоже осуществляется синтез разных знаний, но иначе, за счет тематизации и схватывания («концепирования») разных представлений в сознании мыслящего.

\section{Системный подход как способ преодоления сложности}

Моделесообразность системного подхода часто подводит исследователя, ему кажется, что можно упростить сложный синтез и анализ предметов и знаний, как правило, предполагающие методологическую рефлексию, заменив их системным анализом и синтезом. Пример подобного хода мысли находим у моего учителя Г.П. Щедровицкого (1993, 1995а). Столкнувшись в ходе педагогического исследования человека с ситуацией многих знаний и предметов (эта ситуация создается самим исследованием, заставляющим выделять в ходе анализа и частично обособлять различные стороны и составляющие изучаемого явления), Г.П. Щедровицкий решил облегчить себе задачу, обратившись к системному подходу. «Педагогика требует такого научного знания о человеке, которое бы объединяло все три описанных выше представления о человеке (как личности, социального индивида и биологического существа. B.P.), синтезировало бы их в одном многостороннем и конкретном теоретическом знании... Но сегодня теоретическое движение не может ее разрешить, ибо нет необходимых для этого средств и методов анализа. Задачу приходится решать сначала на методологическом уровне, вырабатывая средства для последующего теоретического движения, в частности на уровне методологии системно-структурного исследования» (Щедровицкий, 1995а, с. 370). «Поэтому мы должны попытаться каким-то образом свести все эти моменты к более простым отношениям и механизмам, чтобы затем вывести их из последних и таким образом организовать все в единую систему» (Щедровицкий, 1995b, с. 273).

Системный подход, утверждает Щедровицкий, определяет методы изучения как деятельности вообще, так и любых конкретных видов деятельности. Анализ работы «Человек как предмет исследования» и ряда других показывает, что принципы системного подхода и системные представления для Щедровицкого в этот период заменяют логику. «Каждая из этих схем (речь идет о схемах, по которым строятся в науке модели «человека». - B.P.) требует для своего развертывания особого методического аппарата системно-структурного анализа. Различие между ними распространяется буквально на все на принципы анализа и обработки эмпирических данных. На порядок рассмотрения частей моделей и относящихся к ним свойств, на схемы конструирования разных “сущностей”, превращающих эти схемы в идеальные объекты, 
на схемы связи и объединения свойств, относящихся к разным слоям описания объекта» (Щедровицкий, 1995а, с. 376). Другая функция системно-структурного анализа в работах Щедровицкого - обеспечивать синтез и конфигурирование разных предметов знания, разных объектных представлений, что тоже можно отнести к ведению логики, правда, понимаемой широко. Дело в том, что Щедровицкий еще в начале своего творчества противопоставил две логики - формальную, которую он критиковал за принцип «параллелизма формы и содержания», и «содержательно-генетическую» (именно ее Щедровицкий со своими коллегами развивает и трактует достаточно широко, отчасти в духе методологии).

В основном с этими положениями можно согласиться, за исключением широкого обобщения: не все явления можно рассмотреть как деятельность, кроме системного подхода, существуют другие (феноменологический, семиотический, психоаналитический, когнитивный, биологический, информационный и др.).

\section{Системно-структурный и предметно-системный языки описания изучаемой реальности}

Стоит отметить, что вариант построения Г.П. Щедровицким системного подхода отличался от существовавших в тот период (А. Богданова, Л. Берталанфи, Т. Парсонса, А. Уемова, В. Садовского). Дело в том, что предметом методологического изучения и конструирования для Щедровицкого выступала деятельность. Правда, трактовка им деятельности серьезно отличалась от психологической, он понимал деятельность не как активность и процесс субъекта (индивида), а как деиндивидуальную структуру, для которой характерны не только «акт деятельности» (здесь можно увидеть совпадение с психологической традицией), но и воспроизводство, разделение и кооперация труда, процессы трансляции и коммуникации.

Щедровицкий знал, что существуют различные варианты системного подхода, в частности, предполагал, что системный подход может противоречить деятельностному подходу в том виде, как он задавался в методологии. В результате Щедровицкий выходит на следующее решение - системный подход нужно построить заново в рамках самой методологии.

«Главная идея нашего предложения состоит в том, чтобы объединить разработку системного подхода с разработкой новых приемов и способов мышления, которые мы называем “методологическими”... специфика системного подхода может быть определена только при описании структуры и форм организации методологической работы, ибо, по нашему убеждению, системный подход существует только как подразделение и особая организованность методологии и методологического подхода» (Щедровицкий, 1995б, с. 94, 101-102). Отсюда вытекало, что, если системный подход должен быть построен в рамках методологии, его нужно спроектировать, исходя из методологических задач. Одновременно предполагалось, что сами методологические построения нужно проработать с точки зрения заново выстроенных системно-структурных категорий. 
Поскольку предмет методологии мыслился как деятельность, ее необходимо было представить в рамках системного подхода, что и было сделано. «Исходное фундаментальное представление: деятельность - система», пишет Щедровицкий в работе 1975 г. (Щедровицкий, 1995в, с. 241).

Если обобщить эту программу построения системного подхода, то можно сформулировать следующую гипотезу. Реализация системного подхода предполагает построения сразу двух скоординированных между собой языков «системно-структурного» $и$ «предметно-системного». Для Г.П. Щедровицкого второй язык - это язык теории деятельности, где деятельность истолкована как система. Для В.М. Петрова, вероятно, теория информации. Психология для обоих авторов не является основным предметом осмысления, они ее рассматривают как одну из научных дисциплин в рамках предлагаемых онтологий. Необходимость построения предметно-системного языка можно пояснить, вспомнив историю формирования естествознания. Именно там впервые встала обсуждаемая нами проблема и была решена путем построения указанных двух языков. Обращение к истории науки всегда полезно, оно позволяет многое понять и в отношении психологии.

\section{Экскурс в историю естествознания: «теория широты форм» в роли предметно-системного языка}

Еще в XIII столетии Роджер Бэкон, следуя за Платоном, заявил, что языком описания природы («подлунного мира») выступает математика. В «Opus Tertium» читаем: «Вторые же важнейшие ворота, которых нам по природе недостает, есть знание математики... ясно, что она простая наука и как бы врожденная или близкая врожденному знанию. Из этого следует, что она - первейшая из наук, без которой другие не могут познаваться... Адам и его сыновья получили ее от Бога... понятно, что бо́льшая и лучшая часть математики повествует о вещах небесных, как астрология, спекулятивная и практическая... благодаря этим [двум наукам о небесном] подготавливается тем не менее познание этого подлунного мира... познание всего подлунного зависит от возможностей математики» (Бэкон, 2002, с. 103-109).

Однако понятия поздней эллинистической античной математики (теории пропорций и геометрии) существенно отличались от построенных Аристотелем физических понятий, с помощью которых описывались природные явления. Чтобы реализовать замысел математизации науки о природе, в Средние века создается промежуточный язык - особая дисциплина, получившая название «учение о широте форм», или «интенсификация и ремиссия качеств», без которой не состоялась бы естественная наука Нового времени. Эта дисциплина, пишут А.Т. Григорьян и В.П. Зубов, «столь не похожая по своему облику на позднейшую кинематику, сколь не похожи друг на друга человеческий зародыш и сформировавшийся человек», ставила своей целью «математизировать учение об интенсивности качеств и его изменении, то ли предпочтительно в арифметико-алгебраической форме, как делали это в первой половине XIV в. ученые Мертон-колледжа в Оксфорде, то ли в форме 
геометрической, как это делали Николай Орем и его последователи, то ли, наконец, сочетая оба пути, как это делали итальянцы в XV-XVI вв.» (Григорьян, Зубов, 1962, с. 122).

Понятия «учения широты форм», с одной стороны, опирались на философские категории «отношение», «форма», «качество», «количество», с другой - могли быть рассмотрены как схемы, позволяющие описывать природные явления, чем позднее и воспользовался Галилей, создавая свое знаменитое учение о свободном падении тел. Как показывают Григорьян и Зубов, Галилей читал «учение о широте форм», в частности, использовал в своем творчестве основную работу Орема («Трактат о конфигурации качеств»), из которой он заимствовал, во-первых, закон свободного падения тел («треугольник Орема»), во-вторых, идею и геометрический метод доказательства теоремы об эквивалентности движений, в-третьих, терминологию и ряд основных понятий (Там же, с. 133, 144, 145).

Предметно-структурный язык, о котором мы говорили выше, выполняет примерно такую же роль, как «теория широты форм», выступившая посредником между математикой и физическими понятиями, он позволил реализовать системный подход применительно к конкретным предметам (дисциплинам). Анализ этого кейса позволяет утверждать, что нет одного универсального и одинакового для всех предметов и дисциплин системного подхода. Напротив, для отдельной области предметов создается свой вариант такого подхода, включающий два языка - системно-структурный и предметносистемный. Говоря о «системно-информационном» подходе, Петров фактически признает наличие таких двух языков. Но в связи с этим можно задать и более общий вопрос: в каком системном подходе нуждается психология?

\section{«Перезагрузка психологии» или решение актуальных методологических проблем психологии?}

Мне трудно, однако, согласиться с тем, какую главную задачу видит Петров в гуманитарных науках, говоря о необходимости их «перезагрузки». Если иметь в виду психологию, то подобную задачу, по Петрову, можно было бы сформулировать так: главная проблема, каким образом преодолеть множество разных представлений психики, построив единую науку, единую модель, выйдя на целостную концепцию ментальной жизни человека.

Но так можно было бы рассуждать, предполагая, что существует один тип человека (точка зрения, характерная для Древнего мира и Средних веков). В культуре Нового времени («модерна») мыслить подобным образом уже невозможно. Культура модерна допускает не только разные каналы и способы социализации, но и разные типы человека, тем более разные типы личности. Мало того, именно психология вместе с современной философией разработали разные концепции (схемы) для разных типов людей модерна.

Например, человек «по Фрейду» и «по Роджерсу» - это не два варианта одной и той же психической структуры, а два разных типа личности и человека. Первый мыслится, во-первых, как конфликтное существо (конфликт личности 
и культуры, сознания и бессознательного, психоаналитика и клиента, отсюда феномен сопротивления), во-вторых, как этически слабая личность, разрешающая себе многое (поскольку бессознательное сильнее сознания), в-третьих, психоанализ предполагает и особый тип коммуникации (психолог знает, как устроен его клиент, и незаметно вменяет, навязывает ему это знание, даже против его воли). Человек по Роджерсу, напротив, ориентирован на эмпатию и сотрудничество, на доверительную коммуникацию, не склонен отдаваться бессознательным влечениям, стремится перебарывать свои слабости. В культуре модерна мы, естественно, найдем соответствующие этим двум антропологическим типам каналы социализации и общения.

Таким образом, с моей точки зрения, построение единой психологии не только не является главной задачей, но, напротив, создало бы в психологии дополнительные проблемы. Центральные проблемы в психологии другие: необходимость конвергенции естественно-научного и гуманитарного подходов, переосмысление связи психологической науки и практики, а также самой психологической науки, осмысление нового статуса и природы человека, попавшего в процессы перехода и сложную реальность постмодерна (посткультуры). Например, как показывает Ф.Е. Василюк, обособление психологической науки и практики стало уже совершенно недопустимым, грозя самой системе психологического знания. Не менее удручающе выглядит распадение психологии на два типа - естественно-научной психологии и гуманитарной. Ну, а проблемы жизни и существования человека в переходной период у всех на слуху. В данном случае я только указываю на эти проблемы, постановка и направление их решения рассмотрены подробно в нескольких моих книгах и статьях.

Другой вывод, следующий из рассмотренного материала, такой: системный подход помогает в изучении психики в рамках отдельной науки (концепции, дисциплины), но не реагирует на различие парадигм. И психоаналитик, и сторонник концепции Роджерса могут использовать понятия системы и системные методы, но это не сближает и не связывает эти концепции, они продолжают оставаться разными в парадигмальном отношении. Задачи синтеза и конфигурирования многих знаний и предметов, а также мышления с учетом целого одинаково актуальны для любой сложной парадигмы.

В споре физиков и гуманитариев Выготский решительно встал на позицию первых. «Существуют две психологии,- писал он,- естественно-научная, материалистическая, и спиритуалистическая: этот тезис вернее выражает смысл кризиса, чем тезис о существовании многих психологий; именно психологий существует две, т.е. два разных, непримиримых типа науки, две принципиально разные конструкции системы знания <...> Психотехника поэтому не может колебаться в выборе той психологии, которая ей нужна (даже если ее разрабатывают последовательные идеалисты), она имеет дело исключительно с каузальной, с психологией объективной; некаузальная психология не играет никакой роли для психотехники... эта психология, кроме того, есть наука эмпирическая, сравнительная, наука, пользующаяся данными физиологии, и, наконец, экспериментальная наука» (Выготский, 1982, с. 387, 390). 
На мой взгляд, в психологии нельзя отказаться ни от естественно-научного, ни от гуманитарного подходов, но они реализуются лишь частично и в связи друг с другом (Розин, 2018, с. 130-131). С одной стороны, Выготский правильно отмечал, что именно личность представляет главный интерес для психологии, но с другой - существуют общие условия жизни (например, все люди в своем развитии проходят культуру детства, культуру подросткового возраста и юношества, культуру взрослого человека, культуру пожилого возраста и старости; и все мы живем в условиях завершающегося модерна и становления посткультуры).

Так вот, для психологического осмысления разных типов человека модерна и разных типов личности (массовой, уникальной, девиантной, социальной и асоциальной, эгоистической и пр.) необходим гуманитарный (социогуманитарный) подход, а для осмысления характеристик психики, формирующихся в общих условиях,- естественно-научный, точнее, его гибридный вариант, ведь человек все же только частично принадлежит первой природе, он в значительной степени семиотическое, деятельностное, рефлексивное и духовное существо.

\section{Авторская концепция науки}

В свою очередь, для подобного осмысления нужно решить проблему конвергенции этих подходов и построить новую концепцию науки. Эта концепция должна включать в себя на равных правах разные типы наук-естественные, гуманитарные, сощиальные, возможно, «технонауку» и новый тип науки, назовем ее «комплексной» (для комплексной науки характерны современные «междисциплинарные» и «трансдисциплинарные» исследования) (Розин, 2012). В последнем варианте подобной концепции я различил два плана науки. Первый был получен в ходе генезиса науки (я его назвал «геном науки»), второй - анализа особенностей современной науки (соответственно «наука как институт модерна»). Вот характеристики генома науки.

Наука представляет собой ращиональную форму познания действительности. Познание осуществляется путем построения идеальных объектов. Идеальным объектам философ или ученый приписывает такие свойства, которые позволяют в рамках рассуждений или доказательств получить непротиворечивые знания, решить стоящие перед исследователем проблемы и задачи, описать и осмыслить эмпирические проявления изучаемого явления. Наука предполагает концептуализащию, т.е. построение концепций науки, представляющих собой осмысление и описание науки в философии или методологии. Именно в контексте концептуализации науки вырабатываются такие понятия, как наука, теория, истина, знание, доказательство, строгость, объективность и др.

Теперь обозначим характеристики науки как института модерна. Научные знания, схемы и законы понимаются как репрезентирующие объективно существуюшую реальность. Они ориентированы на использование в определенных практиках (инженерной, педагогической, реабилитации, политики и др.). 
Миссия науки состоит, с одной стороны, в указанном объективном описании действительности, с другой - в получении знаний, позволяющих овладеть природными процессами (рассчитывать их, управлять ими).

При этом природа понимается не однозначно: это и первая природа, законы которой изучаются в естествознании, и социальная природа, и природа психики и т.д. Для функционирования и развития науки необходимы подготовленные спещиалисты, а также немалье средства (финансовые и материальные).

Способы получения в науке знаний, соответственно, схем, закономерностей, законов, теорий и т.д., а также большинство других процедур, составляющих функционирование науки, как правило, нормированы. Наука как институт предполагает организацию и управление, а также самоорганизацию и активность научного сообщества. Наука живет не в пустом пространстве, а взаимодействуя с другими институтами (власти, образования, промышленности и др.) и обществом. В науке как институте модерна разрабатываются концепции науки. В Новое время геном науки адаптировался к требованиям институтов модерна. Например, научные исследования (построение идеальных объектов и знаний) ориентированы на практические приложения, возросла роль методологического сопровождения, позволяющая оценивать научные исследования на объективность и эффективность.

Можно показать, что предложенная здесь концепция позволяет решить проблему конвергенции естественно-научного и гуманитарного подходов. Во-первых, оба подхода удовлетворяют требованиям генома науки: в них осуществляется познание (в первом явлений и процессов природы, во втором произведений и стоящих за ними явлений - личности, культуры, истории и пр.), решаются проблемы, строятся идеальные объекты и опирающиеся на них теоретические знания, имеет место осознание (концептуализация). По содержанию указанные здесь характеристики естественной науки отличаются от характеристик гуманитарной науки (Розин, 2018).

Во-вторых, естественные и гуманитарные науки удовлетворяют нормам науки как института модерна. В них описывается объективно существующая реальность, имеет место ориентация на практические приложения, разрабатываются требования к научному познанию и концепции науки, подготавливаются специалисты (ученые), оба типа науки поддерживаются и финансируются государством.

Психология, конечно, наука, но наука особая, ориентированная на психологические практики и указанное выше разнообразие типов человека и личности. В этом отношении важно понять, каким образом создаются и используются ее идеальные объекты. Как я показываю, идеальные объекты создаются с опорой на схемы, т.е. первоначально строятся схемы (яркий пример в психологии - схемы 3. Фрейда), позволяющие разрешить проблемы и вызовы времени; схемы задают новую реальность и позволяют по-новому действовать (таблица 1) (Розин, 2017, с. 21, 29, 39).

Затем на основе схем строятся идеальные объекты. Существуют два варианта (пути) дальнейшего развития - теоретический, когда с опорой на одни 
Таблица 1

Методологическая схема

\begin{tabular}{|c|c|c|}
\hline $\begin{array}{c}\text { Проблемная } \\
\text { ситуация }\end{array}$ & $\begin{array}{c}\text { СХЕМА } \\
\text { семиотический предмет }\end{array}$ & $\begin{array}{c}\text { новая деятельность } \\
\text { новая реальность }\end{array}$ \\
\hline первая фаза & вторая фаза & третья фаза \\
\hline
\end{tabular}

идеальные объекты создаются другие и таким образом выстраивается теория (что предполагает рефлексию и формирование доказательств), и прикладной, в рамках которого идеальные объекты используются для построения новых схем, необходимых для решения практических задач.

Психология в своем развитии прошла два этапа. На первом преимущественно реализовался первый вариант, т.е. психология мыслилась и строилась как теория (наука). На втором этапе перевес получил второй вариант: здесь идеальные объекты создавались, не столько исходя из чисто познавательного отношения (как там на самом деле устроена психика), а для решения практических задач (помощи личности в ее развитии, задач реабилитации, восстановлении психического здоровья, совершенствовании эффективности поведения, деятельности и пр.). При этом, безусловно, психологические теории помогали строить новые схемы для психологических практик, но не стоит забывать, что за теориями стояли определенные проблемы и вызовы времени, для которых были характерны прагматически-ценностные отношения.

Кризис современной психологической науки, на мой взгляд, во многом связан с трактовкой науки по образцу естествознания, а также с непониманием того, что идеальные объекты психологических теорий создаются на основе схем, которые используются двояко - для построения самой теории и решения прикладных задач. Разнообразие типов человека и личности осмысляется в психологическом знании и науке в форме множества психологических концепций, теорий и практик, что совершенно нормально и не вовсе требует реформирования («перезагрузки»). Другое дело методологическая культура (например, различение схем и идеальных объектов, теории и ее онтологии, критериев истинности и эффективности знаний и др.), она оставляет желать лучшего. Конечно, психологи за редким исключением не могут совмещать собственно психологическую и методологическую компетенции, как это, например, было характерно для Федора Василюка или в настоящее время для Андрея Пузырея, но сейчас методологическая грамотность совершенно необходима в любой науке и практике, тем более антропологически ориентированной.

Достаточно очевидно, что разные типы личности и человека обусловлены характером сложившейся культуры и социального порядка (социальными институтами и социальными нормами), а также состоянием общества. Но в настоящее время все это пришло в движение, претерпевает трансформацию. Как уже отмечалось, завершается культура модерна, налицо становление посткультуры. 
С одной стороны, перестают удовлетворительно работать социальные институты, не исключая государства, и ослабевает, распадается общество, с другой - формируются новые типы социальности - метакультуры (Общий рынок, Китай и США с зонами экономического и культурного влияния и т.д.), на основе Интернета и мобильной связи складываются сетевые сообщества, происходит конвергенция социалистических и капиталистических форм хозяйствования и управления, бурно развиваются новые технологии, в том числе такие, которые позволяют использовать социальные институты не по назначению.

Как одно из следствий этих процессов (мы указали только некоторые), под их влиянием начинают трансформироваться и сложившиеся типы личности и человека. Возрастает маргинальность, девиантное поведение, все чаще в одном человеке сходятся психические структуры, ранее принадлежавшие отдельным типам, или, наоборот, психика деградирует к вроде бы канувшим в Лету архаическим типам. Все труднее современному человеку понять, что происходит, выработать сценарий и стратегию поведения и жизни, справляться с многочисленными проблемами. Понятно, что для психологии это означает новые вызовы, а также необходимость переосмыслить сложившиеся схемы и концепции. Не «перезагрузка» нужна психологии, она вступает в новый этап развития, где возникают новые проблемы и возможности для творчества и служения человеку.

\section{Литература}

Бэкон, Р. (2002). Opus Tertium. В кн. Антология средневековой мысли (т. 2, с. 89-122). СПб.: РХГИ. Выготский, Л. С. (1982). Исторический смысл психологического кризиса. В кн. Л. С. Выготский, Собрание сочинений (т. 1, с. 291-437). М.: Педагогика.

Григорьян, А. Т., Зубов, В. П. (1962). Очерки развития основных понятий механики. М.: Изд-во AH CCCP.

На досках. Публичные лекции по философии Г.П. Щедровицкого. (2004). М.: ШКП.

Петров, В. М. (2019). Предстоящая «перезагрузка» гуманитарных наук: вызов времени (A la recherché du noyau perdu - В поисках за утраченным локусом). Мир психологии, 3, 220-230.

Розин, В. М. (2012). Обсуждение феномена трансдисциплинарности - событие новой научной революции. Вопросы философии, 11, 85-96.

Розин, В. М. (2017). Введение в схемологию: схемы в философии, культуре, науке, проектировании. M.: URSS.

Розин, В. М. (2018). Особенности дискурса и образцыь исследования в гуманитарной науке. M.: URSS. Щедровицкий, Г. П. (1993). Система педагогических исследований. Методологический анализ. В кн. Педагогика и логика (с. 12-132). М.: Касталь. Также см.: https://gtmarket.ru/laboratory/basis/6738

Щедровицкий, Г. П. (1995, а). «Человек» как предмет исследования. В кн. Г. П. Щедровицкий, Избранные труды (с. 367-399). М.: ШКП.

Щедровицкий, Г. П. $(1995,6)$. Принципы и общая схема методологической организации системо-структурных исследований и разработок. В кн. Г. П. Щедровицкий, Избранные труды (c. 88-115). М.: ШКП. 
Щедровицкий, Г. П. (1995, в). Исходные представления и категориальные средства теории деятельности. В кн. Г. П. Щедровицкий, Избранные труды (с. 233-281). М.: ШКП.

Розин Вадим Маркович - главный научный сотрудник, ФГБУН «Институт философии РАН», доктор философских наук, профессор.

Сфера научных интересов: методология, психология, философия.

Контакты: rozinvm@gmail.com

\title{
Is the Implementation of a System-Information Approach by V.M. Petrov a Method for Overcoming Crisis in Psychology and Other Human Sciences?
}

\author{
V.M. Rozin ${ }^{\mathrm{a}}$ \\ a Institute of Philosophy, Russian Academy of Sciences, 12/1 Goncharnaya Str., Moscow, 109240, \\ Russian Federation
}

\begin{abstract}
The article analyzes the work by V.M. Petrov, published in the journal World of Psychology, in which he proposes a restructuring of the humanities based on a system-information approach. The author of the present article compares this proposal with the ideas by L.S. Vygotsky, 1927, set out in his work The Historical Meaning of the Psychological Crisis. Methodological Research). The present article tries to show that the systemic approach must be understood differently than Petrov does, namely not as the ultimate ontology, but as a transformed form of methodology. In addition, relying on systemic development of G.P. Shchedrovitsky, as well as the reconstruction of the history of the natural sciences, a hypothesis is proposed, according to which the implementation of the systemic approach involves the construction of two coordinated languages - "systemic-structural" and "objective-systemic". For Shchedrovitsky, the second language is the language of the theory of activity, where activity is interpreted as a system, while for Petrov, probably, it is the theory of information. The author has a different view from Petrov's on the main tasks of reforming psychology: there is a need for convergence of natural-scientific and humanitarian approaches, rethinking the connection between psychological science and practice, as well as reconsideration the psychological science itself, understanding the new status and nature of a person who has fallen into the transition processes and the complex reality of postmodernism (post-culture). He discusses the conditions required for solving these problems. These include the author's concept of science, accounting for the two stages of psychology development and specifics of psychological science, as well as some specifics of the current state of culture. The author comes to the conclusion that the systemic approach helps in the study of the mind within the framework of a separate science (concept), but does not respond to the difference in paradigms, in addition, the diversity of human and personality types is conceptualized in psychological knowledge and science in the form of many psychological concepts, theories and practices, which is completely normal and does not require reform. But the methodological culture of psychologists needs to be improved.
\end{abstract}


Keywords: system, systemic approach, subject, discipline, science, schemes, ideal objects, concept, reconstruction, practice.

\section{References}

Bacon, R. (2002). Opus Tertium. In Antologiya srednevekovoi mysli [Anthology of medieval thought] (Vol. 2, pp. 89-122). Saint Petersburg: RKhGI. (in Russian)

Grigor'yan, A. T., \& Zubov, V. P. (1962). Ocherki razvitiya osnovnykh ponyatii mekhaniki [Essays on the development of basic concepts of mechanics]. Moscow: Izdatel'stvo AN SSSR. (in Russian)

Na doskakh. Publichnye lektsii po filosofii G.P. Shchedrovitskogo [On the boards. Public lectures in philosophy by G. P. Shchedrovitsky]. (2004). Moscow: ShKP. (in Russian)

Petrov, V. M. (2019). Towards changing the foundations of human sciences: the challenge of time (A la recherché du noyau perdu). Mir Psikhologii, 3, 220-230. (in Russian)

Rozin, V. M. (2012). Obsuzhdenie fenomena transdistsiplinarnosti - sobytie novoi nauchnoi revolyutsii [Discussion of the phenomenon of transdisciplinarity - an event of a new scientific revolution]. Voprosy Filosofii, 11, 85-96. (in Russian)

Rozin, V. M. (2017). Vvedenie v skhemologiyu: skhemy v filosofii, kul'ture, nauke, proektirovanii [Introduction to schematics: schemas in philosophy, culture, science, design]. Moscow: URSS. (in Russian)

Rozin, V. M. (2018). Osobennosti diskursa i obraztsy issledovaniya v gumanitarnoi nauke [Specifics of discourse and the research patterns in the humanities]. Moscow: URSS.

Shchedrovitsky, G. P. (1993). Sistema pedagogicheskikh issledovanii. Metodologicheskii analiz [The system of pedagogical research. Methodological analysis]. In Pedagogika i logika [Pedagogy and logic] (pp. 12-132). Moscow: Kastal'. Retrieved from https://gtmarket.ru/laboratory/basis/6738 (in Russian)

Shchedrovitsky, G. P. (1995, a). "Chelovek" kak predmet issledovaniya ["Human" as a subject of research]. In G. P. Shchedrovitsky, Izbrannye trudy [Selected works] (pp. 367-399). Moscow: ShKP. (in Russian)

Shchedrovitsky, G. P. (1995, b). Printsipy i obshchaya skhema metodologicheskoi organizatsii sistemostrukturnykh issledovanii i razrabotok [Principles and general scheme of the methodological organization of systemic-structural research and development]. In G. P. Shchedrovitsky, Izbrannye trudy [Selected works] (pp. 88-115). Moscow: ShKP. (in Russian)

Shchedrovitsky, G. P. (1995, c). Iskhodnye predstavleniya i kategorial'nye sredstva teorii deyatel'nosti [Initial representations and categorical means of the activity theory]. In G. P. Shchedrovitsky, Izbrannye trudy [Selected works] (pp. 233-281). Moscow: ShKP. (in Russian)

Vygotsky, L. S. (1982). Istoricheskii smysl psikhologicheskogo krizisa [The historical meaning of the psychological crisis]. In L. S. Vygotsky, Sobranie sochinenii [Collected works] (Vol. 1, pp. 291437). Moscow: Pedagogika. (in Russian)

Vadim M. Rozin - Chief Research Fellow, Institute of Philosophy, Russian Academy of Sciences, DSc in Philosophy, Professor.

Research Area: methodology, psychology, philosophy.

E-mail: rozinvm@gmail.com 
Psychology. Journal of the Higher School of Economics.

2021. Vol. 18. N 1. P. 182-202. DOI: 10.17323/1813-8918-2021-1-182-202

\title{
SPIRITUAL CAPACITIES OF PERSONALITY AND PRODUCTIVE LIFE ACTIVITY
}

\begin{abstract}
G.V. OZHIGANOVA
${ }^{a}$ Institute of Psychology, Russian Academy of Sciences, 13 build. 1, Yaroslavskaya Str., Moscore, 129366, Russian Federation

Abstract

The article deals with the psychological aspects of spirituality. The concepts of spiritual intelligence, spiritual capacities, and spiritual personality are analyzed. The study was based on the idea of a psychological model of spiritual capacities proposed by the author. This model includes three components: moral, mental, and transcendent. The moral component was selected to be explored in detail and was empirically studied. The principal constituent of the moral component of spiritual capacities is a spiritual altruistic tendency; its connection with productive life is analyzed in the article. The objective of the study was the investigation of the relationships between spiritual personality, spiritual capacities and productive life activity. The participants were 662 adults (206 males, 456 females): students and full-time employees aged $18-45$ years $(\mathrm{M}=26.08)$ from two cities of the Russian Federation (Kostroma and Taganrog). Correlational and comparative analysis was used for data processing. It was found that respondents with higher levels of "spiritual personality" significantly differed, according to the Mann-Whitney U test by a higher productivity of life activity $(\mathrm{U}=43028 ; p<.001)$ and had higher levels of spiritual capacities the spiritual altruistic tendency $(\mathrm{U}=46328,5 ; p<.022)$. The correlational analysis showed that the higher was the level of manifestation of spiritual capacities - the spiritual altruistic tendency, the higher was the productivity of life activity. The results obtained make it possible to note the importance of the construct "spiritual capacities" and the need for its further scientific psychological research, as well as to emphasize the practical significance of spiritual capacities for the prosperous and productive functioning of society.
\end{abstract}

Keywords: spiritual intelligence, spiritual capacities, spiritual altruistic tendency, spiritual personality, productive life activity.

\section{Introduction}

\section{Spiritual Intelligence}

Interest in the study of the spiritual aspects of personality has increased in the scientific community. One of the important areas of such research is related to spiritual intelligence. Emmons (1999) determined spiritual intelligence as an adaptive use of spiritual guidance to help goal attainment and to solve problems of day-to-day life.

This research was supported by the Russian Science Foundation (RSF) (project № 18-18-00386), Institute of Psychology of Russian Academy of Sciences. 
According to Zohar and Marshall (2000), spiritual intelligence is connected to questions of value and allows people to insert their lives in a more significant, meaningful context. It is “...the intelligence with which we address and solve problems of meaning and value, the intelligence with which we can place our actions and our lives in a wider, richer, meaning-giving context, the intelligence with which we can assess that one course of action or one life-path is more meaningful that another" (Zohar \& Marshall, 2000, pp. 3-4). Vaughan (2002) considers that spiritual intelligence exceeds a single mental ability. It involves a capability for a profound comprehension of existential issues and discernment of numerous layers of consciousness. It implies not only deep self-awareness, but also the realization of a bond with the transcendent dimension and all people. Spiritual intelligence is connected with love and service to others and includes wisdom. Noble (2000) thinks that spiritual intelligence is a quality of awareness that contributes to cultivating awareness of oneself, empathy and psychological health. In her opinion, spiritual intelligence is linked to spiritual experience and leads to the psychological growth of a person.

Wolman (2001) defines spiritual intelligence as the capability for striving to seek meaning in life, to feel connections between all people and to the universe. It is "...the human capacity to ask ultimate questions about the meaning of life, and to simultaneously experience the seamless connection between each of us and the world in which we live" (Wolman, 2001, pp. 84-85).

D. B. King (2010) states that "spiritual intelligence is currently defined as a set of adaptive mental capacities which contribute to the awareness, integration, and adaptive application of the nonmaterial and transcendent aspects of one's existence, leading to such outcomes as deep existential reflection, enhancement of meaning, recognition of a transcendent self, and mastery of spiritual states. Four core components are proposed: critical existential thinking, personal meaning production, transcendental awareness, and conscious state expansion” (King, 2010, pp. 1-2).

Spiritual intelligence is considered as the capability to manifest spiritual resource, values, and dignities to increase everyday effective running and welfare (Amram, 2007; Amram \& Dryer, 2008). Srivastava (2016) states that "spiritual intelligence helps to fulfill the potentialities of the individuals' abilities through the non-cognitive virtues to prepare them to solve the everyday problems for life creatively and constructively in the new situation of the socio-psycho-physical environment for attaining the highest knowledge and wisdom" (Srivastava, 2016, p. 227).

\section{Spiritual Capacities}

Spiritual intelligence is considered as a set of spiritual capacities. Emmons (2000) proposed the following capacities and abilities as components of spiritual intelligence:

"(a) the capacity for transcendence; (b) the ability to enter into heightened spiritual states of consciousness; (c) the ability to invest everyday activities, 
events, and relationships with a sense of the sacred; $(d)$ the ability to utilize spiritual resources to solve problems in living; and (e) the capacity to engage in virtuous behavior or to be virtuous (to show forgiveness, to express gratitude, to be humble, to display compassion)" (Emmons, 2000, p. 10).

K. D. Noble (2000) agreed with the list of abilities and capacities proposed by Emmons and added two more: "the conscious recognition that physical reality is embedded within a larger, multidimensional reality, and the choice to develop psycho-spiritual awareness in order to promote the health of both the individual and the global community (Green \& Noble, 2010, p. 29).

In the study conducted by Zarei Matin, Kheirandish, and Jahani (2011), the components of spiritual intelligence are described including spiritual abilities and personality aspects related to values and life meaning: the ability to ask fundamental questions and find fundamental answers; knowing and believing in God; making work and life meaningful (for the sake of God); having high life aims; paying attention to spiritual values; having positive feelings; spiritual wisdom; willingness to serve; work conscience; deep self-awareness; capacity to utilize intelligence and mental resource for solving everyday problems; having insight, understanding, diagnosing, and distinguishing; the ability to align individual and organizational goals; the capacity to act virtuously.

In the model of spiritual capacities (Ozhiganova, 2009; 2010; 2016) three components were suggested: 1) moral, 2) mental, and 3) transcendent.

1. The moral component/level includes virtuous behaviour based on the universal moral principles, and higher values and life meanings connected with a pronounced tendency to altruism.

2. The mental component/level is related to mental processes and cognitive abilities; it involves higher reflexive, self-regulatory, creative capacities, and other abilities.

The mental component in its various manifestations is concerned with the instrumental aspect of spiritual capacities.

3. The transcendent component/level is understood as going beyond the bounds of the self and making an impact on the well-being and development of society (for example, in creativity, service to people, etc.) to achieve the welfare of other people and society; it includes special spiritual mental states (concerning altered states of consciousness and sublime transcendental experiences).

The concept of «transcendence» is not simple, it is open to more than one interpretation. First of all, this is a philosophical concept used in the doctrine of I. Kant who considered the term "transcendent" in tandem with the term "transcendental" in order "to oppose the transcendental (as immanent) to the transcendent - such knowledge that transcends the boundaries of human reason and in this sense is inaccessible to a theoretical knowledge, becoming exclusively a matter of faith... In Kant's philosophy the transcendental is everything that refers to a priori (i.e., outside or pre-experience) conditions of the possibility of cognition, its formal prerequisites that organize experience... Transcendent - this is everything that goes beyond the limits of possible experience, for example, God, the immortality of the soul, etc." (Rumyantseva, 2012). 
There are other broader interpretations of transcendence. "The term transcendence, from the Latin transcendere (to climb up), means to go beyond, surpass, or rise above, particularly what is given in personal experience" (Simmons, 2003, p. 901).

My understanding of transcendence as going beyond "the present Me" and moving to the "spiritual I", and the use of the term «transcendent» is based on the concepts of humanistic and existential psychology. According to A. Maslow, transcendence refers to the highest and most integrative, holistic levels of human consciousness, behavior and relationships. In this case, transcendence acts not as a means, but as a result that brings a person closer to their own humanity, to their environment, and to humankind as a whole (Maslow, 1999, p. 291). In this research I too proceeded from the understanding of transcendence proposed by V. Frankl. He wrote about self-transcendence characterizing it as the aspiration of a person to go beyond themselves, as the striving for meaning, which she or he should follow up, realizing themselves in serving a cause or through love for another person.

According to Frankl, if a person representing a bodily-mental-spiritual unity is able to transcend their psychophysical component, then he or she passes into the sphere of a spiritual personality filled with the meaning of being. Frankl showed that in situations of limiting the manifestation of spirituality, when a life situation outwardly reduced a person's existence to satisfying only vital basic needs for food and warmth (such as in a concentration camp), the spiritual of some people could manifest itself especially clearly: a spiritual position and a spiritual orientation could fill existence with meaning and become a resource for survival or for a calm and majestic parting with life. Frankl wrote that in the concentration camp there were people who went around the camp barracks, sharing a kind word and their last piece of bread (Frankl, 2020, p. 131).

The aspects of transcendence depicted in humanistic and existential psychology, in my opinion, most clearly reflect the essential characteristic of spiritual personality and spiritual capacities - the manifestation of humanity, which is related to a spiritual altruistic tendency.

The present research is focused on the moral component/level of the model of spiritual capacities that I have proposed.

The moral aspect is an essential part of spirituality and spiritual capacities. Morality and spirituality are tightly intertwined (Husain, Luqman, \& Jahan, 2012; Swaminathan, Bindhu, \& Mythili, 2009). Wolman (2001) states that spiritual intelligence "is the ground on which morality stands" (Wolman, 2001, p. 115). Morality is the core dimension of a human being. Psychological research (Strohminger \& Nichols, 2014) claimed that the moral self is central to identity; the empirical study showed that people considered morality as principal to identity. The authors concluded that "The self is not so much the sum of cognitive faculties as it is an expression of moral sensibility" (ibid., p. 169).

In the model of spiritual capacities suggested by the author of this article, the essential capacity of the moral component is unselfish love for other people related to the spiritual tendency - altruistic relationship to others manifested through the capacity to act for the good of others, and to help and support people. 
Altruism means doing things for the benefit of others, without the expectation of a reward; it is an unselfish concern for other people.

Thus, the present study takes into account that altruism implies behaving generously, helpfully and usefully to others without expecting any benefit for oneself.

Altruistic behavior is generated by moral motivation. Hoffman (2000) characterized an internal moral motive as:

- having an imperative, obligatory quality;

- experienced as deriving from within oneself;

- making one feel guilty when one acts or considers acting in ways that may harm others;

- inclining one to consider another's needs even when they are in conflict with one's own.

The moral motives serve as a basis for spiritual motivation, which, according to V.D. Shadrikov, is generated by spiritual values. Among them, he highlighted the most important two values - faith and love. So, the fundamental spiritual values that determine spiritual motivation are: believing in God, in an idea, in goodness, in a hero, etc.; love for God, for a woman, for one's Fatherland (Shadrikov, 2020). The qualities identified by Shadrikov as representing the highest moral values that are part of the structure of conscience can be pointed out among the characteristics of a spiritual personality. They are virtue (benevolence), power over one's own passions, love for others, empathy and reflexivity (ibid.). These value-oriented spiritual and moral qualities contribute to the creation of the corresponding motivational fusion and lead to the formation of a spiritual altruistic aspiration, (a core characteristic of a spiritual personality) that is actualized due to spiritual capacities (the moral aspect).

The specificity of moral motives is clearly described in the works of A.A. Guseynov. He wrote that human motives and corresponding actions, in all their constantly multiplying variety, that enable the construction of various complex and long series of classifications, in the most general form can be divided in two classes, moral and extra moral. The moral motives are unconditional in the sense that they contain their goal in themselves; they denote the last highest range of human aspirations. The extra moral motives are conditioned in the sense that they are related to other goals that lie outside of them and they are elements of a series that has a continuation (Guseynov, 2012, p. 149). The emphasis on the unconditionality of moral motives corresponds to my interpretation of the spiritual altruistic tendency that is defined as a disinterested aspiration to take care of the welfare of other people, associated with the realization of higher values and meanings. This aspiration, driven by moral motives, leads to moral action and virtuous behavior performed through spiritual capacities.

Compassion (Rilling, 2008; Spikins, Rutherford, \& Needham, 2010), sympathy (Smith, 2006; Trivers, 1971), and empathy (Eisenberg, 1983; Gilligan, 1977; Hoffman, 2000; Midlarsky \& Kahana, 2007) are considered to be incentives for altruism.

Altruistic behavior in relation to spiritual capacities can be regarded, using the conception of Eisenberg (1986), where it is represented as a sequence of social and 
cognitive operations, including: decentration and taking into account the point of view of the other; assessment of a person's ability to solve a problem on their own or the need for help; the formation of motivation for altruistic behavior based on empathy; an assessment of one's own capabilities to provide the necessary assistance; aid planning (altruistic act) in the process of interpersonal cooperation.

The current research is focused on the spiritual tendency - altruistic relationship to others as a base of the essential capacity of moral component in my model of spiritual capacities.

\section{Spiritual Intelligence, Spiritual Capacities and Spiritual Personality}

S. L. Rubinstein (2002) stated that different aspects of personality are interrelated. He emphasized the inextricable link between abilities and character determined by main life aspirations, attitudes, ideals, and peculiarities of personality.

V. D. Shadrikov $(1998,2019)$, developing the subject of spiritual abilities in Russian psychology, noted a connection between abilities and personality. He defined spiritual abilities as an integral manifestation of the intellect and spirituality of a person (Shadrikov, 2019). According to his view, spirituality is demonstrated in the fact that reality is known not only rationally, but also emotionally, through experiences (ibid., p. 128). In spiritual abilities, cognition is closely intertwined with experience (ibid., p. 124). Shadrikov stated that spiritual abilities are directly related to spiritual states in which the motivational and emotional dimensions, spiritual values and qualities of personality are manifested. In his opinion, the spiritual state is characterized by high selectivity of thinking determined by the spiritual values of an individual... The world appears as a world of interconnected values related to the spiritual values of an individual. If utilitarian, practical and objective significance is important for rational thinking, then the moral meaning defined in the system of personal spiritual coordinates is essential for ethical thinking (ibid., p. 125).

Shadrikov listed personal qualities that trigger the manifestation of spirituality: conscience, honor, faith in people, virtue, will, aspiration for freedom, the desire for creativity, and the desire to go beyond the time frame of existence. He emphasized that spiritual abilities are closely related to the concept of «virtue», and help in the understanding of another person.

He proposed a definition of spiritual abilities that reflected the idea that abilities are personally oriented: "Spiritual abilities are abilities for self-knowledge, selfawareness and self-comprehension; they contribute to relation of oneself to the world, other people, and to the knowledge of others" (ibid., p. 123).

The interconnection of capacities and personality traits becomes apparent through the analysis of description of spiritual intelligence.

Amram \& Dryer (2008) describing spiritual intelligence used many characteristics close to the properties of spiritual personality. The authors pointed out five dimensions of spiritual intelligence: 1) consciousness, 2) grace, 3) meaning, 4) transcendence, and 5) truth, including 22 spiritual capabilities. "Consciousness" reveals the capacity for making better quotidian running and well-being. It has 
three subdivisions: 1) intuition, 2) mindfulness and 3) synthesis. "Grace" includes the "inner-directedness" and "love for life". It has six subareas: 1) beauty, 2) discernment, 3) freedom, 4) gratitude, 5) immanence, and 6) joy. "Meaning" regards the ability to understand and analyze events that helps to improve the work and well-being of personality even in difficult conditions. "Meaning" can be divided into two elements: 1) purpose and 2) service. "Transcendence" is related to the capability to exceed the selfishness based on connectedness. "Transcendence" includes five units: 1) higher-self, 2) holism, 3) practice, 4) relatedness, and 5) sacredness. "Truth" refers to the capacity for manifesting love, attachment and humbleness. It can be divided into six subdivisions: 1) egolessness, 2) equanimity, 3) inner-wholeness, 4) openness, 5) presence, and 6) trust.

R. Wolman (2001) pointed out seven factors of spiritual intelligence that represented the extent of spiritual experience and behavior: divinity, mindfulness, intellectuality, community, extrasensory perception, childhood spirituality and trauma as an incentive to develop spiritual awareness.

All these factors contribute to the formation of a spiritual personality, as well as to the manifestation and development of spiritual capacities.

Having reviewed the descriptions of spiritual intelligence comprising various spiritual capacities, spiritual experience and behavior, it can be concluded that spiritual intelligence and aspects of spiritual personality are interconnected. The characteristics of spiritual personality have much in common with characteristics of spiritual capacities.

"As a personality trait, spirituality encompasses values like altruism, unity, charity, inner peace, generosity, and purpose in life" (Ahmad, 2015, p. 155). Love and oneness to other people is an essential trait of spiritual personality and is linked to emotional empathy. The results of the study show that those students of helping professions who have spiritual personality traits manifest more empathy toward other people that contributes to the faster recuperation of their patients (Ahmad, 2015).

According to Husain, Luqman, and Jahan (2012), manifestation of spiritual personality is related to "a process by which an individual who knows how to anchoring his life style around his noble attitude toward others and follow the path of moral rectitude" (Husain et al., 2012, p. 2).

Love, peace and unity are the main qualities of the spiritual personality. The spiritual personality's properties are wholeness, trustworthiness, righteousness, faithfulness, kindness, generosity. Spiritual personality has positive emotions, desires and ideas, keeping thoughts focused and disciplined (Husain, Nishat, \& Jahan, 2015).

Husain, Luqman, \& Jahan (2012) have distinguished two basic components of spiritual personality: noble attitude toward others and moral rectitude.

1. A noble attitude toward others is linked to living for the good of others, righteousness, trustworthiness, faithfulness, generosity, kindness, and trustfulness.

2. Moral rectitude is related to the self-discipline, staunchness, and personality characteristics such as being firm, patient, pure and clean, satisfied. 
According to Husain \& Anas (2018), the spiritual personality can be described and studied using six dimensions: spiritual virtues, positive outlook on life, spiritual discipline, goodness, spiritual service, and moral rectitude.

It is clear that "spiritual personality" and "spiritual intelligence" are interrelated, but each of these notions have their own specifics.

For example, kindness is considered as a trait of personality, but it can be only declarative. Spiritual capacities allow the expression of the kindness in the best optimal way through a real virtuous action and behavior, to help other people, making them happier. Spiritual capacities realize the spiritual qualities of a personality in the process of life activity.

It seems important to consider the issue of limitations in the positive manifestation of spirituality in a person. In my opinion, there are external and internal restrictions of this kind.

External limitations comprise different aspects: social (a social environment with low spiritual needs, and lack of interest in spiritual and cultural values); ideological (perversion of spirituality, for example, in the form of religious fanaticism, extremism); situational (concentration camps, prisons), etc.

Internal limitations may include: an insufficiently formed internal spiritual position, the overriding priority of material values, lack of desire for spiritual selfdevelopment, absence of higher meanings of being, egocentrism, unbridled will to power, obsession with the idea of one's own superiority over people, and low human qualities (cruelty, greed, envy, malice, aggressiveness, deceitfulness, indicating unawakened conscience). Within the framework of an ethical psychology of personality (Popov \& Maksumova, 2010), personal types are described such as authoritarian, avaricious, consumer, intriguer, malicious (destructive), provocateur, doubter, opportunist, etc. These types of personality are incompatible with the notion of the spiritual personality and show limitations in spirituality manifestation.

In regard to the limitations in the manifestation of spirituality, it is necessary to note the importance of spiritual capacities that both realize the already existing qualities of spiritual personality and contribute to the formation of these qualities, and enable the discovery and development of the spiritual side of personality.

The predisposition to the manifestation of spiritual capacities is inherent in a person, and spiritual capacities can be actualized at any time. This may explain a sudden spiritual transformation (for example, a criminal's repentance and the awakening of her or his conscience), as well as a long, conscious, purposeful process of spiritual evolution, for example, in the case of spiritual and religious selfimprovement, as described by Symeon the New Theologian in his work depicting the use of spiritual psychological practices for spiritual self-development (Symeon the New Theologian, 1999).

Sometimes, in a paradoxical way, external obstacles become an impetus for the manifestation of spirituality, as was shown, for example, by V. Frankl who described altruistic behavior in the inhuman conditions of a concentration camp. This confirms the idea that, in general, the manifestation of true spirituality cannot be limited; it is unlimited. 


\section{Spiritual Capacities and Productive Life Activity}

Spiritual capacities are manifested in life activities. Recently many researchers have investigated the effect of spiritual intelligence at work: the effect of spiritual intelligence on business processes (Ayranci \& Ayranci, 2015), on performance at a workplace (Hosseini \& Marei, 2017; Rani, Abidin, \& Ab Hamid, 2013); on job stress and job performance (Ahmadian, Hakimzadeh, \& Kordestani, 2013; Baezzat \& Sharifzadeh, 2013; Othman, Abas, \& Ishak, 2017); on work satisfaction (Kaur, Singh, \& Bhatia, 2016; Rastgar, Davoudi, Oraji, \& Abbasian, 2012); the impact of spiritual intelligence on other life activities: the influence of spiritual intelligence on organizational citizenship behavior (Anwar \& Osman-Gani, 2015); on organizational commitment (Awais, Malik, \& Qaisar, 2015); on organizational performance (Malik \& Tariq, 2016); and on creativity and innovation of entrepreneurs (Chin, Raman, Yeow, \& Eze, 2014).

All the mentioned studies lead to the idea that spiritual intelligence as a set of spiritual capacities positively influences different professional and other life activities.

Spiritual capacities in the workplace contribute to a better working environment that facilitates higher levels of productivity.

Productive activities (paid or unpaid) are understood as providing goods or services that have social value (Bass \& Caro, 1996; Herzog, Kahn, Morgan, Jackson, \& Antonucci, 1989; Morrow-Howell \& Wang, 2013). Productive activities "include activities such as full- or part-time employment, formal and informal volunteering, grandparenting, and caregiving for frail family members and friends" (Lum, 2013, p. 172).

Productive activities are widely studied in relation to aging (Burr, Mutchler, \& Caro, 2007; Choi \& Kim, 2011; Grano, Lucidi, Zelli, \& Violani, 2008; Hao, 2008; Jung, Gruenewald, Seeman, \& Sarkisian, 2010; Litwin \& Shiovitz-Ezra, 2006; Morrow-Howell, Hinterlong, Rozario, \& Tang, 2003; Tang, Chen, Zhang, \& Mui, 2018; Warburton, Paynter, \& Petriwskyj, 2007; Windsor, Anstey, \& Rodgers, 2008).

Our research suggests a broader understanding of productive life activity that may cover various aspects of life. Productive life activity can impact the efficacy of:

- Learning in students

- Professional activity

- Different unpaid activities

- Creative activity

- Activities aimed at helping one's family

- Activities aimed at a positive self-change

- Activities aimed at useful, beneficial, and valuable leisure

In the present research the above mentioned aspects of productive life activity are considered in relation to spiritual tendency - altruism as indicators of the moral component of spiritual capacities.

The spiritual tendency - altruistic relationship to others is manifested through the capacity to act for the good of others, to help and support them, and to provide 
unselfish disinterested services to people. It is opposed to an egoistic - non-spiritual tendency - to act only for the good of oneself associated with material enrichment, high social status, ambition, and striving for fame and success.

\section{Methods}

\section{Research Objective}

The purpose of the study was to examine the relationship between spiritual personality, spiritual capacities and productive life activity.

\section{Participants}

The participants were 662 adults (206 males, 456 females): students, full-time employees in various occupations aged $18-45$ years $(\mathrm{M}=26.08)$ from two cities of the Russian Federation (Kostroma and Taganrog). Participants were selected on a voluntary basis.

\section{Measures}

1. Spiritual Personality Inventory-Revised (SPI-R) by A. Husain and M. Anas, 2018 (adaptation of the Russian version by G.V. Ozhiganova, 2019).

SPI-R is used for the measurement of spiritual personality among adults. It may be used for research purposes. It contains in total 28 items (on a 5-point Likert scale).

SPI-R (Russian)

Reliability: Cronbach's alpha $=.927$. Includes five factors:

1. High morality and wisdom $(\alpha=.811)$

2. Self-control $(\alpha=0.801)$

3. Trustworthiness and responsibility $(\alpha=.743)$

4. Spirituality of relationships $(\alpha=.802)$

5 . Truthfulness and satisfaction $(\alpha=.742)$

2. Questionnaire "Productive Life Activity" (PLA) developed by G.V. Ozhiganova.

In accordance with the objectives of this research regarding the study of the moral component of spiritual capacities associated with the spiritual altruistic tendency and its relationship to productive life activities, a research questionnaire specific to this particular study was developed by the author.

It encompasses seven aspects of life activities:

1) Learning activity of students

2) Professional activity

3) Unpaid activities

4) Creative activity

5) Activities aimed at helping one's family

6) Activities aimed at a positive self-change

7) Activities aimed at useful, beneficial, and valuable leisure 
Each aspect of the seven life activities contains three items related to measuring: 1) productivity; 2) egoistic tendency; and 3) altruistic tendency. In total there are 21 items. Psychometric characteristics were evaluated and a reliability-consistency check was carried out for three dimensions:

1. Productivity in the seven above mentioned life activities $($ KR20 $=.68)$;

2. Non-spiritual egoistic tendency - to act only for the good of oneself $(\mathrm{KR} 20=.66)$;

3. Spiritual tendency - altruistic relationship to others manifested through the capacity to act for the good of others $(\mathrm{KR} 20=.74)$.

To identify the reliability of three dimensions of the questionnaire, the analogue of Alpha Cronbach's, the Kuder and Richardson Formula was used, because answers to the items proposed in the questionnaire were related to a yes/no dichotomous scale. The Kuder and Richardson Formula 20 is intended to estimate the reliability of binary measurements.

An example of general instructions related to all seven life activities in the Questionnaire "Productive Life Activity"

Instructions: You are offered a number of statements that may be related to your life activity (from 2018 to the present). You should circle "Yes" or "No". If you choose "Yes", agreeing with the first statement, then you need to list specific achievements in detail and respond to the statements № 2 and № 3. If you choose "No" for the first statement, you do not need to proceed to the statements № 2 and № 3.

An example of statements concerning "Unpaid activities" in the Questionnaire "Productive Life Activity"

1. I am actively involved in unpaid activities (Yes/No).

If "Yes", then indicate what you have done (for example: organized a group of volunteers, created a drawing group for children, etc.).

2. I am actively involved in unpaid activities, because they allow me to be an important person (a leader), to dominate, to rule over people, and contribute to my fame. (Yes/No).

3. I am actively involved in unpaid activities, because I like when my activities benefit and help people, and make them happier. (Yes/No).

All seven aspects of the Questionnaire "Productive Life Activity" have the same three part structure (as was shown in the example with "Unpaid activities"), supplying information about 1) the person's productivity in a particular life activity; 2) a non-spiritual (egoistic) tendency - to act only for the good and the benefit of oneself; 3) a spiritual (altruistic) tendency - a capacity to act for the good and the benefit of others.

IBM SPSS Statistics 22.0 was used for the data processing.

\section{Results}

\section{Correlational Analysis}

Results of descriptive statistics showed that the indicators did not correspond to normal distribution that led to the use of nonparametric methods for data analysis. 
The correlational analysis (Spearman's rank correlation coefficient) revealed that the higher the levels of manifestation of spiritual capacities - spiritual (altruistic) tendency, the higher was the productivity of life activity $(r=.680, \mathrm{df}=660$, $p<.001$ ) (Table 1). A high Spearman's rank correlation for a large sample can be considered an indicator of significance of the obtained data.

A significant but weak link was identified between the non-spiritual egoistic tendency and the productivity of life activity $(r=.316, \mathrm{df}=660, p<.001)$; on the contrary, the correlation between spiritual capacities - spiritual altruistic tendency and the productivity of life activity, was very strong. That means that selfishness is only to a small extent related to productive activities, but the spiritual altruistic tendency greatly contributes to the productivity of life activity.

There was no connection between "spiritual personality" and the egoistic nonspiritual orientation $(r=.033, \mathrm{df}=660, p<.400)$, while a significant but weak correlation of the "spiritual personality" and altruistic spiritual tendency was revealed $(r=.149, \mathrm{df}=660, p<.001)$.

A significant but weak relationship was found between the indicators of "spiritual personality" and productive life activity $(r=.198, \mathrm{df}=660, p<.001)$.

A supplementary unexpected result was found, a correlation between altruism and egoism $(r=.374, \mathrm{df}=660, p<.001)$ that showed complexity of human personality.

A comparative analysis was carried out for a more in-depth analysis of the data obtained dividing groups by median and using contrast groups (the MannWhitney U test was applied).

\section{Comparative Analysis}

I. Two groups were identified on the basis of the median (a total of 643 people remained):

1) participants (318 people) with a higher rate of "spiritual personality" (above the median > 107);

2) participants (325 people) with a lower rate of "spiritual personality" (below the median $<107)$.

It was found that the participants with higher levels of "spiritual personality" significantly differed according to the Mann-Whitney U test by a higher productivity

Table 1

The Results of Correlational Analysis $(\mathrm{N}=662)$

\begin{tabular}{|l|c|c|c|}
\hline \multicolumn{1}{|c|}{ Indices } & Productivity & $\begin{array}{c}\text { Non-spiritual } \\
\text { egoistic tendency }\end{array}$ & $\begin{array}{c}\text { Spiritual altruistic } \\
\text { tendency }\end{array}$ \\
\hline Spiritual personality & $.198^{* *}$ & .033 & $.149^{* *}$ \\
\hline Productivity & & $.316^{* *}$ & $.680^{* *}$ \\
\hline Non-spiritual egoistic tendency & & & $.374^{* *}$ \\
\hline
\end{tabular}

$* * p<.001$. 
of life activity $(\mathrm{U}=43028 ; p<.001)$ and had higher levels of spiritual capacities spiritual altruistic tendency $(\mathrm{U}=46328,5 ; p<.022)$ (Table 2). Tables 2 and 3 do not indicate the median, but the mean, as it turned out to be more informative (the mean showed more subtle and clearer differences in relation to our data compared to the median).

II. Two contrast groups were identified on the basis of high and low indicators of the level of "spiritual personality". Contrast groups were created by respondents whose spirituality level indices were included in $25 \%$ of the lowest and in $25 \%$ of the highest observations (a total of 335 people remained):

1) respondents (159 people) with high levels of "spiritual personality" (above Q3 = 115);

2) respondents (176 people) with low levels of "spiritual personality" (below Q1 = 97).

It was revealed that respondents with high levels of "spiritual personality" significantly differed according to the Mann-Whitney U test by a higher productivity of life activity $(\mathrm{U}=10070.5 ; p<.001)$ and higher levels of spiritual capacities spiritual (altruistic) tendency $(\mathrm{U}=10779 ; p<.001)$ (Table 3$)$.

Table 2

Differences between groups according to the level of "spiritual personality" (groups identification on the basis of the median)

\begin{tabular}{|c|c|c|c|c|}
\hline \multirow[b]{2}{*}{ Indices } & \multicolumn{2}{|c|}{$\begin{array}{l}\text { Means of "spiritual personality" level } \\
\text { in groups }\end{array}$} & \multirow{2}{*}{$\begin{array}{l}\text { Mann-Whitney } \\
\text { U test }\end{array}$} & \multirow[b]{2}{*}{$p$} \\
\hline & $\begin{array}{c}\text { Higher level of "spiri- } \\
\text { tual personality" } \\
\text { N = } 318\end{array}$ & $\begin{array}{l}\text { Lower level of "spiri- } \\
\text { tual personality" } \\
\mathrm{N}=325\end{array}$ & & \\
\hline 1. Productivity & 7.85 & 6.35 & 43028 & $<.001$ \\
\hline $\begin{array}{l}\text { 2. Non-spiritual } \\
\text { egoistic tendency }\end{array}$ & 1.42 & 1.35 & 49810.5 & .409 \\
\hline $\begin{array}{l}\text { 3. Spiritual altruistic } \\
\text { tendency }\end{array}$ & 3.34 & 2.96 & 46328.5 & .022 \\
\hline
\end{tabular}

Table 3

Differences between groups according to the level of "spiritual personality" (contrast groups)

\begin{tabular}{|l|c|c|c|c|}
\hline \multirow{2}{*}{ Indices } & \multicolumn{2}{|c|}{$\begin{array}{c}\text { Means of "spiritual personality" level } \\
\text { in groups }\end{array}$} & Mann-Whitney \\
\cline { 2 - 5 } & $\begin{array}{c}\text { High level of "spiritu- } \\
\text { al personality" indices } \\
\mathrm{N}=159\end{array}$ & $\begin{array}{c}\text { cow level of "spiritual } \\
\text { personality" indices } \\
\mathrm{N}=176\end{array}$ & $\boldsymbol{p}$ \\
\hline 1. Productivity & 7.60 & 5.20 & 10070.5 & $<.001$ \\
\hline $\begin{array}{l}\text { 2. Non-spiritual } \\
\text { egoistic tendency }\end{array}$ & 1.37 & 1.33 & 13411.5 & .491 \\
\hline $\begin{array}{l}\text { 3. Spiritual altruis- } \\
\text { tic tendency }\end{array}$ & 3.45 & 2.57 & 10779 & $<.001$ \\
\hline
\end{tabular}


The results of the analysis by creating the contrast groups are consistent with the results obtained by splitting the groups on the basis of the median that indicates their reliability. Thus, an additional analysis of the contrast groups confirmed the results obtained by dividing the groups by median.

The results of the comparative analysis are consistent with the results of the correlation analysis showing more subtle differences between groups of people with high and low levels of "spiritual personality".

\section{Discussion}

The obtained results confirm that "spiritual personality" and spiritual capacities (altruistic tendency - the moral component of the model of spiritual capacities) are related. A "spiritual personality" has a higher level of spiritual capacities - spiritual altruistic tendency $(\mathrm{U}=10779 ; p<.001)$ and no links with the non-spiritual (egoistic) tendency.

The present research shows that the traits of personality can be linked to spiritual capacities that is consistent with the results of previous studies showing a connection of some personality traits and spiritual capacities. For instance, in the research conducted by Mahasneh, Shammout, Alkhazaleh, Al-Alwan, and AbuEita (2015) it was found that a relationship existed between spiritual intelligence and some personality traits such as extraversion, openness to experience, agreeableness, conscientiousness and neuroticism - personality characteristics included in McCrae \& Costa's (1997) Big Five Personality Theory. Similar results were obtained by Jahan, Shaheen, and Shaheen (2013). They examined the relationship between a "spiritual personality" using a Spiritual personality inventory (SPI) and personality traits (NEO-FFI). It was revealed that a significant relationship existed between the scores obtained on SPI with the conscientiousness characteristic (the Five Factor Model of Personality). Such traits as extraversion and conscientiousness predicted spiritual personality.

A significant relationship was revealed between personality factors and the value of helping activity. The respondents with "...higher scores on the Social Cooperation scale were willing to offer more costly help ("Providing assistance for mentally handicapped children"), compared to those who offered less costly help ("Participating as an organizer in a blood drive") (Wald $=7.263$, odds ratio $=.848$, $p<.01$ )" (Bereczkei, Birkas, \& Kerekes, 2010, p. 242). In this study people offering most costly help can be associated with respondents manifesting spiritual (altruistic) tendency in my research.

Thus, it is possible to say that the findings in the present research are consistent with the results of previous studies.

In this work an unexpected interesting result was obtained - a correlation between altruism and egoism that shows complexity of human personality having both positive and negative traits. I.G. Laverycheva wrote that it is well known that almost every person is capable of egoism and altruism, and the kind of an action mainly depends on the situation. Moreover, the person's internal state (that is also situational), is of great importance. However, there are more constant behavioral 
trends depending on the general level of culture, people's training in behavioral norms and the habit of following them, which brings these forms of behavior to automatism (Laverycheva, 2016). Thus, despite the possibility that one and the same individual may manifest both altruistic and egoistic motives and actions, it is possible to speak of the existence of a certain core, the main line in the behavior of personality associated with the orientation or the true core of personality, according to S.L. Rubinstein. That is, to talk about the fact that one person is more dominated by an altruistic spiritual orientation, and the other has a selfish non-spiritual trend.

2. The "Spiritual personality" differs through a higher productivity of life activity. The spiritual personality with a higher level of spiritual capacities can achieve more productivity in various life activities that is connected to the discussion of the above mentioned and following results.

3. The spiritual capacities are connected to the productive life activity. The people with spiritual (altruistic) tendency - the moral component of spiritual capacities showed more productivity in life activity than people with egoistic - non-spiritual tendency.

The question arises how the productivity of altruistic people can increase if they lose energy in self-sacrificing behaviors. The findings of $\mathrm{Hu}, \mathrm{Li}, \mathrm{Jia}, \&$ Xie (2016) suggest that people who render assistance to others feel warmer of the ambient environment than people who did not. It was shown that altruistic behavior enhanced warmth feelings of the ambient environment. Thus, altruistic performers restore their own resources and energy potential by receiving an immediate internal physical reward of altruism.

In the present study it was found that spiritual capacities are important for productive life activity.

This result seems to be consistent with the findings of earlier studies revealing positive links between spiritual intelligence and productive efficiency in different life activities, for example, a positive significant connection was shown for spiritual intelligence and nurse's work effectiveness (Rani et al., 2013). The findings of other research indicate that top managers' spiritual intelligence is strongly and positively linked to their thoughts concerning business process reengineering that is regarded as a crucial means for achieving advance in business (Ayranci \& Ayranci, 2015). Similar results showing the impact of spiritual intelligence on life productivity were obtained in different studies. Arbabisarjou, Maede-Sadat, Narges, and Shekoofeh-Sadat (2013) found that spiritual intelligence had an effect on students' achievements $(r=.93)$ and also explained $86 \%$ of achievement variance among the students. Corresponding results were obtained in the study conducted by Hosseini, \& Marei (2017). They found that spiritual intelligence had a positive, direct and meaningful impact on the workplace and a direct and significant effect on the evaluation of managers' performance. Another study showed that spiritual intelligence enhanced the organizational performance (Malik \& Tariq, 2016). Chin at al. (2014) established that successful entrepreneurs had higher levels of "Spiritual Intelligence" as higher strong connections with many spiritual capacities 
related to "Discernment", "Egolessness", "Freedom", "Higher self", "Intuition", "Joy", "Practice", "Purpose" and "Relatedness".

It is necessary to note that one of the predictors of work productivity is job satisfaction, and spiritual capacities play an important role in it. The study conducted by Kaur, Singh, and Bhatia (2016) showed that there was a significant relationship between the spiritual quotient of employees and their job satisfaction through the mediating effect of the feeling of oneness of employees. Other research has shown that there was a strong connection between spiritual intelligence and job satisfaction within the service industry (Rastgar et al., 2012). A restraining impact of spiritual intelligence was revealed concerning the stress in connection between job stress and working performance of employees (Othman et al., 2017).

\section{Limitation of the study}

The predominance of the female sample over the male group (the participants were 456 females and 206 males) could influence the results of this study. Considering the results obtained in this study, the age of the respondents (18-45 years old) should be taken into account. The age outside the range specified in this research may affect the change in results.

\section{Conclusion}

The impact of spiritual capacities, and especially of their moral component, on productive life activity can be explained by the spiritual (altruistic) tendency that fosters the creation of a good, positive, benevolent, and healthy atmosphere and environment. According to Post (2017), "Altruism results in deeper and more positive social integration, distraction from personal problems and the anxiety of selfpreoccupation, enhanced meaning and purpose as related to well-being, a more active lifestyle that counters cultural pressures toward isolated passivity, and the presence of positive emotions such as kindness that displace harmful negative emotional states. It is entirely quite plausible, then, to assert that altruism enhances happiness and health" (Post, 2017, p. 356). Thus, the altruistic spiritual tendency - a core part of spiritual capacities, can be viewed as one of the mechanisms of productive life activity that work as a foundation of efficient human relationships in social interaction.

\section{Acknowledgements}

The author is thankful to Dr. E.V. Volkova - Head of the Laboratory of Psychology of Abilities and Mental Resources named after V.N. Druzhinin, Institute of Psychology, Russian Academy of Sciences for the assistance in organizing data collection in different cities of the Russian Federation. 


\section{References}

Ahmad, A. (2015). Exploring the relationship between spiritual personality and emotional empathy among medical and unani students. The International Journal of Indian Psychology, 2(3), 152-169.

Ahmadian, E., Hakimzadeh, A., \& Kordestani, S. (2013). Job stress and spiritual intelligence: A case study. World Applied Sciences Journal, 22(11), 1667-1676.

Amram, Y.(2007). The Seven dimensions of spiritual intelligence: An ecumenical grounded theory. In 115th Anmual Conference of the American Psychological Association. San Francisco, CA, August 17-20, 2007. Retrieved from http://www.yosiamram.net/docs/7_Dimensions_of_SI_APA_confr_paper_Yosi_Amram.pdf

Amram, Y., \& Dryer, C. (2008). The Integrated spiritual intelligence scale (ISIS): Development and preliminary validation. In 116th Anmual Conference of the American Psychological Association. Boston, MA, August 14-17, 2008. Retrieved from http://www.yosiamram.net/docs/ISIS_APA_Paper_Presentation_2008_08_17.pdf

Anwar, M. A., \& Osman-Gani, A. M. (2015). The effects of spiritual intelligence and its dimensions on organizational citizenship behaviour. Journal of Industrial Engineering and Management, 8(4), 1162-1178.

Arbabisarjou, A., Maede-Sadat, R., Narges, M., \& Shekoofeh-Sadat, R. (2013). Relationship between different types of intelligence and student achievement. Life Science Journal, 10(7s), 128-133. doi:10.13140/2.1.4974.5927

Awais, M., Malik, M. S., \& Qaisar, A. (2015). A review: The job satisfaction act as mediator between spiritual intelligence and organizational commitment. International Review of Management and Marketing, 5(4), 203-210.

Ayranci, E., \& Ayranci, A. E. (2015). A research on the relationship between top managers' intelligence and their ideas about business process reengineering: consideration of emotionality and spirituality. International Business Research, 8(10), 66-80. doi:10.5539/ibr.v8n10p66

Baezzat, F., \& Sharifzadeh, H. (2013). Relationship between spiritual intelligence and emotional intelligence with job stress in university employees. Quarterly Journal of Career and Organizational Counselling, 4(13), 55-68.

Bass, S. A., \& Caro, F. G. (1996). Theoretical perspectives in productive aging. In W. H. Crown (Ed.), Handbook on employment and the elderly (pp. 265-275). Westport, CT: Greenwood.

Bereczkei, T., Birkas, B., \& Kerekes, Z. (2010). The Presence of Others, Prosocial Traits, Machiavellianism. A Personality $\times$ Situation Approach. Social Psychology, 41, 238-245. doi:10.1027/1864-9335/a000032

Burr, J. A., Mutchler, J. E., \& Caro, F. G. (2007). Productive activity clusters among middle aged and older adults: Intersecting forms and time commitments. The Journals of Gerontology Series B: Psychological Sciences and Social Sciences, 62(4), 267-275.

Chin, S. T., Raman, K., Yeow, J. A., \& Eze, U. C. (2014). The contributing roles of Emotional Intelligence and Spiritual Intelligence in entrepreneurial innovation and creativity. World Journal of Management, 5(2), 66-77.

Choi, N. G., \& Kim, J. (2011). The effect of time volunteering and charitable donations in later life on psychological well-being. Ageing and Society, 31, 590-610. doi:10.1017/S0144686X10001224

Eisenberg, N. (1983). The relation between empathy and altruism. Academic Psychology Bulletin, 5, 195-207.

Eisenberg, N. (1986). Altruistic emotion, cognition, and behavior. Hillsdale, NJ: Lawrence Erlbaum Associates.

Emmons, R. (1999). The psychology of ultimate concerns: Motivation and spirituality in personality. New York, NY/London, UK: The Guilford Press.

Emmons, R. (2000). Is spirituality an intelligence? Motivation, cognition and the psychology of the ultimate concern. The International Journal for the Psychology of Religion, 10(1), 3-26.

Frankl, V. E. (2020). Doktor i dusha: logoterapiya i ekzistentsial'nyy analiz [Doctor and soul: Logotherapy and existential analysis]. Moscow: Alpina non-fiction. (in Russian; trans. of: Frankl, V. E. (1955). Doctor and the soul. New York, NY: Random House.) 
Gilligan, C. (1977). In a different voice: Women's conceptions of self and morality. Harvard Educational Review, 47, 481-517.

Grano, C., Lucidi, F., Zelli, A., \& Violani, C. (2008). Motives and determinants of volunteering in older adults: An integrated model. The International Journal of Aging and Human Development, 67(4), 305-326.

Green, W. N., \& Noble, K. D. (2010). Fostering spiritual intelligence: Undergraduates' growth in a course about consciousness. Advanced Development Journal, 12, 26-48.

Guseynov, A. A. (2012). Filosofiya - mysl' i postupok: stat'i, doklady, lektsii, interv'yu [Philosophy thought and deed: articles, reports, lectures, interviews]. Saint Petersburg: SPbGUP. (in Russian)

Hao, Y. (2008). Productive activities and psychological well-being among older adults. The Journals of Gerontology Series B: Psychological Sciences and Social Sciences, 63(2), 64-72. doi:10.1093/geronb/63.2.S64

Herzog, A. R., Kahn, R. L., Morgan, J. N., Jackson, J. S., \& Antonucci, T. C. (1989). Age differences in productive activities. Journal of Gerontology, 44, 129-138.

Hoffman, M. L. (2000). Empathy and moral development: Implications for caring and justice. Cambridge, UK: Cambridge University Press.

Hosseini, M., \& Marei, S. P. (2017). Relationship between spiritual intelligence and spiritual leadership with the performance of directors of Bank of Tehran and the effect of spirituality mediation in the workplace. Journal of Accounting and Management, 3(1), 41-51. doi:10.21634/SJAM.3.1.4151

Hu, T., Li, J., Jia, H., \& Xie, X. (2016). Helping others, warming yourself: Altruistic behaviors increase warmth feelings of the ambient environment. Frontiers in Psychology, 7, 1-12. doi:10.3389/fpsyg.2016.01349

Husain, A., \& Anas, M. (2018). The manual of spiritual personality (Revised). Agra, India: Agra Psychological Research Cell.

Husain, A., Luqman, N., \& Jahan, M. (2012). Spiritual Personality Inventory Manual. New Delhi, India: Prasad Psycho Corporation.

Husain, A., Nishat, A., \& Jahan, M. (2015). Spiritual personality as related to perfectionism among undergraduate students. ACADEMICIA: An International Multidisciplinary Research Journal, 5(11), 84-90.

Jahan, M., Shaheen, H., \& Shaheen, F. (2013). Spiritual personality and five factor model of personality. Psychology of India, 2(1), 23-30.

Jung, Y., Gruenewald, T. L., Seeman, T. E., \& Sarkisian, C. A. (2010). Productive activities and development of frailty in older adults. The Journals of Gerontology Series B: Psychological Sciences and Social Sciences, 65B(2), 256-261.

Kaur, S., Singh, S. \& Bhatia B. S. (2016). Exploring relationship among spiritual quotient, feeling of oneness and job satisfaction of employees: an empirical study. International Journal of Human Resources Management, 5(4), 1-12.

King, D. B. (2010). Personal meaning production as a component of spiritual intelligence. International Journal of Existential Psychology and Psychotherapy, 3(1), 1-5.

Laverycheva, I. G. (2016). Al'truizm i egoizm s yestestvennonauchnoy tochki zreniya [Altruism and egoism from a scientific point of view]. Interdisciplinary Scientific and Applied Journal "Biosphere", 8(3), 338-361. (in Russian)

Litwin, H., \& Shiovitz-Ezra, S. (2006). The association between activity and well-being in later life: What really matters? Ageing and Society, 26(2), 225-242.

Lum, T. Y. (2013). Advancing research on productive aging activities in greater Chinese societies. Ageing International, 38, 171-178. doi:10.1007/ s12126-012-9171-2

Mahasneh, A. M., Shammout, N. A., Alkhazaleh, Z. M., Al-Alwan, A. F., \& Abu-Eita, J. D. (2015). The relationship between spiritual intelligence and personality traits among Jordanian university students. Journal of Psychology Research and Behavior Management, 8, 89-97. 
Malik, M. S., \& Tariq, S. (2016). Impact of spiritual intelligence on organizational performance. International Review of Management and Marketing, 6(2), 289-297.

Maslow, A. H. (1999). Dal'nie predely chelovecheskoi psikhiki [The farther reaches of human nature]. Saint Petersburg: Evraziya, 1999. (in Russian; trans. of: Maslow, A. H. (1971). The farther reaches of human nature. Arkana/Penguin Books.)

McCrae, R. R., \& Costa, P. T. (1997). Personality trait structure as a human universal. American Psychologist, 52, 509-516.

Midlarsky, E., \& Kahana, E. (2007). Altruism, well-being, and mental health in late life. In S. G. Post (Ed.), Altruism and health: Perspectives from empirical research (pp. 56-69). New York, NY: Oxford University Press.

Morrow-Howell, N., Hinterlong, J., Rozario, P. A., \& Tang, F. (2003). Effects of volunteering on the well-being of older adults. The Journals of Gerontology Series B: Psychological Sciences and Social Sciences, 58(3), 137-145.

Morrow-Howell, N., \& Wang, Y. (2013). Productive engagement of older adults: Elements of a crosscultural research agenda. Ageing International, 38, 159-170. doi:10.1007/s12126-012-9165-0

Noble, K. D. (2000). Spiritual intelligence: A new frame of mind. Advanced Development Journal, 9, 1-28.

Othman, A. K., Abas, M. K., \& Ishak, M. S. (2017). The moderating role of spiritual intelligence on the relationship between job stress and job performance of employees in a banking sector. Journal of Islamic Management Studies, 1(1), 89-103.

Ozhiganova, G. V. (2009). Psychology of spirituality and spiritual capacities. In A. Husain (Ed.), Twenty First century psychology: Spirituality, behavior and wellness (pp. 193-225). New Delhi, India: Global Vision Publishing House.

Ozhiganova, G. V. (2010). Psychology of spirituality. Part II. Spiritual abilities. Psikhologicheskii Zhurnal, 31(5), 39-53. (in Russian)

Ozhiganova, G. V. (2016). Duhovnye sposobnosti kak resurs zhiznedeyatel'nosti [Spiritual capacities as a resource of life activity]. Moscow: Institute of Psychology of the RAS. (in Russian)

Ozhiganova, G. V. (2019). Adaptation of spiritual personality inventory on the Russian sample. Eksperimental'naya Psihologiya [Experimental Psychology (Russia)], 12(4), 160-176. doi:10.17759/exppsy.2019120413 (in Russian)

Popov, L. M., \& Maksumova, A. O. (2010). Tipologiya lyudey v eticheskoy psikhologii lichnosti [Typology of people in the ethical psychology of personality]. In A. L. Zhuravlev \& A. V. Yurevich (Eds.), Psikhologiya nravstvennosti [Psychology of morality] (pp. 95-115). Moscow: Institute of Psychology of the RAS. (in Russian)

Post, S. G. (2017). Happiness, health and altruism. In International encyclopedia of public health (2nd ed., pp. 354-357). Elsevier Inc.

Rani, A. A., Abidin, M., \& Ab Hamid, M. R. (2013). The impact of spiritual intelligence on work performance: Case studies in government hospitals of East Coast of Malaysia. The Macrotheme Reviere, 2(3), 46-59.

Rastgar, A. A., Davoudi, S. M., Oraji, S., \& Abbasian, M. (2012). A study of the relationship between employees' spiritual intelligence and job satisfaction: A survey in Iran's banking industry. Journal of Multidisciplinary Research, 1(2), 57-74. doi:10.1515/ngoe-2016-0012

Rilling, J. K. (2008). Neuroscientific approaches and applications within anthropology. American Journal of Physical Anthropology, 137(47), 2-32. doi:10.1002/ajpa.20947

Rubinstein, S. L. (2002). Osnovy obshchey psikhologii [Fundamentals of general psychology]. Saint Petersburg: Piter. (in Russian)

Rumyantseva, T. G. (2012). Transtsendentnoye i transtsendental'noye [The transcendent and transcendental]. In Noveyshiy filosofskiy slovar'. Slovar' filosofskikh terminov [The newest philosophical 
dictionary. Dictionary of philosophical terms]. Retrieved from http://www.philosophiterms.ru/word/Трансцендентное и трансцендентальное (in Russian)

Shadrikov, V. D. (1998). Dukhovnyye sposobnosti [Spiritual abilities]. Moscow: Master. (in Russian)

Shadrikov, V. D. (2019). Sposobnosti i odarennost' cheloveka [Abilities and giftedness of human beings].

Moscow: Institute of Psychology of the RAS. (in Russian)

Shadrikov, V. D. (2020). Dukhovnyye sposobnosti [Spiritual abilities] (2nd ed.). Moscow: Institute of Psychology of the RAS. (in Russian)

Simmons, E. (2003). Transcendence. In J. W. Vrede van Huyssteen (Ed.), Encyclopedia of science and religion (p. 901). New York, NY: Macmillan Reference.

Smith, A. (2006). The theory of moral sentiments. São Paulo, Brazil: Metalibri.

Spikins, P., Rutherford, H., \& Needham, A. (2010). The prehistory of compassion. San Francisco, CA: Blurb Inc., Print.

Srivastava, P. S. (2016). Spiritual intelligence: An overview. International Journal of Multidisciplinary Research and Development, 3(3), 224-227.

Strohminger, N., \& Nichols, S. (2014). The essential moral self. Cognition, 131, 159-171.

Swaminathan, V. D., Bindhu, S., \& Mythili, T. (2009). Psychological virtues of spiritual maturity. In A. Husain (Ed.), Twenty First century psychology: Spirituality, behavior and wellness (pp. 21-31). New Delhi, India: Global Vision Publishing House.

Symeon the New Theologian. (1999). Metod svyashchennoy molitvy i vnimaniya [The method of sacred prayer and attention]. In Put' $k$ soyashchennoтu bezmolviyu: Maloizvestnyye tooreniya soyatykh ottsov isikhastov [Path to sacred silence: little-known works of the holy fathers the hesychasts] (pp. 15-27). Moscow: Publishing House of the Orthodox brotherhood of St. Philaret from Moscow. (in Russian)

Tang, F., Chen, H., Zhang, Y., \& Mui, A. C. (2018). Employment and life satisfaction among middle- and old-aged adults in China. Gerontology and Geriatric Medicine, 4, 1-8. doi:10.1177/2333721418778202

Trivers, R. L. (1971). The evolution of reciprocal altruism. The Quarterly Review of Biology, 46(1), 35-57. Vaughan, F. (2002). What is spiritual intelligence? Journal of Humanistic Psychology, 42(2), 16-33.

Warburton, J., Paynter, J., \& Petriwskyj, A. (2007). Volunteering as a productive aging activity: Incentives and barriers to volunteering by Australian seniors. Journal of Applied Gerontology, 26(4), 333-354.

Windsor, T. D., Anstey, K. J., \& Rodgers, B. (2008). Volunteering and psychological well-being among young-old adults: How much is too much? The Gerontologist, 48(1), 59-70.

Wolman, R. (2001). Thinking with your soul: Spiritual intelligence and why it matters. New York, NY: Harmony Books.

Zarei Matin, H., Kheirandish, M., \& Jahani, H. (2011). Identify and measure the components of spiritual intelligence in the workplace: a case study in Tehran labbafinejad hospital. Research General Manager, 12(4), 71-94.

Zohar, D., \& Marshall, J. (2000). Spiritual intelligence, the ultimate intelligence. New York, NY: Bloomsbury Publishing.

Galina V. Ozhiganova - Senior Researcher, Laboratory of Psychology of Abilities and Mental Resources named after V.N. Druzhinin, Institute of Psychology, Russian Academy of Sciences, PhD in Psychology.

Research Area: spirituality of personality, spiritual capacities, psychological aspects of spirituality in ancient Oriental systems of knowledge, higher human abilities: moral, reflective, self-regulatory, creative.

E-mail: symposium2016@rambler.ru 


\title{
Духовные способности личности и продуктивная жизнедеятельность
}

\author{
Г.В. Ожиганова ${ }^{\mathrm{a}}$ \\ ${ }^{a}$ ФГБУН «Институт психологии РАН», 129366, Москва, ул. Ярославскал, д. 13, к. 1
}

\begin{abstract}
Резюме
В статье рассматриваются психологические аспекты духовности: анализируются понятия «духовный интеллект», «духовные способности», «духовная личность». Исходя из психологической модели духовных способностей, предложенной автором, в которой выделяются три компонента: моральный, ментальный, трансцендентный, для подробного изучения был выбран моральный компонент и проведено его эмпирическое исследование. Основу морального компонента духовных способностей составляет духовная альтруистическая направленность. В статье анализируется ее связь с продуктивной жизнедеятельностью. Целью исследования стало изучение взаимосвязи между духовностью личности, духовными способностями и продуктивной жизнедеятельностью. Участниками исследования были 662 чел. - взрослые люди (206 мужчин, 456 женщин): студенты и служащие в возрасте 18-45 лет $(\mathrm{M}=26.08)$ из двух городов Российской Федерации (Кострома и Таганрог). Для обработки данных использовался сравнительный и корреляционный анализ. Было установлено, что респонденты с более высоким уровнем показателей духовности личности достоверно отличались по критерию U Манна-Уитни более высокой продуктивностью жизнедеятельности ( $\mathrm{U}=43028 ; p<0.001)$ и обладали более высокими показателями духовных способностей (альтруистическая духовная направленность) $(\mathrm{U}=46328.5 ; p<0.022)$. Корреляционный анализ показал, что чем выше был уровень индикаторов духовных способностей - духовной альтруистической направленности, тем выше была продуктивность жизнедеятельности. Полученные результаты позволяют отметить важность конструкта «духовные способности» и необходимость его дальнейшей научной разработки в рамках психологии, а также подчеркнуть практическое значение проявления духовных способностей для благополучного и продуктивного функционирования социума.
\end{abstract}

Ключевые слова: духовный интеллект, духовные способности, духовная (альтруистическая) направленность, духовная личность, продуктивная жизнедеятельность.

Ожиганова Галина Валентиновна - старший научный сотрудник, лаборатория способностей и ментальных ресурсов имени В.Н. Дружинина, Институт психологии Российской академии наук, кандидат психологических наук.

Сфера научных интересов: духовность личности, духовные способности, психологические аспекты духовности в древневосточных системах знаний, высшие способности человека: моральные, рефлексивные, саморегулятивные, творческие.

Контакты: symposium2016@rambler.ru

Автор благодарит Е.В. Волкову (заведующую лабораторией психологии способностей и ментальных ресурсов им. В.Н. Дружинина, Институт психологии РАН, Москва) за помощь в организации сбора данных в разных городах России. 


\title{
Короткие сообщения
}

\section{РЕЛИГИОЗНАЯ ПРАКТИКА ПРАВОСЛАВНЫХ РОССИЯН КАК ФАКТОР ЭКЗИСТЕНЦИАЛЬНОГО БЛАГОПОЛУЧИЯ}

\begin{abstract}
А.Ю. КЛИМОЧКИНА
${ }^{a}$ Российская академия народного хозяйства и государственной службы при Президенте Российской Федерации, 119571, Россия, Москва, просп. Вернадского, 82, стр. 1

\section{Резюме}

В работе ставится вопрос о взаимосвязи религиозности и психологического благополучия человека в экзистенциально-психологическом понимании. Корреляционное исследование проводилось методом онлайн-опроса на открытых платформах. Из полученной выборки были отобраны респонденты, соответствующие двум критериям: первый - самоопределение респондента как верующего в Бога, второй - аффилиация респондента с Русской православной церковью. Итоговую выборку составили 153 человека. Оценка экзистенциального благополучия основывалась на понятии исполненности, которая измерялась валидизированным опросником Тест экзистенциальных мотиваций (ТЭМ). Был измерен частный и совокупный вклад частоты нескольких религиозных практик в показатель экзистенциальной исполненности - молитвы, посещения церкви, чтения Священного Писания, участия в религиозных праздниках и соблюдения поста. Для оценки совокупного вклада религиозных практик составлена шкала Объективная религиозность $(\alpha$ Кронбаха $=0.89)$. Обработка результатов включала методы: сравнение средних, корреляционный анализ, иерархический регрессионный анализ. Гипотеза о положительной взаимосвязи между экзистенциальной исполненностью религиозных людей и частотой реализации ими религиозных практик подтвердилась. Результаты исследования указывают на более высокий уровень экзистенциальной исполненности у православных христиан относительно ожидаемых средних по ТЭМ в предыдущих российских исследованиях. Частота религиозных практик является значимым предиктором исполненности: православные, активно участвующие в религиозной жизни, сообщают о более высоком уровне экзистенциальной исполненности. Наибольшая значимая связь $(\beta=0.31)$ обнаружена с субшкалой переживания жизни как наполненной смыслом. В соответствии с экзистенциально-аналитической теорией предложена интерпретация обнаруженной взаимосвязи: религиозность является персональным ресурсом благодаря «упражнению» человека в духовной активности. Обозначены ограничения и перспективы исследования.
\end{abstract}

Ключевые слова: экзистенциальная исполненность, благополучие, религиозность, религиозные практики, православные христиане. 


\section{Введение}

Религиозность личности традиционно рассматривается в связи с различными компонентами и коррелятами психологического благополучия: самоконтролем, аффективностью и просоциальностью (Hobson, Inzlicht, 2016); совладанием с дистрессами и тревожностью, адаптацией в ситуации тяжелой утраты (Frantz et al., 1996; Lord, Gramling, 2014); переживанием осмысленности и упорядоченности жизни (Inzlicht et al., 2011). Недавнее крупное исследование, проведенное НИУ ВШЭ на данных Российского мониторинга экономического положения и здоровья населения, показывает позитивную связь между религиозностью и удовлетворенностью жизнью (Bryukhanov, Fedotenkov, 2017). Однако исследователи обнаруживают как позитивные, так и негативные следствия религиозности для психологического благополучия человека (Diener et al., 2011; Koenig, 2001; Pargament et al., 1988).

В рамках экзистенциально-психологической парадигмы проблема взаимосвязи благополучия и религиозности личности систематически не была изучена. Данная работа посвящена специфическому аспекту благополучия экзистенциальной исполненности. Экзистенциальная исполненность - термин, введенный в теорию экзистенциального анализа А. Лэнгле для обозначения показателя психологического здоровья и благополучия (Шумский и др., 2016, с. 780). Экзистенциальная исполненность выражается в переживании внутреннего согласия с жизнью и «глубокого удовлетворения» (Лэнгле, $2005)$, в «персональном» (соответствующем самому себе) внутреннем и внешнем поведении (Längle et al., 2003, p. 145). Уровень экзистенциальной исполненности зависит от решения четырех экзистенциальных вопросов, которые ставит жизнь перед каждым человеком: (1) «Могу ли я быть в этом мире?»; (2) «Нравится ли мне моя жизнь?»; (3) «Имею ли я право быть таким (какой я есть)?»; (4) «Ради чего я живу?» (Лэнгле, 2009). Поиском ответов на эти вопросы человек мотивирован в своей жизни, поэтому им соответствуют четыре фундаментальные мотивации (ФМ). Позитивной реализации $Ф \mathrm{M} \mathrm{в}$ жизни человека соответствуют переживания: (1) фундаментального доверия миру, (2) ценности жизни, (3) самоценности, (4) смысла жизни.

ФМ реализуются человеком в каждый момент времени: «Нет ни одного решительного действия... которые не были бы связаны, по крайней мере, с одной из четырех фундаментальных мотиваций» (Там же, с. 17). Реализация ФМ верующего происходит в условиях религиозного контекста, в который человек включен в большей или меньшей степени, будучи «воцерковленным», практикующим предписанные ритуалы, или «невоцерковленным». В качестве гипотезы мы предполагаем наличие взаимосвязи между экзистенциальной исполненностью человека и частотой реализации им религиозных практик. Гипотеза основана на результатах М.М. Полома и Б.Ф. Пендлтона (Poloma, Pendleton, 1989), которые указывают на положительную связь частоты молитвы с экзистенциальным благополучием. Авторы объясняют эту связь созерцательной природой медитативной молитвы, которая взаимосвязана с компонентом «смысла жизни». А также мы основываемся на наших 
предыдущих исследованиях (Shumskiy, Klimochkina, 2018), где была показана положительная взаимосвязь частоты религиозных практик и экзистенциальной исполненности у мусульман и буддистов, проживающих в России.

\section{Метод}

\section{Процедура и выборка}

Сбор данных проводился в форме анонимного онлайн-опроса. Респонденты рекрутировались с помощью онлайн-приглашения в социальных сетях, в том числе в профильных религиозных сообществах. При этом сообщалась цель исследования - «изучение психологического благополучия».

Отбор респондентов осуществлялся по двум критериям: первый - самоопределение респондента как верующего (позитивный ответ на вопрос «Верите ли вы в Бога?»), второй - аффилиация респондента с Русской православной церковью (в ответе на вопрос «Относите ли вы себя к какому-либо вероисповеданию?»). Итоговую выборку составили 153 человека, исповедующих православие и проживающих в России (таблица 1).

\section{Memoдbl}

Показатель религиозности измерялся как частота исполнения религиозных практик, существующих в православии, с помощью вопросов: «Как часто вы посещаете храм?», «Как часто вы читаете Священное Писание?», «Как часто вы участвуете в религиозных праздниках и соблюдаете пост?», «Как часто вы совершаете молитвы?». Эти вопросы являются традиционными для измерения «объективной» религиозности (Hill, Hood, 1999). Оценка частоты

Таблица 1

Характеристики выборки православных христиан

\begin{tabular}{|l|l|c|c|}
\hline \multicolumn{2}{|c|}{} & $\begin{array}{c}\text { Кол-во } \\
\text { респондентов }\end{array}$ & \% выборки \\
\hline \multirow{5}{*}{ Возраст } & $16-20$ лет & 19 & 12.4 \\
\cline { 2 - 4 } & $21-30$ лет & 30 & 19.6 \\
\cline { 2 - 4 } & $31-40$ лет & 39 & 25.5 \\
\cline { 2 - 4 } & $41-50$ лет & 40 & 26.1 \\
\cline { 2 - 4 } & $50-70$ лет & 130 & 16.3 \\
\hline \multirow{3}{*}{ Пол } & женский & 23 & 85 \\
\cline { 2 - 4 } & ород \\
проживания & 78 & 51 \\
\cline { 2 - 4 } & большой город (более 1 млн жителей) & 75 & 49 \\
\hline
\end{tabular}


производилась по шкале от 1 до 5, где 1 - «никогда», 2 - «редко», 3 - «иногда», 4 - «часто», 5 - «регулярно (всегда)».

Для оценки экзистенциальной исполненности был использован Тест экзистенциальных мотиваций (ТЭМ), валидизированный на российской выборке $(\mathrm{N}=818$ и $\mathrm{N}=215)$ (Шумский и др., 2016). Опросник содержит интегральный показатель экзистенциальной исполненности (ЭИ), а также четыре шкалы, описывающие четыре экзистенциальные мотивации (ФМ): 1-я ФМ - фундаментальное доверие; 2-я ФМ - фундаментальная ценность жизни; 3-я ФМ самоценность; 4-я ФМ - смысл жизни.

\section{Результаты}

В выборке православных христиан показатели исполненности по шкалам ТЭМ значимо выше средних показателей общей российской выборки (Шумский и др., 2016). Наибольший размер эффекта проявляется в показателях 1-й ФМ и 4-й ФМ (таблица 2).

Корреляционный анализ показал, что все четыре религиозные практики слабоположительно связаны с показателем ЭИ и со всеми ФМ (таблица 3). Учитывая поправку Холма на множественную проверку, значимые связи со всеми показателями ФМ обнаруживают частота участия респондента в религиозных праздниках и соблюдение поста; частота чтения Священного Писания

Таблица 2

Сравнение средних показателей ФМ и экзистенциальной исполненности (ЭИ) между выборкой православных христиан и общей российской выборкой

\begin{tabular}{|l|c|c|c|}
\hline & $\begin{array}{c}\text { Православные христиане } \\
\mathbf{N}=\mathbf{1 5 3}, \mathbf{M}(\mathbf{S D})\end{array}$ & $\begin{array}{c}\text { Общая российская выборка } \\
\mathbf{N = ~ 8 1 8 , ~ M ~ ( S D ) ~}\end{array}$ & $\begin{array}{c}\text { Размер эффекта } \\
\text { d Коэна }\end{array}$ \\
\hline $1 Ф \mathrm{M}$ & $27.22(4.82)$ & $24.54(5.06)$ & 0.53 \\
\hline $2 Ф \mathrm{M}$ & $27.01(4.71)$ & $24.53(5.11)$ & 0.49 \\
\hline $3 Ф \mathrm{M}$ & $29.65(3.99)$ & $28.03(4.45)$ & 0.37 \\
\hline $4 Ф \mathrm{M}$ & $28.70(4.63)$ & $25.58(5.67)$ & 0.57 \\
\hline ЭИ & $112.58(15.35)$ & $102.76(17.21)$ & 0.58 \\
\hline
\end{tabular}

Таблица 3

Корреляции Спирмена между показателями ФМ и экзистенциальной исполненности (ЭИ) и частотой религиозных практик

\begin{tabular}{|l|l|l|l|l|c|}
\hline & $\mathbf{1 \Phi М}$ & $\mathbf{2 \Phi M}$ & $\mathbf{3 \Phi M}$ & $\mathbf{4 Ф M}$ & ЭИ \\
\hline Как часто вы посещаете храм? & 0.13 & 0.22 & 0.22 & 0.20 & 0.22 \\
\hline Как часто вы читаете Священное Писание? & 0.16 & 0.16 & 0.19 & $0.29^{*}$ & 0.24 \\
\hline $\begin{array}{l}\text { Как часто вы участвуете в религиозных } \\
\text { праздниках и соблюдаете пост? }\end{array}$ & $0.25^{*}$ & $0.25^{*}$ & $0.28^{*}$ & $0.33^{* *}$ & $0.32^{* *}$ \\
\hline Как часто вы совершаете молитвы? & 0.20 & $0.28^{* *}$ & 0.17 & 0.22 & $0.25^{*}$ \\
\hline
\end{tabular}

${ }^{*} p<0.05,{ }^{* *} p<0.01$. 
значимо связана только с 4-й ФМ; частота молитв - со 2-й ФМ и показателем ЭИ. Для оценки общего уровня следования религиозным практикам была составлена шкала Объективная религиозность (ОР). Надежность шкалы проверялась с помощью альфы Кронбаха (0.892), пункты шкалы хорошо согласованы (корреляции пункт - шкала > 0.7).

Проведен иерархический регрессионный анализ, на первом шаге введены социодемографические факторы (город проживания, пол и возраст респондента), а на втором шаге исследуется уникальный вклад ОР в показатели ФМ (таблица 4). Показатель по шкале ОР продемонстрировал значимый вклад во все четыре ФМ и экзистенциальную исполненность при контроле социодемографических факторов. Наибольший коэффициент вклада ОР обнаружен на уровне 4-й ФМ.

\section{Обсуждение}

Значимость пола респондентов для показателей ФМ обусловлена асимметрией выборки, где большинство составляют женщины. Эта асимметрия соответствует особенностям генеральной совокупности - христианки придают бо́льшую значимость религии и активнее исполняют практики (Pew Research Center, 2016). Значимость возраста респондентов для показателей 1-й ФМ, 4-й ФМ и ЭИ исчезла при введении в регрессионную модель данных о частоте религиозных практик, что может быть объяснено слабой положительной корреляцией между возрастом респондентов и частотой религиозных практик.

Высокие в сравнении с ожидаемыми средними показатели ФМ показывают, что православные христиане сообщают о более высоком уровне экзистенцииальнои исполненности, а в особенности фундаментального доверия миру и смысла жизни. При этом важный вклад в реализацию ФМ вносит именно «объективная» религиозность: православные христиане, активно участвующие в религиозной жизни, регулярно исполняющие предписанные практики, склоннь воспринимать свою жизнь более экзистенщиально исполненной.

Таблища 4

Результаты регрессионного анализа

\begin{tabular}{|c|c|c|c|c|c|}
\hline & $1 \Phi M$ & $2 \Phi M$ & 3ФМ & 4ФМ & ЭИ \\
\hline Шаг 1. $\Delta \mathrm{R}^{2}$ & $0.052^{*}$ & $0.075^{* *}$ & 0.046 & 0.044 & $0.065^{* *}$ \\
\hline$\beta$, возраст & 0.10 & $0.21^{* *}$ & 0.16 & $0.20^{*}$ & $0.20 *$ \\
\hline$\beta$, пол (0 - жен., 1 - муж.) & $0.16^{*}$ & $0.16^{*}$ & 0.14 & 0.10 & $0.17^{*}$ \\
\hline$\beta$, город (0 - большой, 1 - малый $)$ & 0.09 & 0.02 & -0.01 & -0.10 & 0.00 \\
\hline Шаг 2. $\Delta \mathrm{R}^{2}$ & $0.039 * *$ & $0.042^{* *}$ & $0.059 * *$ & $0.069^{* * *}$ & $0.070 * * *$ \\
\hline$\beta$, возраст & -0.01 & 0.10 & 0.03 & 0.05 & 0.05 \\
\hline$\beta$, пол (0 - жен., 1 - муж.) & $0.19 * *$ & $0.19^{* *}$ & $0.18^{*}$ & 0.14 & $0.20^{* *}$ \\
\hline$\beta$, город (0 - большой, 1 - малый $)$ & 0.07 & 0.00 & -0.03 & -0.13 & -0.03 \\
\hline$\beta$, ОР (объективная религиозность) & $0.23 * *$ & $0.24 * *$ & $0.28 * *$ & $0.31 * * *$ & $0.31 * * *$ \\
\hline
\end{tabular}

${ }^{*} p<0.05, * * p<0.01, * * * p<0.001$; метод: enter. 
Возможная интерпретация данного результата такова: исполнение религиозных практик мобилизует духовные силы в человеке. Согласно А. Лэнгле (2011), доступ к духовному началу человека возможен путем «упражнений» в установке отпускания и открытости, а также в установке внимательности к себе и к миру. Религиозные практики, существующие в православии, содержат элементы этих «упражнений». Например, в молитве человек на время изымает себя из суеты повседневности и обращается к более широкому взгляду на свою жизнь, вновь открывая для себя перспективу смысла. Коллективные богослужения дают возможность пережить близость с другими верующими, причастность к общему делу и диалогичную связь с миром.

Таким образом, религиозность предоставляет возможности и инструменты, благодаря которым могут быть воплощены фундаментальные стремления человека. Религиозность выступает своего рода ресурсом для развития экзистенциальной исполненности.

Однако обнаруженные тенденции могут объясняться спецификой самого ТЭМ - тест не защищен от социальной желательности. Кроме того, гетерогенность генеральной совокупности российских православных затрудняет обобщение результатов. В данном исследовании особенности онлайн-рекрутирования могли внести вклад в смещение результатов ТЭМ по сравнению с популяцией: поскольку попадание в выборку определялось инициативой респондента, то выборку составили люди, обладающие высокой социальной активностью в Интернете, а также заинтересованные в познании своего внутреннего мира, что могло позитивно отразиться на уровне их благополучия. Отметим, что в исследовании авторов валидизации ТЭМ, в котором были установлены средние значения для общей российской выборки, был использован тот же способ рекрутирования (Шумский и др., 2016).

Измерение религиозности было ограничено: не учитывалось качество религиозных переживаний верующих, а также индивидуальный генез религиозности. Для уточнения механизмов, стоящих за обнаруженными тенденциями, необходимо исследование субъективного опыта верующих в переживании экзистенциальных тем в контексте религии.

\section{Литература}

Лэнгле, А. (2005). Person. Экзистенциально-аналитическая теория личности (4-е изд.). М.: Генезис.

Лэнгле, А. (2009). Фундаментальные мотивации экзистенции как действенная структура экзистенциально-аналитической терапии. Экзистенциальный анализ. Бюллетень, 1, 9-29.

Лэнгле, А. (2011). Дух и экзистенция: о духовном начале, имманентно присущем экзистенциальному анализу. Экзистенциальньй анализ. Бюллетень, 3, 11-23.

Шумский, В. Б., Уколова, Е. М., Осин, Е. Н., Лупандина, Я. Д. (2016). Диагностика экзистенциальной исполненности: Оригинальная русскоязычная версия Теста экзистенциальных мотиваций. Психология. Журнал Высшей школь экономики, 13(4), 763-788.

Ссылки на зарубежные источники см. в разделе References после англоязычного блока. 
Климочкина Анастасия Юрьевна - преподаватель, Российская академия народного хозяйства и государственной службы при Президенте Российской Федерации.

Сфера научных интересов: экзистенциальная психология, психология религии, психологическое здоровье и благополучие.

Контакты: anaklimochkina@yandex.ru

\title{
Religious Practice of Russian Orthodox Christians as a Factor of Existential Well-Being
}

\author{
A.Yu. Klimochkina ${ }^{a}$ \\ ${ }^{a}$ Russian Presidential Academy of National Economy and Public Administration (The Presidential \\ Academy, RANEPA), 82 build. 1 Prospect Vernadskogo, Moscow, 119571, Russian Federation
}

\begin{abstract}
The article addresses the issue of the relation between religiosity and psychological wellbeing of a person in an existential-psychological understanding. A correlational study has been conducted by means of an online survey on public platforms. From the original sample, the respondents have been chosen according to two criteria: the respondents' self-identification as individuals who believe in God and the respondents' affiliation to the Russian Orthodox Church. The final sample consisted of 153 people. Assessment of their existential well-being was based on the notion of "fulfillment", which was measured with the Test of Existential Motivations (TEM). The frequency of several spiritual practices such as prayer, church attendance, reading the Bible, participation in religious celebrations and fasting, has been analyzed in terms of its partial and cumulative effect on the levels of existential fulfillment. For the purposes of assessment of the cumulative contribution that spiritual practices have on an individual, a scale of Objective Religiousness was created (Cronbach's $\alpha=.89$ ). The following methods were used for processing the results: one sample T-Test, correlation analysis, and hierarchical regression analysis. The hypothesis about the positive correlation between the existential fulfillment of religious people and the frequency with which they carry out their spiritual practices has been confirmed. The results of this study demonstrate a higher level of existential fulfillment shown by Orthodox Christians as compared to the expected average levels of fulfillment according to TEM in the previous Russian studies. The frequency of religious practices is a significant predictor of fulfillment: Christians having an active spiritual life report higher levels of existential fulfillment. The most significant correlation ( $\beta=0.31$ ) has been revealed on the subscale, according to which life is perceived as meaningful. An interpretation of the revealed correlation has been suggested in accordance with the existential analytical theory: religiosity serves as a personal resource due to "exercising" spiritual activity by a person. The limitations and the prospects of the study have also been outlined.
\end{abstract}

Keywords: existential fulfillment, well-being, religiosity, religious practice, Orthodox Christians. 


\section{References}

Bryukhanov, M., \& Fedotenkov, I. (2017). Religiosity and life satisfaction in Russia: Evidence from the Russian data. National Research University Higher School of Economics. Series WP BRP 180 "Economics/EC". Retrieved from https://www.hse.ru/data/2017/11/13/1158251830/ 180EC2017.pdf

Diener, E., Tay, L., \& Myers, D. G. (2011). The religion paradox: If religion makes people happy, why are so many dropping out? Journal of Personality and Social Psychology, 101(6), 1278-1290.

Frantz, T., Trolley, B., \& Johll, M. (1996). Religious aspects of bereavement. Pastoral Psychology, 44(3), 151-163.

Hill, P. C., \& Hood, R. W. Jr. (1999). Measures of religiosity. Birmingham, AL: Religious Education Press.

Hobson, N., \& Inzlicht, M. (2016). Recognizing religion's dark side: Religious ritual increases antisociality and hinders self-control. Behavioral and Brain Sciences, 39, e14.

Inzlicht, M., Tullett, A., \& Good, M. (2011). The need to believe: A neuroscience account of religion as a motivated process. Religion, Brain, \& Behavior, 1, 192-212.

Koenig, H. (2001). Handbook of religion and mental health. San Diego, CA: Elsevier Science.

Längle, A. (2005). Person. Ekzistentsial'no-analiticheskaya teoriya lichnosti [Existential-analytical theory of personality] ( $4^{\text {th }}$ ed.). Moscow: Genesis. (in Russian)

Längle, A. (2009). Fundamental'nye motivatsii ekzistentsii kak deistvennaya struktura ekzistentsial'no-analiticheskoi terapii [Fundamental motivations of existence as an effective structure of existential-analytical therapy]. Ekzistentsial'nyi analiz. Byulleten' [Existential analysis. Bulletin], 1, 9-29. (in Russian)

Längle, A. (2011). Dukh i ekzistentsiya: o dukhovnom nachale, immanentno prisushchem ekzistentsial'nomu analizu [Spirit and existence: The inherent spirituality of existential analysis]. Ekzistentsial'nyi analiz. Byulleten' [Existential analysis. Bulletin], 3, 11-23. (in Russian)

Längle, A., Orgler, C., \& Kundi, M. (2003). The Existence Scale. European Psychotherapy, 4(1), 135-151.

Lord, B. D., \& Gramling, S. E. (2014). Patterns of religious coping among bereaved college students. Journal of Religion and Health, 53(1), 157-177.

Pargament, K. I., Kennell, J., Hathaway, W., Grevengoed, N., Newman, J., \& Jones, W. (1988). Religion and the problem-solving process: Three styles of coping. Journal for the Scientific Study of Religion, 27(1), 90-104.

Pew Research Center. (2016, March 22). The Gender Gap in Religion Around the World. Retrieved from https://www.pewresearch.org/wp-content/uploads/sites/7/2016/03/Religion-and-GenderFull-Report.pdf

Poloma, M. M., \& Pendleton, B. F. (1989). Exploring types of prayer and quality of life: A research note. Review of Religious Research, 31, 46-53.

Shumskiy, V., \& Klimochkina, A. (2018). Religiosity and existential fulfillment of Muslims and Buddhists living in Russia. Existenzanalyse, 35(2), 19-30.

Shumsky, V. B., Ukolova, E. M., Osin, E. N., \& Lupandina, Y. D. (2016). Measuring existential fulfillment: An original Russian version of Test of Existential Motivations. Psychology. Journal of the Higher School of Economics, 13(4), 763-788. (in Russian).

A.Yu. Klimochkina - Lecturer, The Russian Presidential Academy of National Economy and Public Administration.

Research Area: existential psychology, psychology of religion, psychological well-being and mental health.

E-mail: anaklimochkina@yandex.ru 
Психология. Журнал Высшей школы экономики.

2021. T. 18. № 1. C. 211-223. DOI: 10.17323/1813-8918-2021-1-211-223

\title{
ЭФФЕКТ ВЗГЛЯДА-ПОДСКАЗКИ В ВИРТУАЛЬНОЙ СРЕДЕ: ВЛИЯНИЕ СОЦИАЛЬНОЙ УСТАНОВКИ И СОЦИАЛЬНОЙ ДИСТАНЦИИ
}

\author{
А.О. ПЕТРОВА , Е.Г. ЛУНЯКОВА \\ ${ }^{a}$ Московский государственньй университет имени М.В. Ломоносова, 119991, Россия, Москва, \\ Ленинские горы, д. 1 \\ ${ }^{b}$ Национальньй исследовательский университет «Высшая школа экономики», 101000, Россия, \\ Москва, ул. Мясницкая, д. 20 \\ ' Российская академия народного хозяйства и государственной службы при Президенте \\ Российской Федеращии, 119571, Россия, Москва, просп. Вернадского, д. 82, стр. 1
}

\begin{abstract}
Резюме
Пространственное внимание людей, вовлеченных в совместную деятельность, часто направлено на одни и те же объекты среды. При этом перенаправление взгляда одного из партнеров становится средством управления вниманием других. Можно предположить, что на выраженность активно исследуемого в последние десятилетия эффекта взгляда-подсказки будут оказывать влияние такие социально-психологические факторы, как установка в отношении подсказывающего и социальная дистанция между испытуемым и подсказывающим. Для проверки этих предположений была создана виртуальная 3D-среда, в которой был реализован модифицированный вариант методики подсказки М. Познера с соавт. (Posner et al., 1978). Использовался межгрупповой экспериментальный план. Для одной группы испытуемых антропоморфный аватар, дающий подсказку взглядом, выступал, согласно предварительной инструкции, в роли помощника, для другой - в роли человека, оценивающего действия испытуемого. Аватар мог давать верные и неверные подсказки взглядом относительно места появления целевого объекта. Обе группы проходили по две экспериментальные серии, различавшиеся дистанцией между испытуемым и аватаром: 1.5 м (комфортная дистанция, соответствующая зоне формальных социальных контактов) и 1 м (некомфортная дистанция, соответствующая зоне личных контактов). Эффект взгляда-подсказки был выявлен во всех экспериментальных условиях в виртуальной среде. При этом он был сильнее выражен в условиях «помогающей» установки, чем в условиях «оценивающей». В условиях помогающей установки эффект был несимметричен: выигрыш при верной подсказке оказался меньше, чем задержка реакции на стимул при неверной. Для обеих установок эффект взгляда-подсказки сильнее проявлялся при дистанции 1 м до аватара, чем при дистанции 1.5 м. Последнее может быть связано как с большими угловыми размерами подсказки, так и с размыванием границ личной зоны в виртуальной среде. Результаты исследования могут быть использованы при создании обучающих виртуальных сред.
\end{abstract}

Ключевые слова: эффект взгляда-подсказки, пространственное внимание, виртуальная реальность, социальная установка, социальная дистанция.

Участие М.В. Фаликман поддержано грантом РФФИ и Фонда «За русский язык и культуру» (РЯИК) в Венгрии № 20-511-23001. 
Все больше внимания в современной когнитивной психологии уделяется изучению влияния мотивационных, эмоциональных и социальных факторов на когнитивные процессы человека. Например, важную роль в управлении пространственным вниманием играет взгляд другого человека, что выражается в активно изучаемом в последние два десятилетия эффекте взгляда-подсказки (Friesen, Kingstone, 1998). Однако накоплено недостаточно данных о том, насколько этот эффект подвержен влиянию социальных факторов, таких как установка в отношении подсказывающего и межличностная дистанция.

Наиболее распространенной методикой исследования пространственного внимания является методика подсказки, которую разработали М. Познер с коллегами (Posner, 1980; Posner et al., 1978). Методика нацелена на изучение «скрытой» ориентировки внимания, не связанной с движениями глаз.

Согласно результатам исследований Познера, верная центральная подсказка-стрелка, указывающая в направлении целевого стимула, ускоряет двигательный ответ на его появление, а неверная - замедляет, но только тогда, когда количество верных подсказок существенно превышает количество неверных. Если же частота предъявления верных и неверных подсказок одинакова, эффект подсказки не проявляется. Однако в последующих исследованиях при использовании в качестве центральной подсказки схематического или фотографического изображения лица человека со взглядом, указывающим вправо или влево (Driver at al., 1999; Kingstone et al., 2003), в случае правильной подсказки вне зависимости от частоты ее предъявления время реакции испытуемого снижалось. В этом плане подсказка взглядом сродни ориентировке внимания на периферические подсказки, дающие выигрыш в случае верной подсказки без проигрыша при неверной (Jonides, 1981).

Эффект более быстрого перенаправления пространственного внимания в соответствии с направлением взгляда другого человека получил название эффекта взгляда-подсказки (gaze-cueing effect) (Friesen, Kingstone, 1998; Kuhn, Kingstone, 2009).

Было установлено, что время реакции в случае с верной подсказкой значимо меньше по сравнению с временем реакции для проб с нейтральной или неверной подсказками. Этот эффект возникает относительно быстро на коротких временны́х интервалах (от 105 мс) и исчезает на более длинных временны́х интервалах.

Дальнейшие исследования показали, что на эффект взгляда-подсказки могут оказывать влияние различные социальные факторы. Среди этих факторов - политические взгляды испытуемого (Dodd et al., 2011), знакомость лиц людей, дающих подсказку взглядом (Deaner et al., 2007), социальный статус этих людей (McDonald, Tatler, 2013), надежность, приписываемая им испытуемыми и модулируемая уровнем тревожности испытуемых (Süßenbach, Schönbrodt, 2014).

Нам представляется, что одним из важных факторов, который может оказывать влияние на выраженность эффекта взгляда-подсказки, является установка испытуемого в отношении подсказывающего: в частности, воспринимается ли он испытуемым как помощник в решении экспериментальной задачи 
или как человек, выносящий оценочное суждение относительно его возможностей. Мы предполагаем, что помогающая установка вызовет больше доверия к виртуальному персонажу у испытуемого, а потому он будет больше ориентироваться на подсказку, что положительно повлияет на выраженность эффекта взгляда-подсказки.

В свою очередь, влияние установки в отношении подсказывающего может модулироваться таким фактором межличностного взаимодействия, как социальная дистанция. В межличностном общении Э. Холл (Hall, 1968) определяет четыре зоны: интимная $(<0.45$ м), личная $(0.45-1.2$ м), социальная (от 1.2 до 3.6 м) и общедоступная (> 3.6 м). С незнакомыми людьми в формальных контактах человек предпочитает общаться, удерживая партнера в зоне социальной дистанции. Допуск в личную зону больше характерен для неформального и дружеского общения, присутствие в этой зоне незнакомого человека может вызывать дискомфорт. Для изучения влияния социальной дистанции и установки на эффект взгляда-подсказки возможно применение технологии виртуальной реальности.

Современные исследования показывают, что восприятие участниками человеческих аватаров, «виртуальных партнеров по общению», существенно не отличается от восприятия реальных людей. 3D-модели человека вызывают у испытуемых сопоставимые физиологические, поведенческие и нейробиологические реакции, как если бы они взаимодействовали с людьми в реальных условиях (Borst, Gelder, 2015). Это сходство в восприятии не ограничивается внешним видом виртуальных персонажей, оно также распространяется на восприятие эмоциональных выражений лица и тела (McDonnell et al., 2008).

В некоторых исследованиях (Peters et al., 2018; Zibrek et al., 2017) выявлено сходство реакций испытуемых на разные типы межличностной дистанции при взаимодействии с реальными людьми и с аватарами в виртуальной среде. Это в целом соответствует гипотезе, согласно которой социальные расстояния внутри смешанной реальности с виртуальными персонажами сопоставимы с теми, которые были найдены для межличностных расстояний человек-человек (Lambert, 2004).

В нашем исследовании мы проверяли гипотезы о том, что тип установки, заданный инструкцией, и расстояние между испытуемым и аватаром, дающим подсказку, влияют на выраженность эффекта взгляда-подсказки в виртуальной среде.

1) При «помогающей» социальной установке эффект взгляда-подсказки будет выражен сильнее, чем при «оценивающей» установке.

2) При более комфортной социальной дистанции между испытуемым и аватаром эффект будет выражен больше, чем при некомфортной.

\section{Методика}

Испытуемые: 46 человек (24 женщины и 22 мужчины) в возрасте от 18 до 28 лет с нормальным или скорректированным до нормального зрением. 
Для исследования эффекта подсказки в различных условиях была создана экспериментальная виртуальная 3D-среда. В ней была реализована авторская модификация методики М. Познера (Posner et al., 1978) с подсказкой взглядом, по которой испытуемые должны были как можно быстрее ответить на появление сигнала справа или слева от аватара нажатием на кнопку.

\section{Annapamypa}

Для предъявления стимулов в 3D-среде использовался шлем виртуальной реальности HTC Vive, угол обзора $110^{\circ}$, разрешение $2160 \times 1200$, разрешение дисплеев для каждого глаза 1200 х 1080, частота обновления 90 Гц. Ответы испытуемых регистрировались при помощи двух беспроводных совместимых со шлемом виртуальной реальности контроллеров.

Для программирования 3D-среды в эксперименте была использована интегрированная среда разработки Unity.

В качестве стимулов выступали виртуальные объекты в виде двух одинаковых серых шаров (диаметр 0.05 м), подвешенных на веревках для обеспечения более точного субъективного определения испытуемыми расстояния до них. Шары находились слева и справа от центральной точки напротив испытуемого, на угловом расстоянии 7 градусов, на расстоянии 70 см.

В роли подсказки выступало направление взгляда аватара - 3D-модели человека в полный рост мужского пола, нормального телосложения, рост подстраивался под рост испытуемого (от 140 до 210 см) так, чтобы глаза аватара находились на линии взгляда испытуемого. Средние черты лица, выразительные глаза. Анимация покоя, без саккад. Во время предъявления фиксационной точки анимация отсутствовала (см. рисунок 1 ).

Аватар располагался напротив испытуемого на платформе, расчерченной сеткой больших квадратов для верной оценки расстояния до аватара. Окружающее пространство - темно-серое.

Рисунок 1

Виртуальная среда для эксперимента: аватар-подсказка, объекты

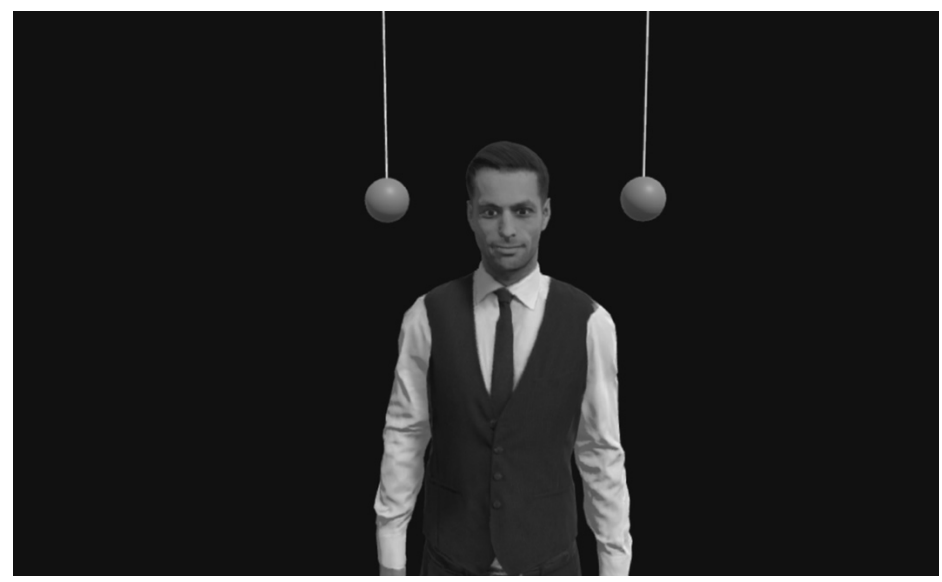


Воспринимаемое расстояние между испытуемым и аватаром в разных экспериментальных условиях составляло 1.5 м или 1 м - согласно предыдущим исследованиям (Hall, 1968; Peters et al., 2018), «комфортное» и «некомфортное».

\section{Прочедура эксперимента}

Использован межгрупповой экспериментальный план. Испытуемые поделены на две группы (23 человека в каждой), для каждой группы дается одна из двух инструкций, которая предполагает разную установку по отношению к аватару-подсказке (помощник или оценщик). Перед испытуемым ставилась задача сфокусироваться на фиксационной точке и как можно быстрее нажать на правую или левую кнопку контроллера, когда справа или слева вспыхнет шар. Испытуемым одной группы сообщалось, что исследователь участвует в разработке системы для поддержки внимания при поиске объектов на экране компьютера и что перед ними находится аватар-помощник, который постарается облегчить решение задачи, но иногда может ошибаться и давать неверную подсказку. Испытуемым другой группы говорилось, что исследователь участвует в разработке системы для оценки переключаемости внимания в рамках батареи методик для подбора и оценки персонала и что аватар будет оценивать, насколько быстро и правильно испытуемый решил задачу, указывая взглядом, где загорится шар, и иногда давая неверную подсказку.

Для каждой группы эксперимент состоял из двух этапов по 200 проб в каждом, из них 100 - верные подсказки, 50 - неверные, 50 - нейтральные (аватар не переводил взгляд). Этапы различались расположением аватара-подсказки - на комфортной социальной дистанции от испытуемого (1.5 м) и на некомфортной (1 м). Испытуемые проходили этапы в разном порядке, перерыв между ними составлял 5 минут, общая продолжительность эксперимента составляла в среднем 20 минут.

Эксперимент начинался с тренировочной серии из 6 проб для ознакомления с процедурой.

Перед началом каждой пробы (см. схему на рисунке 2) в центре (на переносице аватара) предъявлялась фиксационная точка в течение 1000/2000 мс. В качестве подсказки выступал взгляд аватара. Подсказка могла быть верной (в том направлении, где затем появлялся целевой стимул), неверной (в противоположном направлении) и нейтральной

Регистрировались время реакции испытуемого на стимул и правильность ответа.

\section{Результаты}

\section{Обработка результатов}

Сравнивалось время реакции испытуемого на целевой стимул в условиях с верной и неверной подсказкой, а также ее отсутствия при разной дистанции 


\section{Схема экспериментальной пробы}

Рисунок 2

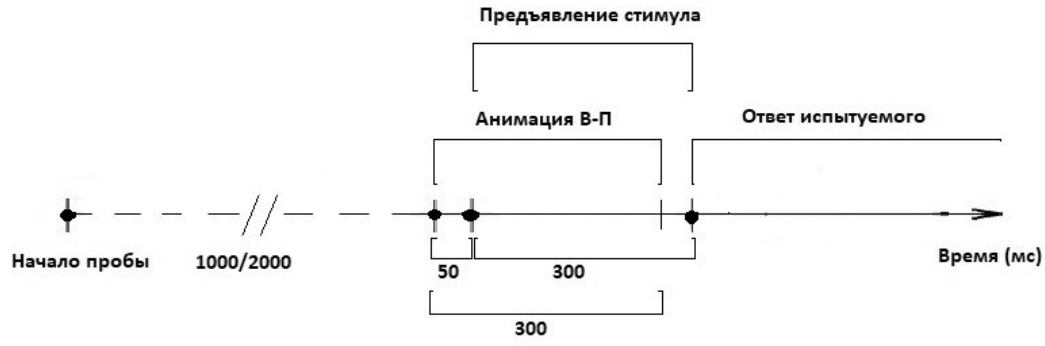

между испытуемым и аватаром и при разной установке («помогающей» и «оценивающей»). Данные обрабатывались с помощью статистических пакетов SPSS 23.0 и Jamovi 1.1. Использовались критерий Манна-Уитни для независимых выборок и многофакторный дисперсионный анализ с повторными измерениями с поправкой на сферичность Гринхауса-Гейсера и поправкой Бонферрони на множественные сравнения.

Перед проведением анализа были исключены данные для случаев, когда испытуемый делал ошибку в локализации стимула (право/лево) либо не давал ответа вообще. Данные были усреднены по каждому случаю для каждого испытуемого, так как выборка неоднородна по количеству проб для разного типа подсказок.

\section{Описание результатов}

Результаты дисперсионного анализа приведены в таблице 1.

Был получен эффект взгляда-подсказки для всех условий: при правильной подсказке скорость поиска уменьшалась, а при неправильной - увеличивалась в сравнении с нейтральной подсказкой.

Многофакторный анализ с повторными измерениями не выявил эффекта установки $(p=0.550)$, однако выявил его значимое взаимодействие с фактором подсказки.

Таблица 1

Влияние и взаимодействие факторов «Подсказка», «Расстояние», «Установка»

\begin{tabular}{|l|c|c|c|c|}
\hline \multicolumn{1}{|c|}{ Факторы/Взаимодействие факторов } & $\mathbf{F}$ & $\mathbf{d f}$ & $\boldsymbol{p}$ & $\boldsymbol{\eta}_{\mathbf{p}}^{\mathbf{2}}$ \\
\hline Подсказка & 531.12 & 2.88 & 0.001 & 0.923 \\
\hline Расстояние & 6.07 & 1.44 & 0.018 & 0.121 \\
\hline Установка & 0.36 & 1.44 & 0.550 & 0.008 \\
\hline Подсказка $\times$ Установка & 38.02 & 1.44 & $<0.001$ & 0.464 \\
\hline Расстояние $\times$ Установка & 0.25 & 1.44 & 0.618 & 0.006 \\
\hline Подсказка $\times$ Расстояние & 39.71 & 1.88 & $<0.001$ & 0.474 \\
\hline Подсказка $\times$ Расстояние $\times$ Установка & 0.43 & 2.88 & 0.601 & 0.010 \\
\hline
\end{tabular}


Обнаружены значимые различия по фактору расстояния ( $p=0.018)$, а также значимое взаимодействие фактора подсказки и фактора расстояния для всех случаев.

Сравнение выборочных средних по критерию Манна-Уитни показало, что эффект взгляда-подсказки выражен больше в случае с «помогающей» установкой, чем в случае с «оценивающей» установкой (см. рисунки 3,4$)$.

Также эффект выражен больше при дистанции 1 м, которая была обозначена нами как «некомфортная», чем при «комфортной» дистанции 1.5 м (см. рисунки 5, 6).

Взаимодействия между фактором установки и фактором расстояния не выявлено.

Рисунок 3

Среднее время реакции для разных типов установок при расстоянии 1.5 м (мс).

Вертикальные штрихи соответствуют стандартному отклонению

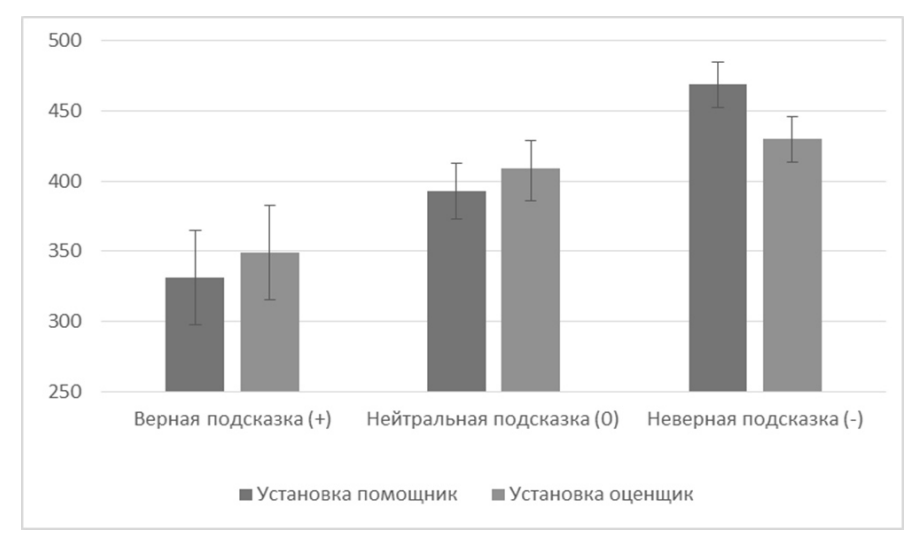

Рисунок 4

Среднее время реакции для разных типов установок при расстоянии 1 м (мс).

Вертикальные штрихи соответствуют стандартному отклонению

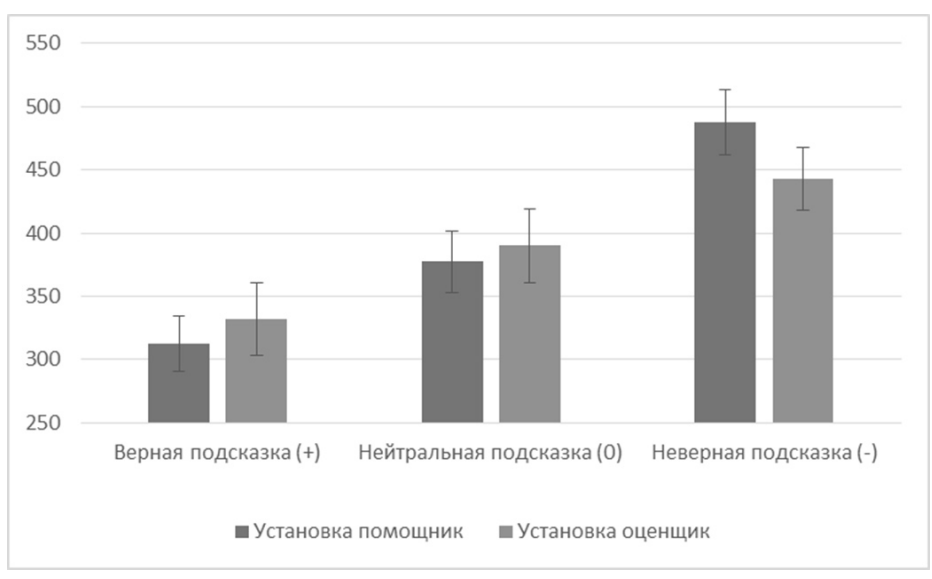


Рисунок 5

Среднее время реакции при разных расстояниях при установке «помощник» (мс). Вертикальные штрихи соответствуют стандартному отклонению

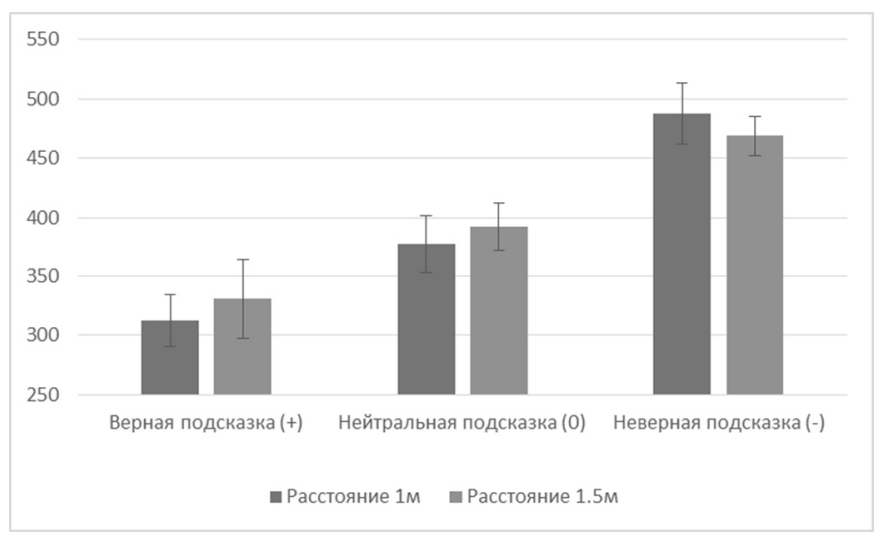

Рисунок 6

Среднее время реакции при разных расстояниях при установке «оценщик» (мс).

Вертикальные штрихи соответствуют стандартному отклонению

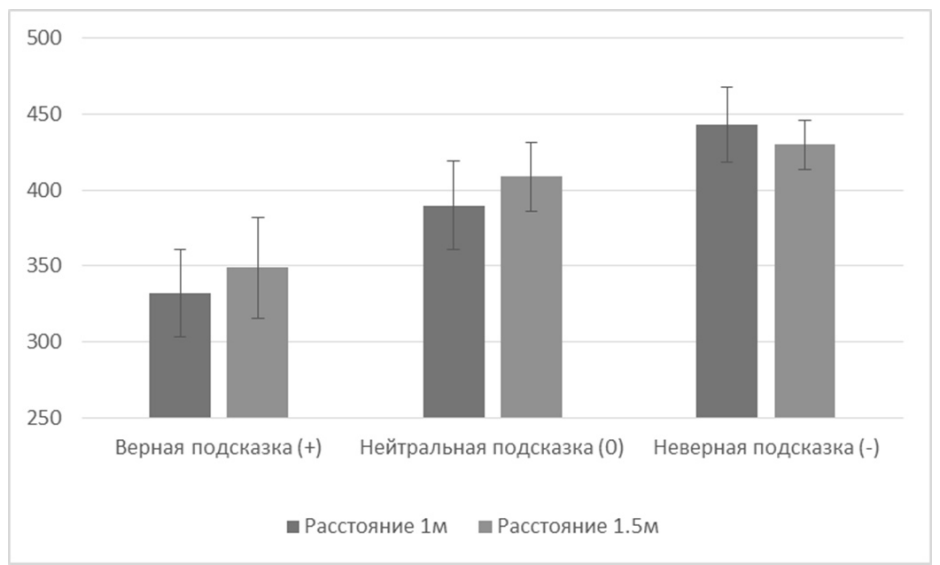

\section{Обсуждение результатов}

При верной или нейтральной подсказке в условии помогающей установки время реакции испытуемого в среднем меньше, чем при оценивающей установке. Возможно, это ускорение ответа связано с тем, что в ситуации отсутствия внешней оценки человек испытывает меньшее напряжение, связанное со страхом совершить ошибку. В случае с неверной подсказкой время реакции испытуемого, наоборот, возрастает при помогающей установке. Мы объясняем это тем, что испытуемый больше доверяет «помогающей» подсказке, 
следовательно, его больше сбивает неверная подсказка, и ему требуется больше времени, чтобы локализовать стимул.

Таким образом, в целом эффект взгляда-подсказки выражен сильнее при помогающей установке, чем при оценивающей установке. Вероятно, при оценивающей установке испытуемый имплицитно настроен на то, что ему могут дать неверные подсказки, а потому в случае с неверной подсказкой его внимание быстрее возвращается к верному местоположению стимула. И напротив, доверие к подсказке при помогающей установке дает сильно выраженный отрицательный эффект неверной подсказки, намного более существенный, чем эффект верной подсказки, тогда как в классическом эксперименте Познера эффекты верной и неверной подсказки примерно одинаковы (Posner et al., 1978). Также в исследовании К. Фризена и А. Кингстоуна со взглядомподсказкой (Friesen, Kingstone, 1998) не было обнаружено значимых различий между нейтральной и неверной подсказкой. Нельзя исключить, что наши данные могут отличаться в силу того, что в эксперименте 1998 г. были использованы схематичные изображения человеческих лиц, а в нашем - реалистичная 3D-модель человека.

Мы можем предположить, что помогающая установка - более социально желательная, чем оценивающая, что располагает к большему доверию и, следовательно, дает больший эффект подсказки. Это согласуется с результатами других исследований, в которых социально желательные черты воспринимаемого человека увеличивают склонность следовать направлению его взгляда (Deaner et al., 2007; Pavan et al., 2011; Süßenbach, Schönbrodt, 2014). Однако не все так однозначно: в двухэтапном эксперименте 2017 г. (Carraro et al., 2017) были получены противоположные результаты. На этапе обучения разные лица систематически ассоциировались с поощряемым или порицаемым поведением, после чего они были использованы в качестве стимулов в задаче со взглядом-подсказкой. Обнаружилось, что лица, связанные с антисоциальным поведением, нарушающим нормы, вызывают более сильные эффекты подсказки, чем лица, связанные с социально поощряемым поведением. Авторы исследования связывают это с тем, что взгляд людей, которым приписывается девиантное поведение, может быть сигналом, позволяющим лучше контролировать потенциально опасную ситуацию. Тем не менее мы можем предположить, что при оценивающей установке позиция аватара не воспринималась испытуемыми как социально нежелательная, в то же время помогающая установка имела больший эффект в силу того, что провоцировала испытуемых больше доверять аватару.

Противоречит нашему исходному предположению то, что эффект подсказки выражен больше при дистанции 1 м, которую мы рассматривали как «некомфортную», чем при «комфортной» дистанции 1.5 м, вне зависимости от того, какая установка была задана инструкцией. Полученный результат может объясняться большей субъективной удаленностью от испытуемого, а следовательно, и качеством опознания объекта. Кроме того, при отдалении аватара на расстояние в 1.5 м происходило уменьшение угловых размеров подсказки. Также можно предположить, что в ситуации коммуникации с виртуальным 
партнером восприятие испытуемым личных границ может размываться, в том числе в зависимости от типа решаемой задачи. Наконец, при разработке процедуры эксперимента не было предусмотрено никаких дополнительных тестов для субъективной оценки испытуемыми комфортности расстояния до аватара. Все это следует учесть при дальнейшем исследовании социальной дистанции в виртуальной реальности.

Таким образом, в нашей работе впервые получен эффект взгляда-подсказки в виртуальной среде, а также установлено, что выраженность этого эффекта меняется в зависимости от установки испытуемого в отношении аватара, дающего подсказку.

Результаты исследования могут быть использованы при создании обучающих виртуальных сред. Одним из основных элементов обучающей виртуальной среды является аватар-тьютор, в задачи которого входит максимально эффективное переключение внимания участников между элементами среды с целью более продуктивного обучения. Вопрос об относительном пространственном расположении участника обучения и аватара также важен в создании обучающих сред, поскольку тоже может оказывать влияние на эффективность переключения внимания, однако данный вопрос нуждается в дальнейшем уточнении.

Ссылки на зарубежные источники см. в разделе References после англоязычного блока.

Петрова Анастасия Олеговна - выпускник, факультет психологии, МГУ имени М.В. Ломоносова.

Сфера научных интересов: виртуальная реальность, зрительное внимание, психология личности.

Контакты: anastasiyap2305@yandex.ru

Лунякова Елизавета Геннадьевна - старший научный сотрудник, лаборатория «Восприятие», факультет психологии, МГУ имени М.В. Ломоносова, кандидат психологических наук.

Сфера научных интересов: психология восприятия, движения глаз в перцептивных процессах.

Контакты: eglun@mail.ru

Фаликман Мария Вячеславовна - руководитель, профессор, департамент психологии, факультет социальных наук; ведущий научный сотрудник, лаборатория когнитивных исследований, НИУ ВШЭ; научный сотрудник, ИОН РАНХиГС, доктор психологических наук.

Сфера научных интересов: зрительное внимание, перцептивные задачи, нисходящие влияния на обработку зрительной информации.

Контакты: mfalikman@hse.ru 


\title{
Gaze Cueing in Virtual Reality: Effects of Social Set and Social Distance
}

\author{
A.O. Petrova ${ }^{a}$, E.G. Luniakova ${ }^{\mathrm{a}}$, M.V. Falikman ${ }^{\mathrm{b}, \mathrm{c}}$ \\ ${ }^{a}$ Lomonosov Moscow State University, 1 Leninskie Gory, Moscow, 119991, Russian Federation \\ ${ }^{b}$ HSE University, 20 Myasnitskaya Str., Moscow, 101000, Russian Federation \\ ${ }^{c}$ Russian Presidential Academy of National Economy and Public Administration (The Presidential \\ Academy, RANEPA), 82 build. 1, Prospect Vernadskogo, Moscow, 119571, Russian Federation
}

\begin{abstract}
Spatial attention of people involved in a co-operative activity is often directed to the same objects in the environment. At the same time, one of the partners' gaze redirection can be involved in controlling attention of others. It could be assumed that the degree of the gaze cueing effect, which has become a focus of growing research interest in recent decades, might be influenced by such social psychological factors as one's attitude towards the partner and social distance between the partners. To test these assumptions, a virtual 3D environment was created, in which a modified version of the cueing paradigm by Posner et al. (1978) was implemented. An intergroup experimental design was used. For one group of participants, the anthropomorphic avatar was introduced in the instruction as a "virtual assistant", for the other group, it was presented as a "virtual assessment specialist". The avatar could provide valid and invalid gaze cues regarding the future target location. Both groups participated in two experimental sessions, in one session the distance between the participant and the avatar was $1.5 \mathrm{~m}$ (comfortable distance corresponding to the zone of formal social contacts) and in the other session the distance was 1 $\mathrm{m}$ (uncomfortable distance corresponding to the zone of personal contacts). The gaze cueing effect was observed through all experimental conditions in a virtual environment. However, it was more pronounced for the "assisting" set than for the "assessing" one. Interestingly, for the assisting set, the effect was asymmetric: the gain due to a valid cue turned out to be less pronounced than the delay in the response to a target after an invalid cue. For both conditions, the gaze cueing effect was more pronounced at a distance of $1 \mathrm{~m}$ between the participant and the avatar than at a distance of $1.5 \mathrm{~m}$. The latter result could be associated either with the large angular dimensions of a gaze cue or with blurring of boundaries of the personal zone in the virtual environment. The results can be applied in the development of educational virtual environments.
\end{abstract}

Keywords: Gaze cueing effect, spatial attention, virtual reality, social set, social distance.

\section{References}

Borst, A. W., \& Gelder, B. D. (2015). Is it the real deal? Perception of virtual characters versus humans: An affective cognitive neuroscience perspective. Frontiers in Psychology, 6, 576.

Carraro, L., Dalmaso, M., \& Castelli, L. (2017). The appeal of the devil's eye: social evaluation affects social attention. Cognitive Processing, 18(1), 97-103. 
Deaner, R. O., Shepherd, S. V., \& Platt, M. L. (2007). Familiarity accentuates gaze cueing in women but not men. Biological Letter, 3, 64-67.

Dodd, M. D., Hibbing, J. R., \& Smith, K. B. (2011). The politics of attention: gaze-cuing effects are moderated by political temperament. Perception, 73(1), 24-29.

Driver, J., Davis, G., Ricciardelli, P., Kidd, P., Maxwell, E., \& Baron-Cohen, S. (1999). Gaze perception triggers reflexive visuospatial orienting. Visual Cognition, 6, 509-540.

Friesen, C. K., \& Kingstone, A. (1998). The eyes have it! Reflexive orienting is triggered by nonpredictive gaze. Psychonomic Bulletin and Revier, 5, 490-495.

Hall, E. T. (1968). Proxemics. Current Anthropology, 2(9). 83-108.

Jonides, J. (1981). Voluntary versus automatic control over the mind's eye's movement. In J. B. Long \& A. D. Baddeley (Eds.), Attention and performance IX (pp. 187-203). Hillsdale, NJ: Erlbaum.

Kingstone, A., Smilek, D., \& Ristic, J. (2003). Attention, researchers! It is time to take a look at the real world. Current Directions in Psychological Science, 12, 176-180.

Kuhn, G., \& Kingstone, A. (2009). Look away! Eyes and arrows engage oculomotor responses automatically. Attention, Perception and Psychophysics, 71, 314-327.

Lambert, D. (2004). Body language. London, UK: Harper Collins.

McDonald, R. G., \& Tatler, B. W. (2013). The effect of social roles on gaze cue utilization in a realworld collaboration. In Proceedings of 35th Annual Cognitive Science Society Meeting (CogSci 2013) (pp. 942-947). Austin, TX: Cognitive Science Society.

McDonnell, R., Jorg, S., \& McHugh, J. (2008). Evaluating the emotional content of human motions on real and virtual characters. In Proceedings of the 5th Symposium on Applied Perception in Graphics and Visualization APGV, Los Angeles, CA, USA, 9-10 August 2008 (pp. 67-74). New York, NY: ACM Press.

Pavan, G., Dalmaso, M., \& Galfano, G. (2011). Racial group membership is associated to gaze-mediated orienting in Italy. Journal of Intellectual Disability Research, 14, 317-326.

Peters, C., Li, C., Yang, F., Avramova, V., \& Skantze, G. (2018). Investigating social distances between humans, virtual humans and virtual robots in mixed reality. In 17th International Conference on Autonomous Agents and Multiagent Systems (AAMAS 2018) (p. 437). Richland, SC: International Foundation for Autonomous Agents and Multiagent Systems.

Posner, M. I. (1980). Orienting of attention. Quarterly Journal of Experimental Psychology, 32, 3-25.

Posner, M. I., Nissen, M. J., \& Ogden, W. C. (1978). Attended and unattended processing modes: The role of set for spatial location. In H. L. Pick \& I. J. Saltzman (Eds.), Modes of perceiving and processing information (pp. 160-174). Hillsdale, NJ: Lawrence Erlbaum Associates.

Süßenbach, F., \& Schönbrodt, F. (2014). Not afraid to trust you: Trustworthiness moderates gaze cueing but not in highly anxious participants. Journal of Cognitive Psychology, 26, 670-678.

Zibrek, K., Kokkinara, E., \& McDonnell, R. (2017). Don't stand so close to me: investigating the effect of control on the appeal of virtual humans using immersion and a proximity-based behavioral task. In Proceedings of the ACM Symposium on Applied Perception (SAP '17) (Vol 41, art. 3, p. 1-11). New York, NY: ACM.

Anastasia O. Petrova - Graduate, Faculty of Psychology, Lomonosov Moscow State University. Research Area: virtual reality, visual attention, personality psychology.

E-mail: anastasiyap2305@yandex.ru 
Elizaveta G. Luniakova - Senior Research Fellow, Laboratory of Perception, Faculty of Psychology, Lomonosov Moscow State University, PhD in Psychology.

Research Area: psychology of perception, eye movements and perception.

E-mail: eglun@mail.ru

Maria V. Falikman - Head, Professor, School of Psychology; Lead Research Fellow, Cognitive Research Laboratory, HSE University; Research Fellow, Institute for Social Sciences, RANEPA, PhD in Psychology, Dr.habil.

Research Area: visual attention, perceptual tasks, top-down influences upon visual information processing.

E-mail: mfalikman@hse.ru 


\title{
TYPES OF VOCALIZATIONS IN SELF-EXPRESSION AND SELF-INQUIRY
}

\begin{abstract}
A.V. ZIRKO
Abstract

The author discusses vocalizations as using non-verbal voice sounds in self-expression and selfinquiry. The purpose of the study was to investigate the experience of self-expression and selfinquiry through vocalizations in the situations of valuing and evaluating. The researcher hypothesized that placing an individual in a safe place for self-expression on the conditions of valuing creates more authentic and genuine feelings, helping to reveal their authentic voice. On the contrary, placing a person under conditions of evaluating and impressiveness leads to a less authentic feeling and sounding. Two groups of participants were separated. The expressive group was created using the condition of valuing. The impressive group was created using the condition of evaluating. Participants in both groups used their voices to express themselves performing research tasks and then filled out the survey applications reflecting the sounder's body, voice, feelings and listener's feelings during the research. The application's indicators were grouped into six factors: "Psychophysiological authenticity", "Psychological authenticity", "Satisfaction", "Vocalization change", "Perceived emotional involvement", and "Perceived satisfaction". The multilinear mixed effect regression models were built to investigate the influence of the research conditions on these factors and their dynamics. The t-test was used to compare the results between the groups. Significant differences were revealed with the factors "Psychophysiological authenticity", "Psychological authenticity", "Satisfaction", and "Perceived satisfaction". They were greater in the expressive group than they were in the impressive group. The indicators of "Perceived satisfaction" were growing.
\end{abstract}

Keywords: vocal psychotherapy, vocalizations, authenticity, inauthenticity, expressiveness, impressiveness.

\section{Introduction}

In the 20th century, scientists from different branches of humanities began researching the use of music and voice for psychotherapy (Austin, 2008; Hiller \& Gardstrom, 2018; Kern \& Tague, 2017; Lewis, 2017; Lindblad, 2016; Monti \& Austin, 2017; Zirko \& Orlov, 2017a). Although there are many vocal practices in self-expression and self-inquiry (Baker, 2015; Stewart \& McAlpin, 2016), little

The article was prepared within the framework of the HSE University Basic Research Program and funded by the Russian Academic Excellence Project "5-100". 
research has been done due to the requirement of strong interdisciplinary skills in this field (Petrushin, 2009). The relevance of this study lies in the integration of the theoretical analysis and results of the empirical study. New vocal methods have been applied, examined, and described. Because there are few investigations into vocal psychotherapy (Markovich \& Tatsumi, 2015; Vaillancourd, Da Costa, Han, \& Lipski, 2018), this study is meant to be exploratory as a first step towards larger empirical investigations.

The purpose of the study was to investigate the experience of self-expression and self-inquiry through vocalizations in situations of valuing and evaluating. Vocalizations are described as expressions of individual experiences with non-verbal voice sounds (Zirko \& Orlov, 2017b) facilitating self-expression, self-inquiry, self-healing, and finding an authentic voice for an individual. The term "authentic vocalizations" was firstly introduced by Sylka Uhlig (2006). The first primary sounds such as a sudden laughter or a scared scream are the most open, authentic, and free voices; they are not influenced by cultural limitations and express a person's inner experience. Inauthentic vocalizations are often limited by cultural norms and do not express a genuine experience (ibid.). Luisa Pascale (2005) classified two types of singing: public and community singing, defining public singing as professional singing on the stage requiring singing skills, and community singing as singing in a company of friends, to reveal the idea that every individual is musically gifted. Public singing is considered impressive, supposing evaluation from a listener. Community singing is expressive, supposing valuing from a listener. Its purpose is to express an individual's inner experience (Orlov, 2015). Community singing is often used in psychotherapy.

The hypothesis of the research was formulated according to the theoretical model of four vocalization types suggested in this study. They create two continuums and four poles: authenticity/inauthenticity and expressiveness/impressiveness. This model strongly correlates with the ability to find an authentic and genuine voice through vocal self-expressions that are expressive vocalizations (Zirko \& Orlov, 2017a; Rogers, 1993). To classify vocalizations, the author proposes a continuum of authentic and inauthentic vocalizations. It stems from the ideas of congruent and incongruent behavior and authenticity and inauthenticity (Babakina, 2016; Rogers, 1993). The continuum of expressive and impressive vocalizations is based on the idea of expressive and impressive arts (Orlov, 2015). Expressive vocalizations express an individual's feelings and impressive vocalizations help a person impress somebody who is listening to them. The individuals who are expressing their experiences with the sounds of their voices will be described as sounders and the individuals who are listening to their self-expression will be described as listeners below.

Next, a wide variety of vocalizations is located on a plain built with two described continuums and four poles (Zirko \& Orlov, 2017b). Authentic and expressive vocalizations express an individual's experience in a situation of valuing. Authentic impressive vocalizations impress a listener, but they do not fully express an individual's true experience. Inauthentic expressive vocalizations distort an individual's inner experience. Inauthentic impressive vocalizations do not impress 
a listener and do not express an individual's experience. Based on this theoretical model, the following hypothesis of the empirical research has been formulated. Expressive vocalizations which individuals use for self-expression and self-inquiry in a situation of valuing receive higher scores of authenticity in comparison to the impressive vocalizations of individuals who are placed into a situation of outer and inner evaluation and are working on the artistic impressiveness and beauty of their voices.

More thorough examination of the continuum of expressiveness/impressiveness lays in the future perspectives of the study. Here the author researched the peculiarities of different types of vocalizations in psychological vocal practices.

\section{Method}

To research this problem the following situations were modeled: a situation of expressiveness and valuing, when the participants could live through their experience and be fully expressive (Melnikova \& Orlov, 2015) and a situation of impressiveness and evaluating, when the participants had to make a specific impression on a listener (Pascale, 2005).

\section{Participants}

There were 42 participants in the study, including 9 men and 33 women. The average age was 35 years old ( $\mathrm{SD}=8.97$, range: $20-57)$. At this age clients typically apply for psychotherapy. The study did not count gender as a factor of selfinquiry. The research was announced on social platforms and at the website of the Doctoral School of Psychology at the National Research University Higher School of Economics. The announcement described the research purpose and procedure, and included the researcher's contacts. Volunteers of the research completed the introductory application and discussed the investigation with the researcher to determine their goals. Each participant chose one goal (self-expression or impression) and worked on it during the research. They joined either the expressive or the impressive group based on their choices. There were 17 people in the impressive group ( 7 men and 10 women) and 25 people in the expressive group ( 2 men and 23 women). The average age in the impressive group was 35 years old $(\mathrm{SD}=9.26$, range: $23-55)$. The average age in the expressive group was 34 years old $(\mathrm{SD}=8.56$, range: 20-57). Next, the participants formed pairs for vocal sessions. Because of time limitations, they were paired up randomly.

\section{Materials}

The introductory form consisted of 9 five-point graded scales and 1 open question for researching voice usage in different situations and conditions. It was used to enable the participants to identify their research goals. They completed this during the first session and provided in-depth responses orally while marking the multiple choices. The main form consisted of 9 five-point scales assessing the process 
and the result of vocalizing. The questions were matched with the criteria of the four types of vocalizations (see Appendix 1). They reflected the individual's body, voice, and feelings. The form for listeners consisted of 9 five-point scales. The listeners gave answers about what they had heard, described the characteristics of the individual's voice, how they were involved in the process of vocalizing and their own feelings (see Appendix 2).

\section{Procedure}

The participants partook in the research in pairs so that each individual could have a listener. Every session had the following order: sharing and warming up exercises (Linklater, Epp, \& Snow, 1976). Next was the first participant's sounding followed by discussion, feedback from the listener and filling out the research forms. Then the participants switched and repeated the same experiment. The sounding time limit was 7 minutes. The participants vocalized during four to twelve 90-minute sessions once a week. The situation of valuing was modeled in the expressive group. The situation of evaluation was modeled in the impressive group.

In the expressive group each participant was given the chance to sound freely, expressing their feelings and experiences. They were encouraged to listen to themselves, and live through their experience with the sounds of their voices. They valued this experience and positively related to it. After this the listener provided the participant who had just vocalized with their unconditional feedback about their vocalizations.

In the impressive group each participant was asked to represent a specific feeling. Several cards with different emotions were handed out. A participant took a card and represented the emotion written on it. The listener guessed which feeling was represented and gave the evaluative feedback on how the participant acted it out. The participants also evaluated their vocalizations during the task and whether they achieved the goal of communicating the emotion on the card.

\section{Results}

To analyze the main quantitative results of the research, 18 scales from the form for the participants who were vocalizing and the form for the participants who were listening, were grouped in 6 factors. These forms will be described as the form for sounders and the form for listeners below. Three factors each were created within the scales from the sounders' and listeners' forms. The scales of the sounder's satisfaction during and after vocalizing were combined in the factor "Satisfaction". The scales of satisfaction during and after vocalizing in the listener's form were combined in the factor "Perceived satisfaction". The correlation between these scales was significant $(r=.685, p<.001)$ for sounding individuals and $(r=.691$, $p<.001$ ) for listening individuals (sounders and listeners, correspondingly). The remaining 14 scales were grouped through exploratory factor analysis separately for the sounders' and listeners' forms. These remaining fourteen scales were most 
optimally grouped in 4 factors, two factors each for sounders and listeners (see Tables 1 and 2).

Each of the final six factors was given the following names and grouped the following scales with the highest factor loadings:

Factor 1 "Psychophysiological authenticity" included relaxedness of muscles, vocal freedom, naturalness, and ease of vocalizing.

Factor 2 "Psychological authenticity" included randomness, predictability of vocalizing, and correspondence between a sounder's feelings and vocalizations.

Factor 3 "Satisfaction" included satisfaction during and after vocalizing from the sounder's view.

Factor 4 "Vocalization change" included the pitch and intonations.

Factor 5 "Perceived emotional involvement" included loudness, the sounder's feelings, involvement, emotional background, the listener's emotional replies to vocalizations.

Factor 6 "Perceived satisfaction" included the scales of sounder's satisfaction during and after vocalizing from the listener's view.

For further analysis of the vocalization's dynamics and the influence of the research conditions on vocalizations and the sounder's experience, 18 multilinear mixed effect regression models were built. They included 6 models by the meeting number and the group influencing each of the 6 factors, and 12 models by the meeting number in each group for each factor separately. The Benjamini-Hochberg procedure adjusted the p-values for multiple comparisons. Three models were significant (see Tables 3-5).

The "Psychological authenticity" factor was influenced by the group number $(\beta=.306 ; p=.048)$ but not influenced by the meeting number $(\beta=-0.040 ; p=.571)$. The expressive and the impressive groups differed by this factor. The impressive group was \#1 and the expressive group was \#2. This model indicates that the mean scores in "Psychological authenticity" in the expressive group were higher than in the impressive group. The "Satisfaction" factor was also influenced by the group

Table 1

Table 2

Factor model (sounders)

\begin{tabular}{|l|r|r|}
\hline \multicolumn{1}{|c|}{ Indicators } & F1 & F2 \\
\hline SS loadings & 2.00 & 0.63 \\
\hline Proportion Var & 0.29 & 0.09 \\
\hline Cumulative var & 0.29 & 0.37 \\
\hline Relaxedness & 0.71 & 0.00 \\
\hline Constraint & 0.80 & 0.07 \\
\hline Ease & 0.77 & -0.11 \\
\hline Naturalness & 0.43 & 0.18 \\
\hline Predictability & -0.15 & 0.42 \\
\hline Randomness & 0.05 & 0.54 \\
\hline Correspondence & 0.20 & 0.30 \\
\hline
\end{tabular}

Factor model (listeners)

\begin{tabular}{|l|r|r|}
\hline \multicolumn{1}{|c|}{ Indicators } & F1 & F2 \\
\hline SS loadings & 1.61 & 1.08 \\
\hline Proportion Var & 0.23 & 0.15 \\
\hline Cumulative Var & 0.23 & 0.38 \\
\hline Loudness & 0.19 & 0.37 \\
\hline Peach & 0.82 & -0.12 \\
\hline Intonation & 0.77 & 0.11 \\
\hline Feelings & 0.43 & 0.30 \\
\hline Involvement & -0.05 & 0.72 \\
\hline Background & 0.02 & 0.19 \\
\hline Replies & 0.18 & 0.43 \\
\hline
\end{tabular}


The Regression Model with the "Psychological Authenticity" Factor by the Meeting Number and by Group

\begin{tabular}{|l|c|c|c|c|c|}
\hline \multicolumn{1}{|c|}{ Predictor } & Estimate & Std. error & $\boldsymbol{t}$ & $\boldsymbol{p}$ & $\boldsymbol{p}$-adjusted \\
\hline Intercept & 2.946 & .272 & 10.830 & .001 & .001 \\
\hline Meeting number & -0.014 & .020 & -0.665 & .507 & .570 \\
\hline Group & 0.474 & .157 & 3.016 & .005 & .048 \\
\hline
\end{tabular}

Table 4

The Regression Model with the "Satisfaction" Factor by the Meeting Number and by Group

\begin{tabular}{|l|c|c|c|c|c|}
\hline \multicolumn{1}{|c|}{ Predictor } & Estimate & Std. error & $\boldsymbol{t}$ & $\boldsymbol{p}$ & $\boldsymbol{p}$-adjusted \\
\hline Intercept & 3.046 & .282 & 10.820 & .001 & .001 \\
\hline Meeting number & 0.025 & .024 & 1.029 & .305 & .430 \\
\hline Group & 0.519 & .160 & 3.238 & .002 & .048 \\
\hline
\end{tabular}

Table 5

The Regression Model with the "Perceived Satisfaction" Factor by the Meeting Number and by Group

\begin{tabular}{|l|c|c|c|c|c|}
\hline \multicolumn{1}{|c|}{ Predictor } & Estimate & Std. error & $\boldsymbol{t}$ & $\boldsymbol{p}$ & $\boldsymbol{p}$-adjusted \\
\hline Intercept & 3.167 & .235 & 13.487 & .001 & .001 \\
\hline Meeting number & 0.068 & .025 & 2.771 & .006 & .048 \\
\hline Group & 0.277 & .130 & 2.128 & .041 & .157 \\
\hline
\end{tabular}

( $\beta=0.290 ; p=.048)$ but not influenced by the meeting number $(\beta=0.0634 ; p=.430)$. The middle values in this factor were also higher in the expressive than in the impressive group. The "Perceived satisfaction" factor grew with each session $(\beta=0.181$; $p=.048)$ but was not influenced by the group $(\beta=0.164 ; p=.157)$.

The t-test was used to research the differences between groups which the regression models indicated (see Table 6).

The factors "Psychological authenticity" $(p=.001)$ and "Satisfaction" $(p=.001)$ revealed the most significant differences also indicated by the regression models.

The other factors indicating significant differences were "Psychophysiological authenticity" ( $p=.027)$ and "Perceived satisfaction" $(p=.027)$.

\section{Discussion}

The study has several significant limitations. As it was conducted on the basis of person-centered approach and person-centered expressive psychotherapy, the researcher considered the preferences of each participant as the subject of the research. They attended non-equivalent amounts of sessions and chose the groups 
Table 6

T-Test

\begin{tabular}{|l|c|c|c|c|c|c|c|c|}
\hline \multicolumn{1}{|c|}{ Factor } & $\begin{array}{c}\text { Mean } \\
\text { imp. }\end{array}$ & $\begin{array}{c}\text { Mean } \\
\text { exp. }\end{array}$ & $\begin{array}{c}\text { STD } \\
\text { imp. }\end{array}$ & $\begin{array}{c}\text { STD } \\
\text { exp. }\end{array}$ & $\boldsymbol{t}$ & $\boldsymbol{p}$ & $\boldsymbol{p}$-adjusted & Cohen's d \\
\hline $\begin{array}{l}\text { Psychophysiological } \\
\text { authenticity }\end{array}$ & 3.40 & 3.67 & 0.83 & 0.85 & 2.38 & .018 & .027 & 0.317 \\
\hline $\begin{array}{l}\text { Psychological } \\
\text { authenticity }\end{array}$ & 3.38 & 3.85 & 0.85 & 0.64 & 4.58 & .001 & .001 & 0.638 \\
\hline Satisfaction & 3.67 & 4.17 & 1.00 & 0.73 & 4.16 & .001 & .001 & 0.583 \\
\hline Vocalization change & 2.78 & 2.86 & 0.99 & 1.56 & 0.58 & .563 & .562 & 0.076 \\
\hline $\begin{array}{l}\text { Perceived emotional } \\
\text { involvement }\end{array}$ & 3.82 & 3.71 & 0.62 & 0.79 & 1.13 & .262 & .314 & 0.145 \\
\hline $\begin{array}{l}\text { Perceived } \\
\text { satisfaction }\end{array}$ & 3.69 & 3.95 & 0.81 & 0.84 & 2.45 & .015 & .027 & 0.325 \\
\hline
\end{tabular}

they wanted to participate in, resulting in a biased sample. However, it represents people who would choose a similar type of person-centered expressive vocal psychotherapy that has a major input on the perspectives of vocal psychotherapy.

The research was quasi-experimental. The participants may have primary motivations and personality traits making them prone to participate in a specific group. Participants who chose to be in the expressive group were rather interested in selfexploration and self-discovery leading to a more honest and open behavior during the research. Participants who chose the impressive group were prone to conceal their feelings. It was important for the author to investigate the peculiarities of expressive and impressive vocalizations with their characteristics reflected in survey applications for a sounder and for a listener. The task of separating the conditions for vocalizing and the personality traits which influence them was beyond the scope of this research.

Another limitation of this investigation is in the different quantity of sessions for each participant. This was connected to their flexibility when participating in research. In this investigation the researcher concentrated mostly on vocalizations rather than participants. This is why the quantity of each participant's vocalizations lays outside the scope of this study.

The different quantity of sessions with each participant was also related to their personal lives. Only 42 people participated in the research. This limits the opportunity to spread its results to a larger sample. However, this work raises new questions and ideas for new research in the sphere of vocalizations in psychotherapy and develops this field in Russia.

Using the results of this empirical study, the research hypothesis was partially proven. Vocalizations in the expressive group (in the situation of valuing) had significantly higher mean scores by the factors "Psychophysiological authenticity", "Psychological authenticity", "Satisfaction", and "Perceived satisfaction" in comparison to the vocalizations in the impressive group. Significant differences between two groups by "Psychological authenticity" and "Satisfaction" were proven by two methods that allow the opportunity to see a larger authenticity of 
the vocalizations from the expressive group than from the impressive group. All significant factors are involved in the entire concept of authenticity of vocalizations and correspond to the criteria of authentic vocalizations (Zirko \& Orlov, 2017b; Lietaer, 1993) (see Appendix 1). The participants in the expressive group felt more relaxed and free during vocalizing in comparison to the participants from the impressive group. It was also easier for them to vocalize. The feelings they expressed had a greater correspondence to their inner experience than the acted feelings of the participants from the impressive group. Their vocalizations were less random and predictable than vocalizations in the impressive group. The overall satisfaction was significantly higher in the expressive rather than in the impressive group, corresponding to the listener's opinion. The sounder's high satisfaction level indicated their high authenticity (Rogers, 1980). In both groups the scales of the factor "Perceived satisfaction" grew. This is explained by the special peculiarities of each group, which provided similar results. During the research participants from the impressive group felt increasingly confident performing in public and reported this to the researcher and their listeners. They learned to act out different emotions with their voices. This was perceived by their listeners as progress resulting in higher satisfaction. The participants from the expressive group reported feeling more freedom, inner strength, and resources. This also allowed their listener to give higher scores on the factor of "Perceived satisfaction".

Neither the t-test nor regression by group showed any differences between the groups by the factors "Vocalization change" and "Perceived emotional involvement". This indicates that the voices and vocalizations had similar changes in both groups and listeners perceived sounders as similarly involved regardless of the creative task or the process of self-exploration and self-inquiry through their voices. This can be explained because the participants from the expressive group were involved in the process of self-exploration and their voices changed depending on whatever the personal feelings that came out. The participants from the impressive group were involved in the process of doing creative tasks and their voices changed during the task to be more artistic and convey the assigned feelings.

The major factors of authenticity, "Psychophysiological authenticity" and "Psychological authenticity", were significantly higher in the expressive than in the impressive group. They indicated an individual's behavior and corresponded to their feelings and body state, along with what an individual expressed verbally and non-verbally (Uhlig, 2006 et al.).

\section{References}

Austin, D. (2008). The theory and practice of vocal psychotherapy: Songs of the self. London, UK/Philadelphia:, PA Jessica Kingsley Publishers.

Babakina, V. (2016). Kongruentnye I nekongruentnye proyavleniya subjektivnogo opyta klienta (v kontekste praktiki autentichnogo dvizheniya) [Congruent and incongruent manifestations of the client's subjective experience in authentic movement practice] (Master's thesis). Higher School of Economics, Moscow, Russian Federation. (in Russian) 
Baker, F. (2015). Therapeutic songwriting. Developments in theory, methods, and practice. Palgrave Macmillan.

Hiller, J., \& Gardstrom, S. C. (2018). Selection of music experiences in music therapy. Music Therapy Perspectives, 36(1), 79-86.

Kern, P., \& Tague, D. B. (2017). Music therapy practice status and trends worldwide: An international survey study. The Journal of Music Therapy, 54(3), 255-286.

Lewis, G. (2017). "Let your secrets sing out": An auto-ethnographic analysis on how music can afford recovery from child abuse. Voices: A World Forum for Music Therapy, 17(2). doi:10.15845/voices.v17i2.859

Lietaer, G. (1993). Authenticity, congruence and transparency. In D. Brazier (Ed.), Beyond Carl Rogers (pp. 17-46). London, UK: Constable and Company.

Lindblad, K. (2016). Verbal dialogue in music therapy: a hermeneutical analysis of three music therapy sessions. Voices: A World Forum for Music Therapy, 16(1). doi:10.15845/voices.v16i1.842

Linklater, K., Epp, P., \& Snow, W. (1976). Freeing the natural voice. Drama Book Publishers.

Markovich, R., \& Tatsumi, K. (2015). The effects of single-session music therapy interventions in comparison with a cognitive behavioral intervention on mood with adult psychiatric inpatients in an acute-care setting: a quasi-experimental trial. Music Therapy Perspectives, 33(2), 118-127.

Melnikova, M. S., \& Orlov, A. B. (2016). Therapeutic potential of biological feedback: An empirical study. Voprosy Psikhologii, 2, 91-97. (in Russian)

Monti, A., \& Austin, D. (2017). The dialogical self in vocal psychotherapy. Nordic Journal of Music Therapy, 27(2), 158-169. doi:10.1080/08098131.2017.1329227

Orlov, A. B. (2015). Predislovie nauchnogo redaktora [A foreword]. In Tvorcheskaya soyaz'. Istselyayushchaya sila ekspressionykh iskusstv [The creative connection: expressive arts as healing] (pp. 11-15). Moscow: Mann, Ivanov i Ferber. (in Russian)

Pascale, L. M. (2005). Dispelling the myth of the non-singer: Embracing two aesthetics for singing. Philosophy of Music Education Review, 13(2), 165-175.

Petrushin, V. I. (2009). Muzykal'naya psikhologiya [Music psychology]. Moscow: Akademicheskiy prospekt/Gaudeamus. (in Russian)

Rogers, C. R. (1980). A way of being. Boston, MA: Houghton Mifflin.

Rogers, N. (1993). The creative connection: Expressive arts as healing. Science \& Behavior Books.

Stewart, R., \& McAlpin, E. (2016). Prominent elements in songwriting for emotional expression: an integrative review of literature. Music Therapy Perspectives, 34(2), 184-190.

Uhlig, S. (2006). Authentic voices, authentic singing: A multicultural approach to vocal music therapy. Gilsum: Barcelona Publishers.

Vaillancourt, G., Da Costa, D., Han, E. (Yi), \& Lipski, G. (2018). An intergenerational singing group: a community music therapy qualitative research project and graduate student mentoring initiative. Voices: A World Forum for Music Therapy, 18(1). doi:10.15845/voices.v18i1.883

Zirko, A. V., \& Orlov, A. B. (2017, a). Authentic vocalizations: In search of the voice of the inner self. Voprosy Psikhologii, 3, 61-70. (in Russian)

Zirko, A. V., \& Orlov, A. B. (2017, b). Vocal therapy: research perspective. Psikhologicheskie Issledovaniya, 10(53), 3. Retrieved from http://psystudy.ru/index.php/eng/2017v10n53e/1438zirko53e.html (in Russian) 
Appendix 1

Subjective Criteria of Four Types of Vocalizations

\begin{tabular}{|c|c|c|c|c|}
\hline \multirow[b]{2}{*}{ Criteria } & \multicolumn{4}{|c|}{ Types of vocalizations } \\
\hline & $\begin{array}{c}\text { Inauthentic impres- } \\
\text { sive } \\
\text { vocalizations }\end{array}$ & $\begin{array}{c}\text { Inauthentic expres- } \\
\text { sive } \\
\text { vocalizations }\end{array}$ & $\begin{array}{l}\text { Authentic } \\
\text { impressive } \\
\text { vocalizations }\end{array}$ & $\begin{array}{c}\text { Authentic } \\
\text { expressive } \\
\text { vocalizations }\end{array}$ \\
\hline Voice & $\begin{array}{l}\text { Tension; } \\
\text { the intonation } \\
\text { does not change. }\end{array}$ & $\begin{array}{l}\text { Tension; voice } \\
\text { blocks. }\end{array}$ & $\begin{array}{l}\text { Relaxed and free } \\
\text { body and voice. }\end{array}$ & $\begin{array}{l}\text { Relaxed and free } \\
\text { body and voice; } \\
\text { Low pitch. }\end{array}$ \\
\hline Vocalizations & $\begin{array}{l}\text { Vocalizations are } \\
\text { not changing; } \\
\text { a sounder wants } \\
\text { to be accepted by } \\
\text { a listener. }\end{array}$ & $\begin{array}{l}\text { Vocalizations are } \\
\text { changing, but it is } \\
\text { not reflected in } \\
\text { the self-report. }\end{array}$ & $\begin{array}{l}\text { Vocalizations and } \\
\text { the imaginative con- } \\
\text { tents are changing } \\
\text { in order to impress a } \\
\text { listener. }\end{array}$ & $\begin{array}{l}\text { Vocalizations are } \\
\text { changing } \\
\text { through the } \\
\text { experience. }\end{array}$ \\
\hline $\begin{array}{l}\text { Expressing } \\
\text { feelings }\end{array}$ & $\begin{array}{l}\text { A sounder's emo- } \\
\text { tions are not } \\
\text { expressed; } \\
\text { a sounder is } \\
\text { attempting to } \\
\text { impress a listener. }\end{array}$ & $\begin{array}{l}\text { A sounder is con- } \\
\text { centrated on } \\
\text { expressing and liv- } \\
\text { ing through their } \\
\text { experience; } \\
\text { A participant does } \\
\text { not think about } \\
\text { what impression } \\
\text { they make. } \\
\end{array}$ & $\begin{array}{l}\text { The voice communi- } \\
\text { cates imaginative } \\
\text { contents, but not } \\
\text { feelings; The pur- } \\
\text { pose is to impress a } \\
\text { listener. }\end{array}$ & $\begin{array}{l}\text { The voice pre- } \\
\text { cisely expresses } \\
\text { the individual's } \\
\text { experience at the } \\
\text { moment. }\end{array}$ \\
\hline $\begin{array}{l}\text { Limitation or } \\
\text { freedom }\end{array}$ & $\begin{array}{l}\text { A sounder hides } \\
\text { their experience } \\
\text { and deliberately } \\
\text { shows only the } \\
\text { emotions which } \\
\text { can impress people. }\end{array}$ & $\begin{array}{l}\text { Only part of the } \\
\text { experience is } \\
\text { expressed; } \\
\text { The rest of it is } \\
\text { blocked. }\end{array}$ & $\begin{array}{l}\text { Only the feelings } \\
\text { which may impress } \\
\text { a listener are con- } \\
\text { sciously expressed. }\end{array}$ & $\begin{array}{l}\text { The entire expe- } \\
\text { rience is freely } \\
\text { vocalized and is } \\
\text { not blocked. }\end{array}$ \\
\hline $\begin{array}{l}\text { Feelings } \\
\text { during } \\
\text { vocalizing }\end{array}$ & $\begin{array}{l}\text { Tension, unaccep- } \\
\text { tance, anxiety, } \\
\text { irritation, insecu- } \\
\text { rity. }\end{array}$ & $\begin{array}{l}\text { Tension, limita- } \\
\text { tion, incapability, } \\
\text { falsity. }\end{array}$ & Success. & $\begin{array}{l}\text { Feeling right and } \\
\text { precise. }\end{array}$ \\
\hline $\begin{array}{l}\text { Emotional } \\
\text { background }\end{array}$ & $\begin{array}{l}\text { Frustration, } \\
\text { fatigue. }\end{array}$ & Confusion. & $\begin{array}{l}\text { Satisfaction and } \\
\text { pride. }\end{array}$ & Pleasure. \\
\hline Self-image & $\begin{array}{l}\text { The self-image is } \\
\text { unchanging; } \\
\text { If destroyed, a } \\
\text { sounder has nega- } \\
\text { tive feelings. }\end{array}$ & $\begin{array}{l}\text { Self-image may } \\
\text { partly change, but, } \\
\text { the voice mostly } \\
\text { expresses feelings } \\
\text { in a habitual man- } \\
\text { ner. }\end{array}$ & $\begin{array}{l}\text { Self-image is chang- } \\
\text { ing; the voice ran- } \\
\text { domly changes } \\
\text { depending on what- } \\
\text { ever impression } \\
\text { needs to be made. }\end{array}$ & $\begin{array}{l}\text { Self-image is } \\
\text { very dynamic; } \\
\text { The voice } \\
\text { changes depend- } \\
\text { ing on the inner } \\
\text { experience of a } \\
\text { sounder. }\end{array}$ \\
\hline
\end{tabular}




\section{The research applications}

Appendix 2

\section{The introductory application}

Instruction: Write your name or nickname

The application consists of nine 5-point scales and one open question. Please evaluate your vocalizing experience. Mark the multiple-choice on the scale.

1. Do you like the sounds of your voice?

1 - I do not like them.

2 - I rather do not like them

3 - I do not know

4 - I rather like them

5 - I like them

2. In your opinion, is there any connection between the sounds of your voice and your emotions?

$1-$ No, there is no connection

2 - There is rather no connection

3 - I do not know

4 - It rather exists

5 - It exists

3. Are there any situations in your life when you do not use any words but use only the sounds of your voice?

1 - No, never

2 - Very seldom

3 - I do not know

4 - Rather often

5 - All the time

4. How did you usually feel when singing in public?

1 - I felt awful

2 - I had negative feelings

3 - I do not know

4 - I had positive feelings

5 - I felt wonderful

5. In your opinion, can you express your genuine feelings with the sounds of your voice?

1 - No, I never can

2 - Very seldom

3 - I do not know

4 - Rather often

5 - All the time

6. In your opinion, do you conceal your feelings with your voice?

1 - Never

2 - Very seldom

3 - I do not know

4 - Rather often

5 - All the time 
7. In your opinion, can you impress people with your voice?

1 - Never

2 - Very seldom

3 - I do not know

4 - Rather often

5 - Constantly

8. In your opinion, can you be diverted from your actual feelings through your voice?

1 - Never

2 - Very seldom

3 - I do not know

4 - Rather often

5 - All the time

9. In your opinion, does your voice help you better understand your feelings?

1 - Never

2 - Very seldom

3 - I do not know

4 - Very often

5 - All the time

10. Is there anything else about your voice you would like to tell me?

\section{The application for the sounder}

Instruction: Write your name or nickname

The application consists of 95 -point scales. Please evaluate the process and the result of your vocalizations. Mark the multiple-choice on the scale.

1. Evaluate the power of tension in the voice: voice box: diaphragm, body muscles, neck muscles, face muscles, using a 5-point scale. Where in 1 the muscles are tense, and in 5 - the muscles are relaxed.

1. My muscles were very tense

2. My muscles were rather tense

3. My muscles were not tense but not relaxed

4. My muscles were rather relaxed

5. My muscles were relaxed.

2. Evaluate the power of constraint or looseness during sounding using a 5-point scale, where 1 is I felt constraint, 5 - I felt free

1. I felt constraint

2. I felt rather constraint

3. I did not feel constraint and I was not free either

4. I felt rather free

5. I felt free

3. Evaluate the power of difficulty or ease of vocalizing with a 5-point scale, where 1 it was difficult to sound, 5 - it was easy to sound.

1. It was difficult to sound

2. It was rather difficult to sound

3. It was not difficult to sound but it was not easy either

4. It was rather easy to sound 
5. It was easy to sound.

4. Evaluate the power of artificiality or naturalness of vocalizing, where in 1 my vocalizing was artificial, and in 5 my vocalizing was natural.

1. My vocalizing was artificial

2. My vocalizing was rather artificial

3. My vocalizing was not artificial, but was not natural either

4. My vocalizing was rather natural

5. My vocalizing was very natural.

5. Evaluate the power of predictability or unpredictability of vocalizing. 1 is you have always known how you will sound, 5 - you never knew before, which sound will come out.

1. I have always known before, how I will sound

2. More often I have known, how I will sound

3. Sometimes I have known before how I will sound

4. More often I have not known before how I will sound

5. I have never known before, how I will sound.

6. Evaluate the power of randomness or non-randomness of your vocalizing: 1 - vocalizing was random, 5 - vocalizing was not random.

1. My vocalizing was always random

2. My vocalizing was often random

3. My vocalizing was sometimes random

4. My vocalizing was often not random

5. My vocalizing was always not random.

7. Evaluate the correspondents between your feelings and vocalizations, where in 1 the sounds of your voice did not correspond with your feelings at all, and in 5 the sounds of your voice totally corresponded with your feelings.

1. The sounds of my voice did not correspond with my feelings at all

2. The sounds of my voice almost did not correspond with my feelings

3. the sounds of my voice sometimes corresponded with my feelings

4. The sounds of my voice often corresponded with my feelings

5 . The sounds of my voice totally corresponded with my feelings

8. Evaluate the satisfaction level during vocalizing, where in 1 you felt totally dissatisfied during vocalizing, and in 5 you felt totally satisfied during vocalizing.

1. I felt totally dissatisfied during vocalizing

2. I felt dissatisfied during vocalizing

3. I do not know, how much I was satisfied

4. I felt satisfied during vocalizing

5. I felt totally satisfied during vocalizing

9. The satisfaction level after vocalizing, where in 1 you felt totally dissatisfied after vocalizing, and in 5 you felt totally satisfied after vocalizing.

1. I felt totally dissatisfied after vocalizing

2. I felt dissatisfied after vocalizing

3. I do not know, how much I was satisfied

4. I felt satisfied after vocalizing

5. I felt totally satisfied after vocalizing 


\section{The application for the listener}

Instruction: Write your name or nickname

The application consists of 9 5-point scales. Please evaluate the process and the result of vocalizing of the sounder. Mark the multiple-choice on the scale.

1. Evaluate the loudness of vocalizations with the 5-point scale, where 1 is quiet, 5 loud

1. Quiet

2. Rather quiet

3. The medium level of loudness

4. Rather loud

5. Loud

2. The dynamics of pitch

1. The pitch does not change

2. The pitch changes very insignificantly

3 . The pitch changes rather significantly

4. The pitch changes significantly

5 . The pitch changes very significantly

3. The dynamics of intonations

1. The intonations do not change

2. The intonations change insignificantly

3. The intonations change rather significantly

4. The intonations change significantly

5. The intonations change very significantly

4. Feelings in vocalizations

1. There are no feelings

2. There are very few feelings

3. There are not a lot, but not few feelings

4. There are rather a lot of feelings

5. There are a lot of feelings and they are various

5. Involvement of the sounder in the process of vocalizing

1. The sounder is not involved in the process

2 . The sounder is weakly involved in the process

3. The sounder is involved in the process on the medium level

4. The sounder is strongly involved in the process

5 . The sounder is totally involved in the process

6. Negative or positive emotional background during vocalizing

1. Negative emotional background

2. Emotional background is rather negative

3. Neutral emotional background

4. Emotional background is rather positive

5. Positive emotional background

7. Emotional replies from the listener to the vocalizations

1. The vocalizations did not affect me

2 . The vocalizations weakly affected me

3 . The vocalizations affected me on the medium level

4. The vocalizations affected me rather strongly 
5. The vocalizations totally and strongly affected me

8. The satisfaction level during vocalizing

1. The sounder felt totally unsatisfied during vocalizing

2. The sounder felt unsatisfied during vocalizing

3. I do not know, how much the sounder was satisfied

4. The sounder felt satisfied during vocalizing

5 . The sounder felt totally satisfied during vocalizing

9. The satisfaction level of the sounder after vocalizing

1. The sounder felt totally unsatisfied after vocalizing

2. The sounder felt unsatisfied after vocalizing

3. I do not know, how much the sounder was satisfied

4. The sounder felt satisfied after vocalizing

5 . The sounder felt totally satisfied after vocalizing

Alena. V. Zirko - PhD in Psychology.

Research Area: vocal music psychotherapy, person-centered approach, vocal practices in psychotherapy, person-centered expressive psychotherapy.

E-mail: alena@mlbox.ru

\section{Типы вокализаций в самовыражении и самоисследовании}

\section{А.В. Зирко \\ Резюме}

Вокализации рассматриваются как невербальное использование звуков голоса в самовыражении и самоисследовании. Цель исследования состоит в изучении специфики процессов самовыражения и самоисследования человека с помощью вокализаций в условиях принятия и оценки. Мы предположили, что при условии принятия и ценения вокализации будут обладать более высокими показателями аутентичности, чем при условии оценки. Были выделены две группы участников: группа экспрессии, в которой соблюдались условия безоценочного принятия, и группа импрессии, в которой моделировались условия оценки. Участники группы экспрессии выражали свои переживания с помощью звуков голоса, а участники группы импрессии выполняли исследовательские задания, направленные на развитие выразительности своего голоса. После вокализирования участники обеих групп заполняли исследовательские анкеты, в которых изучались состояние тела и голоса звучащего, чувства звучащего и слушающего в ходе исследования. Показатели, полученные с помощью этих анкет, были объединены в шесть факторов: «Психофизиологическая аутентичность», «Психологическая аутентичность», «Удовлетворенность», «Изменение вокализаций», «Воспринимаемая эмоциональная включенность» и «Воспринимаемая удовлетворенность». Для изучения динамики вокализаций и влияния условий исследования на вокализации были построены модели множественной регрессии. С помощью t-критерия Стьюдента группы участников сравнивались между собой. Значимые различия 
наблюдались по факторам «Психофизиологическая аутентичность», «Психологическая аутентичность», «Удовлетворенность» и «Воспринимаемая удовлетворенность». Значения по всем факторам были выше в группе экспрессии, чем в группе импрессии. В обеих группах возрастали показатели по фактору «Воспринимаемая удовлетворенность».

Ключевые слова: вокалопсихотерапия, вокализации, аутентичность, неаутентичность, экспрессивность, импрессивность.

Зирко Алена Владиславовна - кандидат психологических наук.

Сфера научных интересов: вокальные и голосовые практики в психотерапии, человекоцентрированный подход, музыкотерапия, вокалотерапия, человекоцентрированная экспрессивная психотерапия.

Контакты: alena@mlbox.ru 
Правила подачи статей и подписки можно найти на сайте журнала: http://psy-journal.hse.ru

Свидетельство о регистрации средства массовой информации ПИ № ФС77-66610 от 08 августа 2016 г. зарегистрировано Федеральной службой по надзору в сфере связи, информационных технологий и массовых коммуникаций (РОСКОМНАДЗОР).

Адрес издателя и распространителя

Фактический: 117418, Москва, ул. Профсоюзная, 33, к. 4, Издательский дом НИУ ВШЭ

Тел. $+7(495)$ 772-95-90 доб. 15298

Почтовый: 101000, Москва, ул. Мясницкая, д. 20

Тел. +7(495) 772-95-90, E-mail: id.hse@mail.ru

Формат 70х100/16. Тираж 250 экз. Печ. л. 15 